

\title{
TITANIUM
}

01722

\section{Report of Symposium on Titanium}

\author{
sponsored by \\ OFFICE OF NAVAL RESEARCH \\ 16 December 1948
}

OFFICE OF NAVAL RESEARCH Department of the Navy • Washington, D.C.

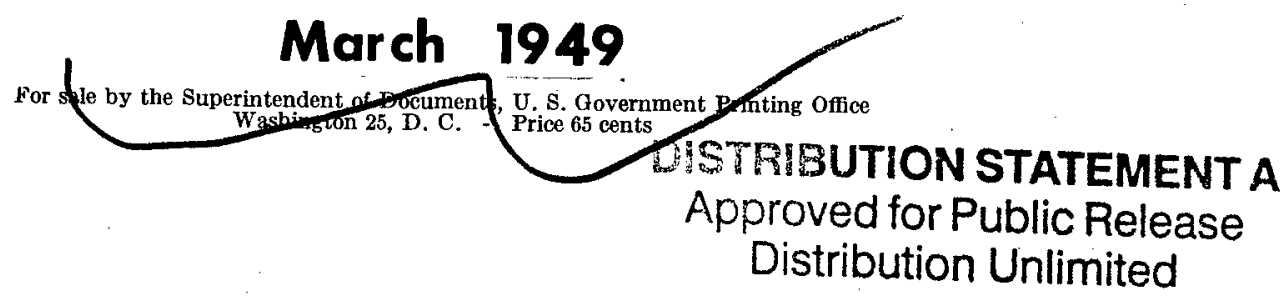




\section{FOREWORD}

This report of the "Symposium on Titanium" is a complete record of the formal talks that were presented at the meeting called by the Office of Naval Research on 16 December, 1948. The purpose of this meeting was to bring together those government agencies and industrial organizations actively engaged in the research and development of titanium and its alloys so as to provide, for the first time, a comprehensive review of the titanium research effort and the progress thus far attained.

Titanium and its alloys represent a potentially important metal system which is currently receiving much interest and attention. The Navy has a vital stake in the development of light, strong and corrosion-resistant metals and looks forward to the full exploitation and development of this most promising metal system.

It is hoped that this report will be of value to those working in the field of titanium and to all potential consumers of titanium and titanium alloys. To all those who took an active part in the symposium, the Office of Naval Research expresses its appreciation.

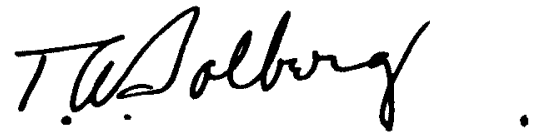

T. A. Solberg

Rear Admiral, USN

Chief of Naval Research

Note: The discussions following each paper were summarized from available transcriptions, and in the interest of expediency were not checked with the discussers. Any inaccuracies or misstatements are due to the summarizers and the shortcomings of the transcriptions. 


\section{TABLE OF CONTENTS}

Program

page

Welcoming Address

Captain William H. Leahy, USN, Assistant Chief of Naval Research

Introduction

J. J. Harwood, Office of Naval Research

The Bureau of Aeronautics' Titanium Program (Paper 1)

N. E. Promisel, Chief, Materials Branch, Bureau of Aeronautics, Navy Department

Discussion, Paper 1

The Program of the Air Materiel Command on Titanium Alloys (Paper 2) Richard R. Kennedy, Wright-Patterson Air Force Base

The Titanium Program of Army Ordnance (Paper 3)

Laurence S. Foster, Watertown Arsenal Laboratory

Discussion, Paper 3

Production of Titanium Powder at Boulder City (Paper 4)

F. S. Wartman, Metallurgist, Bureau of Mines, Boulder City, Nevada

Discussion, Paper 4

Fabrication of Titanium and Investigations of Titanium-Nickel Alloys in the Bureau of Mines Laboratories (Paper 5)

J. R. Long, College Park Branch, Metallurgical Division, Bureau of Mines

Discussion, Paper 5

Physical and Mechanical Properties of Commercially Pure Titanium (Paper 6) C. I. Bradford, J. P. Catlin and E. L. Wemple, Remington Arms Company

Discussion, Paper 6

Production and Properties of Iodide Titanium (Paper 7)

Bruce W. Gonser, Research Supervisor, Battelle Memorial Institute,

Columbus, Ohio

Discussion, Paper 7

Properties of Iodide Type Titanium (Paper 8)

F. B. Litton, Foote Mineral Company

Discussion, Paper 8

Induction Melting of Titanium Metal in Graphite (Paper 9)

J. B. Sutton, Pigments Department, E. I. DuPont de Nemours and Company 
Discussion, Paper 9

The Production and Arc Melting of Titanium (Paper 10)

C. T. Greenidge and L. W. Eastwood, Battelle Memorial Institute

Discussion, Paper 10

Some Preliminary Tests to Determine Applications for Titanium (Paper 11)

W. Lee Williams, U. S. Naval Engineering Experiment Station, Annapolis, Maryland

Discussion, Paper 11

Some Preliminary Data on Alloys of Titanium (Paper 12)

E. I. Larsen, E. F. Swazy, L. S. Busch and R. H. Freyer, P. R. Mallory and Company, Inc.

Discussion, Paper 12

Titanium-Base Alloys (Paper 13)

Howard C. Cross, Battelle Memorial Institute

Discussion, Paper 13

Some Aspects of the Metallurgy of Titanium Alloys (Paper 14)

P. H. Brace, Westinghouse Research Laboratories

Discussion, Paper 14

The Titanium-Base Alloys Program of the Naval Research Laboratory (Paper (Paper 15)

E. J. Chapin, Metallurgy Division, Naval Research Laboratory

Discussion, Paper 15

The Carbon-Oxygen Relationship in Titanium Melted in Carbon Refractories (Paper 16)

S. F. Urban and A. C. Haskell, Titanium Alloy Manufacturing Division, National Lead Company

First Progress Report on Titanium-Carbon and Titanium-Nitrogen Phase Diagrams (Paper 17)

J. P. Nielsen, College of Engineering, New York University

Discussion, Paper 17 


\title{
PROGRAM
}

\author{
CHAIRMEN
}

I.R. Kramer and J.J. Harwood

Office of Naval Research

Welcoming address

Captain William H. Leahy - Assistant Chief of Naval Research

Introduction

J.J. Harwood - Office of Naval Research

Research and Development Programs on Titanium

1. "The Bureau of Aeronautics Titanium Program"

N.E. Promisel - Materials Branch, Bureau of Aeronautics

Navy Department

2. "The Program of the Air Materiel Command on Titanium Alloys"

R.R. Kennedy - Wright-Patterson Air Force Base

3. "Titanium Program of Army Ordnance"

L.S. Foster - Watertown Arsenal, Office of Chief of

Ordnance, U.S. Army

Production and Properties of Titanium Metal

4. "Production of Titanium Powder at Boulder City"

F.S. Wartman - Boulder City, Nevada, Division

Bureau of Mines

5. "A New Method of Consolidating Titanium Powder"

J.R. Long - College Park, Maryland, Division

Bureau of Mines

6. "Physical and Mechanical Properties of Commercially Pure Titanium"

C.I. Bradford, J.P. Catlin and E.L. Wemple Remington Arms Company

7. "Production and Properties of Iodide Titanium"

B.W. Gonser - Battelle Memorial Institute

8. "Properties of Iodide Type Titanium"

F.B. Litton - Foote Mineral Company 
9. "Induction Melting of Titanium Metal in Graphite"

J.B. Sutton - Pigments Department,

E.I. DuPont de Nemours and Company.

10. "Production and Arc-Melting of Titanium"

O.W. Simmons, C.T. Greenidge and L.W. Eastwood

Battelle Memorial Institute

11. "Some Preliminary Tests to Determine Applications of Titanium"

W. Lee Williams - U.S. Naval Engineering

Experimental Station

\section{Alloys of Titanium}

12. "Some Preliminary Data on Alloys of Titanium"

E.I. Larsen - P.R. Mallory and Company, Inc.

13. "Titanium Base Alloys"

H.C. Cross - Battelle Memorial Institute

14. "Some Aspects of the Metallurgy of Titanium Alloys"

P.H. Brace - Westinghouse Research Laboratories

Physical Metallurgy of Titanium and its Alloys

15. "Description of Apparatus for the Melting of Titanium and for the Study of the Titanium-Oxygen System"

E.J. Chapin - Metallurgy Division

Naval Research Laboratory

16. "The Carbon-Oxygen Relationship in Titanium Melted in Carbon Refractories"

S.F. Urban and A.C. Haskell - Titanium Alloy Manufacturing Division, National Lead Company

17. "First Progress Report on Titanium - Carbon and Titanium Nitrogen Phase Diagrams"

John P. Nielsen - College of Engineering,

New York University 


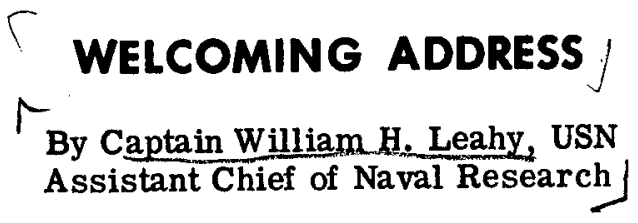

Gentlemen:

It gives me great pleasure to welcome you to this Symposium. Admiral Solberg is unable to be present because he has been called to a meeting of the Naval Research Advisory Committee in New York and he asked me to express his regrets. This is one of a series of Office of Naval Research Symposia on metals aimed at presenting and discussing recent trends in metallurgical research and development. The $\mathrm{Navy}$ is particularly interested in titanium because of its promise as a suitable structural material. Its high strength-weight ratio, its corrosion resistant properties, and its high temperature characteristics are all very attractive. Its natural abundance in the United States is also an important reason for giving it careful consideration.

During the past war the Navy and American industry worked together as a team to build up the greatest naval force in all history. It was a remarkable job which required the closest kind of cooperation, and it clearly indicated how much can be accomplished under the American system when we all put our shoulders to the wheel. Even though the war is over and won, it is still important that we work closely together. For this reason the Office of Naval Research particularly welcomes this meeting. It provides the opportunity for a review and discussion of the titanium programs under way and should stimulate and encourage the application and utilization of this new metal. Titanium shows great promise. It is up to industry and the military services working together to solve the many problems that face us before titanium can be used in quantity. The successful solution of the problem will provide good insurance for the future. 


\title{
(INTRODUCTION
}

\author{
By T.J. Harwood \\ Office of Naval Research
}

With the announcement of the small-scale, commercial production of titanium, a new metal system joins the ranks of our dwindling supply of useful structural metals. Certain characteristics of titanium bid fair to make it a potentially important metal system for the future - namely, it is light, strong, durable and corrosion resistant. To these we might add one other important qualification - it is plentiful. Admittedly, we still speak today in terms of the potentialities of titanium and its alloys, but potentialities which are rapidly being transformed into realities. Even at this early stage of development, titanium is assuming a prominent position and can no longer be categorized as a rare metal. It is the purpose of this symposium to acquaint all of you here who are interested in the future of titanium with the recent status of the research and development work that is currently under way.

The papers that will be presented during today's program logically fall within four general groupings: (a) description of the programs being conducted and/or sponsored by the member agencies of the National Military Establishment, (b) reports on the production and properties of titanium, (c) alloy development studies and (d) physical metallurgy studies of titanium and its alloys. The rather large number of papers on the program is typical of the rapidly expanding research effort in titanium and was motivated by our desire to make today's presentation as comprehensive and as complete as possible. 


\title{
THE BUREAU OF AERONAUTICS' TITANIUM PROGRAM
}

\author{
By N. E. Promisel \\ Materials Branch, Bureau of Aeronautics, Navy Department
}

The clear expression of interest in the metal titanium, evidenced by the attendance here today, the scope of the program and the activities indicated thereby, the steady progress made in the development of this interesting material within the past few years and the unique properties revealed to date, certainly forecast an important role for titanium in the not-too-distant future, in the field of constructional materials.

The Bureau of Aeronautics' interest and activity in this field date back about two years. The potential applications envisioned at the beginning, based primarily on the well-known publications of the Bureau of Mines, have been expanded, if anything, with increasing enthusiasm and optimism, in keeping with developments resulting not only from Bureau of Aeronautics' investigations but also from the cumulative data being generated by other Government agencies and industry. This anticipated utilization is based on the already known favorable relative properties for titanium of high strength combined with moderate specific gravity, apparent ductility, fairly high modulus of elasticity, high melting point, excellent corrosion resistance in chloride environments, apparent workability and, by no means least of all, the abundant availability of the raw material in this country. With full recognition of existing handicaps, of the many problems yet to be solved and of the many "ifs" in the relatively limited evaluations to date, it is possible to envision use of this material or its alloys in many types of applications such as the following:

a. Substitution for aluminum and magnesium alloys and steel in some types of aircraft construction because of improved design properties at normal temperatures. Figure 1 shows some relative design values.

YIGJRE 1

\begin{tabular}{|c|c|c|c|c|c|c|c|c|c|}
\hline Material & Spec. Grav. & $\begin{array}{l}\text { Mod, of } \\
\text { Flaik. } \\
\text { F(x106) }\end{array}$ & $\begin{array}{l}\text { tit. Tens. } \\
\text { strongth } \\
\text { (x1000) }\end{array}$ & $\begin{array}{l}\text { Comp. Id. } \\
\text { strangth } \\
\text { (xacoo) }\end{array}$ & $\begin{array}{l}\text { UMS } \div \text { s.6. } \\
\text { (Note } \mathrm{B})\end{array}$ & 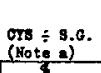 & $\frac{1}{3.0 .3}$ & $\frac{\frac{1}{3 . V^{2}}}{(\text { Notes ate) }}$ & $\frac{1}{8.0 .09}$ \\
\hline $\begin{array}{l}\text { Bare } \\
2458\end{array}$ & 2.8 & 20.5 & 62 & 40 & $\ldots$ & $\ldots$ & $\ldots$ & $\ldots$ & $\ldots$ \\
\hline $\begin{array}{l}\text { Bare } \\
758 T \\
\end{array}$ & 2.8 & 30.5 & .75 & 65 & +21 & +62 & 0 & 0 & 0 \\
\hline $\begin{array}{l}\text { Aluminue } \\
\text { ㅆlog } x\end{array}$ & 2.8 & 10 & 83 & 75 & +34 & +87 & -5 & -5 & -5 \\
\hline 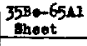 & 2.4 & 20 & 75 & 50 & +39 & Int & +194 & +154 & +55 \\
\hline$\mu_{z} z_{r}$ & 1.8 & 6.5 & 54 & 32 & $+\sqrt{3}$ & +22 & +122 & +45 & -6 \\
\hline 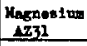 & 1.8 & 6.5 & 32 & 22 & -4 & -16 & +121 & +45 & -6 \\
\hline $\begin{array}{c}\text { Mk-11 } \\
\text { 11loy }\end{array}$ & 1.6 & 6.5 & .50 & 45 & +34 & +100 & +176 & +85 & +7 \\
\hline Ritantum & 4.5 & 16 & 150 & $130(1)$ & +47 & +104 & -65 & -42 & -7 \\
\hline 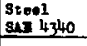 & 1.9 & 30 & 220 & 200 & +24 & +76 & -88 & -65 & 0 \\
\hline Trbor- & 1.8 & 2.2 & 47 & 45 & +20 & +78 & $1-37$ & -48 & -200 \\
\hline & $\begin{array}{l}\text { Yote (a): } \\
\text { Yote (b): } \\
\text { Yote (c): } \\
\text { Yoto (d): }\end{array}$ & $\begin{array}{l}\text { Columin oho } \\
\text { Indicativ } \\
\text { Indicattr } \\
\text { Indicativ }\end{array}$ & $\begin{array}{l}\text { percent in } \\
t \text { buekeling } \\
t \text { buekling } \\
\text { bending }\end{array}$ & $\begin{array}{l}\text { irease (4) } \\
\text { trongth of } \\
\text { it rength o. } \\
\text { gtdity. }\end{array}$ & $\begin{array}{l}\text { decrease (- } \\
\text { lat plate. } \\
\text { urved plate. }\end{array}$ & compered & 1 th 2459 & Do porceat. & \\
\hline
\end{tabular}


b. Substitution for high specific gravity materials, particularly stainless steel, due to its outstanding resistance to chloride and other environmental corrosion, and substitution for light alloys for the same reason. To illustrate the latter, there may be mentioned the problem of protecting leading edges of light alloys in high-speed aircraft. At speeds approaching those of sound, the customary organic protective coatings are abraded away by impingement of dust, various particles, rain, etc., in a relatively few hours, sometimes perhaps in a matter of minutes. The result, unless improved coatings or materials are perfected, is susceptibility to corrosion, loss in airplane performance due to surface roughening, and increased maintenance time and costs.

c. Substitution for steel where space is at a premium. The advent of thin wings in supersonic aircraft and the increasing importance of space for the expanding specialized equipment being carried in military aircraft "nder some conditions necessitate designs and types of construction utilizing materials heavier than aluminum and magnesium which occupy a smaller volume for the same load-carrying ability. Currently steel is the selection, even at a sacrifice in weight. Titanium and its alloys may be the happy compromise.

d. Applications involving moderately elevated temperatures. Temperatures in the order of several hundred degrees Fahrenheit are becoming more common in aircraft, due to higher speeds and aerodynamic heating, the use of heat in de-icing, the proximity of structural parts to very hot installations such as jets and afterburners, the need for increasing temperatures in the compressors of turbines and jets and other causes. The present high-strength light alloys begin to lose their strength very seriously between 300 degrees Fahrenheit and 400 degrees Fahrenheit. There is reason to believe that titanium and its alloys lose their strength very much more slowly under these conditions. Although steels are available for these temperatures, the weight penalty is very severe.

e. There should be mentioned the marked possibility of developing superior alloys with high percentages of titanium for very high temperature applications. Of interest in this respect are the titanium-aluminum and titanium-silicon alloys described in greater detail elsewhere in this symposium by this bureau's contractor, P. R. Mallory and Company, in which the oxidation of titanium at about 1500 degrees Fahrenheit is very markedly retarded by a few percent aluminum or one percent silicon.

f. Finally, there is a miscellaneous assortment of special applications. For example, this bureau is studying the possible use of titanium in high-speed hot-air heater wheels. Its use for armor plate warrants consideration. The electrical properties of titanium may provide unique advantages in electronic work.

With such a span of potential uses, the logical question of what properties are particularly desired in titanium and its alloys for military aircraft applications is very difficult to answer. Qualitatively, we must consider and compare with our best existing alloys the static tensile properties, static compressive properties, static shear properties, various moduli, various ductility and toughness properties (including impact resistance; ability to deform locally; ability to be bent, rolled, forged, squeezed, twisted, etc.), dynamic properties, directional properties, thermal stability, dimensional stability, applicable fabricating techniques, specific gravity, chemical properties, physical constants such as expansion and conductivity coefficients, cost and many other factors. Quantitatively, and purely as a general guide, we might say that to permit use of titanium or its alloys to advantage, at room temperature its ultimate tensile strength should exceed $135,000 \mathrm{psi}$, the tensile and compressive yield 
should exceed $110,000 \mathrm{psi}$, the elongation in two inches should not, if possible, drop below about $10 \%$, the minimum impact strength should be about 10 - 15 foot pounds, and the modulus of elasticity should preferably exceed $16,000,000$ psi and the specific gravity not greatly exceed 4.5. At temperatures of about 500 degrees Fahrenheit, the loss in strength should not drop more than about $10 \%$ of its value at room temperature, preferably when under stress for about 1000 hours. Endurance strength should not be less than about one-third the static strength. Not all these properties may be obtainable in one alloy simultaneously (although even current laboratory work indicates they are entirely reasonable) and not all are necessary at all times, but the more these crude and very approximate criteria are bettered, the more valuable the material becomes. At the same time, some applications may demand additional requirements.

The Bureau of Aeronautics' program aimed at achieving some of the above objectives is divided into several parts, which for convenience may be grouped as follows:

a. Work done in Bureau of Aeronautics' laboratories on metallurgical, fabrication and design studies of existing titanium. This work, being done at the Naval Air Experimental Station in Philadelphia, utilizes as a working medium the objective of constructing several seaplane floats. More will be said about this later.

b. Corrosion studies at the above laboratory and at the Bureau of Aeronautics' exposure sites near Norfolk, Virginia. It might be inter esting to state in passing that, aside from the excellent corrosion resistance to chlorides normally shown, it appears from preliminary results that titanium in contact with cadmium, cadmium-tin and zinc coatings is not affected by such contacts and does not accelerate the corrosion of the coatings. This is of extreme importance in aircraft due to the presence of light alloys throughout.

c. Development and evaluation of titanium alloys, and methods of producing them. This work is being done under a contract with P. R. Mallory and Company and also in collaboration with the Bureau of Mines. Some details of these programs will also be described later in this Symposium, in Malloy and Bureau of Mines reports. tioned.

d. Special problem investigations, such as the heater wheel already men-

In the short time remaining for this talk, I should like to review briefly some information developed under part (a) of the program above, which would otherwise probably not be published publicly for some time. It is important to remember that these are preliminary results only, subject to change as more data become available. The information will be presented under the following headings:

a. Tensile test data.

b. Bearing strength of sheet.

c. Bend tests to determine cold formability.

d. Dimpling tests on sheet (for flush rivets).

e. Upsetting tests on rods (heading rivets).

f. Fatigue data for sheet and rod.

g. Column data.

h. Spot and seam weld data.

Expanding rather briefly on these items, tests have indicated that the average of longitudinal and transverse tensile properties for a variety of gages of cold-worked sheet were approximately: 
97,000 psi ultimate tensile strength .

85,000 psi yield strength.

35,000 psi proportional limit.

$14 \%$ elongation in two inches.

$15.5 \times 10^{6} \mathrm{psi}$ for modulus of elasticity.

The working schedule for preparing the material was selected on the basis of retaining good workability in the sheet even at a sacrifice in strength.

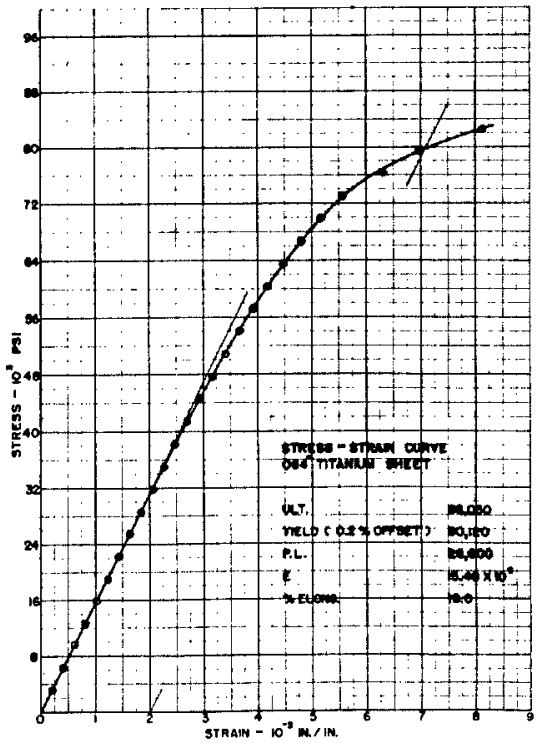

Fig. 2

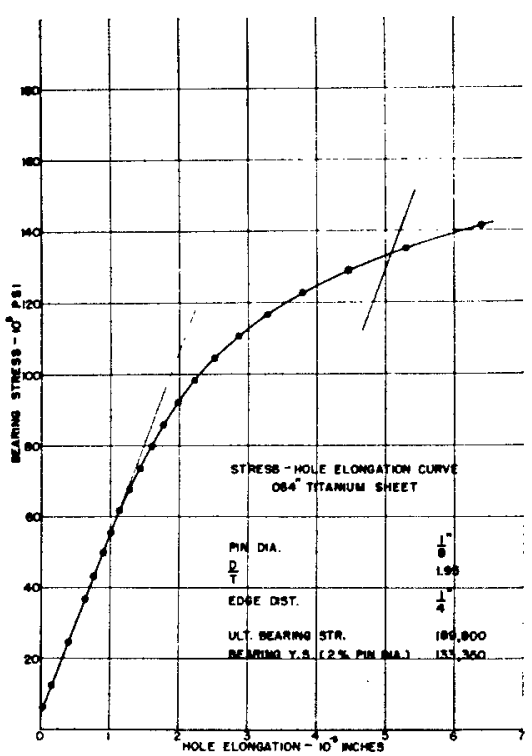

Fig. 3

The second figure shows a stress-strain curve for .064-inch sheet. It should be noted that compared to the for egoing these properties are conservative. Actually, they represent minimum values found for .064 -inch sheet. In general, however, the properties tend to improve with decreasing sheet thickness, the increase being attributed to a greater amount of mechanical working in the lighter gage sheets.

The average bearing strength of titanium sheet for all gages of sheet tested was approximately 200,000 psi ultimate and 142,000 psi yield strength. As would be expected, the bearing strength for specimens tested in the transverse direction is, in general, higher than for the specimens tested longitudinally. Figure 3 represents minimum values obtained for .064 -inch sheet. Lighter gage sheets again exhibit somewhat higher bearing strengths.

The results of dimpling tests and bend tests on sheet as well as upsetting tests on $1 / 8$ inch rod, all performed at room temperature, were generally unsatisfactory indicating that the cold formability of this material is poor. Data for hot dimpling and forming have not been developed as yet.

Figure 4 shows a typical column curve for .042-inch titanium sheet. Although curves for 75ST are not included, titanium as indicated by this curve has similar and only slightly better properties than 75ST aluminum. Both materials break away from the Euler curve at about 50,000 psi. Titanium, however, has a steeper curve thereafter, indicating a higher column strength for the lower values of slenderness ratios. It should be remembered that, although in this curve the titanium shows no significant advantage over aluminum alloy, the material is subject to much improve- 
ment and, in any case, the advantages of titanium increase as the temperature increases.

\section{TITANIUM COLUMN CURVE FOR SHEET .042" THICK (TRANS.)}

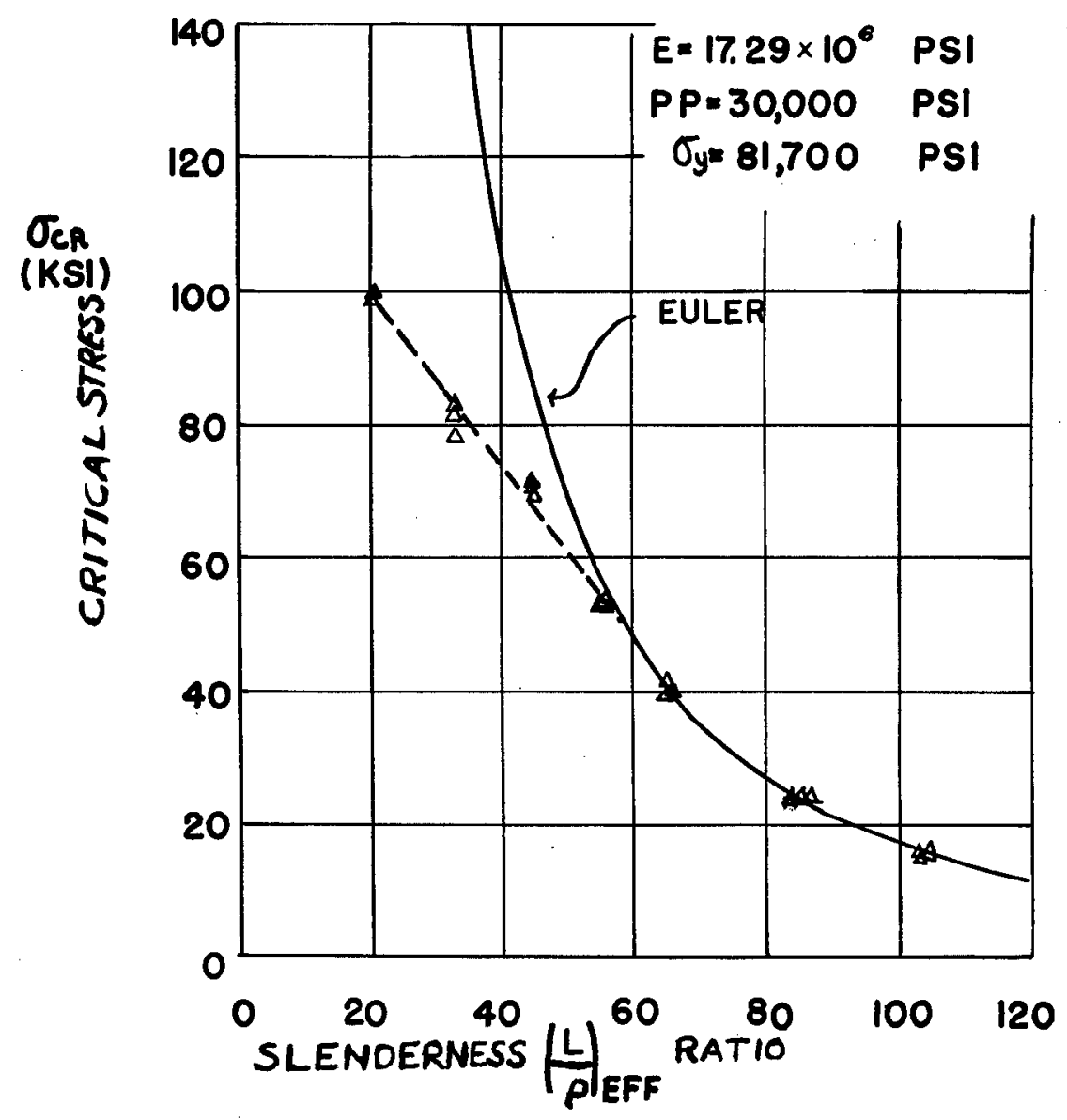

Fig. 4

The results of preliminary fatigue flexure tests on sheet are shown in Figure 5. It will be noted that the endurance curve is plotted for .032 -inch sheet in the transverse direction, made from powder metallurgy compacts. The endurance limit in this case is 25,000 psi. Data for the longitudinal direction were not available in time for presentation due to mechanical difficulties experienced in the test material. The above value is less than one would normally expect from material having the high average static properties stated previously; the difference may be due to the fact that a transverse specimen was used. The opposite trend is shown in additional fatigue data developed for titanium bars, made by melting techniques. These bars were obtained through the courtesy of the Remington Arms Company. Results indicate the 
endurance limit of this material to be approximately 68,000 psi. This value approaches the unusually high figure of about $70 \%$ of typical static strength. Considerable dif ficulty was experienced in these tests due to severe heating of the specimen during the fatigue test. It was ultimately necessary to direct an air stream on the specimens during the test. It is to be noted that the for egoing fatigue data are very preliminary in nature. Considerably more information is required to establish firmly the fatigue strength of unalloyed titanium, and to eliminate or clarify any apparent anomalies in results.

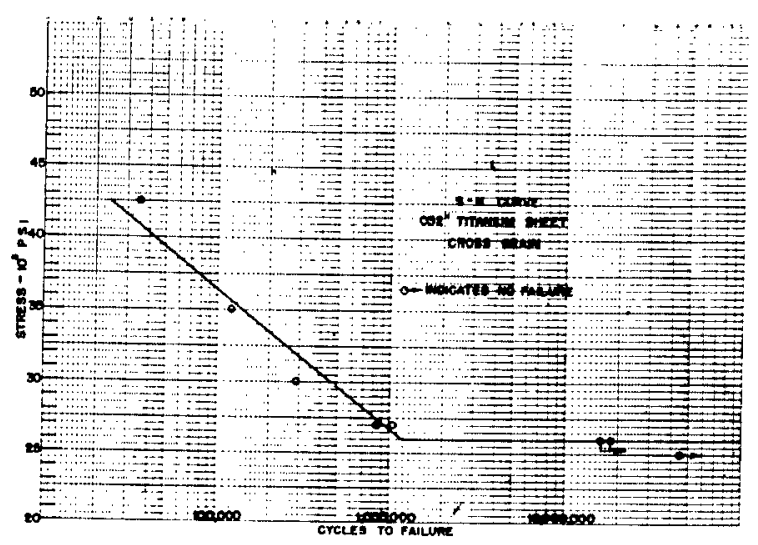

Fig. 5

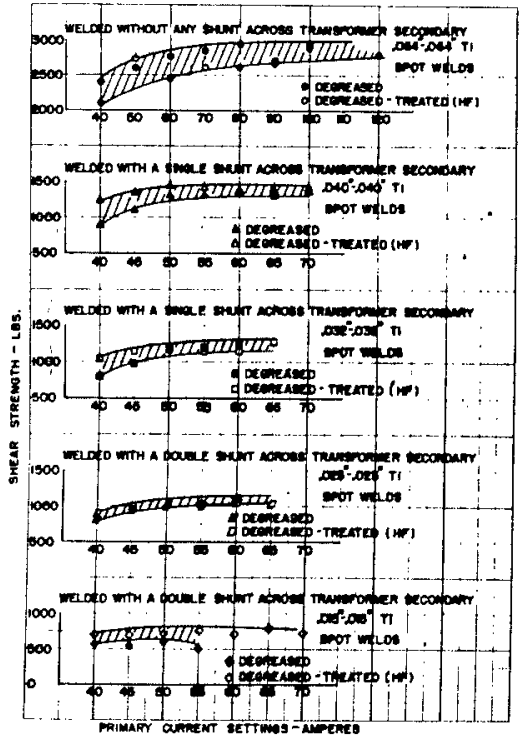

Fig. 6

Tests to determine the spot-welding characteristics and machine settings for welding several gages of titanium sheet were made, using stored energy equipment. Figure 6 shows single specimens representing degreased, and degreased and chemically treated, surface conditions, spot-welded at each setting over the range of welding heats investigated for the different sheet gages. Specimens were tested in shear to establish primary current strength relationships. Six-inch-radius dome tip and a constant electrode force of 880 pounds were used to weld all specimens. This electrode force was selected so as not to exceed the mechanical strength of the of set electrodes required by the design and shape of certain parts of the float to be spotwelded. The results of these tests indicate that metallurgically sound welds with satisfactory shear properties may be obtained using stored energy methods and fairly high electrode forces for spot-welding. It is to be noted that generally higher shear strength at given heat settings were obtained for chemically cleaned specimens.

In conclusion, it is emphasized again that the for egoing data are based on unalloyed titanium produced about a year ago. It is my firm belief that greatly improved titanium alloys already indicated by research and under progressive development will in all probability become available for limited evaluation and test in the near future. Bureau of Aeronautics' plans for development on a larger scale have been already formulated. At that time it is anticipated that we rill be considerably closer to a realization of the material requirements outlined in the early part of this paper and in a position to exploit more specifically and actively the advantages of this most promising of all new materials. 
Grateful acknowledgment is extended to the personnel of the Naval Air Experimental Station and to Mr. H. J. Boertzel of the Bureau of Aeronautics, for their valuable contributions and assistance in preparing this paper.

\section{DISCUSSION}

W. Lee Williams (U. S. Naval Engineering Experiment Station) stated that the endurance ratios reported by Mr. Promisel for Remington Arms Company titanium were surprisingly high and represented the highest values for endurance ratio, in reverse stress, thus far reported for any metal. The endurance ratio values for steels, which are among the highest known, range from $45 \%$ to $50 \%$. Rotating beam (bar) tests of Bureau of Mines titanium at the Experiment Station revealed an endurance ratio of $1 / 3$. Mr. Williams suggested that considerably more work should be done before the very high value of $60 \%$ to $65 \%$ is accepted.

Mr. Promisel agreed with Williams' statements and pointed out that lower values for the endurance limit on sheet materials were also reported in his paper. The high value of 68,000 psi was only presented to show that some factors exist which may be different for titanium than for other materials. He also agreed that a much more intensire study of the endurance properties, particularly with regard to test details, was necessary.

Mr. H. C. Cross (Battelle Memorial Institute) confirmed Mr.

Promisel's figures by reporting unnotched endurance limit values of 65,000 psi (rotating beam-bar specimens) on material with a tensile strength of 100,000 psi. For notched specimens the values fell to 32,000 to 33,000 psi, giving a notched to unnotched ratio of about 2:1. 


\title{
THE PROGRAM OF THE AIR MATERIEL COMMAND ON TITANIUM ALLOYS
}

\author{
By Richard R. Kennedy \\ Wright-Patterson Air Force Base
}

The Air Materiel Command has three projects on titanium at the present time. One of these is a contract with the Battelle Memorial Institute. The work is adequately described in papers presented in this Symposium by members of the staff of that organization.

A second project is a contract with the Ohio State University Research Foundation. This work is described by Dr. M. G. Fontana and Mr. D. G. McPherson of Ohio State University in an appendix to this report.

The third project will be carried out by the Materials Laboratory to determine the properties of commercial titanium, with a few tests on iodide process titanium. Some work has been accomplished on the expansion characteristics of titanium, using the Dilatometer. Tension, compression, fatigue and stress-corrosion tests will be conducted on commercial titanium sheet in both the annealed and the cold-rolled conditions. Tension tests will be performed at reduced and elevated temperatures. The solution potential of titanium will be determined and corrosion tests will be run on titanium coupled to other aircraft structural metals.

TITANIUM-CHROMIUM ALLOYS

By D. G. McPherson and M. G. Fontana

\section{Introduction}

The development of methods for commercial production of titanium metal within the last three years has brought about the possibility of an entirely new group of materials for industrial use, which may supply many of the desired properties lacking in our present metals and alloys. This group of materials consists of titanium metal and its alloys.

Although exploitation of titanium has proceeded rapidly since initial production of the ductile material, the metal still stands in such a position as pure iron or pure aluminum if we assumed that the steels and aluminum alloys were unknown. In other words, a great deal of development work in titanium alloys will be forthcoming.

As a step in this direction, wrork was begun in March, 1947, under the sponsorship of the Air Materiel Command, to make a preliminary study of the binary alloys of chromium and titanium.

Both chromium and titanium have high melting points (above 3000 degrees Fahrenheit). The specific gravity of titanium is 4.5 , a little more than half that of steel and somewhat less than twice that of aluminum. The specific gravity of chromium is 7.1, less than that of steel; so alloys of these two elements are lighter than the ferrous alloys. 
Titanium possesses corrosion resistance similar to that of stainless steel, in some environments, and has a proportional limit about three times that of fully cold-worked stainless steel. Chromium is particularly noted for imparting oxidation resistance to alloys at high temperatures, but it has been remarked that there is a need to develop an alloy of chromium having higher strength and lower vapor pressure than chromium. It was considered that titanium, with its desirable combination of low specific gravity, high strength and low vapor pressure would produce a useful series of alloys with chromium.
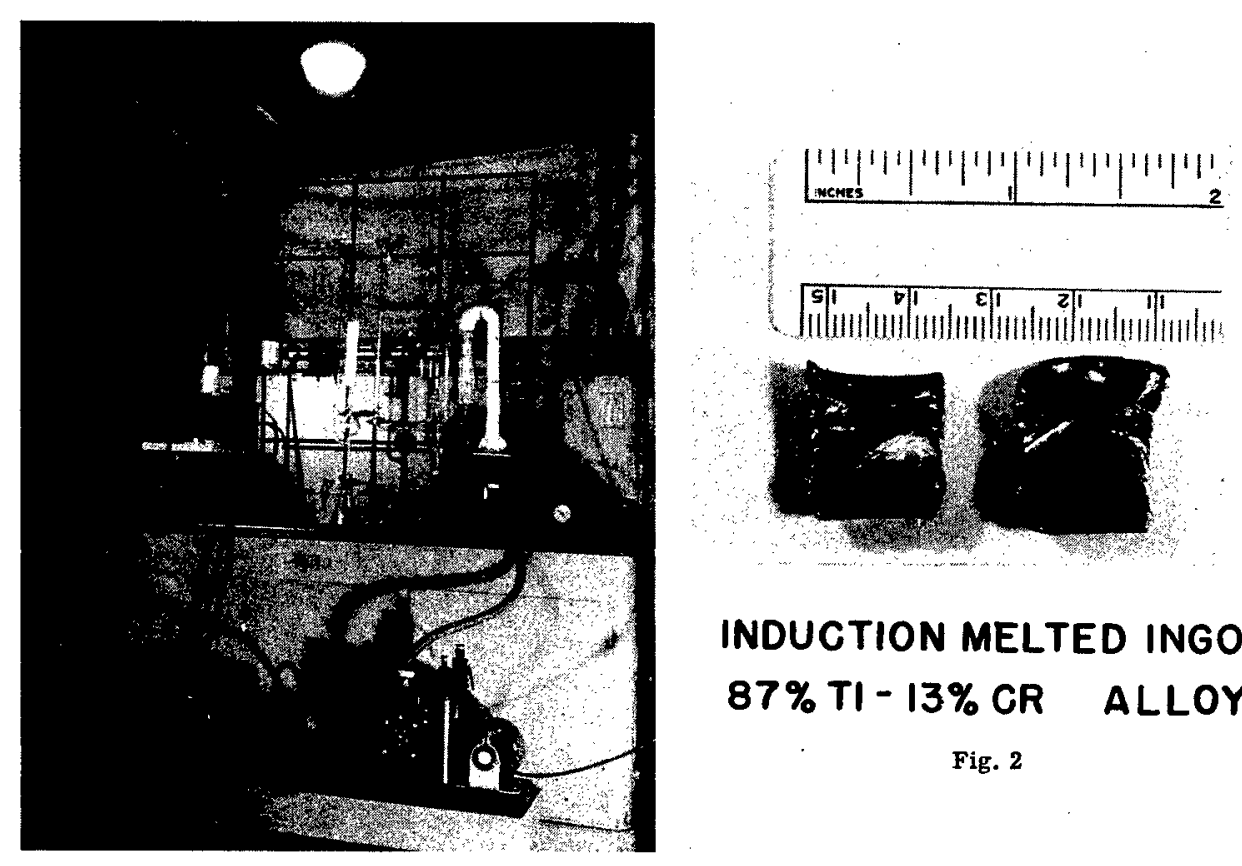

INDUCTION MELTED INGOT $87 \%$ TI-13\% CR ALLOY

Fig. 2

Fig. 1 Vacuum Melting Apparatus

\section{Induction Melting}

Exploratory melts were made in a small induction furnace, shown in Figure 1. Chromium and titanium are both very active elements, and in the molten state will absorb oxygen, nitrogen, hydrogen and carbon in amounts detrimental to ductility. Melting, ther efore, had to be carried out in vacuum or in an inert gas atmosphere. The furnace was adapted to evacuation and, alternatively, to ambient rare gas atmosphere. Purified helium was used in the latter case.

Raw materials for this urork consisted of $99 \%$ quality electrolytic chromium from various manufacturers and the ductile titanium developed by the United States Bureau of Mines. Melts were chilled in crucibles.

The problem of finding a suitable refractory crucible is very difficult. No entirely satisfactory crucible for containing molten titanium has been discovered. After screening the literature for possibilities, we tried crucibles of alundum, zircon, beryllia, stabilized zirconia and thoria. Alundum, Zircon and commercial beryllia crucibles were often eroded completely through by the melts, and resulting ingots analyzed three to five percent of the metal whose oxide was used as refractory. Sta- 
bilized zirconia crucibles were slightly discolored, but little zirconium was found in the ingots. Specially prepared, low-porosity beryllia and thoria crucibles were scarcely attacked and yielded good ingots, free from metallic contamination. The crucibles used were about $7 / 8$ inch in diameter and three inches deep. The usual ingot weight was about 50 grams, permitting only limited testing. A typical ingot is shown in Figure 2. The usual determinations were made - density, hardness, chemical analysis, hand forgeability at 1900 degrees Fahrenheit and microstructure. Vacuum fusion analysis of one vacuum-melted alloy indicated gas contents of $0.002 \%$ oxygen, $0.001 \%$ nitrogen and $0.0014 \%$ hydrogen by weight. The figure for oxygen may be open to some question due to difficulty of completely separating this element from titanium.

Most of the induction-melted alloys were hard (averaging about 40 Rockwell C) and brittle, tending to break up upon hand-forging. Exceptions were the ingots prepared in low-porosity beryllia and thoria crucibles. These averaged about 25 Rockwell $\mathrm{C}$, and were readily forgeable at 1900 degrees Fahrenheit.

\section{Arc Melting}

To circumvent the crucible problem and to produce larger quantities of the alloys for more varied testing, it was decided to try arc-melting the alloys. In this part of the work, small arc-furnaces already existent at Battelle Memorial Institute were used at first. This type of furnace is described elsewhere in the present Symposium.

One-pound ingots of chromium-titanium alloys were prepared in these fur naces. Three arc-melted alloys have been prepared to date, all of high titanium content. These were readily forgeable at 1700 - 1900 degrees Fahrenheit. Experiments with high-chromium compositions have shown that a deoxidation technique will have to be developed for these alloys to be forgeable. This is due to the fact that the electrolytic chromium powder bears a high $(0.50 \%)$ percentage of oxygen.

The high-titanium arc-melted alloys were forged into $\frac{1}{2}$-inch square bars, about 15 inches long, and studied as to chemical and spectrographic analyses, density, metallographic structure and hardness in various conditions of heat treatment, roomtemperature tensile tests, thermal analysis, high-temperature oxidation properties and wet corrosion resistance.

Some of the results of these studies are as follows:

1. The chemical quality of arc-melted alloys was better than $99.5 \%$. The major impurity was tungsten, which increases in content with gassier charges, due to splashing of the melt onto the tungsten electrode and alloying at that point.

2. Density of all three alloys was less than five $\mathrm{gm} . / \mathrm{cc}$.

3. Hardness of the as-forged alloys averaged approximately 40 Rockwell C. The annealed material did not vary greatly from this figure. It was not softened appreciably. Water quenching from 2200 degress Fahrenheit gave an average hardness value of approximately 49 Rockwell $\mathrm{C}$. This was the greatest hardness obtained in arc-melted alloys by heat-treating. .

4. An indication of the strength of this type of alloy is obtained from several room-temperature tensile tests. An $89 \mathrm{Ti}-11 \mathrm{Cr}$ alloy has shown an ultimate strength of 149,500 psi in the stress-relieved condition. The strength-weight ratio of 
this alloy was 31,150 . Limited stock precluded the testing of duplicate bars of each composition, and forging defects present in the test specimens made it impossible to realize the full strength potentialities of the alloys that were tested. No reduction of area or elongation was observed in the specimens. Sufficient strength is present, but ductility must be developed.

5. The $89 \mathrm{Ti}-11 \mathrm{Cr}$ alloy shows excellent resistance to nitric acid $(65 \%$ boiling) and saline solutions (warm and boiling) in wet corrosion tests. Tests in sulfuric acid solutions yield high corrosion rates.

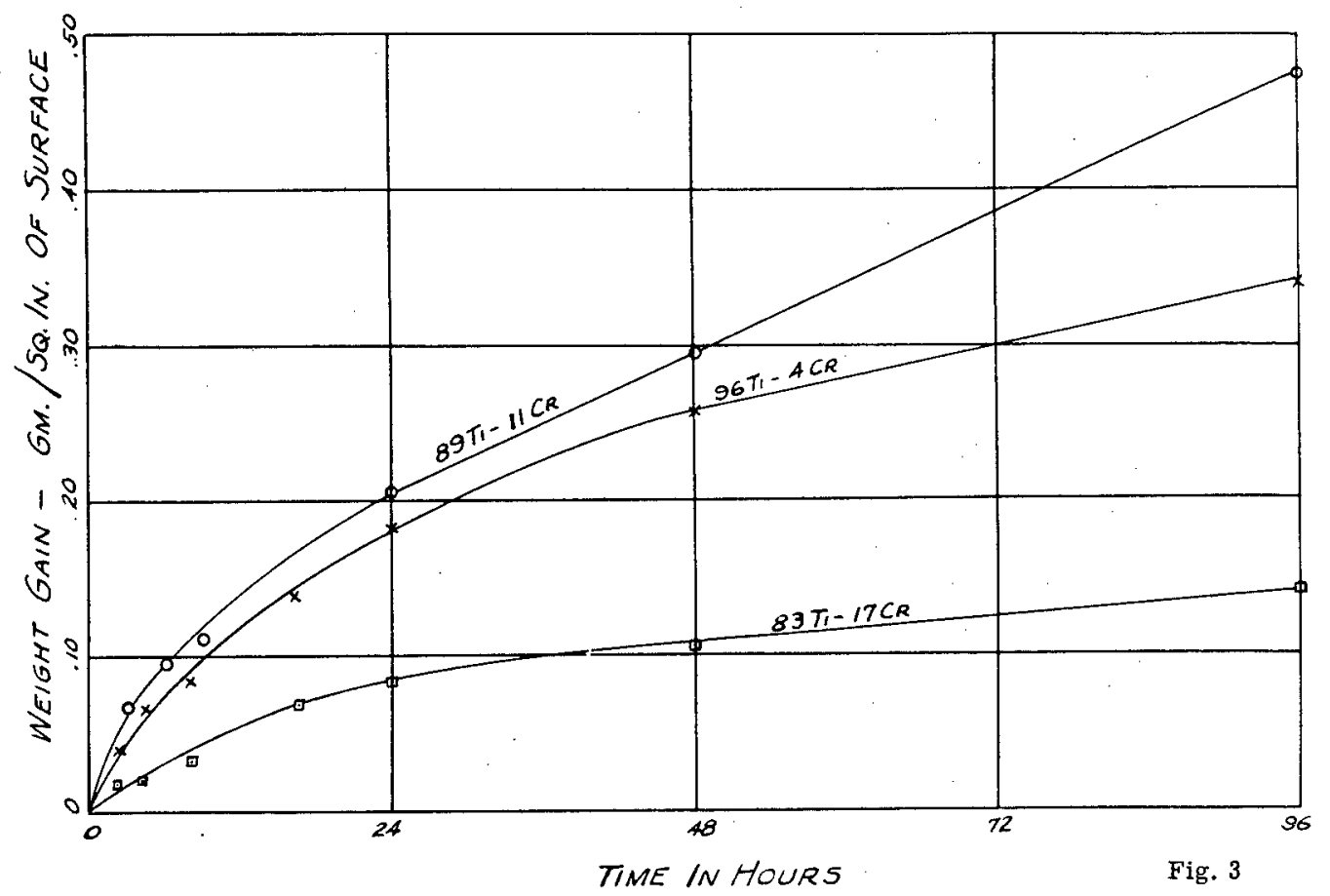

6. The scaling characteristics of the alloys were studied in still air at 1600 degrees Fahrenheit. A double-layer scale forms; the inner (probably chromic oxide) is green in color and quite dense and adherent; the outer (probably titanium oxides and nitride) range in color from yellow-brown through blue-violet to black, and flake off on cooling. The alloy having the highest chromium content (17\%) formed a denser outer scale, having by far the least tendency to flake off. Also, the oxidation rate of this alloy was much lower than those of the other alloys. Figure 3 indicates the type of oxidation curves obtained with these alloys.

7. Metallographic studies indicate that the as-forged structure consists of broken-up polyhedral grains (due to the severe working in forging this type of ingot). Annealing this alloy at 2000 degrees Fahrenheit brings about a heavy precipitation of an unidentified phase, apparently along crystallographic planes, and causes large polyhedral grains to be formed. Water-quenching the alloy from 2200 degrees Fahrenheit retains the large grains, but largely suppresses the precipitation phase. Typical microstructures are presented in Figures 4 to 6 inclusive. 

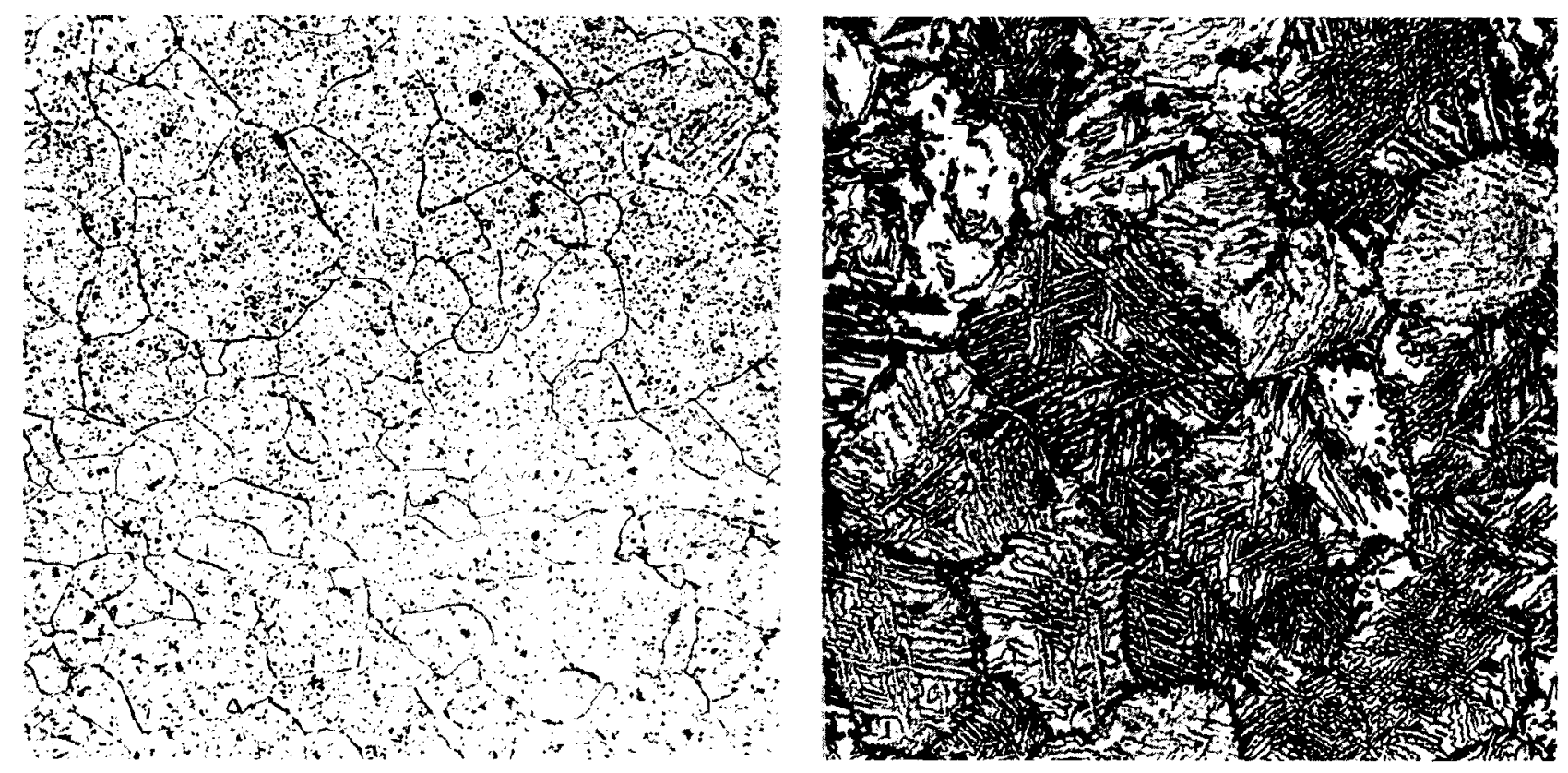

\section{Fig. 4 (upper left) 100x 83\% Ti - 17\% Cr Arc Melted Alloy As Forged}

Fig. 5 (upper right) $100 \mathrm{x}$ $83 \% \mathrm{Ti}-17 \%$ Cr Arc Melted Alloy Furnace Cooled from $2000^{\circ} \mathrm{F}$
Fig. 6 (lower right) 100x $83 \% \mathrm{Ti}-17 \%$ Cr Arc Melted Alloy Water Quenched at $2200^{\circ} \mathrm{F}$

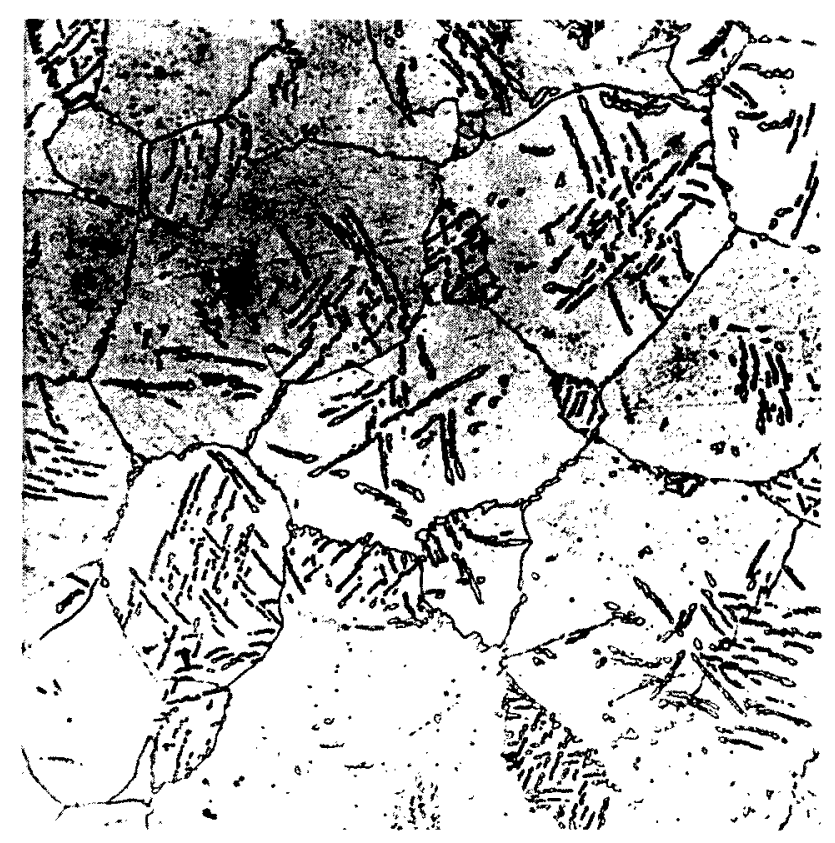

8. Thermal analysis tests showed no breaks in the heating or cooling curves of any of the alloys between room temperature and 1800 degrees Fahrenheit. Assuming, from photomicrographic evidence, that a thermal effect should be noticed somewhere in this range, the failure of the tests to show it is probably due to sluggishness of the reaction or lack of sensitivity of the instrument (designed for steels). 


\section{Future Work}

The work described is still in progress. An improved induction-melting unit (Figure 7) has been completed and an arc furnace adapted to both vacuum and inertgas melting is nearing completion. Du Pont sponge titanium will be used as well as the Bureau of Mines material in future work, and other grades of chromium, lower in oxygen content, will be tried. Arc melting will be utilized for preparing one- to threepound ingots of various compositions for further evaluation. At the same time, some induction-melting experiments will be continued, principally as a means of evaluating promising crucible materials.

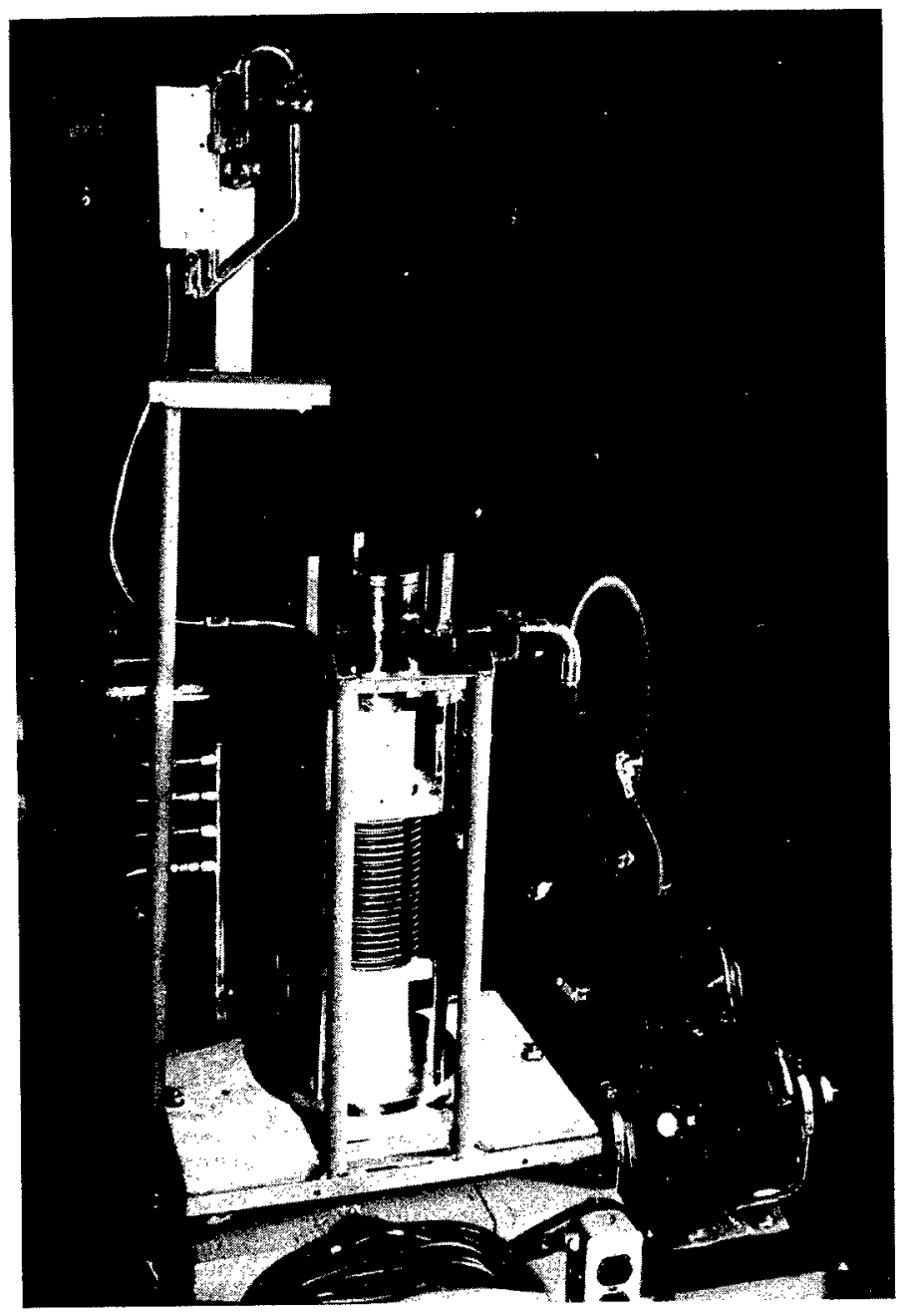

Fig. 7. Induction Melting Furnace 


\title{
THE TITANIUM PROGRAM OF ARMY ORDNANCE
}

\author{
By Laurence S. Foster. \\ Watertown Arsenal Laboratory
}

Watertown Arsenal became actively engaged in the investigation of titanium early in 1946 when samples of cast titanium were forwarded from the Office, Chief of Ordnance. These samples had been supplied by Dr. P. P. Alexander of Metal Hydrides, Inc., and were reported to have been produced from titanium powder, resulting from the decomposition of titanium hydride, $\mathrm{TiH}_{2}$. The $\mathrm{TiH}_{2}$, in turn, had been made from pigment-grade titania, $\mathrm{TiO}_{2}$, by reduction with calcium hydride, $\mathrm{CaH}_{2}$, and leaching with dilute acetic acid.

Examination of the products showed that while the particular samples were not ductile, it could be assumed that the lack of ductility was due to impurities. The presence of these impurities appeared to be accidental and it was assumed that they could be avoided by adoption of better melting techniques. The chief drawback to the material seemed to be the probable price. Use of calcium hydride as the reducing agent and of pigment-grade titania as the source material appears ultimately to be more expensive than use of titanium tetrachloride, that can readily be purified, and of magnesium, that is much cheaper than calcium hydride, as required in the Kroll process.

One factor in favor of the calcium hydride method is the ease of handling titanium hydride. This material is stable at low temperature against oxidation and hydrolysis. It is a convenient intermediate product to handle, does not have to be comminuted and is readily converted to finely divided titanium metal.

While these ideas were being considered, the Bureau of Mines developments were published and the Ordnance Department decided to use for further experimental work titanium produced by the Kroll process rather than that obtained by the calcium hydride method which appeared to be more costly. It is believed, however, that additional work should be undertaken, preferably by Industry, to assess from a manufacturing viewpoint the economic advantages of the various techniques that have been proposed. Until titanium can compete in price with other materials of high strengthweight ratio it will not be used widely for structural purposes except where, regardless of costs, its special properties dictate its adoption.

To assess the potentialities of titanium as structural material the Ordnance Department is contributing to support of work on alloy systems in progress at the College Park Station of the Bureau of Mines; Watertown Arsenal represents the Ordnance Department in the technical direction of that work. Believing that satisfactory heat treatments of alloys of titanium can ultimately be worked out only if more fundamental data about the equilibrium diagrams are available, the Ordnance Department through Watertown Arsenal has engaged Professor John P. Nielsen and his group at New York University to undertake the delineation of the titanium-carbon and the titanium-nitrogen systems. This work has been in progress for only a very short time and will be discussed later by Professor Nielsen. Watertown Arsenal, furthermore, has initiated projects in its own laboratories. These projects include studies of mechanical properties at high and low temperature, resistance to shock conditions, ballistic properties and welding characteristics. Other investigations are concerned with 
the physical metallurgy of titanium-rich alloys, such as titanium-iron alloys, to determine how the mechanical properties are affected by microstructure, temperature and composition.

To visualize the potentialities of titanium alloys in Ordnance applications, one merely needs to remember that, in the future, armies and their equipment must be capable of being largely air-borne. With a metal having such promising characteristics as titanium, only the present high cost and the lack of information about its properties and those of its alloys militate against its large-scale adoption.

\section{DISCUSSION}

In reply to a question by W. Lurie (Naval Gun Factory) concerning the feasibility of electrodeposition of titanium, Dr. Foster stated that a German patent existed for such a process, but that only a powder is obtained. He further remarked that the electrodeposition of titanium from fused salts or non-aqueous solvents is certainly worthy of investigation.

Concerning the explanation for the high corrosion resistance of titanium to chlorides, requested by Dr. J. P. Nielson (New York University), W. L. Williams (Naval Engineering Experimental Station) stated that the corrosion resistance is tentatively attributed to the presence of an oxide film, but the mechanism for its remarkable resistance to salt water and marine environments is not fully understood. Dr. M. G. Fontana (Ohio State University) remarked that his laboratories are engaged in studying the corrosion characteristics of titanium and may be able to contribute some explanations in the near future. 


\title{
PRODUCTION OF TITANIUM POWDER AT BOULDER CITY
}

\author{
By E. S. Wartman \\ Bureau of Mines, Boulder City, Nevada
}

The time allotted for this report permits only a very brief discussion of the process in general, description of the operation of apparatus large enough to produce 220 pounds of titanium powder per batch, and some mention of the nature and amount of the major impurities. A more detailed account of the work will be available soon to the public in a forthcoming Bureau of Mines Report of Investigations.

The Metallurgical Division of the Bureau of Mines, now under the direction of O. C. Ralston, has been conducting an investigation dealing with the production and technology of titanium for several years. That portion of the work done at the Boulder City station under the general direction of C. W. Davis has as its principal objective the production of titanium pure enough to have a considerable degree of malleability. Nearly all elements, when added to pure titanium, decrease the ductility more or less, but the gases nitrogen, oxygen, and hydrogen, when dissolved in the metal, decrease its ductility much more effectively than the metals. This is true to such an extent that ductile titanium can be defined as metal with a minimum of dissolved gases. Titanium embrittled by hydrogen may be rendered ductile by heating in a vacuum, but no method of restoring the ductility of titanium embrittled by oxygen or nitrogen is known. It is necessary, therefore, that titanium be produced in an environment substantially free from nitrogen and oxygen if it is to be ductile.

After a survey of all known methods of making titanium, the Kroll process was selected for further experimentation and development, because it seemed more easily adapted to large-scale work than any of the other processes that were capable of producing metal of the requisite purity.

Essentially, the process consists of reducing titanic chloride by allowing it to react with magnesium contained in a closed iron chamber at a temperature between 800 and 900 degrees Centigrade. A protective atmosphere of helium, at a pressure of one-half to one pound above atmospheric, is maintained in the reaction chamber during the time it is hot to protect the contents from oxidation.

The principal products of the reaction are molten magnesium chloride and solid spongy titanium metal, with some unused magnesium. If the supply of magnesium becomes depleted or inaccessible to contact with the titanic chloride for any reason, the titanic chloride may react with titanium already formed to yield titanous chloride or with the iron walls of the reaction chamber to yield a mixture of titanous and ferrous chlorides. Experience has shown that these side reactions may be held within reasonable limits if the quantity of titanic chloride actually used is only $90 \%$ of that theor etically equivalent to the weight of magnesium and if the temperature is held within the range mentioned.

The reaction is exothermic, so that during reduction the supply of fuel or power to the furnace must be curtailed sharply to avoid overheating.

Titanium metal in relatively pure form may be recovered by either of two methods from the solid mixture of titanium sponge, magnesium chloride, and unused 
magnesium that remains in the reaction chamber after the reaction has been completed and the chamber has cooled. The method used for most of the production work at Boulder City involves reducing the reaction mass to chips by mounting the open reaction chamber in a large lathe and boring out the reaction product. The chips so formed are first leached with dilute hydrochloric acid to remove most of the magnesium chloride and unused magnesium, then wet-ground in a ball mill operating in closed circuit with a shaking screen, to get powder of the desired grain size, leaching again in strong hydrochloric acid, followed by washing, drying, rescreening, and magnetic separation to give finished powder, which is stored in sealed drums for future use.

The second method of purification, used at Boulder City only for small experimental batches, involves heating the opened reaction chamber and reaction product in a vacuum retort. Most of the magnesium chloride and unused magnesium either melts and drains off or evaporates to leave relatively pure titanium in sponge form. Each method has certain advantages.

In the course of the investigation, the scale of operation has been increased many times. The first reduction chambers used were only about two inches in diameter by three inches in height and made only a few grams per batch. No significant trend was noted in yield or quality of powder as a result of these increases in scale of operation, up to the latest.

In the various increases in scale, the reaction chamber has kept very much the same form - a vertical cylinder of mild steel somewhat greater in height than diameter, anci with a flat bottom and top. A vertical feed pipe, long enough to extend through the lid of the furnace used to heat the pot and having a diameter about onefifth that of the pot, was attached at the center of the lid.

When an attempt was made to increase the scale of operation from 130 pounds to 220 pounds of finished powder per batch, serious difficulty was encountered. If the reduction in the larger chamber was attempted with about the same time schedule as had been used previously, the reaction chamber overheated, and the product was contaminated with iron. Experimentation showed that the difficulty could be avoided by adding the titanium tetrachloride at a much slower rate. This suggested that increasing the size of the pot had altered the heat-transfer characteristics in such a way that the heat of reaction could not be dissipated rapidly enough, resulting in a steadily increasing temperature in the reaction chamber. Eventually the magnesium began to boil. Then the zone of reaction was shifted from the surface of the magnesium bath to the point where the magnesium vapor and titanium chloride met at the end of the feed pipe. The heat of reaction, developed close to the lid, caused the metallic titanium formed to react with the lid to form the low-melting iron-titanium eutectic, which dripped down into the reaction mass. If the action continued long enough, a hole was made in the lid or feed pipe.

While the reaction could be controlled satisfactorily simply by slowing down the feed rate, this solution of the problem was not regarded as satisfactory, because it meant spreading the time for the reduction over two shifts, thus virtually doubling the labor cost for that particular step of the process. Further investigation showed two other methods of controlling the excess heat. One was to use as slow a feed as possible and still complete the run in one shift, coupled with addition of part of the magnesium as solid ingots during the run. In melting, the solid magnesium absorbed some of the heat liberated by the reaction. The other method was to use the minimum feed rate consistent with single-shift operation, coupled with the use of a rotating discharge on the titanic chloride feed pipe, so that the zone of reaction was spread out 
over a larger area and the heat generated did not have so far to travel in getting to the walls of the chamber.

Feeding the titanic chloride through a rotating discharge was found easier to practice and has been used with satisfactory results. It had one disadvantage. The more uniformly and quietly the reaction is conducted, the greater is the tendency for the formation of a solid impermeable layer of titanium across the top of the bath. Such a layer, by preventing contact between magnesium and titanic chloride, stops reduction. Use of the swinging feed promoted formation of such crusts. In order to break up such crusts and allow the reduction to proceed satisfactorily, it was necessary to insert a long bar through an opening in the top of the feed pipe at about the midpoint of the run and, using the bar as a prod, break a large hole in the crust. Entrance of air into the pot during this operation was prevented by maintaining a strong outward flow of helium through the hole used for inserting the bar.

This technique has apparently solved the difficulties encountered in operating with 220-pound batches, and batches of this size can now be handled as easily as the smaller ones were previously. It is evident, however, that in any future increase in the size of batch, the problem of heat dissipation will require careful consideration.

Since the plant at Boulder City is no longer the only source of titanium metal, maintenance of a definite production schedule did not appear to be urgent; this has given an opportunity for considering various improvements. One of these has been a study of the nature and amount of impurities in the product, and possible methods of reducing them.

The major impurities in the titanium produced by the method described are magnesium, chlorine, iron, manganese, hydrogen and oxygen.

The presence of magnesium and chlorine in the metal is presumably due to inclusion of metallic magnesium and magnesium chloride in the sponge during reduction. The magnesium content of the finished powder (leach) will range between $0.4 \%$ and $0.5 \%$ while the content of chlorine will vary between $0.1 \%$ and $0.15 \%$. The particle size of both magnesium and magnesium chloride must he quite small, as the quantity present in the minus-200-mesh fraction of the titanium powder is about the same as that in the minus-30-mesh plus-60-mesh fraction. Since there is always more than enough magnesium in the titanium to satisfy the chlorine present, there may be some solubility of magnesium in titanium.

The magnesium content of the sponge produced by vacuum purification of the reaction product is somewhat lower, while the chlorine content is about the same. A composite lot of sponge, made up from the combined output of six small reductions purified by heating in a vacuum, showed a magnesium content of $0.24 \%$ and a chloride content of $0.09 \%$.

The magnesium content of standard powder may be reduced to $0.05 \%$, or about one-tenth the normal amount, by heating in a vacuum for 16 hours at 1000 degrees Centigrade. The powder should be in loosely packed layers not over two inches thick, since the rate of diffusion is low. The magnesium content of thin-pressed compacts may also be reduced by vacuum sintering. Thus, the magnesium content of $1 / 8$ by 6 - by 10 -inch compacts may be reduced from $0.4 \%$ or $0.5 \%$ to less than $0.1 \%$. In the case of thicker compacts, the reduction in magnesium content at the surface is not so great and in the center there is almost no reduction. The surface layer of a compact in the form of a $2-$ by 2 - by 20 -inch bar, sintered 20 hours at 1000 degrees Centigrade, had a magnesium content of $0.14 \%$ while, beginning at a point $\frac{1}{2}$ inch from the 
surface and extending inward, the magnesium content was between $0.3 \%$ and $0.4 \%$.

The magnesium in titanium powder is almost completely volatilized by fusion, so that ingots formed by fusion contain only a trace of magnesium.

In contrast to the magnesium, the chlorine content is affected very little by sintering at any temperature up to 1000 degrees Centigrade. It is almost completely removed by fusion.

Iron, like magnesium, is an impurity inherent in the process, and comes from the use of iron reaction chambers. Iron from the chamber may enter the product either by direct contact between titanium and iron along the walls of the pot or by reduction of volatile iron chloride formed by reaction between hot iron and titanic chloride. Small amounts of iron may also be picked up from the iron balls used in grinding and from the magnesium used as a raw material.

The iron content of titanium is not reduced by heating in vacuum either to the sintering temperature or to actual fusion. However, it is possible to exercise a considerable degree of control over the iron content of the titanium through control of various factors during the reduction and processing. During the reduction, high temperatures and high utilization of magnesium tend to produce a product with higher iron content. During the turning of the reaction product to make chips for leaching, a highiron and a low-iron product may be made by segregating the outer layers which lie adjacent to the walls of the reaction chamber. Iron and iron-titanium alloy dissolve more rapidly in hydrochloric acid than titanium does, so that leaching reduces the ir on content of the product. This may be accentuated by prolonging the time of leaching, by leaching at a higher temperature, or by adding a small amount of sodium fluoride to the leaching acid. Both the second and third techniques are quite effective, but require care on the part of the operator to prevent an uncontrollable temperature rise ending in a violently boiling bath and a ruined batch of powder. A high leaching temperature or addition of fluoride to the leach acid also causes an increase in the hydrogen content of the powder, and using fluorides in the leach gives a solvent for which it is difficult to find sufficiently resistant containers in large-scale work. For these reasons, the first alternative has been adopted and a second leach on the ground and sized powder is run for 20 hours at 18 to 20 degrees Centigrade.

With careful operation, the average iron content of a batch of powder will be under $0.1 \%$ and, usually, about two-thirds of the powder may be obtained from a batch with an iron content of $0.04 \%$ or less.

The small-scale work indicated that it will be more difficult to control the iron content with vacuum purification, as this procedure allows no opportunity to reduce iron content by leaching. The iron content of the composite of vacuum-distilled sponge, mentioned previously, was $0.22 \%$.

The hydrogen content of the standard powder results from adsorption during the first leaching. If grains of such powder are embedded in lucite and then ground and polished to show a cross section of the interior of a grain, the hydrogen-rich layer may actually be seen on many of the grains as a thin rim, brighter than the main mass of the grain.

The volume of hydrogen present in the powder depends on several variables. It will vary with the quantity of magnesium that remains unused after the reaction, with the temperature during leaching, and with the amount of titanium dissolved during leaching. The hydrogen content of the powder will normally be about $0.1 \%$ by 
weight or $11 \mathrm{ml}$. per gram of titanium, but if conditions during leaching favor adsorption, the value may be much higher.

The volume of hydrogen in the metal may be reduced to a few thousandths of a percent by weight by heating for a few hours at 800 degrees Centigrade. This may seem like a very small amount, but a little calculation will show that this is equivalent to one volume of hydrogen per volume of metal, which is enough to cause difficulty under certain conditions.

Unlike the other impurities mentioned, manganese is a purely incidental impurity, not in any way inherent in the process. We know of only one commercial source of magnesium, and the standard grade of ingot supplied contains nearly onetenth percent of manganese, much of which enters the titanium. None of the systems of purification used is very effective in removing manganese. The manganese content is affected little either by vacuum sintering or leaching and is reduced only partly by vacuum fusion. Partial control of the manganese content of the powder is possible by segregation, because the first titanium formed is much higher in manganese than the metal formed later. This method has the weakness that for every pound of powder low in manganese, there will be an equivalent amount high in manganese.

The practical method of control is to use materials free from manganese. For large-scale production, this would be feasible, since it is possible to produce magnesium free from manganese at no additional cost if there is a sufficient demand. For the experimental work, a special lot of magnesium has been purchased which contains less than $0.01 \%$ manganese. It will now be possible to produce titanium which is quite low in manganese.

Oxygen is the last in the list of major impurities given, and most important of all in its effect upon the mechanical properties of the metal under normal conditions.

Unfortunately, we do not yet have a reliable method for estimating the oxygen content of titanium. Various considerations lead us to believe that it ranges between $0.05 \%$ and $0.1 \%$ by weight. A study of various methods of analysis is now under way.

Because of the spongy nature of the titanium formed by the reduction, it seems likely that some moisture and hydrated magnesium compounds will be retained in the pore structure after leaching and thereby increase the oxygen content of the metal.

For this reason, titanium sponge which is produced by vacuum purification and is never exposed to aqueous solutions, probably has a lower oxygen content than titanium powder which has been subjected to leaching. Installation of equipment for the production of substantial amounts of vacuum-purified sponge will be started in the near future in an attempt to provide metal with a lower oxygen content.

\section{SUMMARY}

One of the primary objectives in the titanium program the Bureau of Mines has been conducting is the production of metal pure enough, especially with respect to dissolved gases, to possess a considerable degree of malleability. The Kroll process was chosen from many investigated as being one that accomplished this aim in a practical manner, capable of adaptation to larger-scale production. In this process, titanic chloride and magnesium are allowed to react in a closed iron chamber under a 
protective atmosphere of helium to yield crude titanium sponge. The sponge is then ground and purified to yield finished titanium powder.

Most recent progress in the production of powder has been to perfect the technique for operating equipment capable of producing over 200 pounds of finished powder per batch. Progress has also been made in the technique of purifying the crude reduction product to a point such that a substantial portion of powder recently produced has an iron content of less than $0.04 \%$, and the average iron content of all powder recently produced is less than $0.1 \%$.

\section{DISCUSSION}

In response to a question from W. C. Lilliendahl (Westinghouse Electric Company) concerning the importance of the control of manganese content and the effect of small amounts of manganese, Mr. Wartman replied that the aim of the work at Boulder City was to produce titanium for experimental purposes, and in order to evaluate the effect of minor impurities it was necessary to obtain a base metal as pure as possible. Although $0.1 \%$ manganese probably would not harden titanium to any noticeable extent, it might cause precipitation in grain boundaries and adversely affect the corrosion resistance. Practically all metals harden titanium to some extent. Mr. Lilliendahl further asked whether doubly distilled magnesium was being used, and, if not, whether commercial grades were satisfactory. Mr. Wartman answered that doubly distilled magnesium was too expensive for the scale of their operations and that commercial grade BMI magnesium from the Basic Magnesium plant at Henderson, Nevada, was quite satisfactory.

Dr. W. K. Kroll (Bureau of Mines) pointed out that commercial magnesium generally contains up to $0.02 \%$ calcium. In the production of zirconium by the magnesium reduction of the chloride, the metal contained up to $8 \%$ calcium chloride. He felt quite certain that the calcium chloride could not be eliminated by vacuum treatment. In subsequent melting operations, in crucible or in an arc, bubbles are formed which cause metal-splashing and other difficulties. Therefore, attention must be paid to these impurities that may later cause difficulties in the processing of the metallic sponge or powder.

Mr. Wartman replied that, ordinarily, no attempt is made to distinguish between calcium and magnesium in analytical work. The amount of calcium in the original magnesium is too low to enable accurate determinations, but it is definitely known to be well under one percent. In titanium itself, however, there is about one part of calcium to twenty of magnesium, which confirms Dr. Kroll's comments on the concentrating characteristics of calcium. It is not known in what form the calcium exists in titanium - as calcium metal or calcium chloride.

Mr. O. C. Ralston (Bureau of Mines) remarked that too much emphasis was being placed on such impurities as calcium and manganese. Future large-scale titanium plants will continuously re-use the magnesium chloride to recover the magnesium and chlorine. The chlorine losses will probably be large and will be replenished by fresh chlorine, but the magnesium losses will be low, necessitating only infrequent replenishment, thus avoiding the introduction of new impurities. The recycling process will purify the magnesium and, thus, electrolytic magnesium need not be used. 
Mr. P. W. Brace (Westinghouse Electric Manufacturing Company) inquired about the removal of gases (e. g. hydrogen), which have been causing difficulties in the preparation of sound titanium alloy castings. Mr. F. F. Poland (Revere Copper and Brass Company) suggested that the gas might be eliminated by flushing argon through the melting furnace and recirculating the purified argon. 


\title{
r \\ FABRICATION OF TITANIUM AND \\ INVESTIGATIONS OF TITANIUM-NICKEL ALLOYS \\ IN THE BUREAU OF MINES LABORATORIES
}

\author{
By J. R. Long \\ College Park Branch, Metallurgical Division, Bureau of Mines
}

This paper summarizes two recently completed reports concerning the fabrication of titanium and the studies of the titanium-rich alloys being conducted in the laboratories of the Federal Bureau of Mines. Since these reports will shortly be distributed by the Bureau as reports of investigations, they need not be given in detail at this time.

The first of these reports deals with a new method of consolidating titanium powder. This method has definite advantages over the normal powder-metallurgy procedures, since it will permit the preparation of almost unlimited masses of the metal in a single piece. That is, the high compacting pressures and vacuum sintering ordinarily used do not lend themselves readily to the production of very large single pieces of titanium and, while investigations of melting are being conducted in many laboratories, a number of difficult problems have been encountered. The second report presents data on the phase relationships of the titanium-rich alloys in the titanium-nickel system. These data allow an estimate to be made of the useful alloy composition ranges and indicate that the properties of such alloys may be varied by suitable heat treatment.

\section{CONSOLIDATION OF TITANIUM}

The new method of consolidating titanium powder is a variation from the usual powder-metallurgy procedures and circumvents the restrictions imposed by high compacting pressure and vacuum sintering. Essentially the method consists of sealing the titanium powder in welded metal containers and working the assembly at elevated temperatures. Metal prepared in this manner is dense and sound, in distinct contrast to the porous compact obtained in the usual pressing and sintering operations. Like the standard metal, it is also ductile and is amenable to additional cold working and forming. A comparison of microstructures of titanium bonded by sheath rolling with metal bonded by pressing and sintering is given in Figures 1 and 2, where the absence of voids in the sheath-rolled material is contrasted with the voids present in the normal metal. The sheath-rolled material is equivalent in structure to that of sintered material that has been subsequently worked and annealed. This is illustrated in Figure 3, which shows the microstructure of sintered titanium after cold working and annealing. The voids of the sintered compact have been closed by the working and annealing, and there is no essential difference between the structures of Figures 1 and 3.

The tensile properties of titanium produced by both methods are given in Table 1. These data indicate that the sheath-consolidated material compares favorably with the standard product. It has a higher tensile and yield strength, about the same proportional limit, lower elongation and a slightly higher hardness. The most significant of these differences is the elongation which, however, does not appear to 
be too seriously reduced, since the metal is still capable of being cold rolled to $40 \%$ reduction, the same as the standard sheet. Tensile data on cold worked material are given also in Table 2, where a comparison may be made with the properties obtained in standard compacts sintered and then cold rolled. Again the tensile strength is somewhat higher, the yield strength slightly lower and the proportional limit and elongation considerably lower, while the hardness is a bit higher than that of the standard material. The results indicate that satisfactory properties may be obtained in titanium consolidated by sheath rolling methods and that the properties compare well with those of titanium handled in the standard fashion.
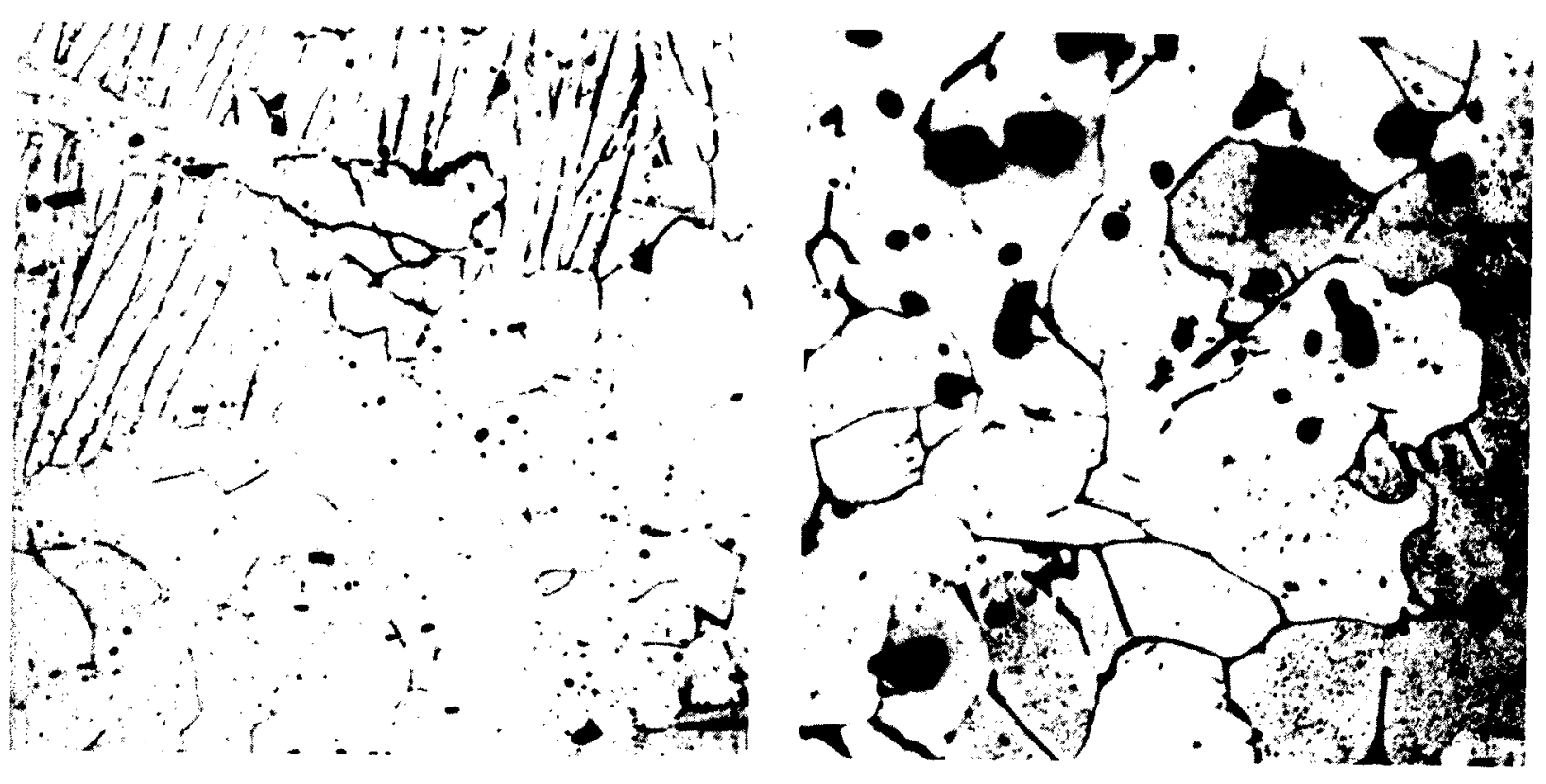

Fig. 1 (upper left) $\mathrm{X} 250$
Titanium Bonded by
Sheath Rolling

Fig. 2 (upper right)

$\mathrm{X} 250$

Titanium Bonded by Standard Powder Methods of Pressing and Sintering

Fig. 3 (lower right) X250

Sintered Titanium Coldworked and Annealed

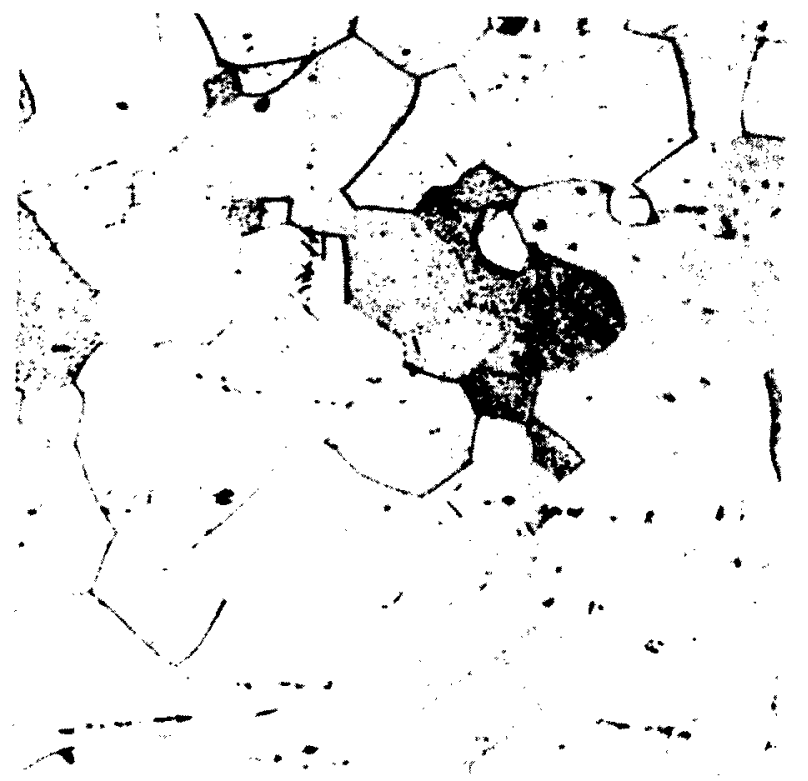


TABLE 1. COMPARISON OF PHYSICAL PROPERTIES OF GREEN SHEATH-ROLLED AND STANDARD TITANIUM SHEET

\begin{tabular}{|c|c|c|c|c|c|}
\hline-5 & $\begin{array}{l}\text { Ultimate } \\
\text { strength, } \\
\text { lb. per } \\
\text { sq. in. }\end{array}$ & $\begin{array}{l}\text { Yield } \\
\text { strength } \\
0.2 \% \\
\text { off ' set } \\
\text { lb./sq. in. } \\
\end{array}$ & $\begin{array}{l}\text { Pro- } \\
\text { portional } \\
\text { limit } \\
0.01 \% \\
\text { off set } \\
\text { lb./sq. in. }\end{array}$ & $\begin{array}{l}\text { Elongation, } \\
\text { percent in } \\
2 \text { inches }\end{array}$ & $\begin{array}{l}\text { Hardness } \\
\text { Rockwell G } \\
\end{array}$ \\
\hline $\begin{array}{l}\text { Green compacts sheath-rolled } \\
\text { at } 800 \text { degrees Centigrade }\end{array}$ & 97,600 & 75,000 & 58,000 & 15.1 & 81 \\
\hline $\begin{array}{l}\text { Standard compacts sintered and } \\
\text { cold-rolled and annealed at } \\
800 \text { degrees Centigrade }\end{array}$ & 79,100 & 64,000 & 58,800 & 24.7 & 76 \\
\hline
\end{tabular}

TABLE 2. COMPARISON OF PHYSICAL PROPERTIES OF GREEN SHEATH-ROLLED AND STANDARD TITANIUM SHEET WITH $40 \%$ COLD WORK

\begin{tabular}{|c|c|c|c|c|c|}
\hline & $\begin{array}{l}\text { Ultimate } \\
\text { strength } \\
\text { lb. per } \\
\text { sq. in. }\end{array}$ & $\begin{array}{l}\text { Yield } \\
\text { strength } \\
0.2 \% \\
\text { off set } \\
\text { lb./sq.in. }\end{array}$ & $\begin{array}{l}\text { Pro- } \\
\text { portional } \\
\text { limit } \\
0.01 \% \\
\text { off set } \\
\text { lb./sq. in. }\end{array}$ & $\begin{array}{l}\text { Elongation, } \\
\text { percent in } \\
2 \text { inches } \\
\end{array}$ & $\begin{array}{l}\text { Hardness } \\
\text { Rockwell G }\end{array}$ \\
\hline $\begin{array}{l}\text { Green compacts sheath-rolled at } \\
800 \text { degrees Centigrade, } \\
\text { cold-worked } 40 \%\end{array}$ & 129,400 & 111,500 & 75,600 & 2.6 & 94 \\
\hline $\begin{array}{l}\text { Standard compacts sintered, cold- } \\
\text { rolled } 40 \%\end{array}$ & 122,200 & 113,300 & 84,400 & 7.5 & 91 \\
\hline
\end{tabular}

The metal containers for sheath rolling may be made of any suitable material and iron, being the most readily available, is perhaps the most desirable. Most of the work so far has been conducted with common hot-rolled sheet, low-carbon steel bars, or pipe, and these were quite satisfactory for that purpose. The sheaths perform two primary functions; namely, they provide protection from active gases and other contaminating influences during the heating and working processes, and they also confine the powder particles during the working. Protection from active gases is necessary at the working temperature because both oxygen and nitrogen react rapidly with titanium, forming oxides and nitrides that diffuse into the solid metal and cause excessive hardening and embrittlement. The confining action of the sheath is likewise essential in that it brings about distortion of the individual particles of the powder, which tends to rupture any surface films that may be present and thus produces good contact among the powder particles so that diffusion and welding into a dense coherent mass may take place. The sheaths are readily removed from the finished metal, by cutting the ends and sides and stripping the sheath off. It is believed that a thin, brittle, iron-titanium alloy layer formed at the contact surfaces makes easy stripping possible. Some contamination of the titanium surface by iron does occur, but such contamination is very slight and is removed by simple pickling.

The compacts were usually worked at 900 degrees Centigrade, although temperatures ranging from 800 to 1000 degrees Centigrade were also used. At 1000 degrees Centigrade excessive oxidation of the sheath may take place and give rise to roughness of the titanium surfaces because of rolled-in scale. The sheath walls also tend to be oxidized completely through when thin sections are rolled at this tempera- 
ture. At still higher temperatures, melting may be encountered because of the formation of iron-rich alloys that melt at 1050 to 1100 degrees Centigrade. Consolidation by sheath rolling below 800 degrees Centigrade is not too satisfactory because of the low diffusion rates as indicated by slow recrystallization and grain growth rates at these temperatures.

In packing the powder into the sheaths, consideration must be given to the fact that the loose titanium powder has a volume three to four times that of the consolidated metal; therefore, maximum utilization of the volume of the sheath requires tightly packed powder. This may be accomplished by pressing the powder directly into the container or by forming pressed compacts that are then inserted into a closely fitting sheath, as was usually done in this work. Another factor of importance is the residual gas sealed in with the metal. The air should either be replaced by an inert gas before the final sealing or its volume should be reduced to a negligible amount by the use of a closely fitting sheath to give a large metal-residual-air ratio. In this connection, it should be noted that the hydrogen normally present in titanium powder will embrittle the metal unless it is removed before consolidation. The hydrogen is readily removed by pumping it out at 700 to 800 degrees Centigrade; since this can be carried out in small batches, it presents no difficulties. In fact, the standard powder was prepared for sheath rolling in this way.

Since the titanium particles are successfully formed into solid metal by sheath rolling, it follows that a number of pressed but unsintered compacts loaded into the same box should also weld together and roll out into a single piece of metal. This was demonstrated with two compacts placed side by side and two compacts placed one on top of the other in the sheaths. In each instance, the two compacts were completely welded together during the rolling and no evidence of the original interface between the blocks could be found on microscopic examination. It is, ther efore, apparent that large masses of solid, ductile titanium can be readily prepared by sealing any number of small pressed blocks in a container of suitable size and hot rolling the assembly. The small blocks, like the individual titanium particles, will weld together, giving a solid piece of titanium with no indication of the original contact faces.

Alloys of titanium with a number of other metals also have been prepared by sheath rolling the mixed powders at appropriate temperatures. Dense, homogeneous alloys can be formed in this manner, with much less trouble than encountered with the normal pressing and sintering method. The prolonged sintering normally required to produce homogeneity because of the differences in the particle sizes of the powder, the porosity of the compact, and the surface films on the individual particles is not necessary. Several examples of the microstructures of alloys prepared by sheath rolling and by normal pressing and sintering methods are given in Figures 4 to 11 , inclusive. These structures emphasize the advantages to be obtained by the sheath rolling methods.

Although the procedure was generally developed for titanium, it has a wide range of applications to all metal powder or fragments. A number of metals have been consolidated by sheath rolling to demonstrate the feasibility of the process. Some of the metal powders bonded in this way are chromium, tantalum, tungsten, molybdenum, beryllium, cobalt, iron, nickel and copper. In a similar fashion, large metallic fragments, such as zirconium-scrap turnings and electrolytic cathode chips of chromium, cobalt and manganese, have also been successfully consolidated. Representative sections and microstructures of some of these metals are shown in Figures 12 to 24 , inclusive. 


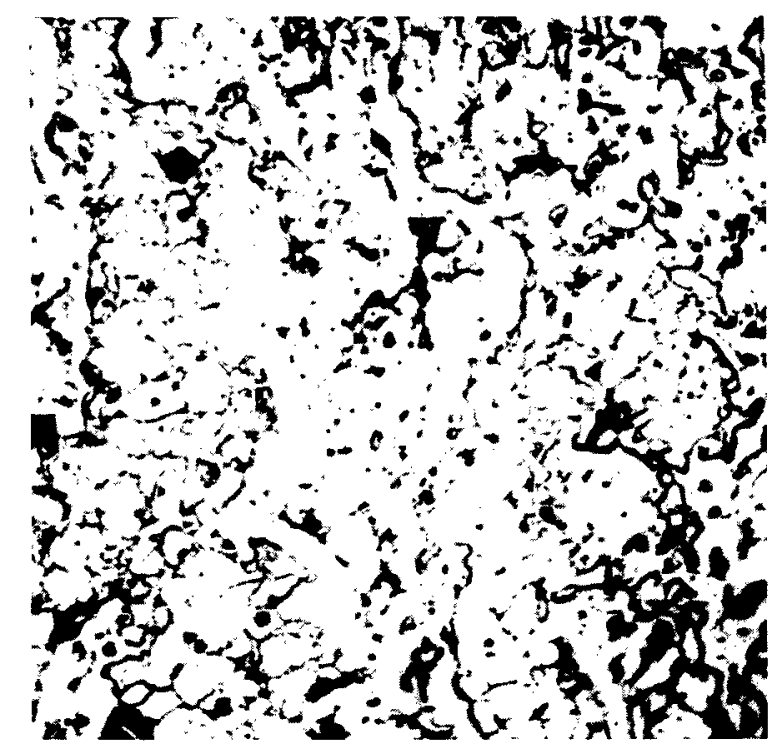

Fig. 4

$\mathrm{X} 250$

Micro Structure of $75 \% \mathrm{Ti}$, $25 \% \mathrm{Cu}$ Alloy As Sintered

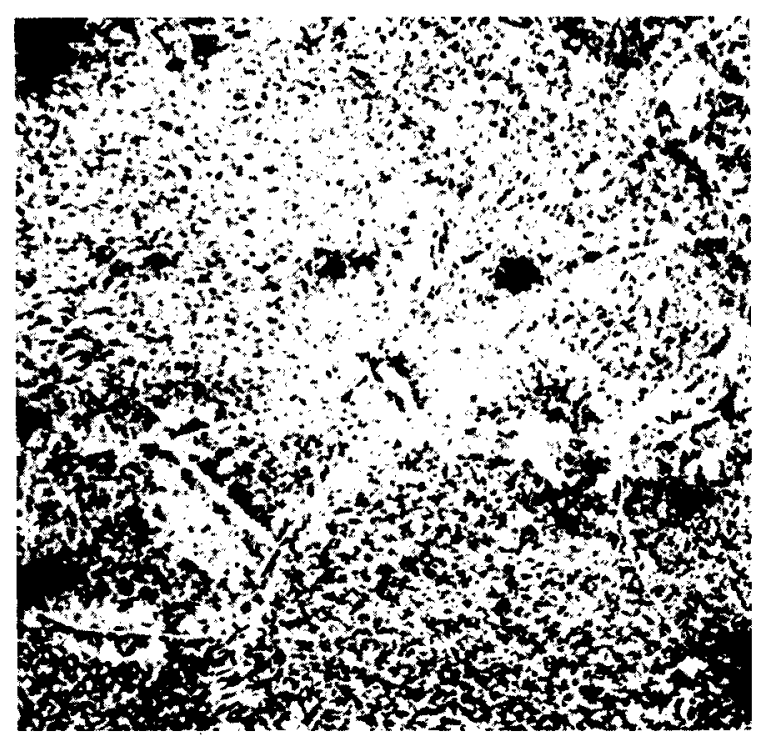

Fig. 6

$\mathrm{X} 250$

Micro Structure of $90 \% \mathrm{Ti}$, 10\% Cu Alloy Bonded by Sheath Rolling

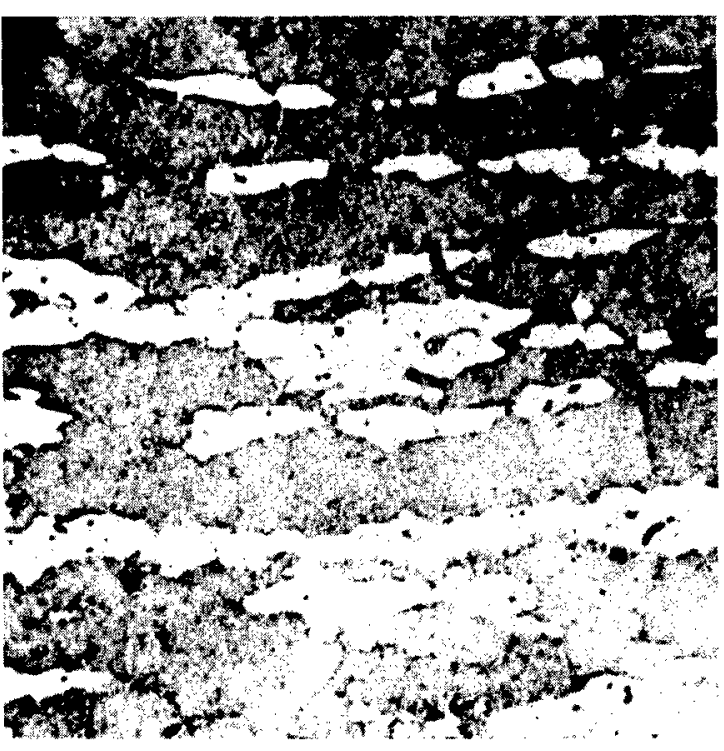

Fig. 5

$\mathrm{X} 250$

Micro Structure of $75 \% \mathrm{Ti}$, 25\% Cu Alloy Consolidated by Sheath Rolling

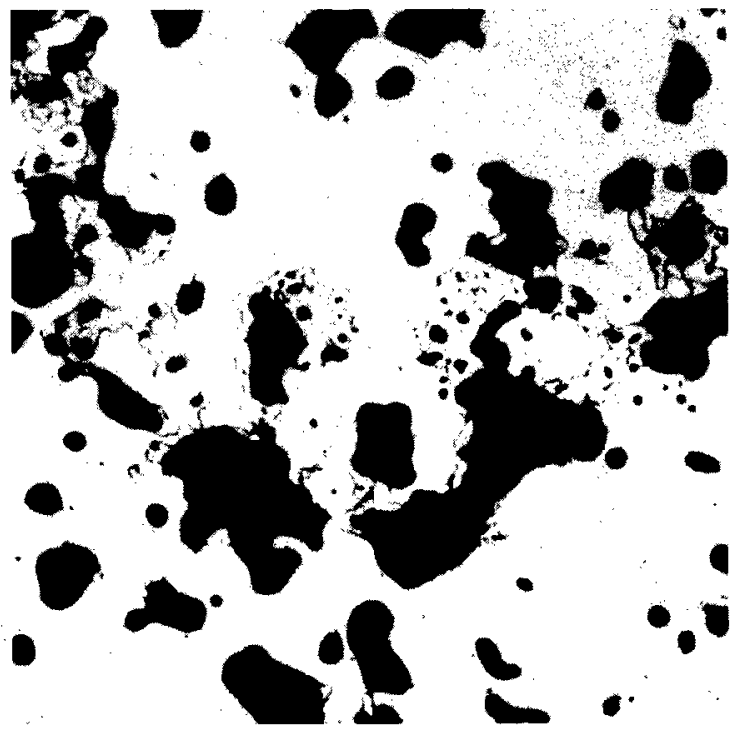

Fig. 7

$\mathrm{X} 250$

Micro Structure of $90 \% \mathrm{Ti}$, $10 \% \mathrm{Cu}$ Alloy As Sintered 


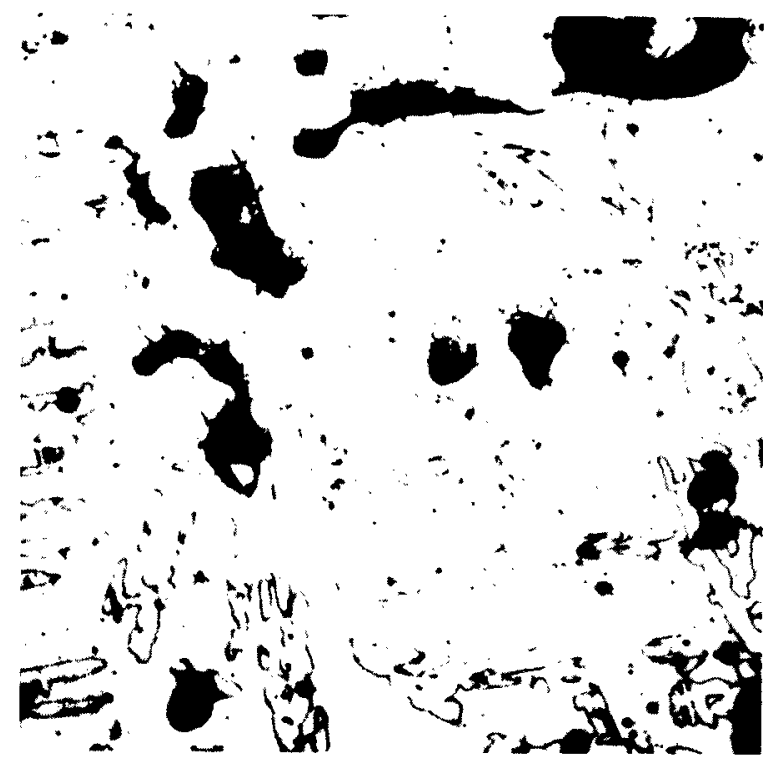

Fig. 8

Titanium-Iron Alloy, $2 \% \mathrm{Fe}$ Sintered, Reheated for four hrs. at $900^{\circ} \mathrm{C}$, and Water Quenched

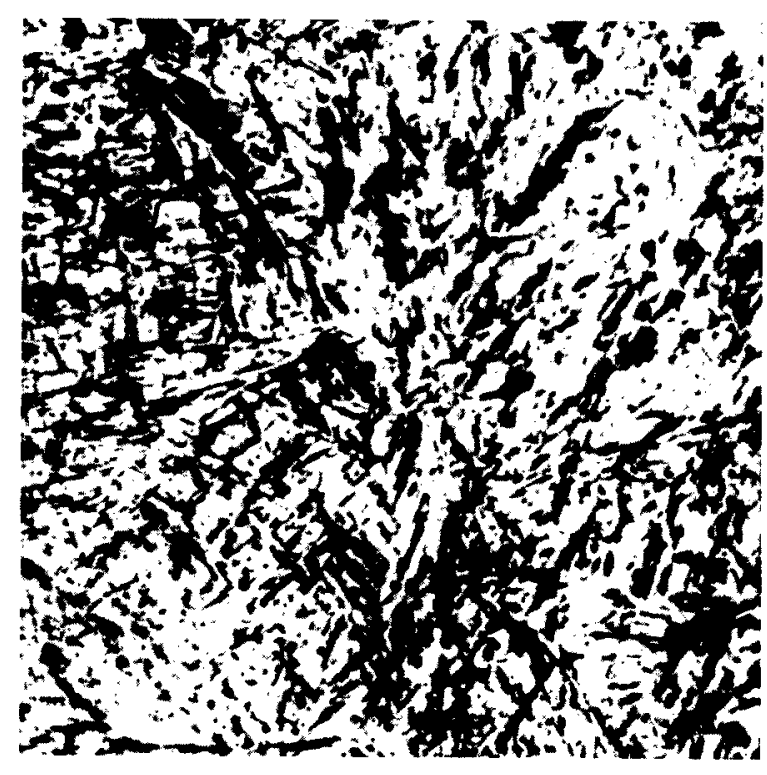

Fig. 9
$\mathrm{X} 250$

Titanium-Iron Alloy, $2 \% \mathrm{Fe}$ Sheath-Rolled at $900^{\circ} \mathrm{C}$., and Water Quenched

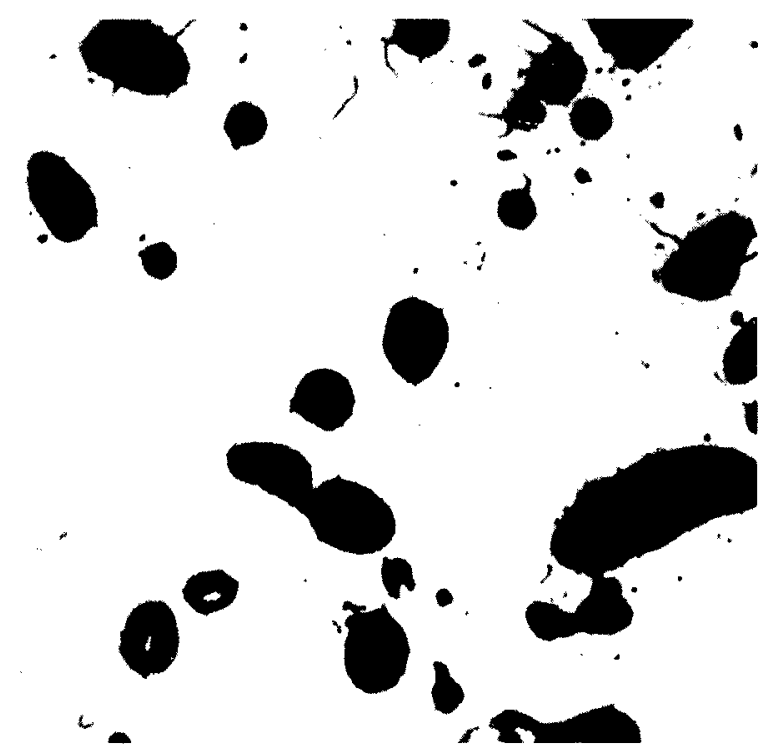

Fig. 10

Sintered Titanium-Cobalt Alloy Containing 5\% Co Sintered, Reheated for four hrs. at $900^{\circ}$ C., and Water Quenched

X250 


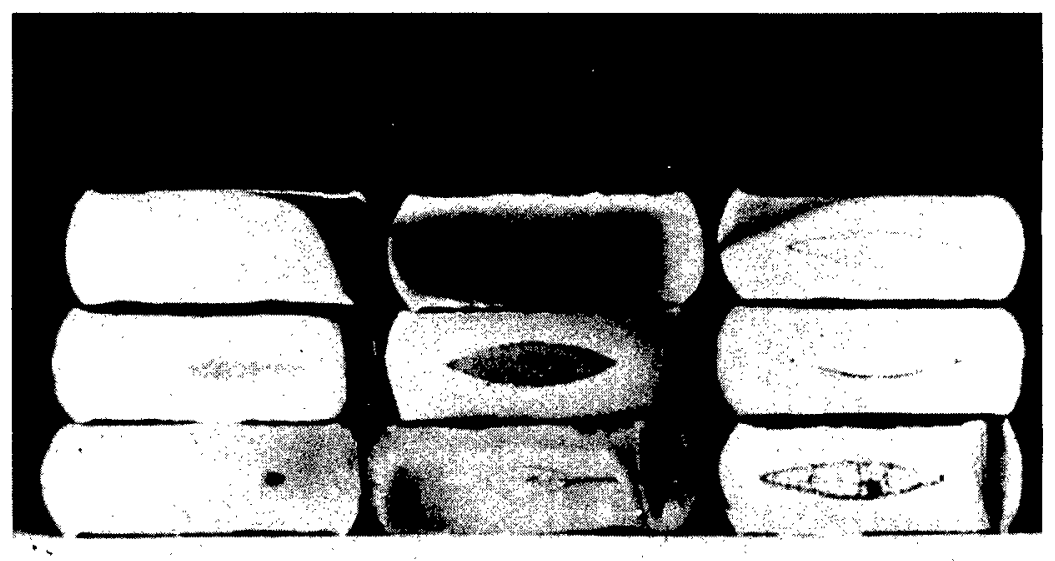

Fig. 12

$\begin{array}{llll} & & & \mathrm{X}^{\frac{1}{2}} \\ \mathrm{Be} & \mathrm{Fe} & \mathrm{Cr} & \\ \mathrm{Co} & \mathrm{Ta} & \mathrm{Mo} & \\ \mathrm{Mn} & \mathrm{Zr} & \mathrm{Ni}\end{array}$

Section thin end of rolled sheath and consolidated metal for 9 of the metals bonded by this method

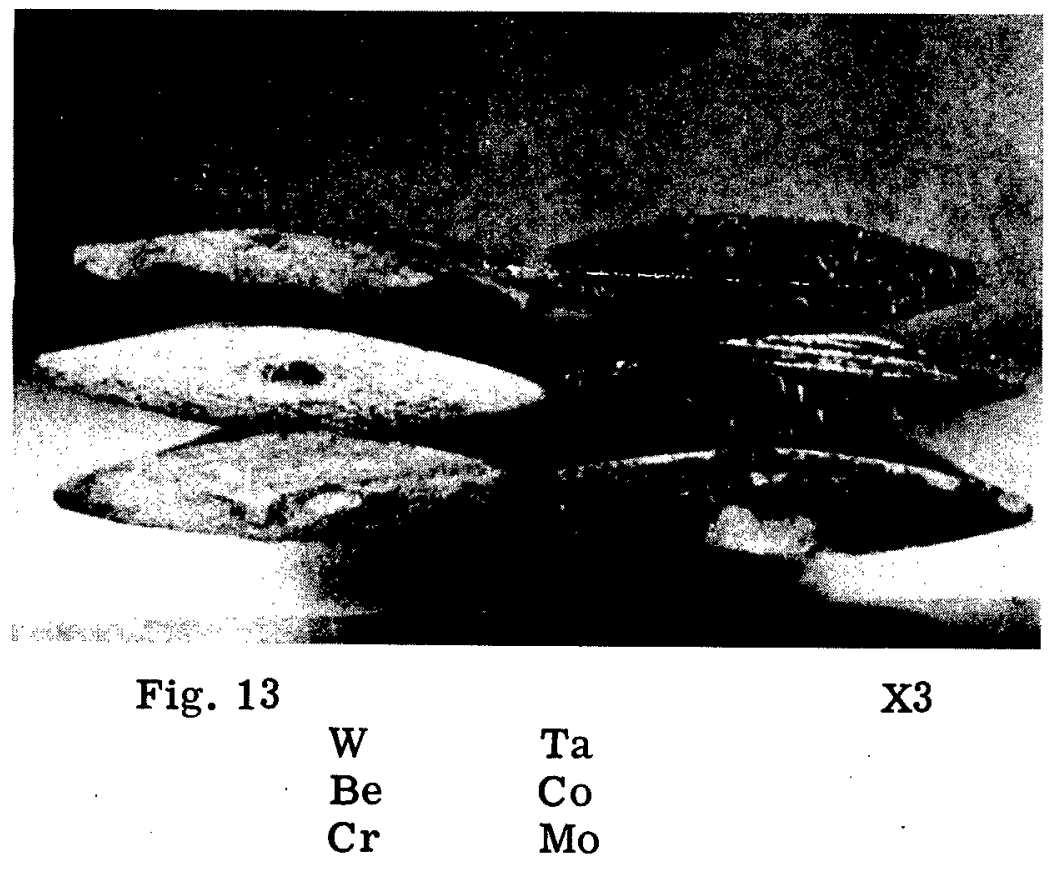

End view of six sheath-rolled metals after removal from sheath 

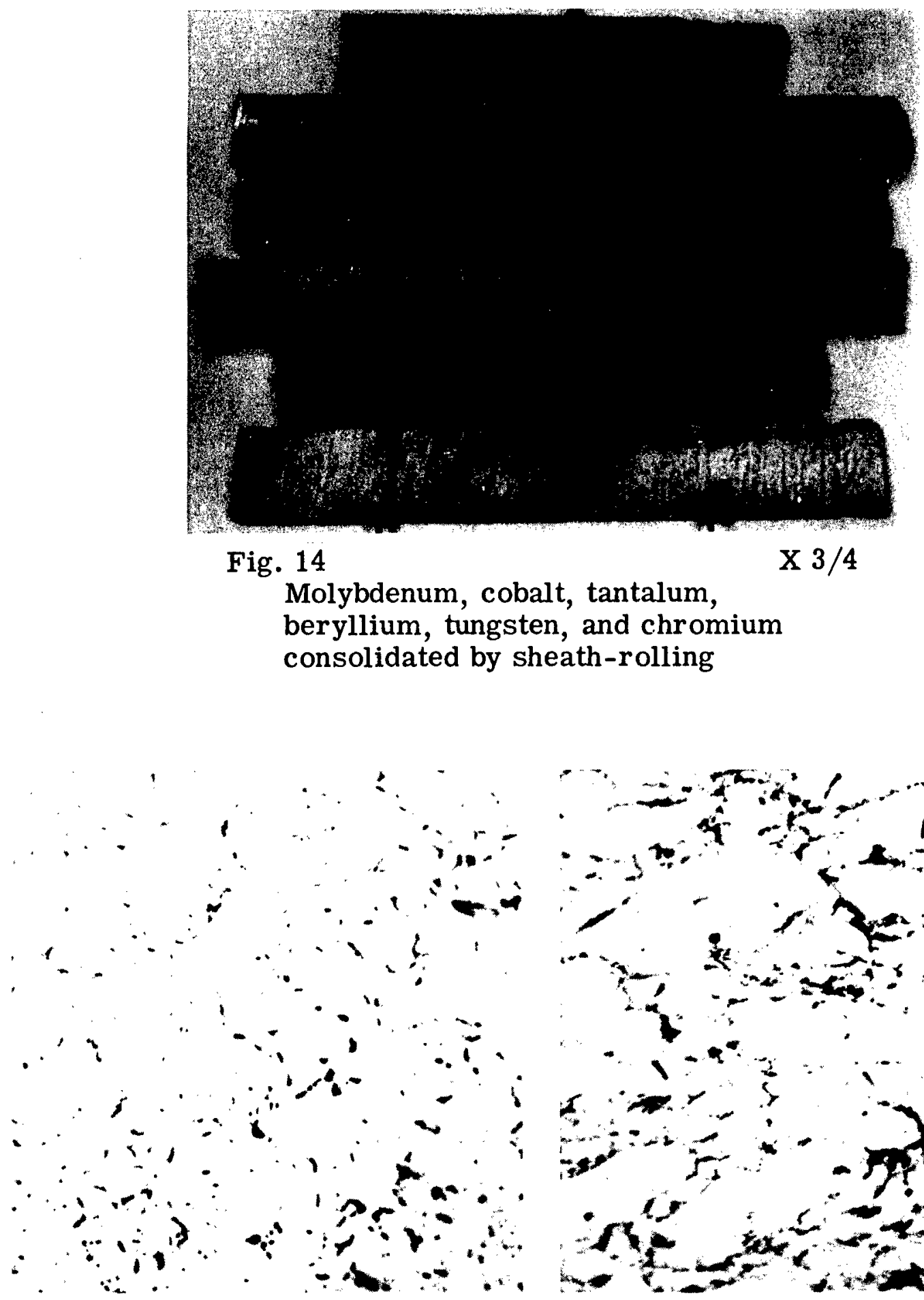

Fig. 15

$\mathrm{X} 250$

Structure of Sheath-Rolled Chromium. Dark constituent due to oxide in original powder

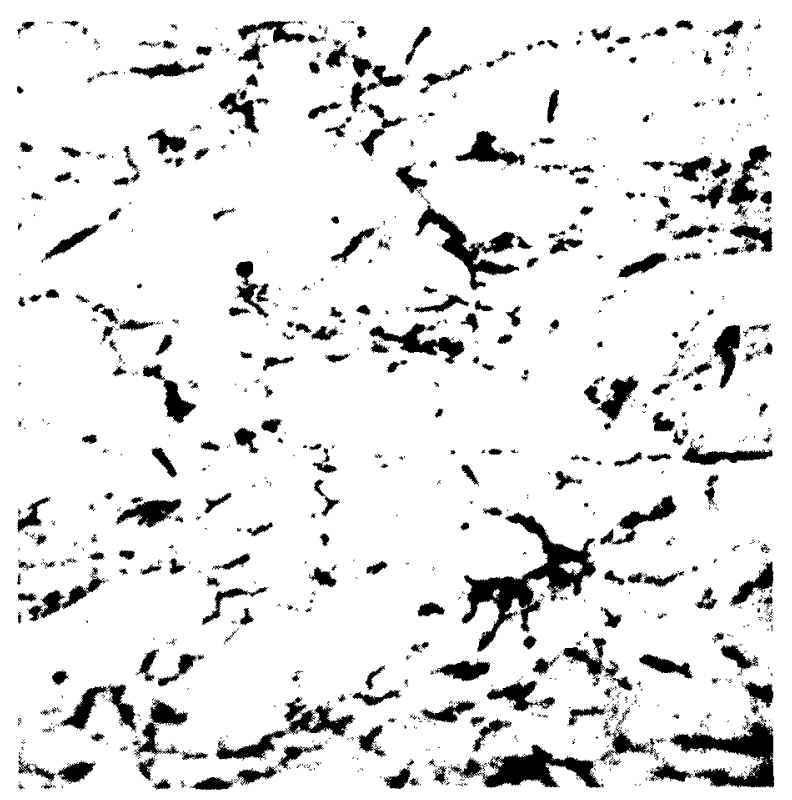

Fig. 16

$\mathrm{X} 250$

Micro Structure of SheathRolled Beryllium. Dark constituent due to oxide in original powder 


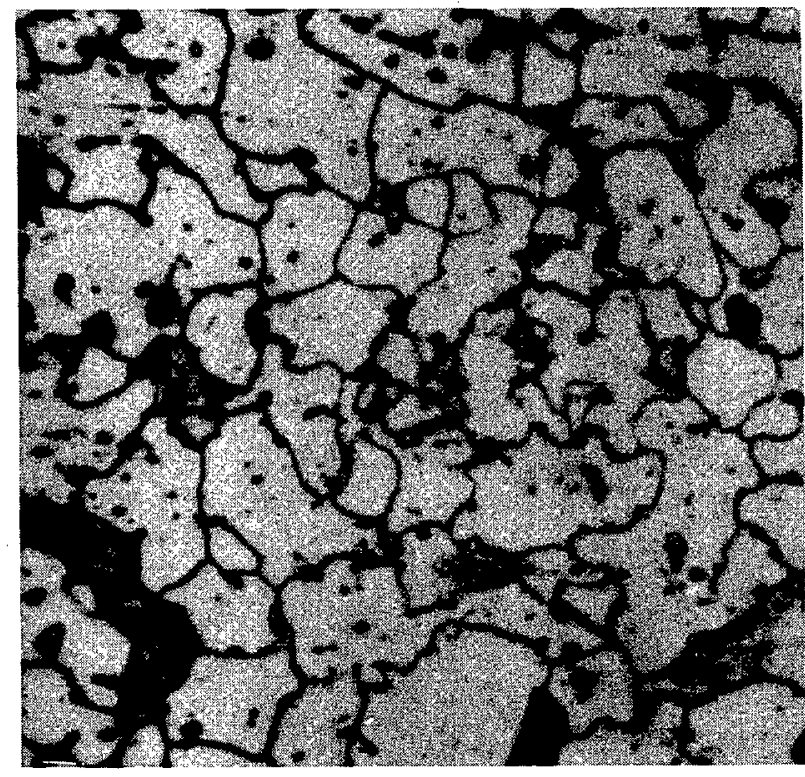

Fig. 17

Sheath-Rolled Nickel

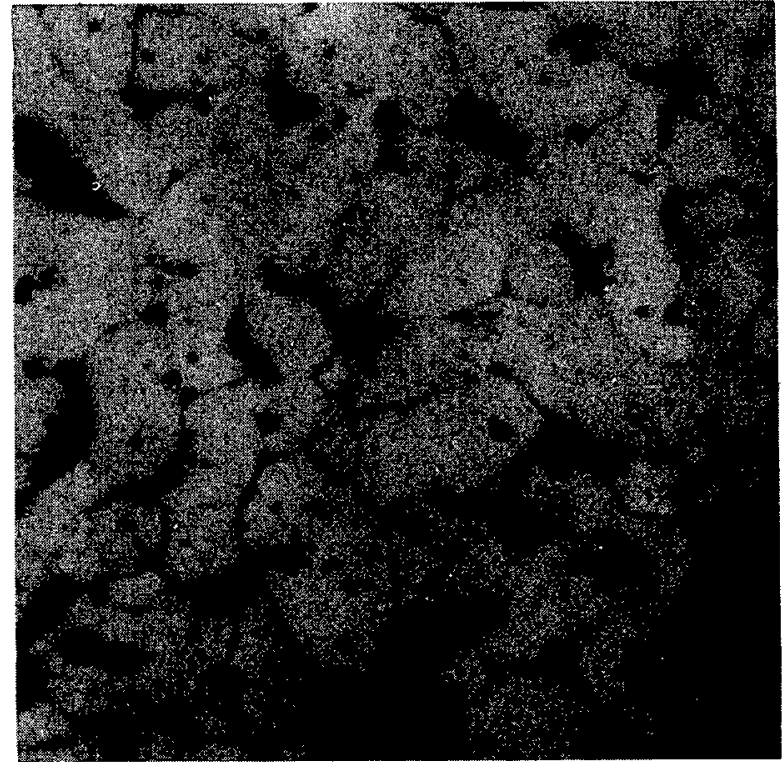

Fig. 18

$\mathrm{X} 250$

Sheath-Rolled Iron.

Pearlite due to carbon absorbed from sheath

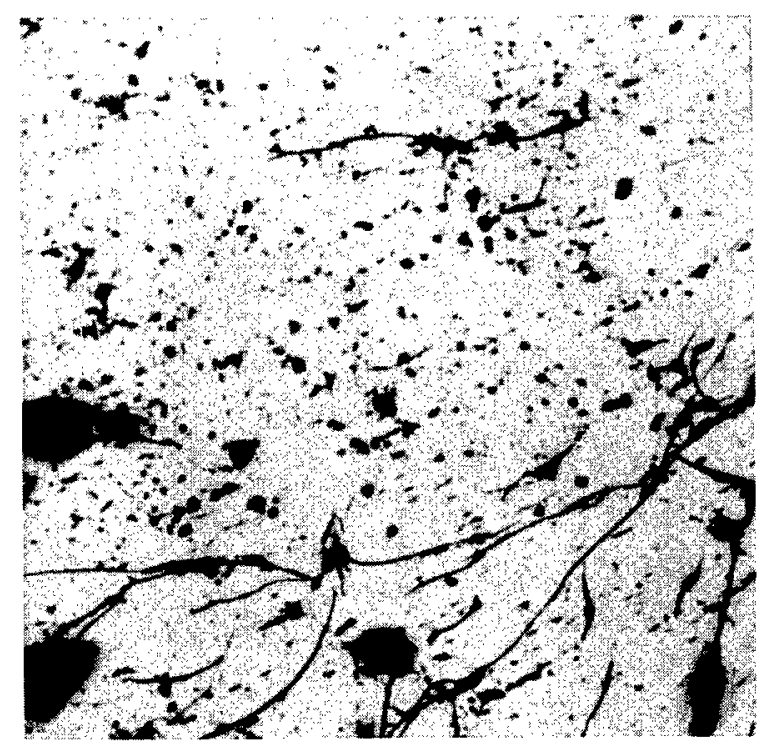

Fig. 19

$\mathrm{X} 250$

Micro Structure of Electrolytic Manganese Cathode Chips Bonded by SheathRolling

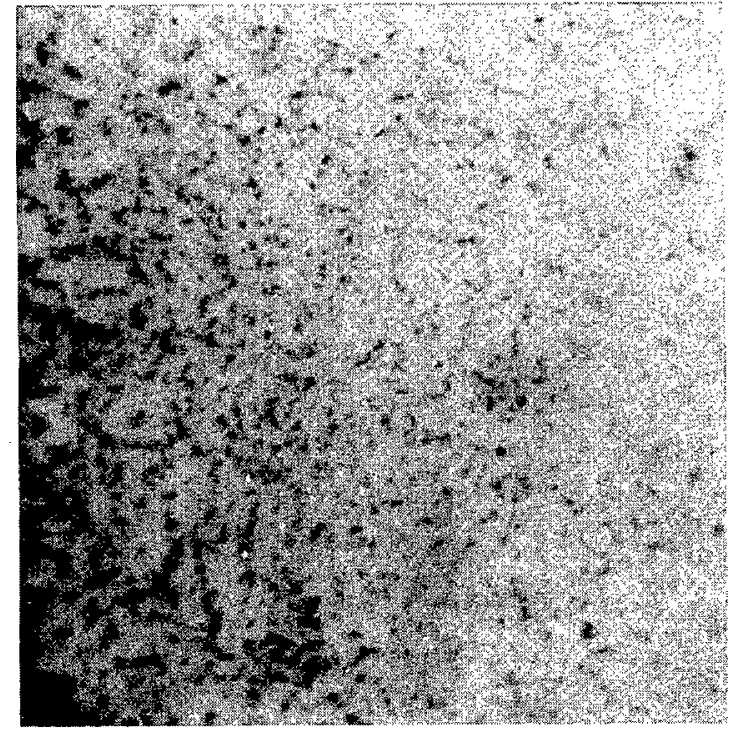

Fig. 20

$\mathrm{X} 250$

Structure of Electrolytic Chromium Flakes Bonded by Sheath-Rolling 


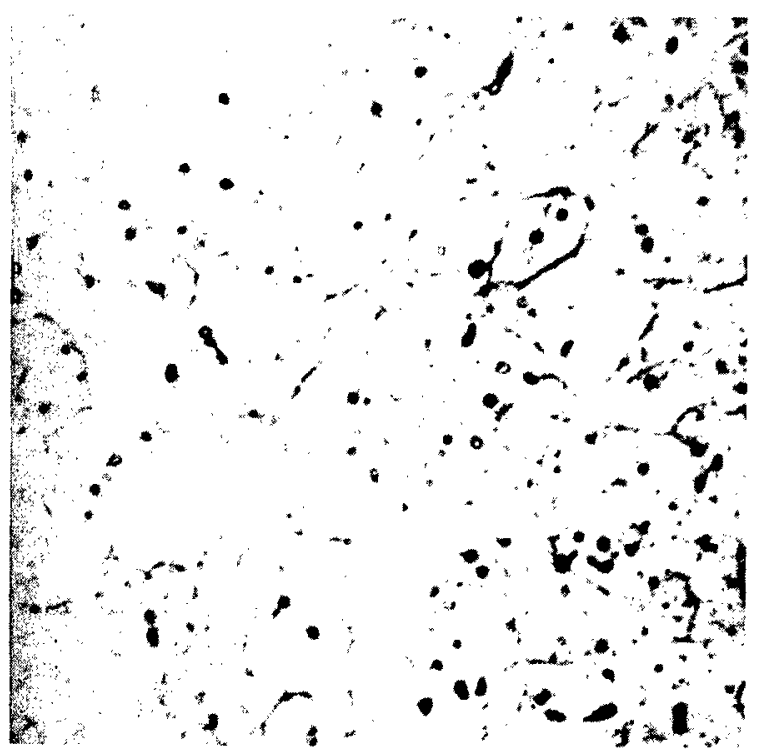

Fig. 21

Electrolytic Cobalt Bonded by Sheath-Rolling

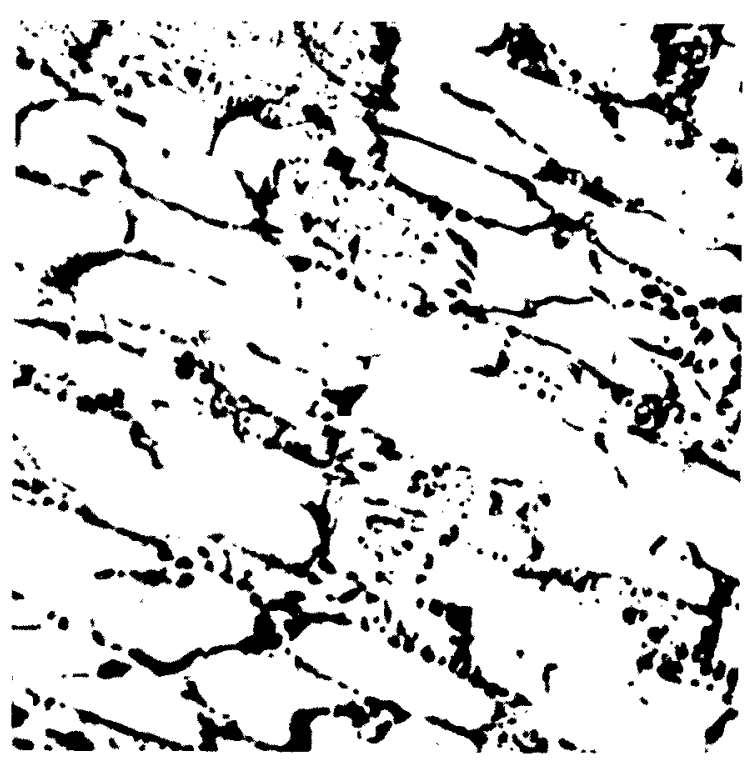

Fig. 22

$\mathrm{X} 250$

Zirconium Scrap Turnings Consolidated by SheathRolling. Light constituent probably iron present in scrap

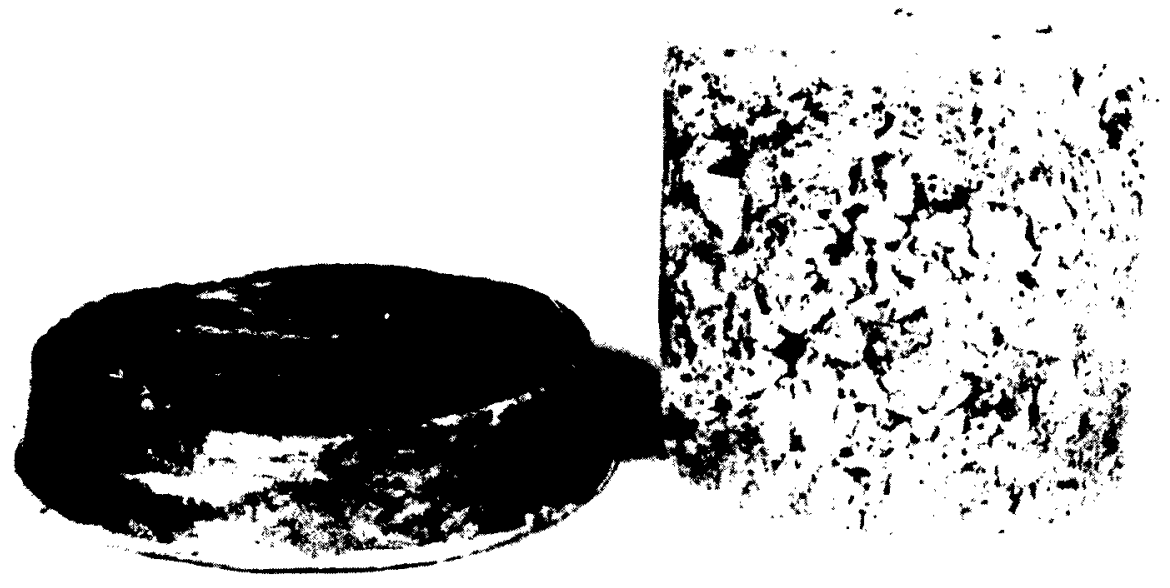

Fig. 23

$\times 3 / 4$

Zirconium Sponge and Consolidated Block 


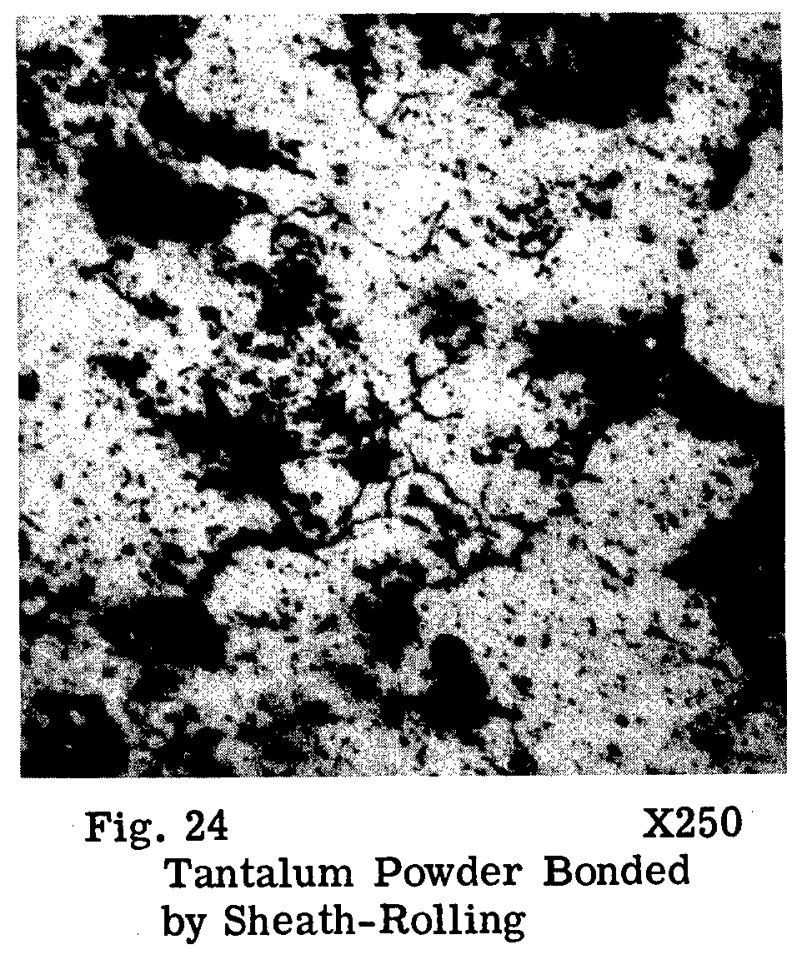

Summary

Sheath rolling of green but unsintered metal compacts, loosely packed powder, or mixture of powders has been shown to be a simple means of forming such material into solid metal. Not all of the results of this study, mainly made on titanium powders but later extended to many other metal powders and mixtures, were predictable or even anticipated. Excellent consolidation was realized even when packing of the powder was not very dense. Voids usually encountered in sintered compacts were absent and the homogeneity of sheath-rolled metal was equivalent to that of the pressed and sintered material that had been subsequently worked. It is believed that the effectiveness of the process is due to the confining action of the sheath which permits distortion of the metal particles, thus disorganizing existing crystalline structures and rupturing any surface films on the particles and promoting metal-to-metal contact and hence rapid diffusion to produce homogeneous metal. Patent applications based on some of the findings in this investigation will be prosecuted.

\section{A TENTATIVE TITANIUM-NICKEL DIAGRAM}

The titanium-nickel alloy system has been under investigation in the Federal Bureau of Mines Laboratories to determine the range of compositions in which useful alloys might be found. Major interest has centered on the properties of such alloys but, because of a lack of necessary information in the literature, it has been desirable to obtain at least a rough outline of the phase relationships of these alloys. This report concerns the data obtained in this study.

The alloys were prepared by normal powder metallurgy methods and also by the sheath-rolling method previously reported. In general, phase boundaries and phases were determined largely from metallographic data, although the identities of 
the microscopic constituents were checked by X-ray diffraction data and supplementary data were obtained by thermal analysis and hardness determinations. To insure rapid approach toward equilibrium, all alloys were studied in the wrought condition after working at the temperature level under investigation. That is, to determine the constitution of the alloys at a given temperature, they were enclosed in iron sheaths to protect them from active gases, hot worked at that temperature, returned to the furnace for recrystallization and to permit diffusion to take place, and then quenched in water. The constitutions of the alloys were then determined by study of the microstructures. The results of the work have been used to construct the constitution diagram of Figure 1.

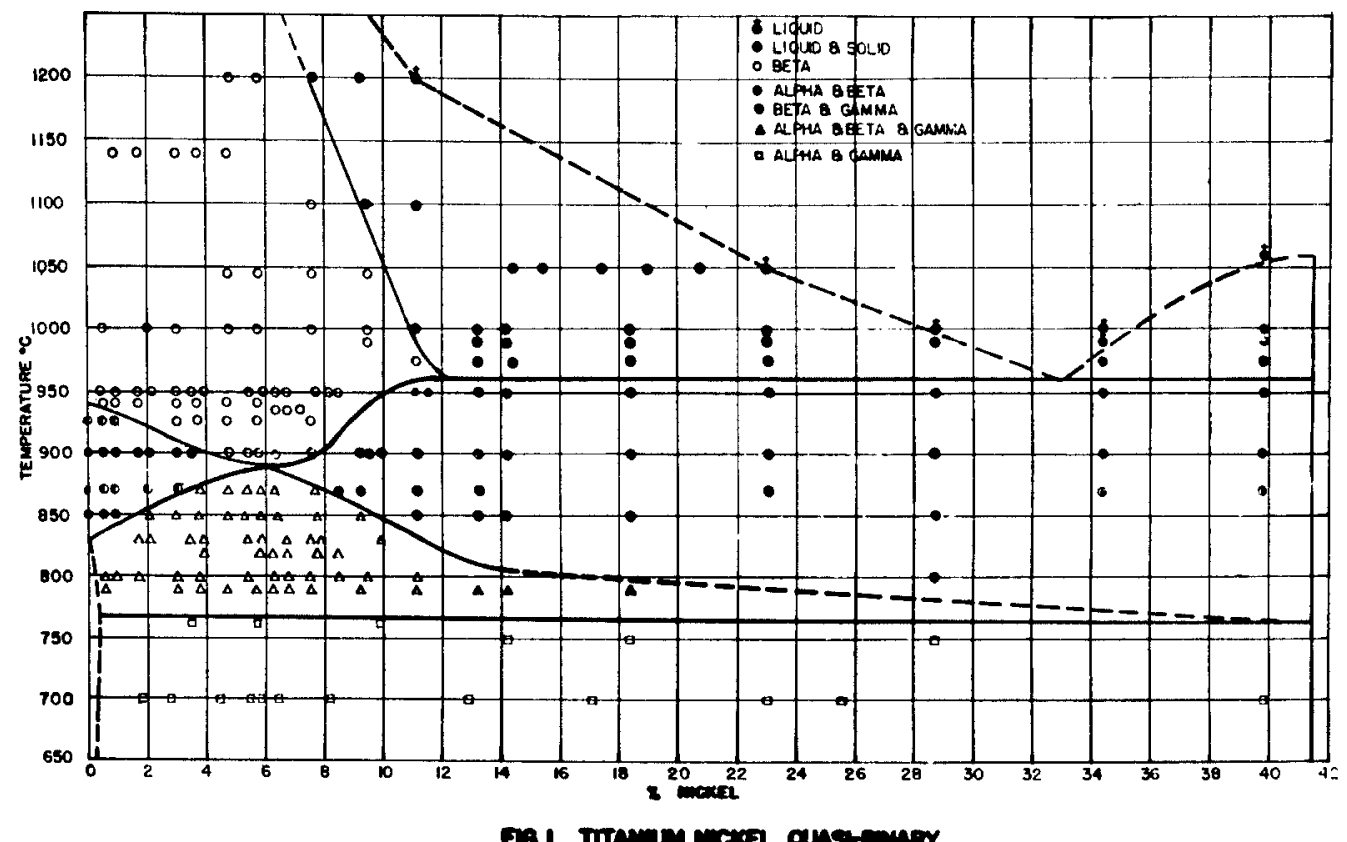

Early in the investigation, it was found that the impurities present in the titanium had a very significant effect on the alloys and that they were not behaving as simple binary alloys. Oxygen, known to be present to the extent of $0.1 \%$ to $0.2 \%$, is believed to play the most important role. This was indicated by other work also under way on the titanium-oxygen system and by the data on several titanium-nickel alloys to which varying amounts of oxygen had been added. The effect of oxygen is such as to make it necessary to consider the alloys as ternary rather than binary alloys and Figure 1 should, therefore, be viewed as a plot of a quasi-binary section through the titanium-nickel oxygen system at the oxygen level of the titanium powder.

This, however, does not detract from the usefulness of the results, since at the present time evaluation of nickel as an alloying element in titanium must necessarily take into account the purity of the titanium available for the work. Although efforts are being made to improve the reduction process and, hence, the quality of the titanium powder, large-scale work on the preparation and properties of titanium alloys must necessarily utilize the type of metal now available and the results should be interpreted in the light of the limitation imposed by the impurities in the powder.

Although the solidus and liquidus of the system were of little interest for 
the immediate purposes, melting was encountered in treatment of some of the alloys above 950 degrees Centigrade and it was, therefore, necessary to determine melting points. These data were obtained by metallographic study of alloys quenched from successively higher temperatures. The beginning of melting was readily observed in single-phase alloys and, while it was more difficult in two-phase alloys, satisfactory results could be obtained. Representative microstructures are shown in Figures 2 to 7.

As can be seen in Figure 1, nickel lowers the melting point from 1745 degrees Centigrade for titanium to 965 degrees Centigrade for the $12 \%$ alloy. This temperature appears to correspond to a eutectic horizontal with the eutectic at about $33 \%$ nickel. Some estimate of the liquidus temperature was also possible and it is shown as a dotted line. These data make it quite plain that any high-temperature alloys that might be developed in this system will necessarily have a limited nickel content. The range of six to eight percent nickel is probably the maximum useful range for investigation of high-temperature possibilities.

In the solid state, nickel is soluble in the high-temperature beta form of titanium but not in the low-temperature alpha form. The maximum solubility occurs at 965 degrees Centigrade and $12 \%$ nickel. The beta solid solution is stable down to 890 degrees Centigrade, where it breaks down, forming two- or three-phase structures. One of these phases is the hexagonal, alpha, titanium, containing less than $0.5 \%$ nickel in solution. The other phase, designated as gamma, is a body-centered constituent containing approximately $41 \%$ nickel. Both of these phases may coexist with beta down to 765 degrees Centigrade. Decomposition of beta is complete below this temperature and the alloys consist entirely of gamma distributed in a ground mass of alpha.

Typical microstructures of the alloys encountered are shown in Figures 8 to 25. The Widmanstatten structures obtained on quenching unstable beta solid solutions are shown in Figures 8, 9, 10 and 13. In alloys with nickel contents above 5\%, the beta can be preserved by quenching as in Figures 14 and 15. It is quite probable that for the greatest response to heat treatment, useful titanium-nickel alloys should contain between $5 \%$ and $12 \%$ nickel. This does not rule out the lower nickel alloys, since structural alteration, and hence controlled variation of physical properties, is still possible. The maximum effects will, however, be found in the higher range of alloy content. Alpha-beta structures encountered are shown in Figures 11 and 12, betagamma in Figures 16 and 17, and typical three-phase structures in Figures 18 through 21. Heat treatment of alloys in the fields represented by these structures would not appear to be particularly promising but additional investigation of the properties of the alloys will be required before positive recommendation can be made. Structures composed of alpha and gamma stable below 765 degrees Centigrade are shown in Figures 22 through 25 . They bear considerable resemblance to the structures obtained in steels on tempering below the transformation point and suggest that similar property variation can be obtained by quenching and tempering treatments.

A tentative titanium-nickel binary diagram is given in Figure 26. This diagram is derived from Figure 1 on the assumption that the true titanium-nickel system will show the same general features. The three-phase field must, of course, disappear and the beta phase will probably be found to break up eutectoidally. Since oxygen raises the eutectoid temperature, it is not likely to be more than 765 degrees Centigrade in the binary system. Similarly, since oxygen has probably lowered the eutectic horizontal, it will not be less than 960 degrees Centigrade. This diagram, of course, is not exact but should be treated as a tentative diagram offered to assist in guiding future work on these alloys. 


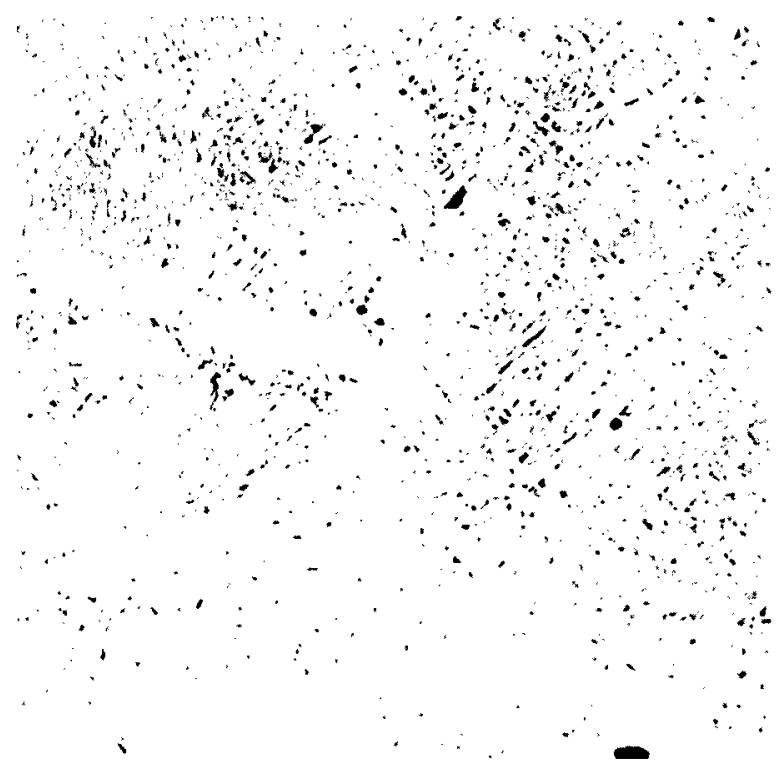

Fig. 2

Micro-Structure of $4.75 \%$ Ni Alloy Quenched from $1200^{\circ} \mathrm{C}$. No melting has occurred at this temperature

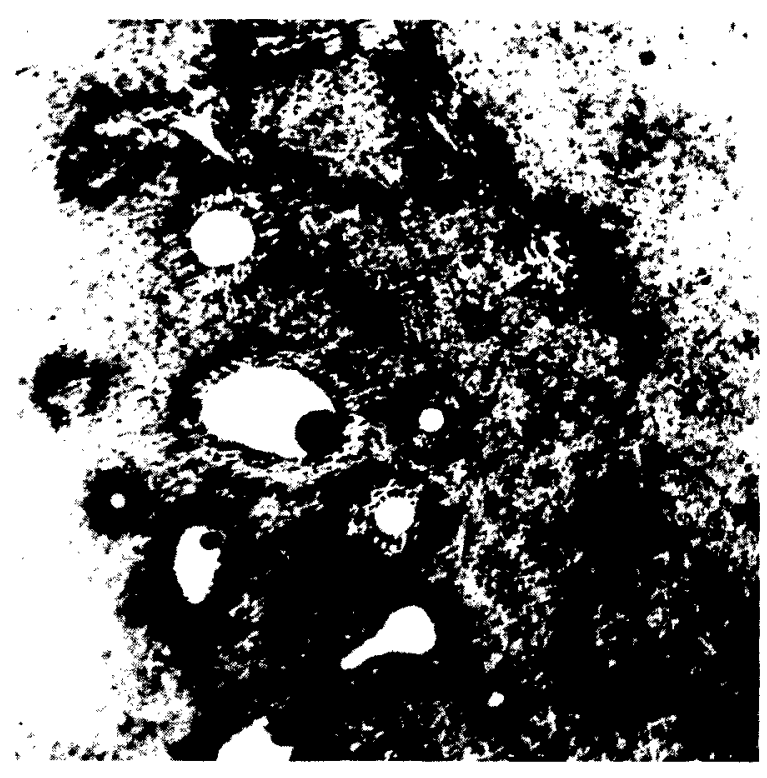

Fig. 3

Micro-Structure of $7.55 \%$ Ni Alloy Quenched from $1200^{\circ} \mathrm{C}$. Some melting has taken place

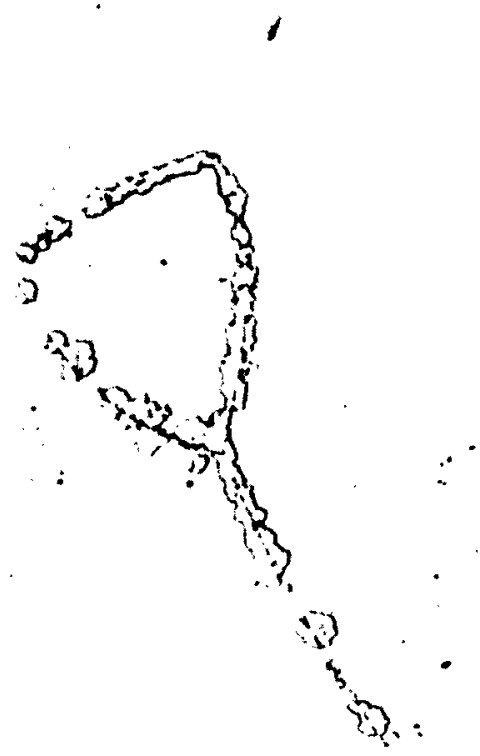

Fig. 4

Micro-Structure of $11.1 \%$ Ni Alloy Quenched from $1000^{\circ} \mathrm{C}$. Traces of melting in the grain boundaries $\mathrm{X} 250$

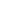




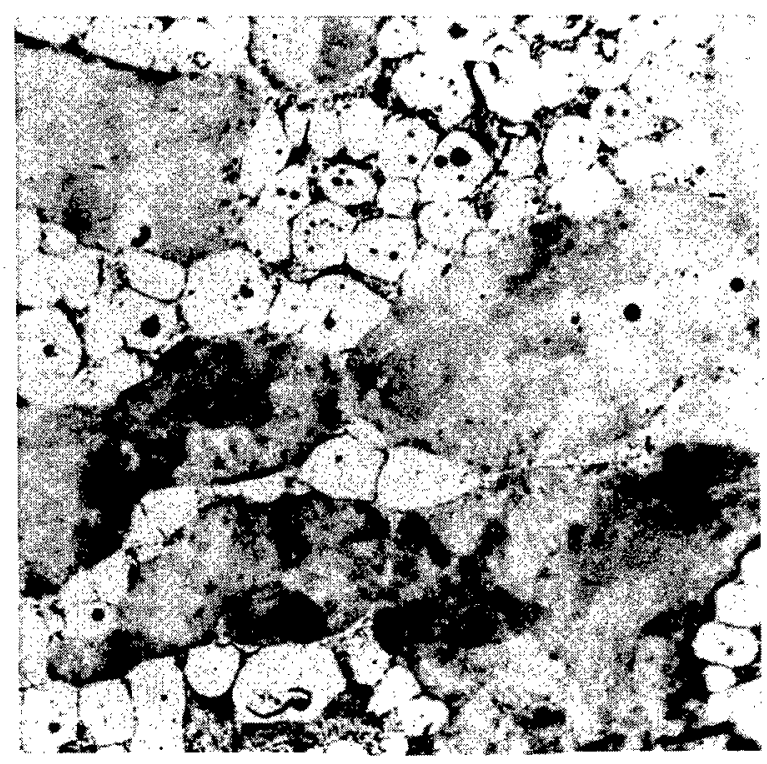

Fig. 6

$\mathrm{X} 250$

Micro-Structure of $20.7 \%$ Ni Alloy Heated to $990^{\circ} \mathrm{C}$. Partial melting has occurred and some eutectic formed on solidification

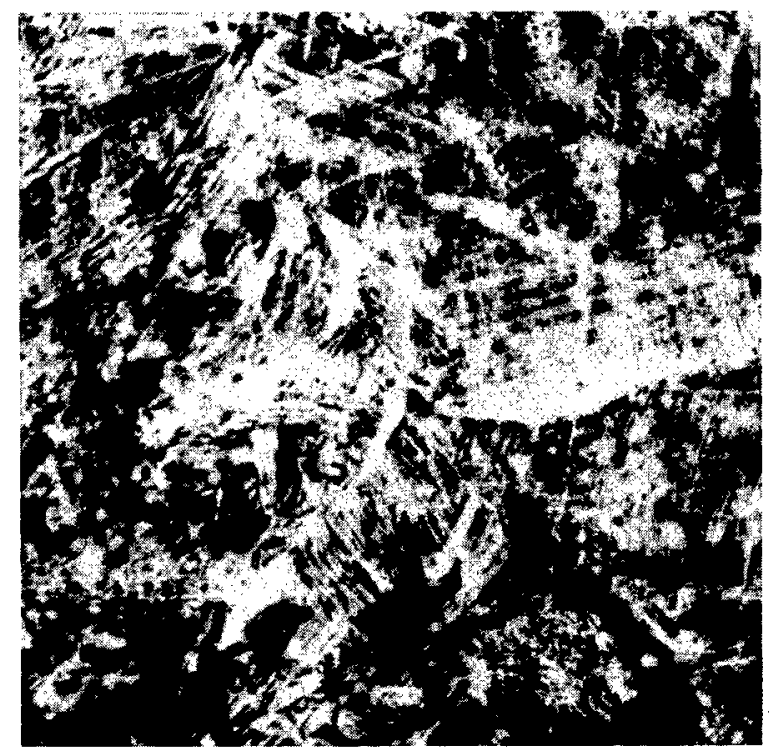

Fig. 8

$\mathrm{X} 250$

Micro-Structure of $0.40 \%$ Ni Alloy Water Quenched from $950^{\circ} \mathrm{C}$. Alloy was composed of beta solid solution at temperature

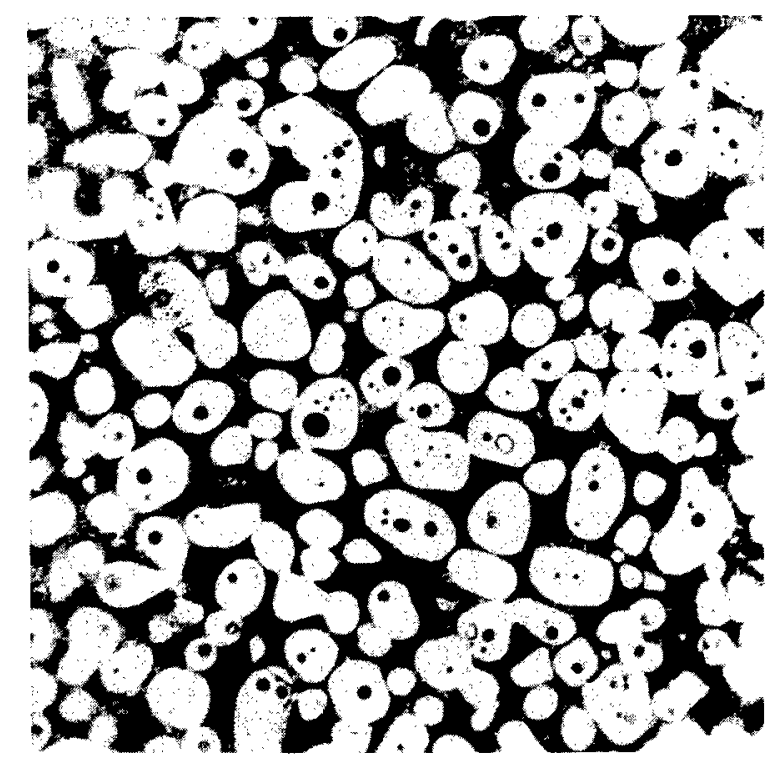

Fig. 7

$\mathrm{X} 250$

28.7\% Ni Alloy Heated to $990^{\circ} \mathrm{C}$. General melting has taken place at this temperature

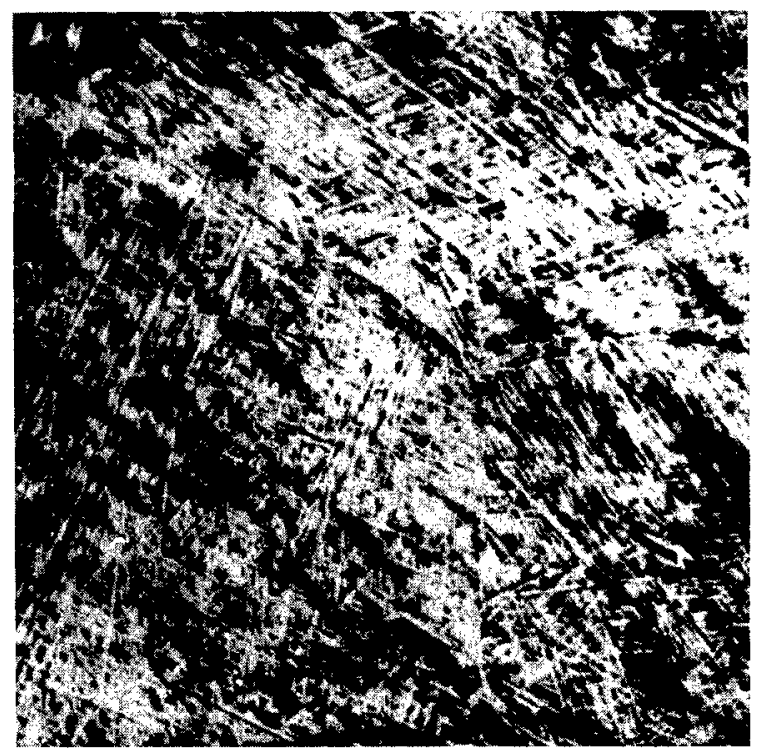

Fig. 9

$\mathrm{X} 250$ Micro-Structure of $0.92 \%$ Ni Alloy Water Quenched from $950^{\circ} \mathrm{C}$. Alloy in beta field at temperature, structure typical of decomposition of - 41 - beta on cooling 


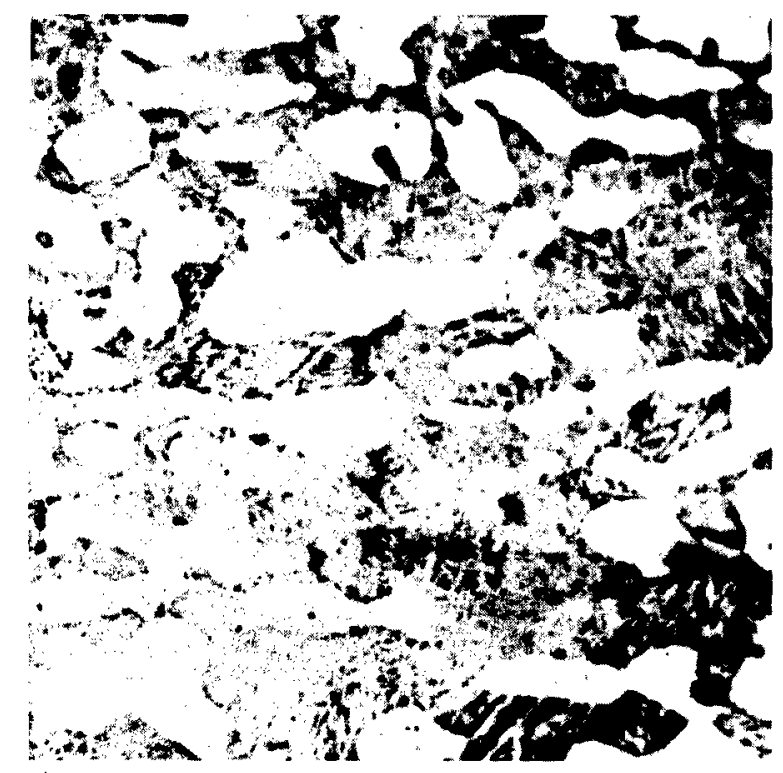

Fig. 10 Micro-Structure of $1.7 \% \mathrm{Ni}$ Alloy Water Quenched from $950 \mathrm{C}$., showing the decomposition product of the beta solid solution formed on quenching

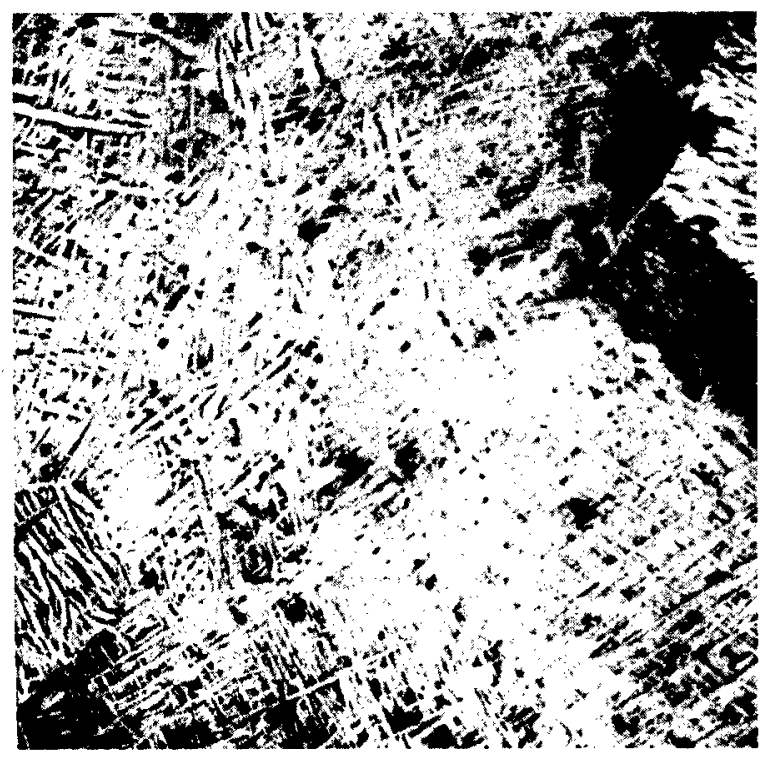

Fig. 12

$\mathrm{X} 250$

Micro-Structure of $1.7 \% \mathrm{Ni}$ Alloy Quenched from 900 C. This alloy is also in the alpha-beta field at temperature

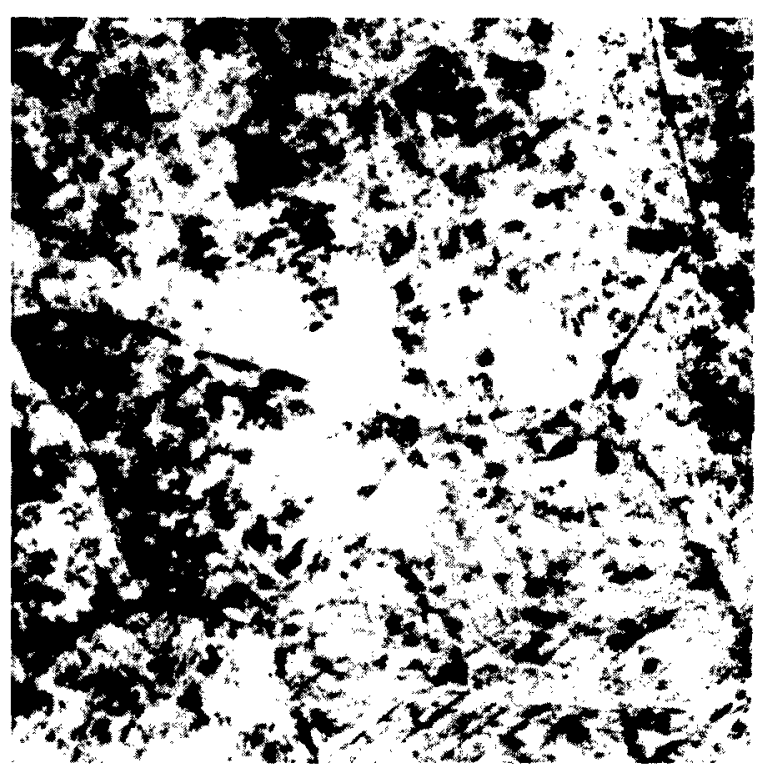

Fig. 11

$\mathrm{X} 250$

Micro-Structure of $0.52 \%$ Ni Alloy Water Quenched from $900 \mathrm{C}$. This alloy is in the alpha-beta field at temperature

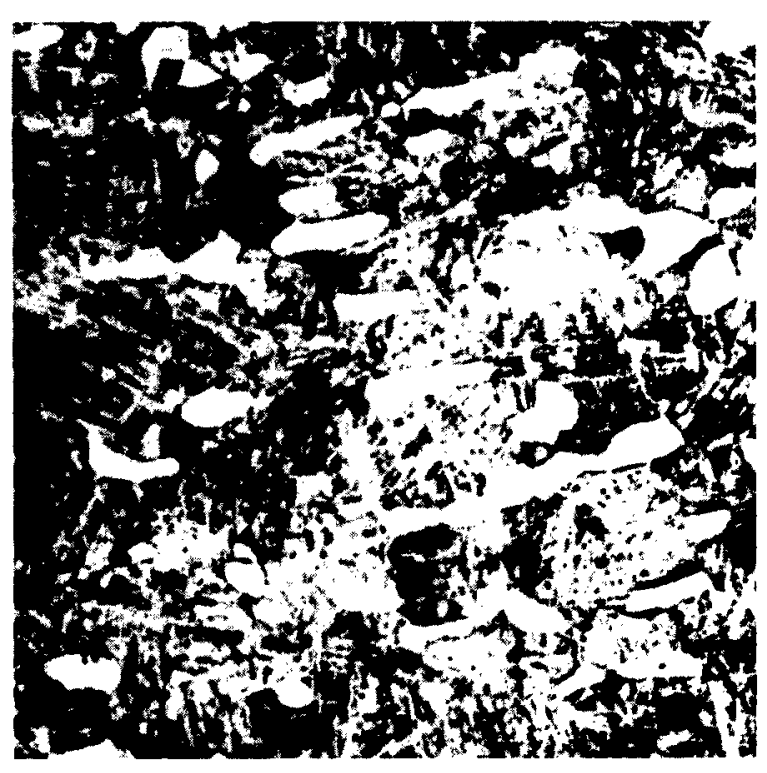

Fig. 13

$\mathrm{X} 250$

Micro-Structure of $4.7 \% \mathrm{Ni}$ Alloy Water Quenched from 900 C. The alloy is entirely beta solid solution at temperature 


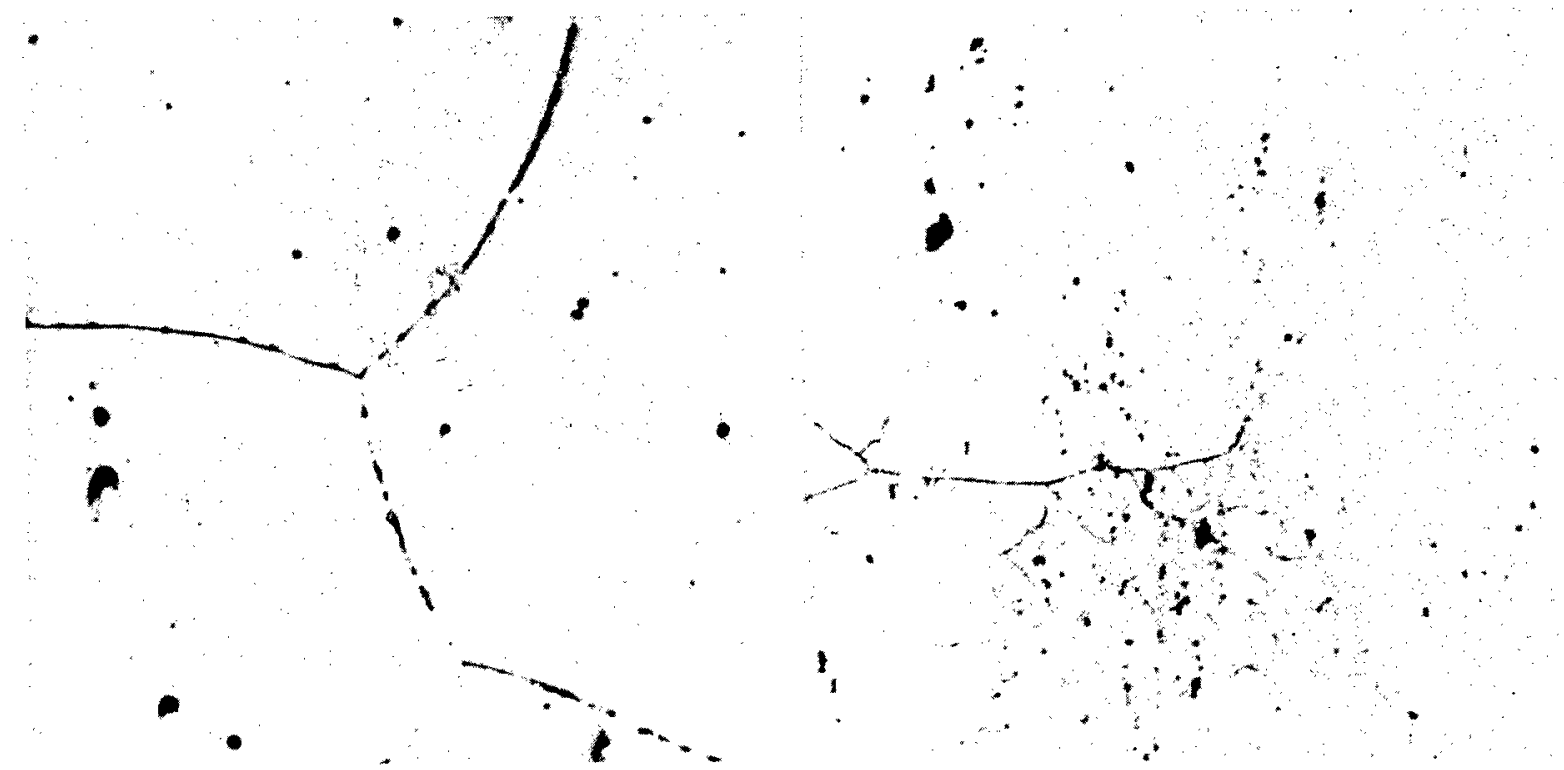

Fig. 14

Fig. $15 \quad \times 250$ Beta Solid Solution in $9.45 \%$ Beta Solid Solution in a $7.90 \% \mathrm{Ni}$ Alloy as Quenched Ni Alloy As Quenched from $950^{\circ} \mathrm{C}$. from $900^{\circ} \mathrm{C}$.

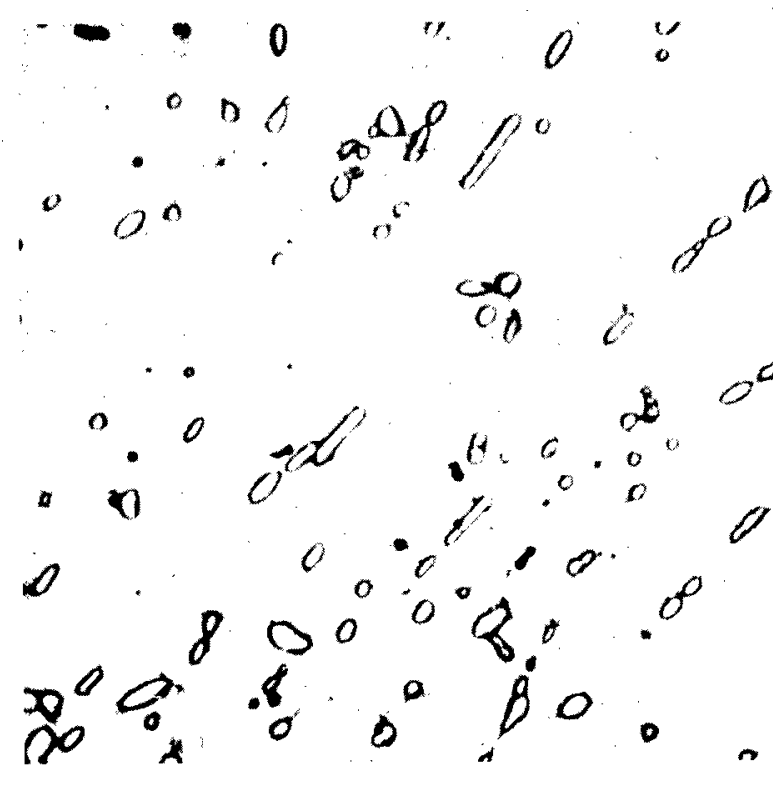

Fig. 16 $\mathrm{X} 250$

Beta and Gamma in the $9.45 \%$ Alloy Quenched from $900^{\circ} \mathrm{C}$.

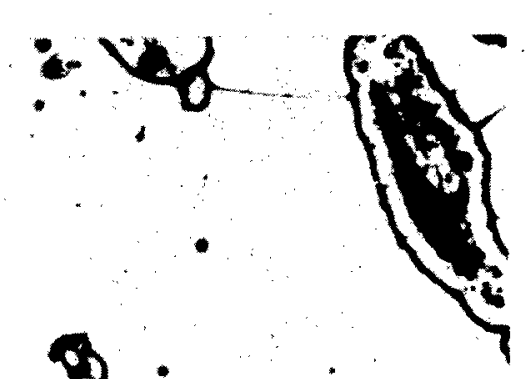

6

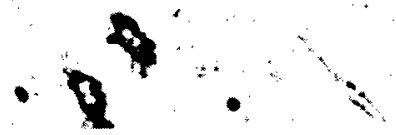

Fig. 17

$\mathrm{X} 250$

Beta and Gamma in the $14.2 \%$ Ni Alloy Quenched from $900^{\circ} \mathrm{C}$. 

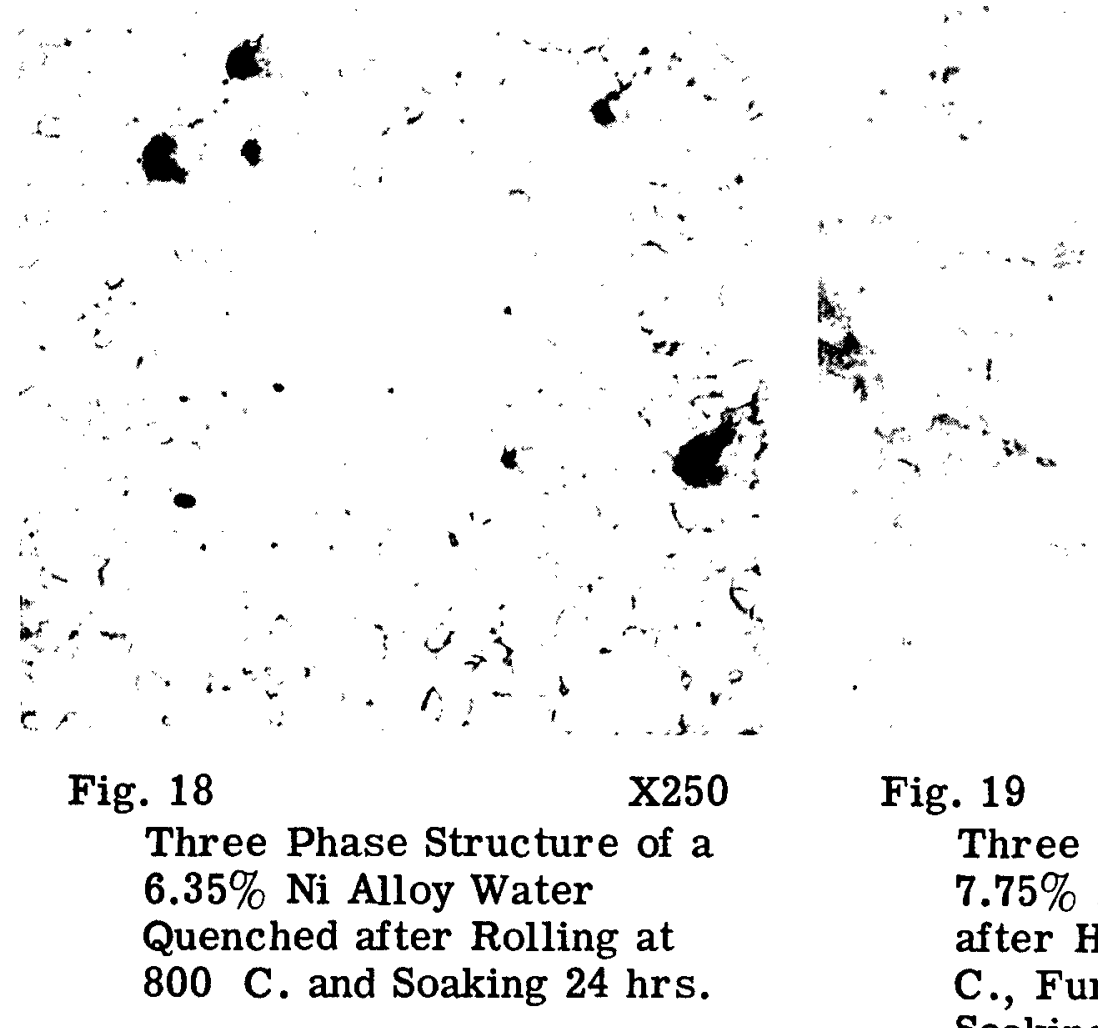

Fig. 19

X250

Three Phase Structure in a 7.75\% Ni Alloy Quenched after Heating $18 \mathrm{hrs}$. at $980^{\circ}$ C., Furnace Cooling to and Soaking $48 \mathrm{hrs}$. at $800^{\circ} \mathrm{C}$.

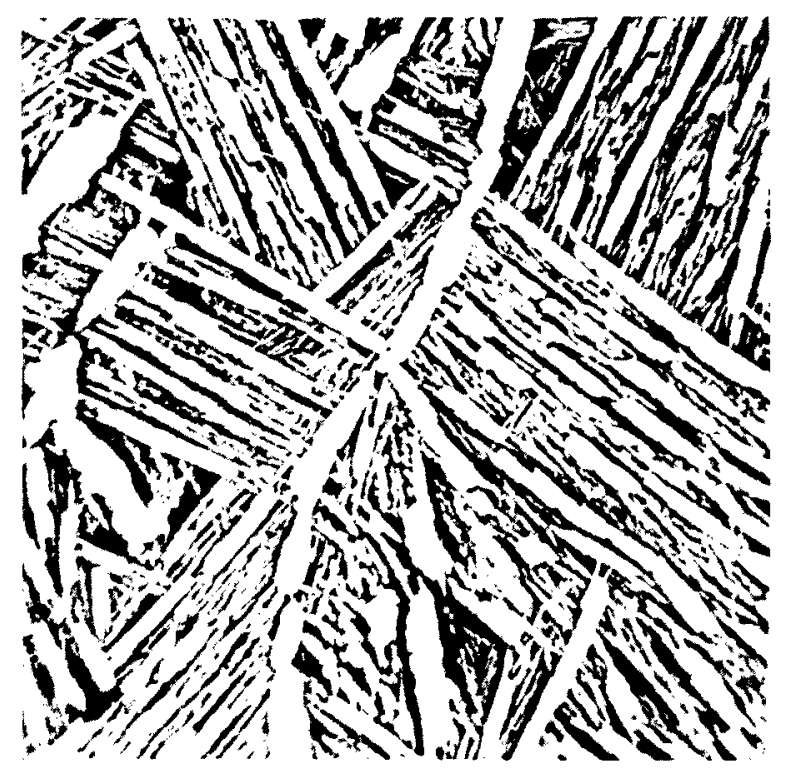

Fig. 20

$\mathrm{X} 250$

Three Phase Structure in 5.9\% Alloy Quenched after Heating $16 \mathrm{hrs}$. at $990^{\circ} \mathrm{C}$., Furnace Cooling to $870^{\circ} \mathrm{C}$. and Soaking $24 \mathrm{hrs}$. at this Temperature. Gamma and Alpha not distinguishable.

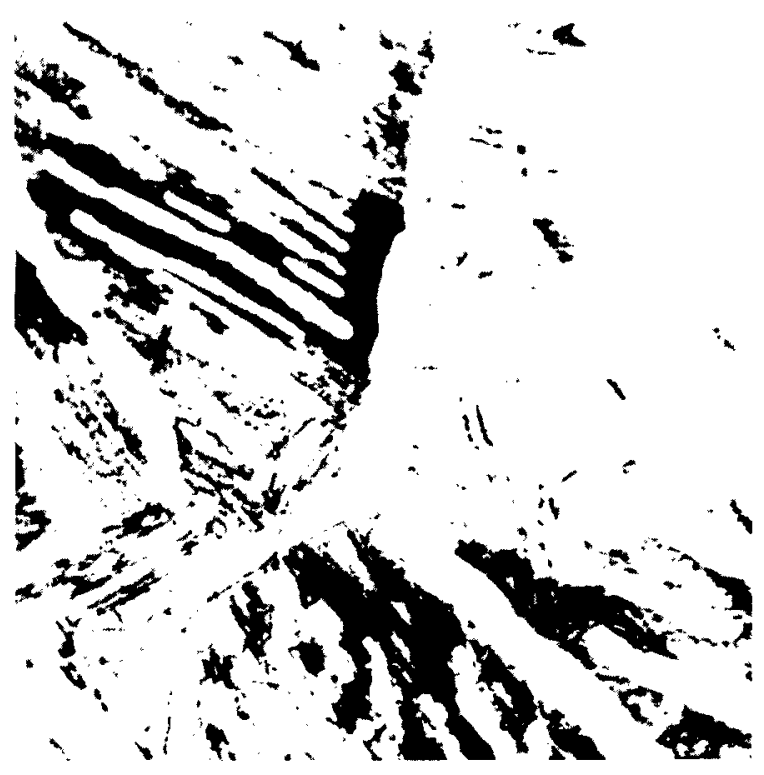

Fig. 21 $\mathrm{X} 250$

Three Phase Structure in $5.4 \%$ Ni Alloy Quenched after $18 \mathrm{hrs}$. at $990^{\circ} \mathrm{C}$., Furnace Cooling to $820^{\circ} \mathrm{C}$., and Soaking $24 \mathrm{hrs}$. at this temperature. Alpha etched somewhat darker, gamma bright. 


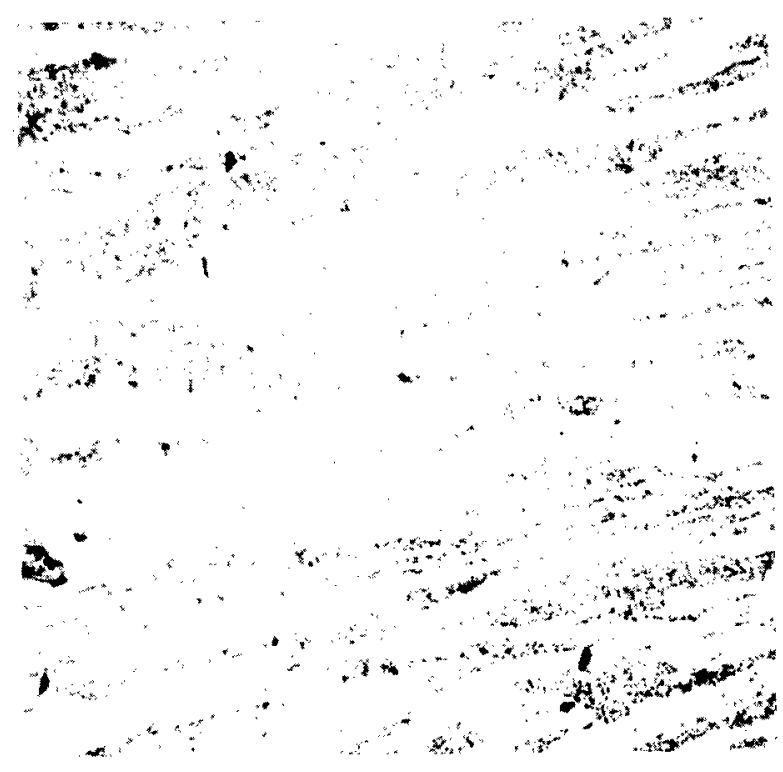

Fig. 22

$\mathrm{X} 250$

Alpha-Gamma Structure in 1.7\% Ni Alloy Water Quenched after Hot Rolling and Soaking at $750^{\circ} \mathrm{C}$.

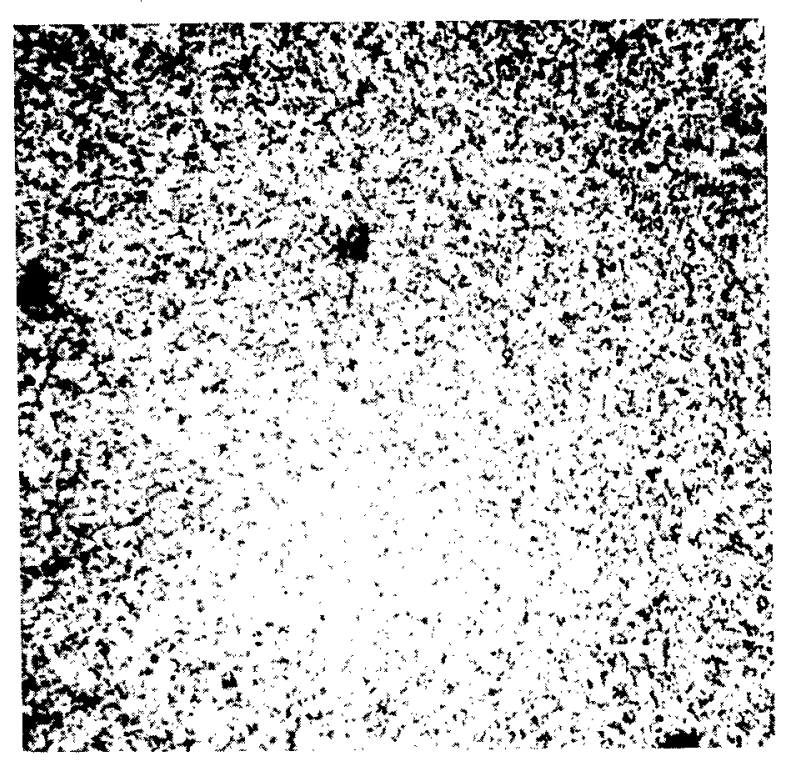

Fig. 24

$\mathrm{X} 250$ Alpha-Gamma Structure of 8.15\% Ni Alloy Quenched after Hot Rolling and Soaking at $700^{\circ} \mathrm{C}$.

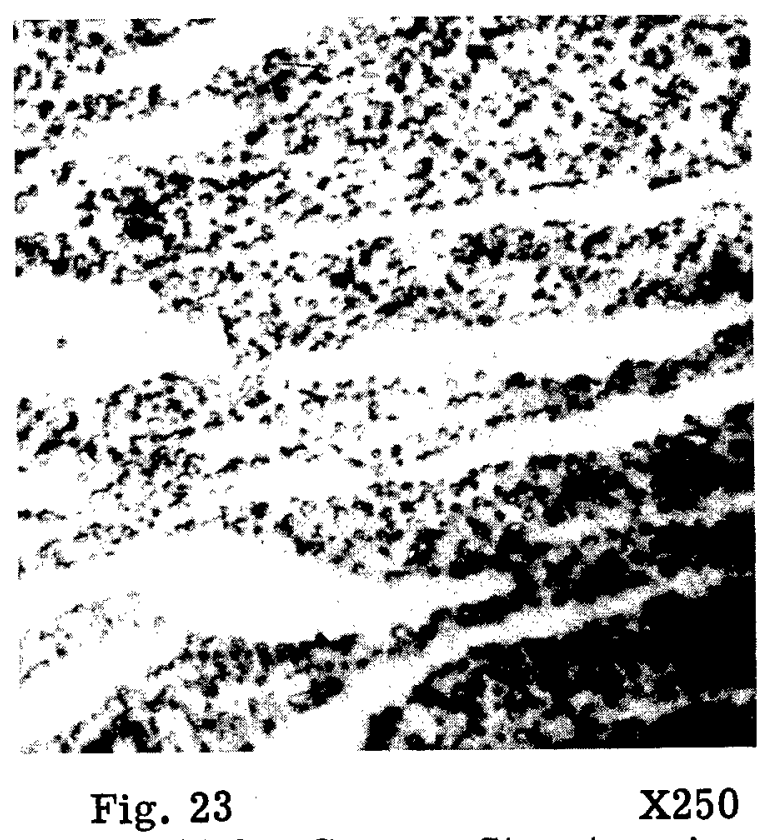

Alpha-Gamma Structure in 4.7\% Alloy Quenched after Hot Rolling and Soaking at $750^{\circ} \mathrm{C}$.

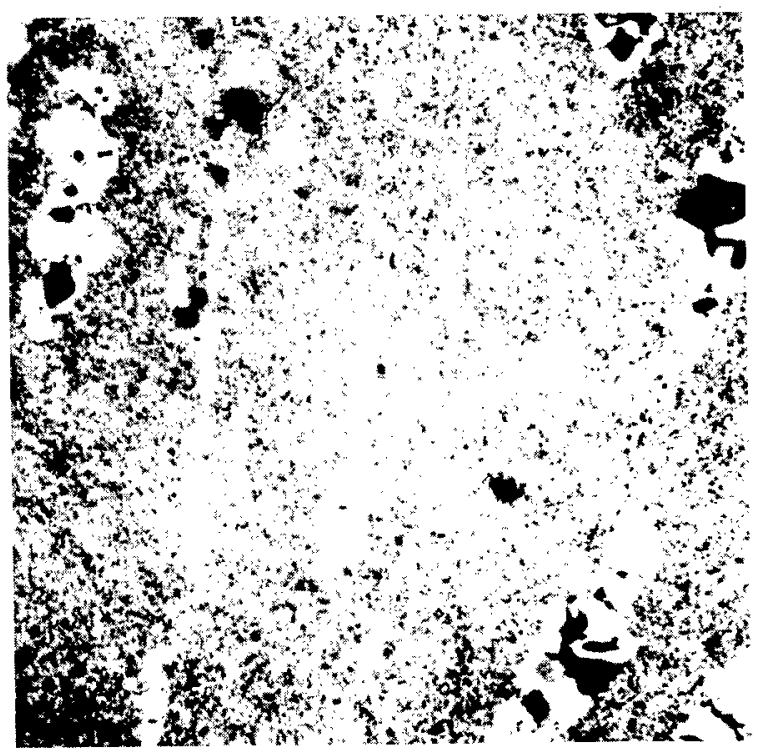

Fig. 25

$\mathrm{X} 250$

Alpha-Gamma Structure in $17.05 \%$ Ni Alloy Quenched after Hot Rolling and Soaking at $700^{\circ} \mathrm{C}$. 


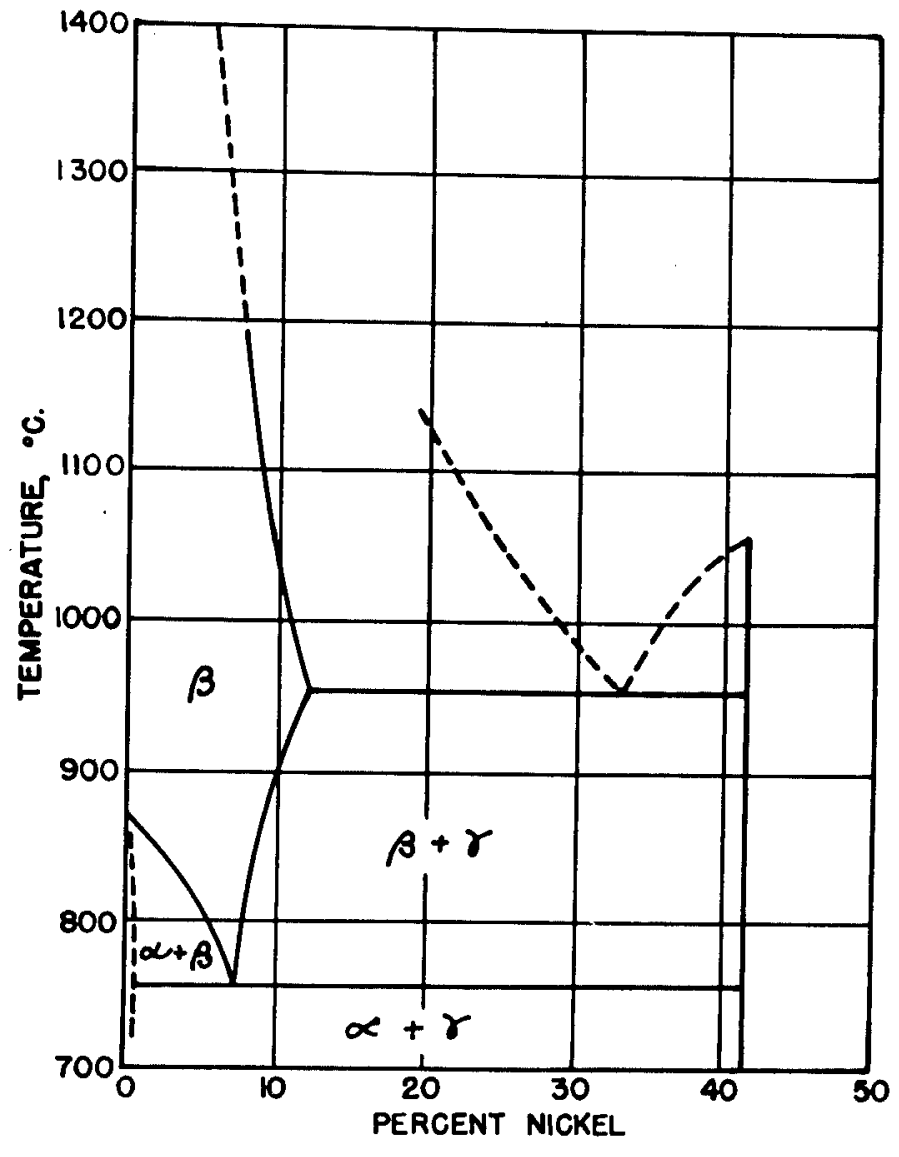

FIG. 26 TENTATIVE EQUILIBRIUM DIAGRAM, TITANIUM-NICKEL

\section{Summary}

A quasi-binary diagram for titanium-nickel alloys containing $0.1 \%$ to $0.2 \%$ oxygen has been constructed. This diagram indicates that addition of nickel rapidly lowers the melting point to 965 degrees Centigrade for alloys containing more than $12 \%$ nickel and that a eutectic melting at this temperature occurs at approximately $33 \%$ nickel. One constituent of the eutectic is the beta solution, the high-temperature form of titanium containing $12 \%$ nickel in solution. The other is a nickel-rich constituent designated as gamma and containing approximately $41 \%$ nickel. The beta solution breaks down below 890 degrees Centigrade, forming two- and three-phase alloys, and completely disappears below 765 degrees Centigrade, where the alloys are composed of alpha titanium containing less than $0.5 \%$ nickel in solution and the gamma phase.

The diagram suggests that the useful titanium-nickel alloys will probably contain up to $12 \%$ nickel and that, for high-temperature use, the nickel content should not exceed $6 \%$ to $8 \%$. The alloys are subject to heat treatment and a wide variation of physical properties should be obtainable with proper quenching and tempering treatments.

The data also permit an estimate to be made of the true titanium-nickel system and a tentative binary diagram is presented. 


\section{DISCUSSION}

In the discussion, Mr. Long pointed out that densities obtained by sheath-rolling techniques were essentially the same as those obtained with conventionally processed sintered materials. He further stated that all samples of Bureau of Mines titanium wihch had been made available to other laboratories were fabricated by conventional powder metallurgy techniques; however, sheath-rolled samples will be available in the near future.

Prof. A. W. Schlecten (Missouri School of Mines) discussed his experiences with sheath rolling of zirconium and issued a warning about use of the method at high temperatures. In rolling a series of samples of zirconium sheathed in iron, over a range of temperatures, the method worked nicely below about 1050 degrees Centigrade or 1100 degrees Centigrade. However, when a sheathed sample, which had been held at that temperature, was subjected to a sizable reduction on the first pass, the sheath broke open and sprayed hot-burning, liquid metal. The phenomenon was interpreted by $\mathrm{Dr}$. Kroll as a result of an exothermic combination of zirconium and iron under the great pressure of the rolls and the formation of a low-melting eutectic which came out of the sheath and burned when exposed to the atmosphere. Mr. Long agreed with the warning and emphasized the necessity for not exceeding 1000 degrees Centigrade for rolling titanium in iron sheets. At 1050 degrees Centigrade, a reaction similar to that described by Prof. Schlecten occurs which is believed to be due to the formation of a low-melting iron-titanium alloy which may escape from the sheath. The usable range of temperatures for sheath-rolling depends upon the nature of the sheath materials.

In discussing the physical properties of titanium-nickel alloys, $\mathrm{Mr}$. Long stated that the data available so far is still incomplete. With about $5 \%$ to $8 \%$ of nickel, the alloys have a tensile strength of 110,000 to $120,000 \mathrm{psi}$ in the hot-rolled condition. The data is now being interpreted and evaluated in the light of the titaniumnickel phase diagram which has been established and work is continuing on heattreatment of these alloys.

In reply to a question by Dr. D. S. Eppelsheimer (Missouri School of Mines), concerning the homogenization of titanium-copper alloys, Mr. Long stated that homogenization is conducted in a temperature range of 800 to 1100 degrees Fahrenheit, depending upon the alloy composition. As with nickel, there is a restricted solubility region and, in working outside of this range, the temperature will make little difference and incomplete homogenization will occur.

Mr. Lilliendahl (Westinghouse Electric Manufacturing Company) inquired about the rolling temperature for the consolidation of pure tantalum, to which $\mathrm{Mr}$. Long replied that 2000 degrees Fahrenheit was insufficient for complete consolidation of tantalum and that higher temperatures were necessary. In subsequent general discussion, it was pointed out that in powder consolidation by the sheathrolling method, existing organized atomic structures as well as surface films were broken up by the deformation in rolling, which helps speed up the diffusion processes. With titanium and tantalum powders, considerable growth of particle size was observed although there was incomplete consolidation.

Dr. J. P. Nielsen (New York University) asked about the use of sheathrolling for the preparation of titanium-carbon alloys, and $\mathrm{Mr}$. Long replied that the Bureau of Mines was currently working on that problem. Powder distribution, work- 
ing temperatures, etc., are all important problems, but it is believed that alloys will be successfully prepared by this method. In fact, Mr. Long stated that the sheathrolling process has a general application to a wide range of metals and alloys, both known and as yet undeveloped ones. 


\title{
PHYSICAL AND MECHANICAL PROPERTIES OF COMMERCIALLY PURE TITANIUM
}

\author{
By C. I. Bradford, J. P. Catlin and E. L. Wemple \\ Remington Arms Company, Inc.
}

\section{Introduction}

The Remington Arms Company, Inc., an affiliate of the E. I. du Pont de Nemours and Company, Inc., embarked a few years ago on a broad general program to diversify and expand the Company's business outside of arms and ammunition. One study which received early attention in this program was the possibility of fabricating ductile titanium metal.

The current overall objective of the Remington program is to produce titanium and titanium base alloys in fabricated forms at a price which will permit titanium to be made available on a tonnage basis for structural and engineering uses. This program is directed toward the development of alloys and the development of processing techniques for producing simple fabricated forms such as rod, sheet and wire.

Remington's program has progressed to the point where $20-25$ pound ingots are being cast and small quantities of narrow sheet and round rod are being produced. The majority of Remington's effort is being devoted to research on titaniumrich alloys.

The unusually attractive properties of unalloyed titanium discussed in this paper, plus titanium's alloying potentialities, explain the basis for our optimism and enthusiasm regarding the development of truly outstanding titanium base alloys. $\mathrm{Al}-$ though no alloys have been developed to the point where they can be discussed in this paper, our alloy research has confirmed that this is a promising field of endeavor.

\section{General Properties}

A recent popular article has referred to titanium as the "Cinderella of Metals". A more appropriate comparison to use in a technical paper of this type is to state that titanium possesses a combination of the properties of aluminum alloys and stainless steels. In one sentence, titanium is light, strong, corrosion resistant and ductile. When commercially pure titanium is compared to commercially pure aluminum and iron, we find that its density is intermediate between aluminum and iron (See Figure 1) and its melting point and strength are higher than both aluminum and iron.

\section{Comparative Physical Properties}

Data on the more pertinent physical properties of titanium compared with 75ST aluminum alloy and 18-8 austenitic stainless steel are shown in the following tabulation: 
18-8 Austenitic

Titanium 75ST Aluminum Stainless Steel

Density - gm./cc

Young's Modulus - psi

Melting point $-{ }^{0} \mathrm{~F}$

Thermal expansion $/{ }^{\circ} \mathrm{F}$

Electrical conductivity - \%I.A.C.A.
Thermal conductivity - BTU $/ \mathrm{ft}^{2} /$ in $/{ }^{\circ} \mathrm{F} / \mathrm{hr} \quad 105$

*For pure aluminum or iron

$\begin{array}{cr} & 4.5 \\ 15.5 \times 10^{6} & 10.3 \times 10^{6} \\ 3140 & 1220^{*} \\ 5.0 \times 10^{-6} & 12.7 \times 10^{-6} \\ 3.2 & 30 \\ \text { hr } 105 & 835\end{array}$

$28 \times 10^{7.9}$

$2800 *$

$9.5 \times 10^{-6}$

2.5

115

Young's modulus for titanium is intermediate between that of the aluminum alloys and that of steel. This relatively high modulus makes titanium a good structural material. The extremely high melting point for titanium should develop into a considerable advantage for the metal when used in today's high-temperature mechanical devices. The low coefficient of thermal expansion will be another advantage for titanium in applications that require high-temperature exposure. This low coefficient reduces thermal stresses to a minimum in structures made of titanium and makes close tolerances practical for devices that operate over a considerable temperature range.

Titanium has relatively low thermal and electrical conductivity.
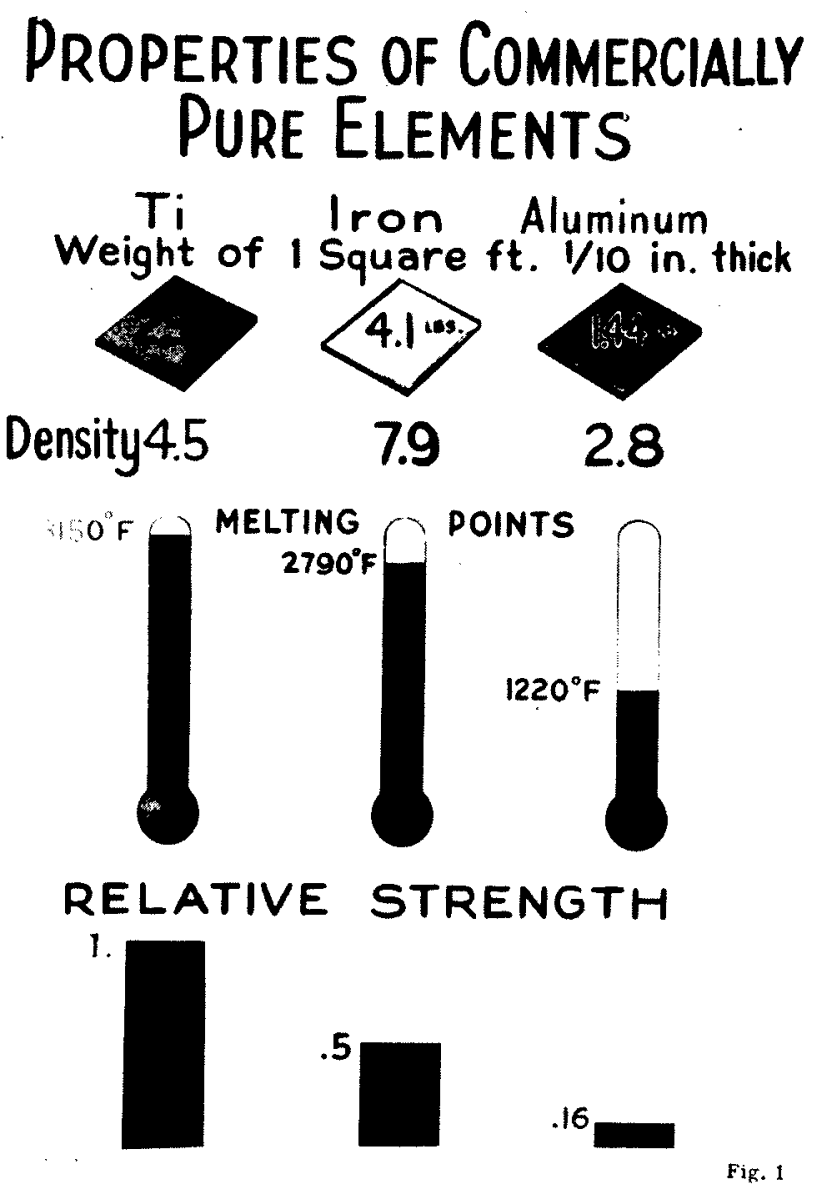
IV. Mechanical Properties

Many of the data discussed in this paper on the physical and mechanical properties of commercially pure titanium were taken by the Battelle Memorial Institute at Columbus, Ohio, on rod and sheet produced by Remington from Du Pont sponge. Since all of Remington's material has been produced by melting and casting, some of the properties do not agree completely with data published by others on titanium produced by powder metallurgy techniques. Furthermore, all test data in this paper should be regarded as preliminary and subject to revision.

Figure 2 shows the effect of cold work on the tensile properties of Remington commercially pure titanium. In this Figure ultimate tensile strength, $0.2 \%$ yield strength, elongation, and hardness are plotted against cold work. There are several points that are evident upon examination of these curves.

A significant item is the relatively high tensile and yield strengths of the annealed material in combination with good elongation. A second factor is the increase in tensile properties with only moderate amounts of cold work. For example, $20 \%$ cold work raises the yield strength to about 100,000 psi, which is only slightly less than the yield strength obtained through $50 \%$ or $60 \%$ cold work. Moderate cold working by commercial forming processes will result in a considerable increase in the strength. On the other hand, small amounts of cold work reduce the ductility considerably. This is indicated by the curve showing elongation in a two-inch gage length plotted against cold work. This curve drops very rapidly and is nearly horizontal after $20 \%$ cold work is attained. At $50 \%$ cold work titanium still shows $12 \%$ elongation.

It is interesting to compare the room temperature tensile properties of titanium with its competitive materials. The bar' graph (Figure 3 ) shows comparative tensile properties for titanium, 75ST aluminum, and 18-8 stainless steel. Ultimate strengths and yield strengths are shown for annealed and hardened material. No bar is shown for annealed $75 \mathrm{~S}$ material since it normally is not used in this condition. The significance of the word "hardened" for titanium and austenitic stainless steel refers to hardening by means of cold work as these materials in their usual condition will not ordinarily respond to heat treatment to raise the physical properties.

An important point brought out by this graph is the relatively low yield strength of 18-8 stainless steel in the annealed condition. The yield strength of annealed titanium is nearly double the yield strength of annealed stainless.

On the basis of strength-weight ratio, titanium compares very favorably with 75ST aluminum and stainless steel. There are many applications where a considerable weight saving is possible through the substitution of titanium. This is particularly true in applications where equivalent sections of titanium can be substituted for stainless steel.

The tensile properties of forged titanium bar over a considerable range of temperatures are shown in Figure 4. In this figure, ultimate tensile strength, $0.2 \%$ yield strength, and Young's Modulus are plotted against temperature. These data represent short-time tensile test results where the specimen is held at temperature about 30 minutes prior to testing.

These curves indicate the following interesting properties:

1. Titanium has usable strength up through 800 degrees Fahrenheit. This 
compares very favorably with the best aluminum alloys which ordinarily are not used to any great extent over 400 degrees Fahrenheit.

2. Young's modulus for titanium holds up well up to 800 degrees Fahrenheit. This is important in applications involving elastic stability at intermediate temperature.

3. The sub-zero strength and modulus are high.

Although it is not shown on the chart, sub-zero ductility is also good. In general, the elongation of forged titanium bar is roughly constant between -75 degrees Fahrenheit and 800 degrees Fahrenheit, the actual value being $15 \%$ to $20 \%$ over a twoinch gage length.

Although in many cases complete data are lacking at the present time, there are a number of physical properties which deserve mention. For example, compression data on sheet and forged bar show about the same values as corresponding tensile data. The modulus of elasticity, however, in compression is slightly higher than in tension.

Torsion tests on forged titanium bar indicate a modulus of rigidity of $6.6 \mathrm{x}$ $10^{6} \mathrm{psi}$ and a modulus of rupture of $101,300 \mathrm{psi}$

Rivet shear data on titanium with comparative values for 75ST and 24ST aluminum are given below.

\begin{tabular}{lc} 
Material & Ultimate Shear Strength $(1 / 8, '$ Dia. Rivet) \\
\cline { 2 - 2 } Titanium & $82,000 \mathrm{psi}$ \\
75ST aluminum alloy & $47,000 \mathrm{psi}$ \\
24ST aluminum alloy & $41,000 \mathrm{psi}$
\end{tabular}

Data on bearing strength tests on titanium sheet show the following results:

Material

Annealed sheet titanium $25 \%$ cold worked titanium

$$
\begin{array}{ll}
\begin{array}{l}
0.5 \% \text { Offset Yield } \\
\text { Strength - psi }
\end{array} & \begin{array}{l}
\text { Ultimate Bearing } \\
\text { Stress - psi }
\end{array} \\
\begin{array}{c}
117,000 \mathrm{psi} \\
170,000 \mathrm{psi}
\end{array} & \begin{array}{l}
177,000 \mathrm{psi} \\
216,000 \mathrm{psi}
\end{array}
\end{array}
$$

Charpy impact test results on titanium are shown in Figure 5. This graph indicates that there is no transition temperature below which impact strength is greatly reduced as in the case of mild steel. At room temperature and above, titanium has a higher Charpy impact value than 75ST and 24ST. At -75 degrees Fahrenheit the Charpy value for titanium is approximately the same as for 24ST aluminum.

Fatigue data obtained to date are rather meager. An endurance limit of 55,000 psi was obtained, however, on sheet material having an ultimate strength of 138,000 psi. This test was run in a Krouse Direct Repeated Stress Testing Machine. Rotating beam fatigue tests on several samples of bar stock indicate that the endurance limit is approximately $50 \%$ of the ultimate tensile strength. Specimens with a V notch show a corresponding endurance limit of approximately $25 \%$ of the ultimate tensile strength.

Creep data on titanium indicate negligible creep at a stress of $25,000 \mathrm{psi}$ and at a temperature of 600 degrees Fahrenheit. At 800 degrees Fahrenheit, at a stress level of $16,000 \mathrm{psi}$, an average creep rate of $0.000015 \%$ per hour was attained 
over a period of 1,125 hours. Stress rupture tests for a period of 100 hours indicate the following:

600 degrees Fahrenheit

800 degrees Fahrenheit 1000 degrees Fahrenheit

$$
\begin{array}{r}
55,000 \text { psi } \\
32,000 \text { psi } \\
7,400 \text { psi }
\end{array}
$$

No rupture

Stress to rupture

Stress to rupture

PEXINGTON ARMS CO., INC.

WORK HARDENING CHARACTERIS TICS OF COMRERCIALLY PURE TI TANIUM

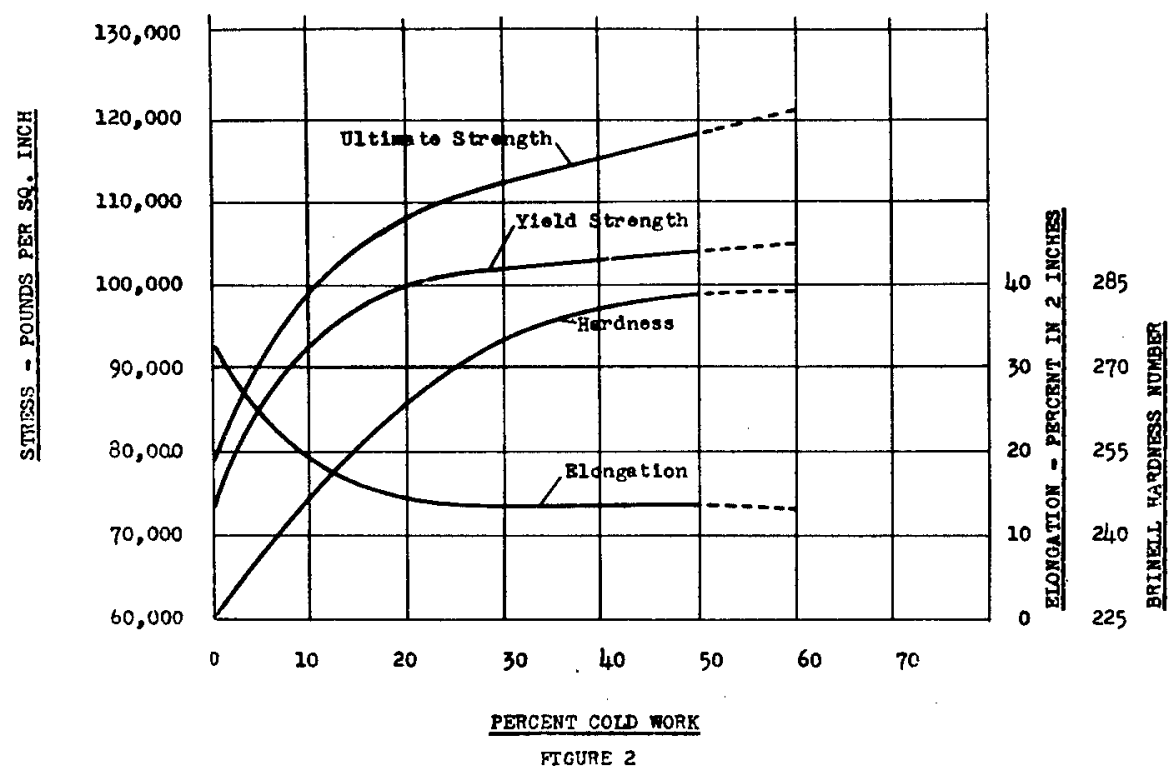

REYINGTON $A R L S$ CO., INC,

COMPARATIVE TENSIIE STRENGTH PROPERTIES AT ROOM TEXFERATURE

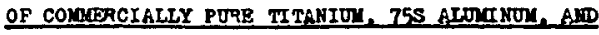

$18-8$ STAINLESS STRBL

ANNEALED

Vltin to strongth

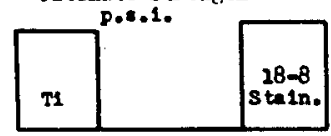

0.24 yiold strength

p.s.1.

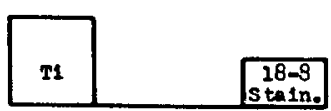

HARDENED

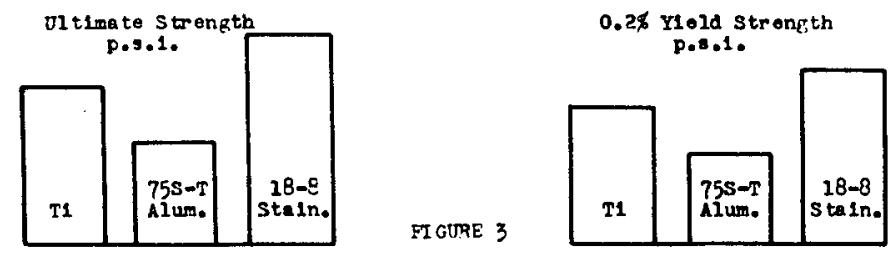


REMINGTON ARNS COMPANY, INC.

CONOERCIALLY PURE TI TANIUM FORGED BAR STOCK

TENSILE PROPEHTIES AS A PUNCTION OF TEMPERATURE

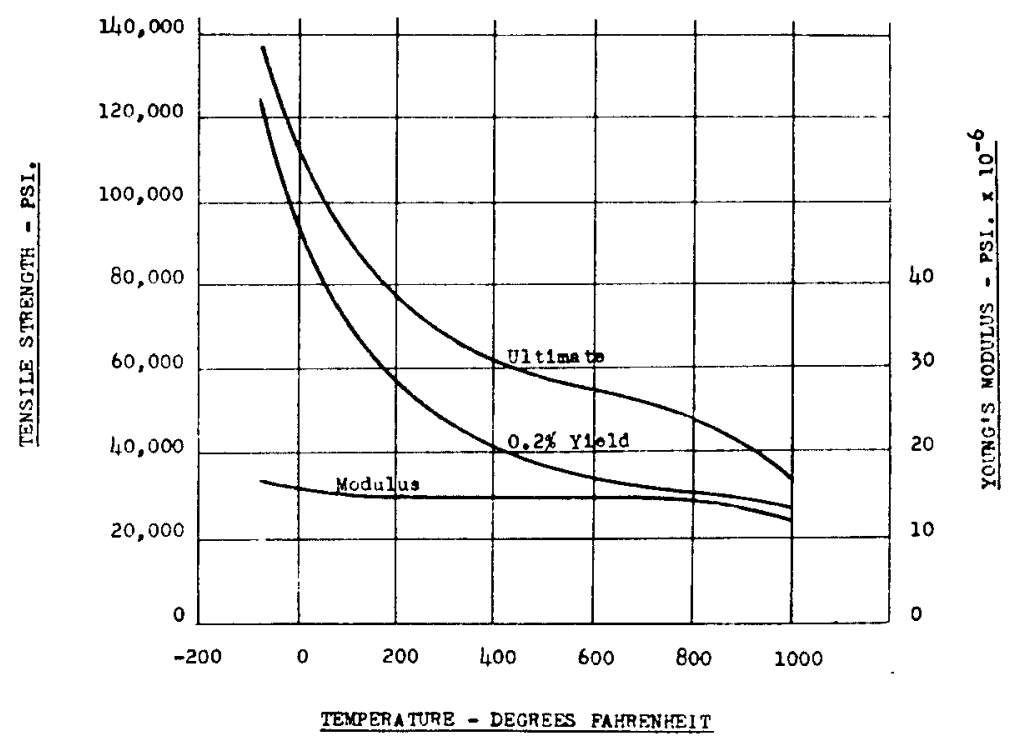

FIGURE 4

NOTCHED BAR IMPACT TEST RESULTS,

COMMERCIALLY PURE TITANIUM

CHARPY BAR WITH " $\mathrm{V}$ NOTCH

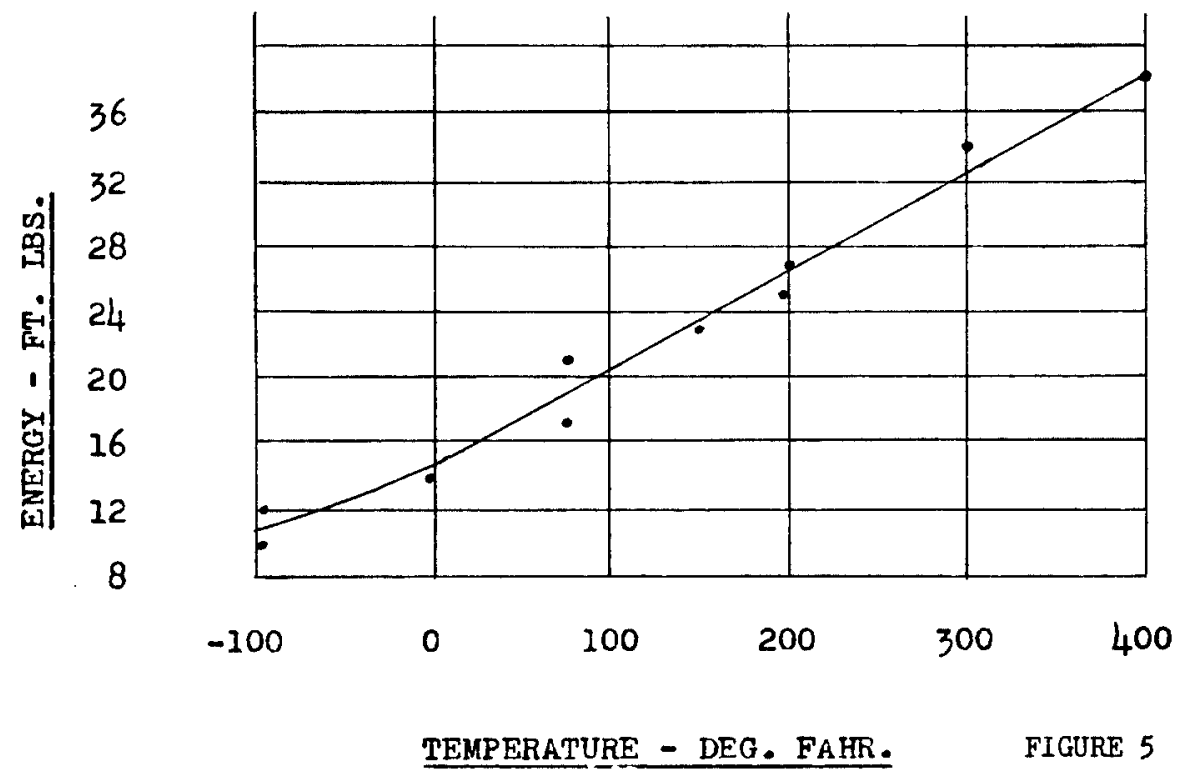




\section{Miscellaneous Properties}

Commercially pure titanium is readily forged within the temperature range of 1600-1800 degrees Fahrenheit. Preliminary work indicates that the machinability of titanium is similar to that of austenitic stainless steels. In general, the same tool angles, cutting speeds and feeds required for 18-8 stainless steel are recommended. Titanium in the "as forged" condition may have a hard surface scale which will require carbide tools to remove. Chips from the drilling of titanium are tough and stringy and it is frequently necessary to clear the drill by removing it from the work.

The General Electric Company River Works at West Lynn, Massachusetts, and several other companies have been conducting preliminary welding experiments with Remington Arms Company titanium. These experiments indicate that titanium can be readily spot welded, seam welded and inert arc welded to other pieces of titanium. Other types of welding, brazing and soldering, have not yet been developed for titanium and we have no experience with welding titanium to other common structural materials. The Bureau of Mines published a paper on the spot welding of titanium in the October, 1946, issue of Metals Technology.

Annealed titanium will take a 3-T bend radius and quarter hard titanium a 5-T minimum bend radius. We expect it to be completely practical to brake form titanium but considerable development work remains to be done on drawing, cupping, spinning, die forming, extruding, etc.

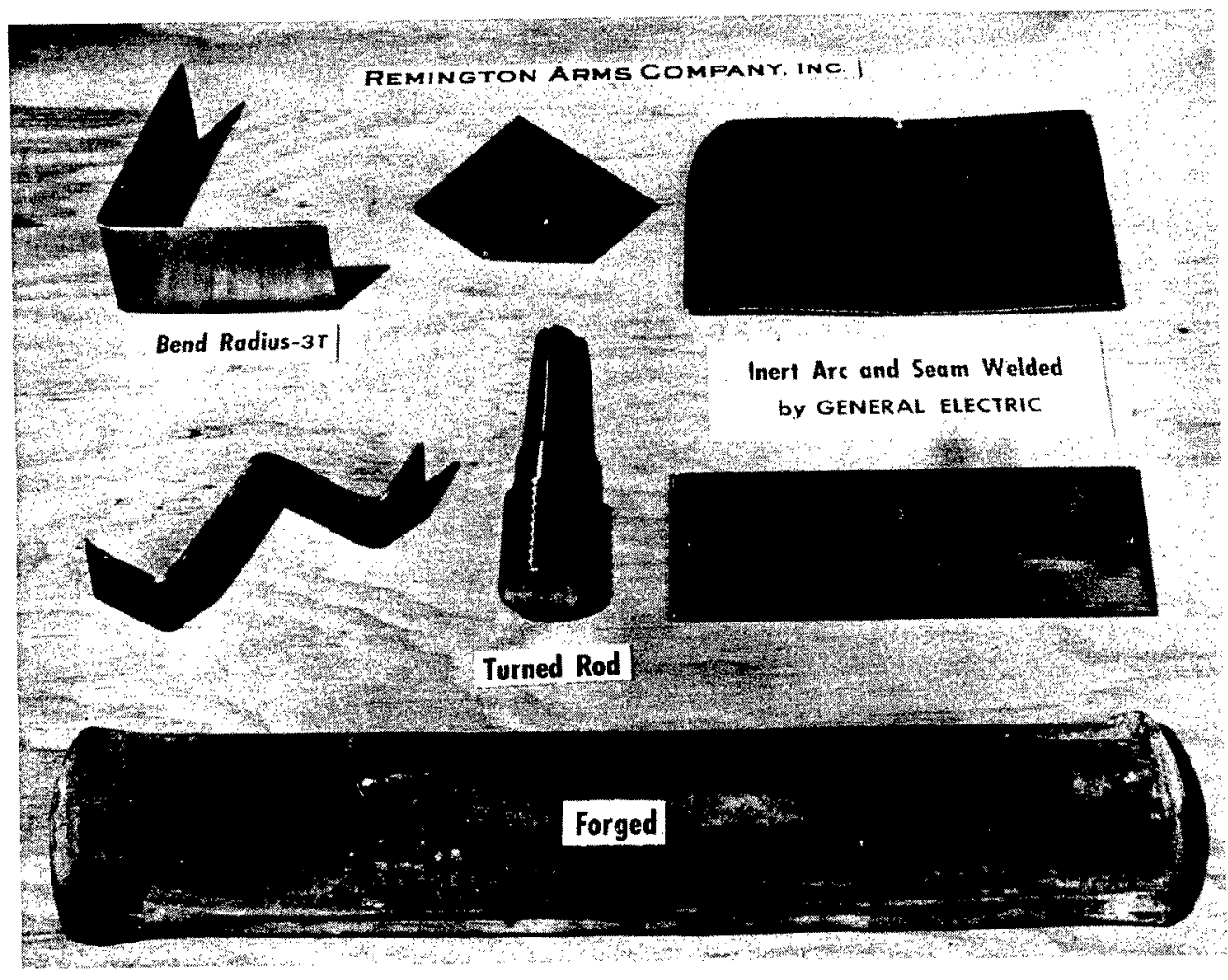

Fig. 6 

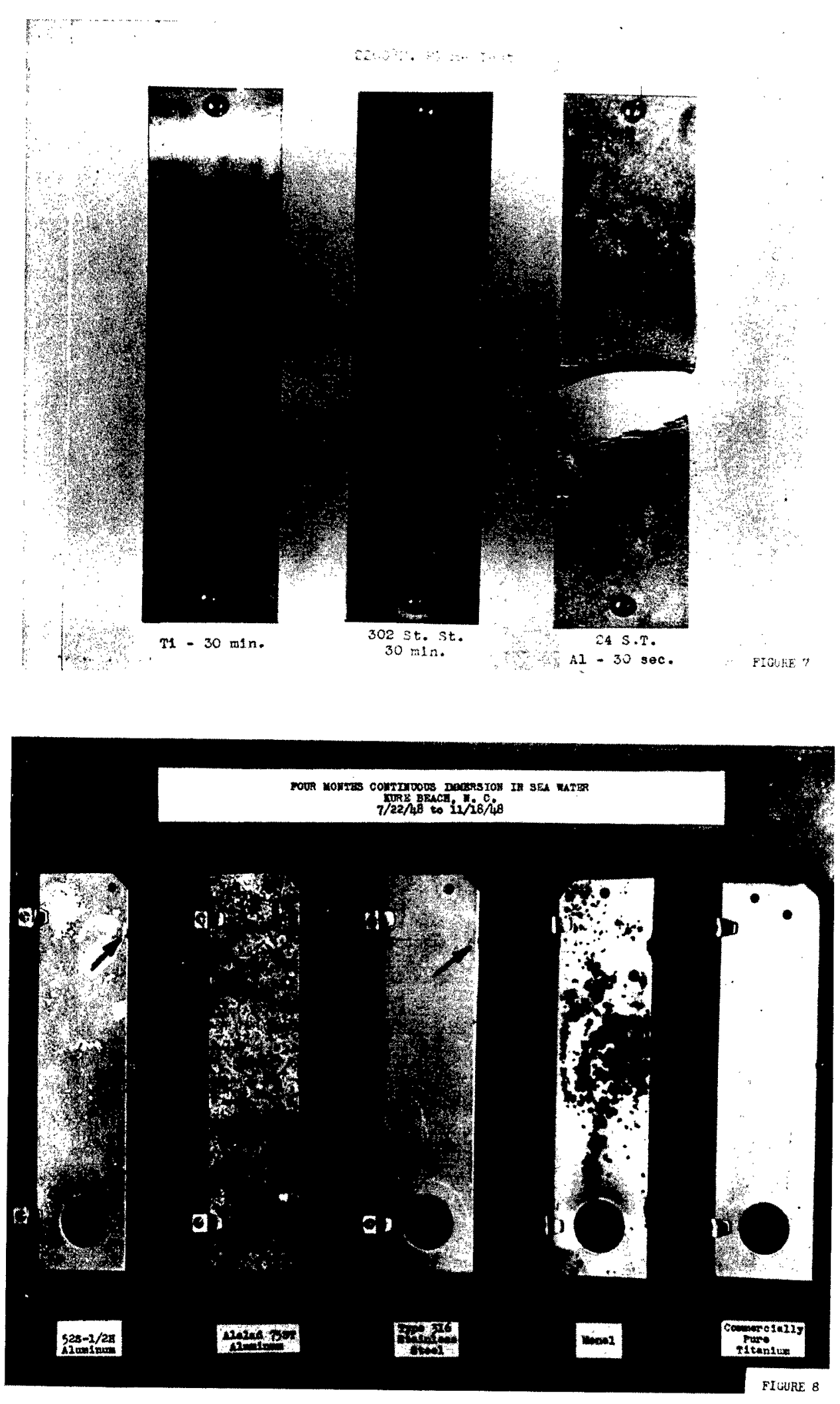
Figure 6.

Exhibits of machined, formed, forged and welded titanium are shown in

Exposure of titanium, 18-8 stainless and an aluminum alloy to a 2200degree-Fahrenheit gas flame burned the aluminum alloy in thirty seconds, but did not affect the strength of the titanium or the stainless steel after thirty minutes exposure. These samples are shown in Figure 7.

Samples of Remington Arms Company titanium have been exposed to air at temperatures from 600 degrees Fahrenheit to 1500 degrees Fahrenheit for 1000 hour periods. Weight and strength measurements after these exposures indicate that titanium is suitable for long-term exposure to air up to temperatures of 1300 degrees Fahrenheit. Above this temperature, appreciable embrittlement occurs.

Samples of Remington Arms Company titanium have been exposed to the following tests at the International Nickel Company Test Station at Kure Beach, North Carolina, for periods up to four months:

\title{
Jet Aspirator \\ Basin Immersion \\ Flowing sea water immersion \\ Shore rack exposure (100 yards from water) \\ Lot rack exposure (1000 yards from water)
}

Titanium was completely resistant to attack under all of these conditions of exposure. This indicates that titanium is in the same class as platinum and Hastelloy $\mathrm{C}$ in its resistance to marine corrosion. Figure 8 shows a comparison of attack on various metals when immersed in sea water for four months.

Laboratory tests on titanium's chemical corrosion resistance indicate that titanium is resistant to the following:

\author{
Nitric acid \\ Relatively dilute warm hydrochloric and sulphuric acids \\ Aqua regia \\ Chlorine \\ Sodium hydroxide
}

VI. Conclusions

To summarize, commercially pure titanium fills a gap between aluminum alloys and stainless steel insofar as modulus, density and strength at intermediate temperatures are concerned. Its strength-weight ratio as compared to aluminum alloys and stainless steel is favorable depending on the specific application.

Where titanium can be substituted directly section-for-section in place of stainless, a $40 \%$ saving in weight will result.

Titanium's sea water and marine atmospheric corrosion resistance are truly outstanding - being better than austenitic stainless, Monel, and the cupro-nickel alloys and as good as the best known materials - platinum and Hastelloy C.

In consideration of these properties, it has been suggested that commercially pure titanium might find application in the following services:

1. Airframe skins and structures where intermediate temperatures or corrosicn problems are encountered. 
2. Aircraft power plants where temperatures between 300 and 800 degrees Fahrenheit are involved.

3. Naval or marine applications in which the combination of superior corrosion resistance and light weight are important.

4. Industrial equipment in which titanium's particular corrosion resistance can be utilized.

5. Miscellaneous applications in which a combination of light weight, corrosion resistance, high strength and intermediate temperature properties are required.

Commercially pure titanium at this stage of the development should not be considered equivalent to another new alloy but as truly a new base metal insofar as engineering availability is concerned. It is in its infancy and an enormous amount of work is ahead in all phases of the program. Typical data have been developed on many of its common characteristics but a substantial amount of information on properties and on fabrication remains to be obtained.

Through the efforts of organizations such as those represented here and the interest and cooperation of potential users such as the aircraft industry, there is every reason to believe that the problems associated with production, fabricating, and applying titanium can be solved and it will become an important engineering material of the future.

\section{DISCUSSION}

In answer to a question raised by Dr. S. C. Ogburn (Foote Mineral Company), Mr. Bradford stated that Remington Arms had produced no titanium wire themselves, but were having some made for them.

Discussion of the low-temperature properties of titanium brought out that $\mathbf{- 7 5}$ degrees Fahrenheit was the lowest temperature at which the mechanical properties were determined. Mr. H. C. Cross (Battelle Memorial Institute) added that impact tests were conducted with Charpy "V" notch specimens and one series of tests showed practically a straight-line relationship between impact strength and temperature in the range from well above room temperature to below -75 degrees Fahrenheit. No information was a vailable on the type of fracture obtained. Mr. Bradford further stated that the impact strength was about 20 foot-pounds at 100 degrees Fahrenheit and dropped to about 10 to 12 foot-pounds at -100 degrees Fahrenheit in a linear manner.

Mr. F. F. Poland (Revere Copper and Brass) asked about the carbon content of the samples for which the data had been presented, and it was pointed out that the titanium had been made from DuPont sponge titanium which contained $0.01 \%$ to $0.02 \%$ carbon prior to consolidation of the sponge. After consolidation, however, the Remington titanium contains between $0.2 \%$ and $0.3 \%$ carbon. In discussion of the high-temperature tensile tests, it was stated that the specimens were held at temperature for 30 minutes, prior to testing, and then tested at temperature. Remington has not conducted tests with other holding times, but $\mathrm{Mr}$. Bradford added that in other laboratories a 1000-hour test at 600 degrees Fahrenheit on bar stock showed results very comparable to those obtained by Remington at 600 degrees Fahrenheit for a half- 
hour exposure. These tests were also conducted at temperature, and specimens, which were subsequently cooled to room temperature and tested, exhibited the same room-temperature properties as specimens which were not exposed to the elevated temperatures.

In answer to Mr. Harwood's (Office of Naval Research) question, Mr. Bradford stated that marine exposure specimens exhibited marine growth. Mr. Williams (Naval Engineering Experimental Station) pointed out that the subject of marine fouling would be discussed in more detail in his paper.

Further discussion revealed that no information was yet available as to the form in which carbon is present in titanium or as to which of the carbides is present, $\mathrm{TiC}, \mathrm{Ti}_{2} \mathrm{C}$ or $\mathrm{Ti}_{4} \mathrm{C}$. 


\title{
PRODUCTION AND PROPERTIES OF IODIDE TITANIUM
}

\author{
By Bruce W. Gonser \\ Research Supervisor, Battelle Memorial Institute, Columbus, Ohio
}

In metallurgy, as in other fields of science, an investigator likes to work with the purest materials he can get. This is particularly true with titanium, since it is known to be extremely sensitive to slight contamination by some elements. So far, production of titanium by thermal decomposition of a volatilized iodide has appeared to be the most practical means of obtaining the relatively pure metal, hence this method has been used to secure metal for fundamental information on titanium and its alloys.

Interest in the production of titanium by the iodide process is broader than merely the production of a relatively pure metal as a base for investigations, almost regardless of cost. It is a method for making a high-quality metal in a compact form, which can be processed directly without smelting or without compacting and sintering into ingots by powder metallurgy. As such, it has advantages, as well as disadvantages, over other suggested means for making titanium commercially, and continued development may make it fully competitive with other methods for at least part of the field.

\section{Background of the Process}

The iodide process was first described by Van Arkel and De Boer 1 in 1925 as applied to the production of titanium, zirconium, hafnium and thorium. Several technical articles $2,3,4,5$ by these investigators and by J. D. Fast in the following 14 years gave additional information on the process and the deposited product. The emphasis in subsequent commercial development of the general process by the N. V. Phillips Gloeilampenfabrieken in Eindhoven, Netherlands 6 , was on production of zirconium; however, sufficient work was done on titanium to generally outline some of the conditions and equipment for deposition, and to get metal for determining properties.

Essentially, the process depends upon the formation of a volatile iodide by reacting crude titanium with iodine in the absence of any other reactive gas, then depositing the titanium on a hot filament by thermal decomposition of the iodide. This action is cyclic, as the gaseous product of decomposition reacts with more crude metal; so the action in its simplest form is one of refining in a closed container.

The reactions involved, as described by the early investigators, depend upon the temperature at which the crude metal is held. Thus, with metal held between room temperature and 250 degrees Centigrade, iodine reacts with the crude metal to form TiI4, which dissociates at the hot filament, as: $\mathrm{TiT}_{4} \rightleftharpoons \mathrm{Ti}+2 \mathrm{I}_{2}$. At a higher temperature, however, the tetraiodide reacts with more metal to form iodides of lower valence. These have a much lower vapor pressure than the tetraiodide, hence practically no deposition of metal occurs until the temperature of the charge is increased to above 425 degrees Centigrade. In both cases, the filament temperature for deposition is kept at 1100 to 1500 degrees Centigrade.

Some idea of the equipment used, or that could have been used, for making 
iodide titanium in the European work may be gained from the tubes designed by the Phillips Company for making zirconium. As duplicated in early work at Battelle Memorial Institute, leading to commercial production of zirconium by the Foote Mineral Company, a Pyrex glass tube about 20 inches long and four inches in diameter was used. This was equipped with a glass head containing three sealed-in tungsten rods for electrodes, to which were attached tungsten wire filaments so arranged that if one filament burned out, the run could be continued on the remaining two. A side arm contained the iodine supply which was refrigerated to prevent loss while the tube was evacuated and sealed. The charge of crude metal lumps, formed by sodium or calcium reduction of the oxide, was held in place around the periphery of the tube by a screen of woven molybdenum wire. Two rods of metal about 15 inches long and $1 / 4$ inch in diameter could be produced each run.

During the war, some titanium was produced in Germany by reduction of titanium tetrabromide which was carried by a stream of purified hydrogen into a quartz tube containing tungsten filaments heated to 1200 - 1400 degrees Centigrade?. Although reduction of the bromide is workable, it does not seem to offer any advantages, and has some disadvantages, over use of the iodide. Chlorides require a much higher dissociation temperature and experimental work has indicated generally unsatisfactory results when using them.

\section{Current Production Equipment and Operation}

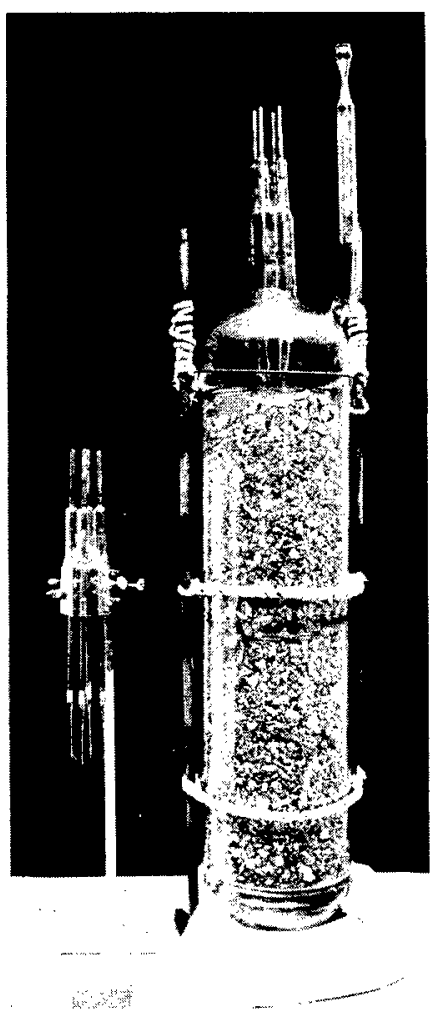

Fig. 1. Assembled glass unit, $7 \frac{1}{2}$ inch diameter, used to produce two 24 -inch "hairpins" of about 300 grams each. Titanium or tungsten filaments are attached to the heavy tungsten sealed-in leads and extend nearly to the base of the bulb.

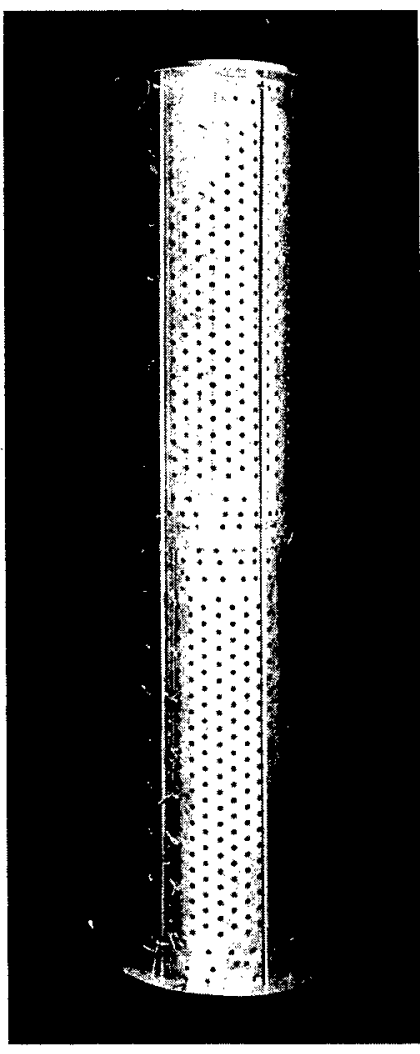

Fig. 2. Perforated molybdenum retainer used to hold the charge of crude metal in place. It also acts as a heat shield to keep the charge from becoming overheated by the hot filaments in the center.

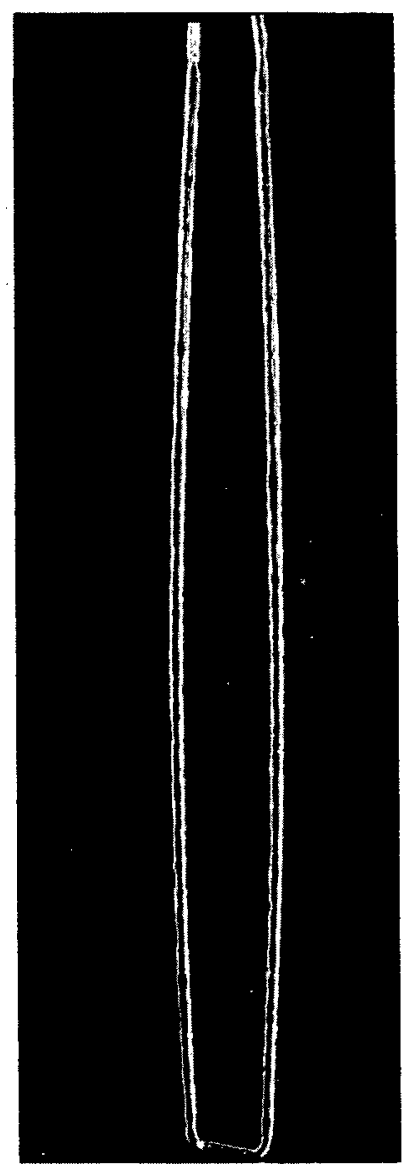

Fig. 3, Hairpin of ductile titanium. 
The production of iodide titanium in glass equipment is under a severe handicap because of the low softening temperature of glass, its fragility and the difficulty of sealing-in sufficiently large electrodes to permit the building of relatively heavy deposits. To a surprising extent success depends upon the glass blower who makes, opens, and repairs the tubes. However, in several steps, production units for titanium have been increased in size to glass tubes 35 inches long and $7 \frac{1}{2}$ inches in diameter, each capable of producing two 24-inch "hairpins" ( 300 grams each) per run at 165 degrees Centigrade. Their construction and operation have been described previously. (Figures 1, 2 and 3)

Such units have been operated successfully either at the lower temperature of 165 degrees Centigrade or at the comparatively high temperature of 550 degrees Centigrade. Operating at the low temperature has some obvious advantages, but the purity of the product, as measured by hardness, has not been so satisfactory as when running at 550 degrees Centigrade. The tendency consequently has been to run at the highest temperature that the glass equipment can safely withstand. It is to be noted that in the iodide process, the reaction tube problem of heat control is largely one of dissipating energy, rather than supplying heat, since little energy is consumed in the titanium refining reactions. As the deposit builds on the starting filament, more and more current is required to maintain the filament temperature, until the heat dissipation problem becomes of major importance. This is particularly true with large glass equipment since the danger of cracking or collapse makes undesirable the use of a molten cooling bath around the tube.

To avoid some of the weaknesses of glass, attention has been given to building metal reaction tubes. One currently in production is 30 inches long and $41 / 4$ inches in diameter, giving one double rod or "hairpin," 24 inches long. Titanium rods $5 / 8$ inch in diameter and weighing $700-750$ grams have been produced in it. Operation is much simpler and so much more satisfactory that glass tubes may be considered as obsolete except for experimental work. A temperature of 165 degrees Centigrade is easily maintained by immersing the metal tube in a circulating oil bath during deposition. Quality of product has been entirely satisfactory. This probably is partly because of the larger volume of metal deposited which would tend to dilute any impurities deposited at the start of deposition.

The charge of fused lumps of crude metal amounts to $12-15$ pounds for the metal tube and about 20 pounds for each of the large glass tubes currently in use. This is held in a $\frac{1}{2}$ inch space between the tube wall and a perforated sheet molybdenum screen, as shown in Figures 1 and 2. Several runs are made with the same charge, then it is thoroughly washed in water to avoid diminished activity, and the charge is then reused repeatedly. Time for a run varies with conditions, usually being 24 to 30 hours for a high-temperature run in a glass tube to build a rod requiring up to 300 amperes to maintain filament temperature. A minimum of 10 hours has been attained. With a metal bulb, in building a rod of $5 / 8$ inch diameter, or requiring up to 580 amper es to maintain heat, from 30 to 48 hours has been required. Power consumption has been as low as $40 \mathrm{Kwh}$. per pound of metal deposited, but is usually 60 to $75 \mathrm{Kwh}$.

\section{$\underline{\text { Iodide Titanium Metal }}$}

The metal as deposited is coarsely crystalline, the type of deposit depending upon the temperature of the operation. That from a run with the charge at 550 degrees Centigrade tends to be finer grained but rough; deposits from low temperature runs are larger grained but each grain tends to be smooth (Figure 5). Both types are bright and attractive in appearance unless slowly cooled so that residual iodine in the tube condenses on the deposit. 


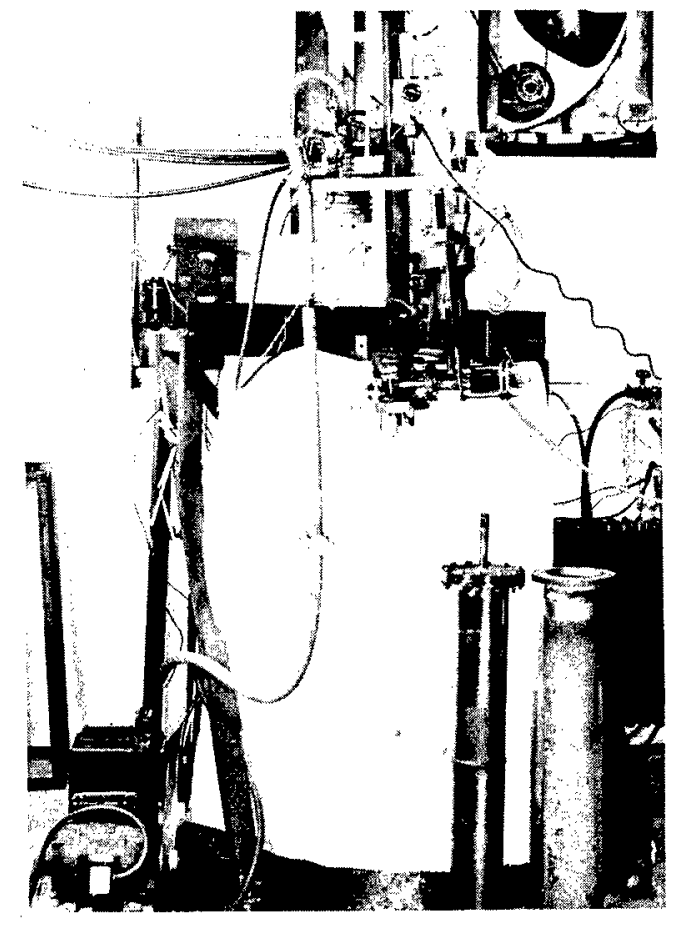

Fig. 4. (left) Ceneral equipment for refining titanium by the iodide process using a metal tube. The larre container in the center holds a circulated oil bath for maintaining the chare temperature. The titanium filament shown in the center is weighted with tungsten.

Fig. 5. (right) Crystalline deposit of titanium as deposited from a low temperature charge.

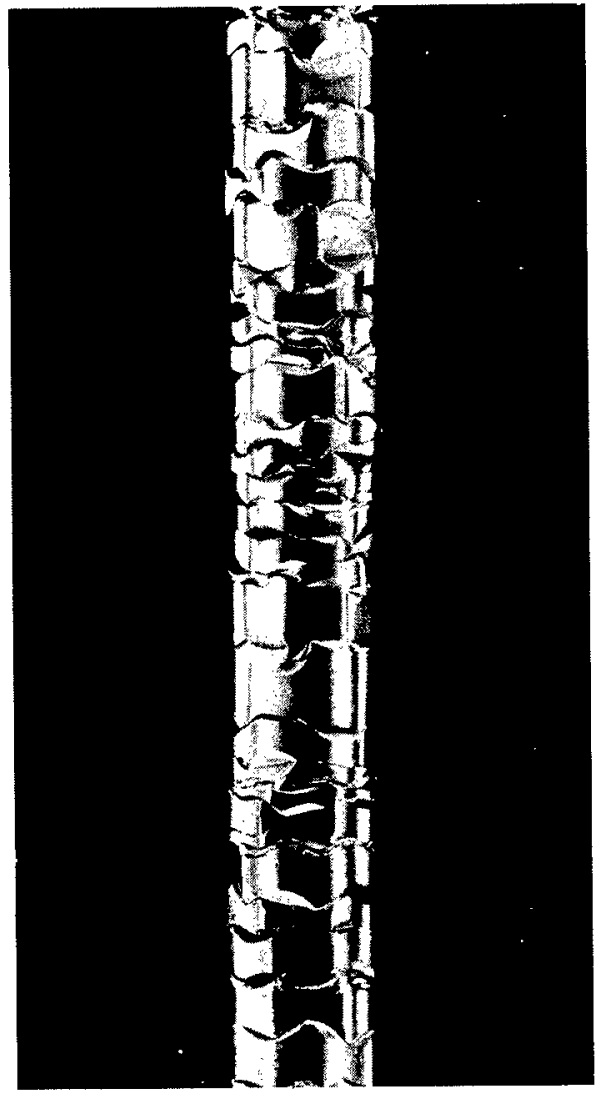

Purity

Analyses for minute amounts of impurities in titanium by no means have been standardized. Chemical analyses show the car efully prepared soft-metal to contain $0.02-0.03 \mathrm{C}$ and $0.002-0.003 \mathrm{~N}$, with occasional products running up to $0.009 \mathrm{~N}$. Unfortunately, no oxygen analyses are available, but the oxygen content is believed to be lower than the nitrogen. Spectrographic analyses show, also, less than $0.04 \mathrm{Si}$, less than $0.04 \mathrm{Fe}$, less than $0.002 \mathrm{~S}$ and less than $0.05 \mathrm{Al}$.

Hardness of the metal as deposited is commonly taken as an indication of purity for an operating guide. Vickers hardness values have been found over a range from 60 to 115. The normal metal from high-temperature runs in a glass unit usually averages about $70-80$; that from a "cold" bulb has been harder, as $80-100$; and titanium from a metal bulb averages $75-85$.

\section{Metallographic Structure}

The structure of an iodide titanium sample after arc melting, hot rolling at 850 degrees Centigrade in air, surface grinding, and vacuum annealing for three hours at 850 degrees Centigrade, is shown in Figure 6. A similar specimen after the same treatment, then held at $\mathbf{9 5 0}$ degrees Centigrade for a half-hour and rapidly cooled (equivalent to air cooling), is shown in Figure 7. This shows the plate-like Widmanstätten structure that results from rapid cooling through the transformation temperature (888 degrees Centigrade). The substructure is a coring effect that results as 
the last of the beta titanium transforms in thin plates which have not entirely coalesced. When water-quenched, a fine needle-like martensitic structure is obtained.

Similar treatments and their effect on commercial titanium produced by magnesium reduction of the chloride are shown in Figures 8 and 9 respectively. The more pronounced needle structure shown in Figure 9 (as compared to Figure 7) is characteristic of titanium containing some nitrogen.

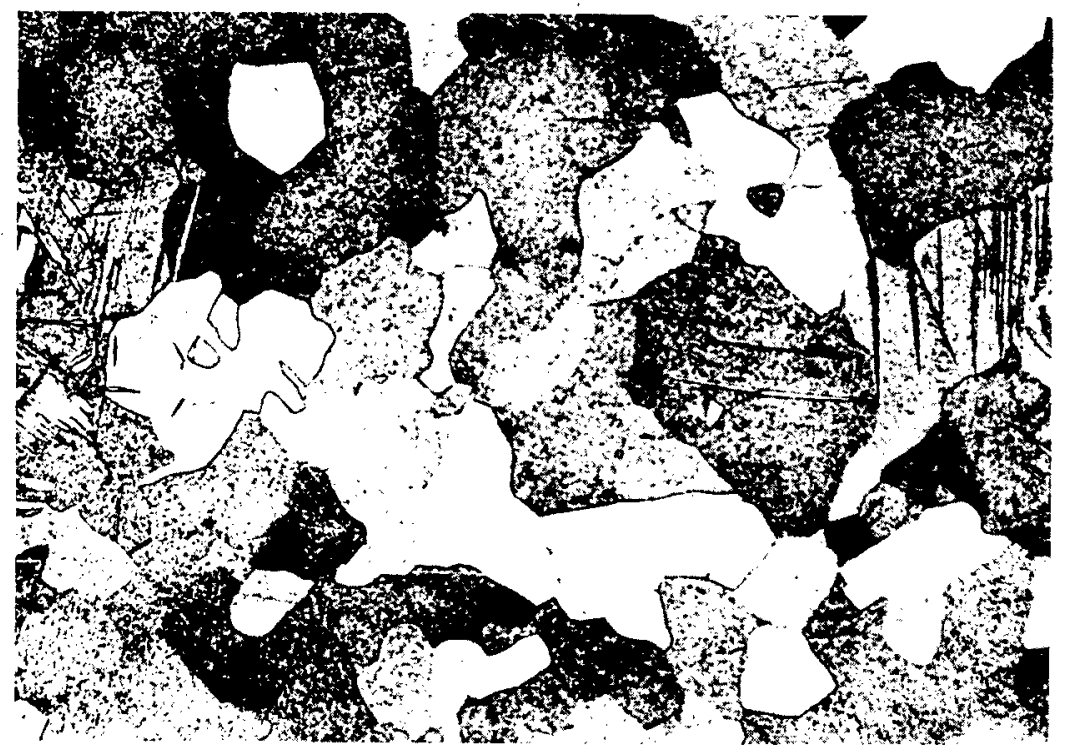

Fig. 6. Iodide titanium, after melting, hot rolling, and vacuum annealing.

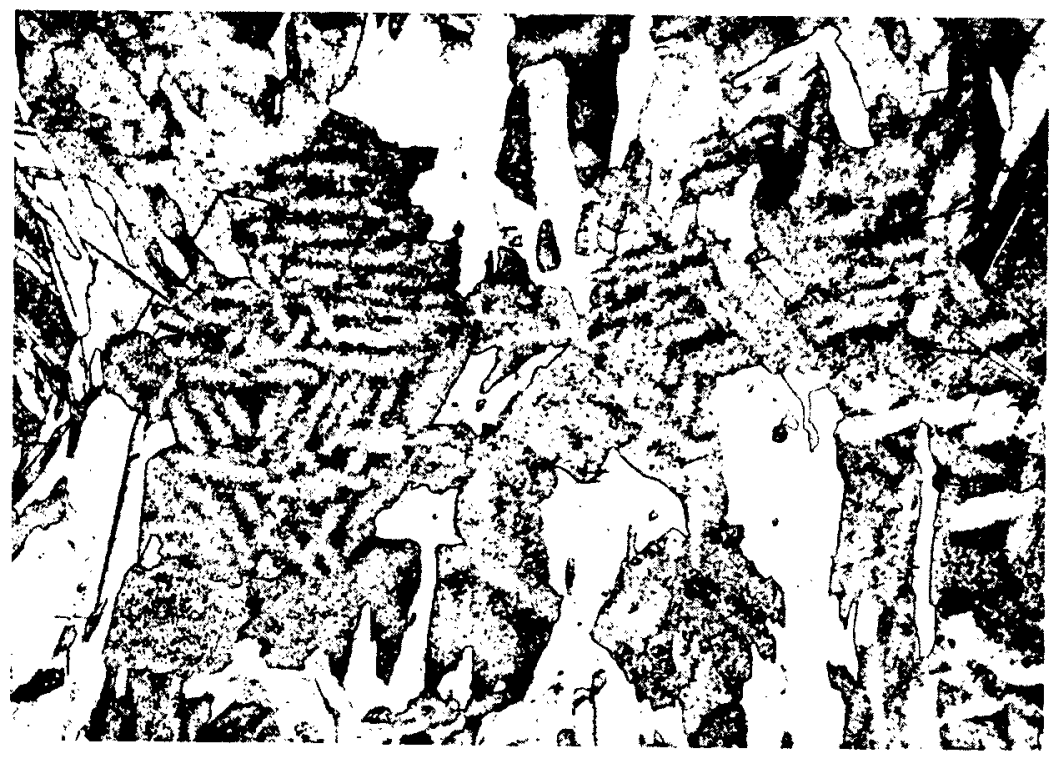

Fig. 7. Same after heating to 950 degrees Centigrade and rapid cooling through the transformation temperature. 


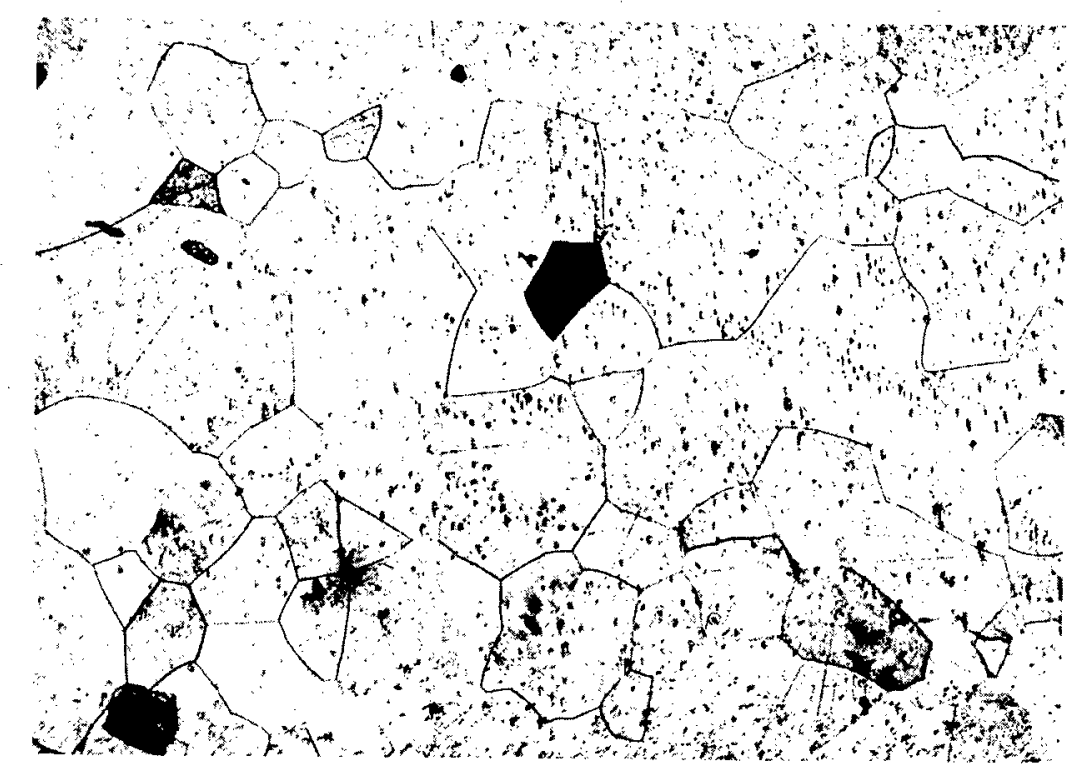

Fig. 8. Commercial magnesium-reduced titanium. Treatment as in Fig. 6.

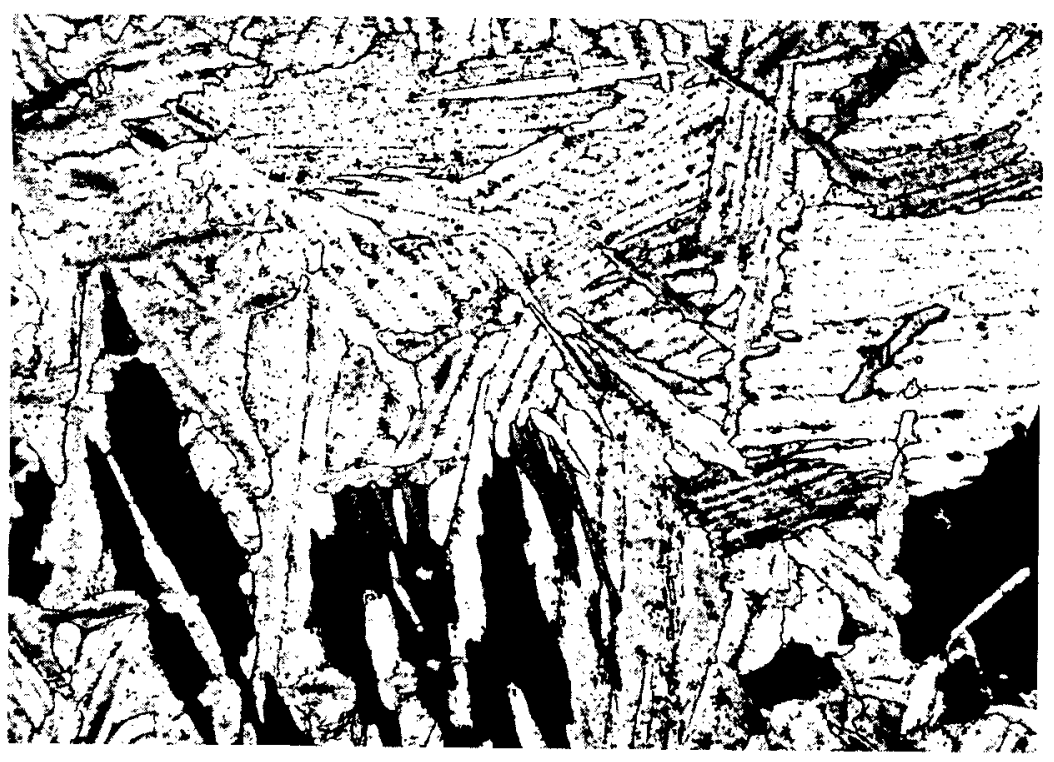

Fig. 9. Same, treatment as in Fig. 7.

Etchant: $2 \% \mathrm{HF}, 3 \% \mathrm{HNO}_{3}$ by vol.

Magnification: $100 \mathrm{X}$ 


\section{Physical Properties}

in Table 1.

A compilation of some of the physical properties of iodide titanium is given

TABLE 1. PHYSICAL, PROPERTIFS OF IODTDE TITANTOM

\begin{tabular}{|c|c|c|c|c|}
\hline Quantity & Unit & $\begin{array}{l}\text { Tempera- } \\
\text { ture, "C. }\end{array}$ & Value & Raference \\
\hline $\begin{array}{l}\text { Atomic number } \\
\text { Atomic weight } \\
\text { Density }\end{array}$ & $\mathrm{g} \cdot / \mathrm{cm}^{3}$ & 20 & $\begin{array}{c}22 \\
47.90 \\
4.507\end{array}$ & 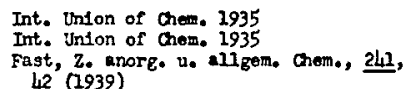 \\
\hline Crystal structure & Angstroms & Room & $\begin{aligned} \text { H.C.P. } \\
\text { E } 2.946 \\
\text { c } 4.686 \\
\text { c/a } 1.591\end{aligned}$ & Unpubil shod data, Battelle Insti tute \\
\hline & Angstroms & Above 880 & B.C.C. & $\begin{array}{l}\text { Burzers and Jacobs, z. Krist, } 2 \text { L, } 299 \\
\text { (1936) }\end{array}$ \\
\hline Welting point & ${ }^{\bullet} \mathrm{c}$ & & $1725 \pm 10$ & $\begin{array}{l}\text { de Boer, private communication to } \\
\text { ran Arkei }\end{array}$ \\
\hline $\begin{array}{l}\text { Bolling point } \\
\text { Resistivity }\end{array}$ & ohm-cm. & 20 & $\begin{array}{l}\text { above } 3000 \\
42 \times 10^{-6}\end{array}$ & $\begin{array}{l}\text { Handbook, Chemistry and Phystes } \\
\text { Fast, Z, anorg, v, allgom, Cheme, 24, } \\
\text { L2 (1939) }\end{array}$ \\
\hline $\begin{array}{l}\text { Temperature coeffi } \\
\text { cient of regiativity }\end{array}$ & ${ }^{\bullet} \mathrm{C} \cdot-1$ & not given & $5.46 \times 10^{-3}$ & Fast, 1bid. \\
\hline Hean specific heat & car. $/ 5$ & $\begin{array}{l}0-219 \\
0-266 \\
0-320 \\
0-500\end{array}$ & $\begin{array}{l}0.1291 \\
0.1316 \\
0.1334 \\
0.1396\end{array}$ & $\begin{array}{l}\text { Jaeger, ot al., Procelcad,Sc1, Amster- } \\
\text { dent, } 39,412,453 \text {, } 462 \text { (1936) }\end{array}$ \\
\hline $\begin{array}{l}\text { Lean Iinear coeffict- } \\
\text { ont of therrual ex- } \\
\text { pansion }\end{array}$ & $\cdot{ }^{-1}-1$ & $20-300$ & $8.2 \times 10^{-6}$ & $\begin{array}{l}\text { Fast, z. anorg, u. all gem, chem, , 2lit, } \\
42 \text { (1939) }\end{array}$ \\
\hline Spectral enissivity & $\begin{array}{l}\text { (wave length) } \\
\text { (6500 Angstroms) }\end{array}$ & $\begin{array}{l}1150^{\circ} \mathrm{K} . \\
1250^{\circ} \mathrm{K} . \\
1350^{\circ} \mathrm{K} . \\
1 \mathrm{~L}^{\circ} 0^{\circ} \mathrm{K} . \\
1550^{\circ} \mathrm{K} . \\
1650^{\circ} \mathrm{K} .\end{array}$ & $\begin{array}{l}0.533 \\
0.523 \\
0.502 \\
0.480 \\
0.450 \\
0.119\end{array}$ & $\begin{array}{l}\text { J. Wont, in frivate communtcation to } \\
\text { ran Arkel, "Reine Motalle," } 1939\end{array}$ \\
\hline
\end{tabular}

The higher purity of iodide titanium does not result in a substantially different density from that of magnesium-reduced titanium. Likewise, the lattice constants are very similar to those reported by Griner and Ellis for magnesium-reduced titanium obtained from the Bureau of Mines. Thermal expansion characteristics are similar also.

Allotropic transformation temperatures for ductile titanium have been obtained in the range of 880 to 888 degrees Centigrade. Values reported for iodide titanium - Burgers (See Table 1) 880 degrees Centigrade by X-ray work, De Boer et. al 882 degrees Centigrade by resistance, and from unpublished work at Battelle 888 degrees Centigrade by thermal analysis - are in good agreement with the value of 885 degrees Centigrade reported by Griner and Ellis 9 . With both iodide- and magnesium-reduced titanium, quenching from the beta field does not materially affect the hardness.

The most marked difference between iodide- and magnesium-reduced titanium is shown by electrical resistivity. This is not unexpected, since metals usually show marked increase in conductivity as the purity is increased. The resistivity of iodide titanium, $42 \times 10^{-6} \mathrm{ohm}-\mathrm{cm}$. (Table 1) compares with $55 \times 10^{-6} \mathrm{ohm}-\mathrm{cm}$. obtained by Griner and Ellis ${ }^{9}$; the temperature coefficients are 5.5 and $3.3 \times 10^{-3}$ per degree Centigrade, respectively. 


\section{Mechanical Properties}

Iodide titanium is characterized by low hardness, ability to be drastically cold worked, relatively low yield and tensile strength and high elongation. A general comparison of some of the mechanical properties with those from commercial Du Pont magnesium-reduced titanium is given in Table 2.

The rate of work hardening is about the same for both types of metal. That is, with the iodide titanium the ultimate tensile strength goes from 45,000 psi to 125,000 psi by $85 \%$ reduction, whereas the magnesium-reduced product goes from 80,000 psi to 125,000 psi by $50 \%$ reduction, or an average increase of about 900 psi for each percent reduction in each case.

TABLE 2. SOME MECHANICAL PROPERTIES OF TITANIUM

Iodide

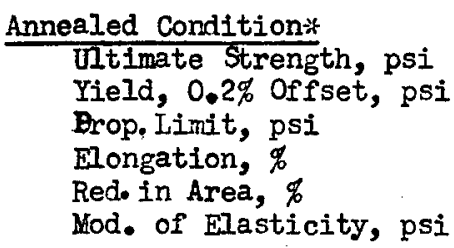

\begin{tabular}{cc} 
Iodide & Mg. Reduced** \\
\hline $38-48,000$ & 80,000 \\
$20-24,000$ & 72,000 \\
10,000 & 38,000 \\
40 (1") $^{\prime \prime}$ & 25 (2") $^{\prime \prime}$ \\
75 & 55 \\
$14-15,500,000$ & $16-16,500,000$ \\
& \\
97,000 & 125,000 \\
87,000 & 110,000 \\
11 (1") & $12\left(2^{\prime \prime}\right)$ \\
75 & 30 \\
over 95 & $50-60$ \\
ca.130,000 & ca. 130,000 \\
&
\end{tabular}

*Meited, hot worked, and vacuum annealed. * Data largely from publications by Pigments Dept., E. I. du Pont de Nemours \& Co.

\section{Conclusions}

At present iodide titanium production is still on a laboratory scale, since it is required only in minor quantities for experimental use. As experience has been gained many early troubles have disappeared and progress in simplifying the process is likely to continue. The metal produced by this method forms an excellent base for alloying and for studies of fundamental properties.

\section{References}

1. A. E. van Arkel and J. H. de Boer. Preparation of Pure Titanium, Zirconium, Hafnium and Thorium Metal. Z. anorg. u. allgem. Chem., $148,345(1925)$

2. J. H. de Boer and J. D. Fast. The Preparation of Pure Metals of the Titanium Group by Thermal Decomposition of Their Iodides. Z. anorg. u. allgem. Chem., 153, 1 (1926); ibid., 187, 193 (1930). 
3. J. D. Fast. The Preparation of Pure Metals of the Titanium Group by Thermal Decomposition of Their Iodides. Z. anorg. u. allgem. Chem., 239, 145 (1938); ibid., 241, 42 (1939).

4. J. D. Fast. Crack-free Forming of Zirconium and Titanium. Metallwirtschaft. 13, 405 (1934).

5. A. E. van Arkel. Reine Metalle. Julius Springer. Berlin, 1939, p. 181 191.

6. A. E. van Arkel and J. H. de Boer (to N. V. Phillips Gloeilampenfabrieken). U. S. Pat. 1,671,213. May 29, 1928. The Preparation of the Group IV A Metals by Decomposition of Their Iodides.

7. Titanium. Three German Methods of Production. A Report by the British Intelligence Objectives Subcommittee. Metal Ind. 70363 - 4 (1947); Chem. Abs. $\underline{41}, 4421$ (July 20, 1947).

8. I. E. Campbell, R. I. Jaffee, J. M. Blocher, J. Gurland and B. W. Gonser. The Preparation and Properties of Pure Titanium. Electrochem. Soc. 93, 271-285 (June, 1948).

9. E. S. Griner and W. C. Ellis. Thermal and Electrical Properties of Ductile Titanium. A.I.M.E. T. P. No. 2466, Metals Tech. (Sept., 1948).

\section{DISCUSSION}

Mr. J. R. Long (Bureau of Mines) inquired about the relative oxygen content of the iodide- and magnesium-reduced titanium and whether the transformation-temperature range is broadened by the presence of oxygen. In magnesium-reduced titanium, it is believed that the transformation occurs over a relatively wide temperature range. Dr. Gonser replied that work still remains to be done to definitely establish the transformation range. There is still no accurate method available for the determination of small amounts of oxygen in titanium in the range of a few parts per thousand, but it was estimated that iodide titanium contained about $0.001 \%$ to $0.002 \%$ oxygen. The oxygen content would be expected to be low, since oxygen does not transfer in the iodide process. This is known because titanium oxide can be added to the charge with no trace apparent in the purified metal. In fact, Dr. Gonser added, in order to speed up the process, the tube is evacuated roughly and heated up with the charge present; the charge then acts as its own getter for any remaining nitrogen and oxygen and removes these gases without particular difficulty.

In further discussion of the reason for the existence of a transformation temperature range, $\mathrm{Mr}$. Long brought out that it may be due to the presence of impurities, of which oxygen is believed to be a principal one at this time. Iodide titanium may exhibit similar characteristics. Although no data are available, Mr. Long did not think that isothermal transformation would occur in material that is now available. In answer to Dr. P. A. Beck (University of Notre Dame), Dr. Gonser thought that the transformation was of a martensite nature. Dr.W. Finley (Remington Arms 
Company) added that an article by W. G. Burgers, published by Phillips-Eindhoven in 1936, contained information on the effect of impurities in titanium. Measurement of the electrical resistance of the titanium filament, after removal from the iodide tube, as a function of temperature revealed a very sharp break at the transition temperature, and then the curve rose sharply again for the high-temperature beta phase. When small amounts of oxygen were introduced, the curve rose linearly with temperature but then curved off. This was interpreted to mean that oxygen and perhaps other impurities cause the transformation to occur over a range of temperatures, whereas, with pure titanium, the transition occurs quite sharply.

In answer to Mr. Linsmayer (Air Materiel Command), Dr. Gonser stated that although tungsten filaments were used in the earlier work on the iodide process, filaments of titanium rods of square cross section are now being used. By changing the temperature of the filament, some control over the grain (or crystal) size can be obtained. At high temperatures, the tendency is for the crystals to be closely packed, like buttons on a string.

In reply to Mr. F. G. Brockman (Phillips Laboratories), Dr. Gonser pointed out that the di-iodide would also decompose if the reaction took place at high temperatures in the metal tube. It is more convenient, however, to operate at lower temperatures, and the hardness and purity obtained have been satisfactory. With glass tubes, a better product is obtained by the use of higher temperatures, but other factors enter into the picture with the metal tube. A much larger diameter is possible and, as the initial impurities are diluted during the reaction, the subsequent metal deposited has a "normal" hardness.

Dr. W. J. Kroll (Bureau of Mines) pointed out that the iodide process is essentially a refining process - impure metal is converted to pure metal by passage through an iodide phase. As to the transfer of oxygen, he added that if carbon and oxygen are present, they may combine to form carbon monoxide which may then transfer oxygen to the filament. The question that then (logically) follows is if more carbon is present in raw zirconium (or titanium), does the deposited filament contain greater percentages of oxygen? Since zirconium and titanium contain nitrogen, Dr. Kroll wondered about the transfer and decomposition of the nitrides on the filament in the presence of chlorine or iodine. He suspected that this reaction would be a function of temperature and that the nitride would be decomposed on the filament with the liberation of nitrogen. Other types of impurities, such as aluminum or iron, may be transferred and the raw material used must, ther efore, be closely controlled.

In reply, Dr. Gonser stated that the operating temperature was important and that, at higher temperatures than he had used, a greater transfer of nonmetallics would occur. At some temperatures, the charge may retain the impurities and a fairly impure charge may be used. The charge is generally extremely brittle and is easily broken up. Silicon will also transfer, in addition to the metals mentioned by Dr. Kroll. Although the possibility exists for transfer, from charge to filament, of numerous metals, only little contamination actually occurs. He presumed that if spectroscopically pure metal was used for the charge, the filament hardness might run as low as 50 VPN, whereas the hardness of the titanium filaments now being obtained runs between 60 and $85 \mathrm{VPN}$. 


\title{
PROPERTIES. OF IODIDE TYPE TITANIUM
}

\author{
By F.. B. Litton \\ Foote Mineral Company
}

The iodide process for preparing high purity metals was developed in 1925

by Van Arkel and De Boer 1 . Preliminary to this, experiments were carried out in an attempt to prepare zirconium by passing a mixture of zirconium tetrachloride and hydrogen over a heated filament. Since they observed that zirconium tetraiodide was less stable than the tetrachloride at the filament temperature, subsequent work resulted in development of the iodide process. They used the process for preparing zirconium, titanium, hafnium and thorium metals, and several of their alloys.

The Foote Mineral Company in 1942 purchased the iodide process for ductile zirconium production from the $N$. V. Philips Company. Immediately thereafter, a project was initiated by the Foote Nineral Company at Battelle Memorial Institute to prepare zirconium by this process. On successful completion, the apparatus was moved to Foote's Laboratory and adapted to a more commercial operation by Mr. C. L. Scheer, of Foote's Research and Development staff.

Titanium preparation by the iodide process has been adequately reported by Dr. Bruce Gonser 2 . It is a simple process: crude titanium is reacted with iodine in an evacuated bulb at such temperature to form volatile titanium iodides which are decomposed on a heated titanium filament. It is a purification process in which crude titanium is separated from embrittling elements, such as oxygen, hydrogen, nitrogen and carbon. Also, it is a consolidating process in that the resulting mass can be drastically cold fabricated into desired shape.

The manufacture of iodide titanium as produced by Foote is not currently operated for large-scale production. The average rate of metal deposition is approximately $0.8 \mathrm{gram}$ per hour per square inch surface area. That is equivalent to approximately $250 \mathrm{grams}$ of metal per bulb per 16-hour day. Obviously, this rate of metal production is not comparable to the magnesium reduction method of $\mathrm{Dr}$. Kroll 3 and as developed by the Metallurgical section of the Bureau of Mines 4 .

The iodide process, however, is probably the most satisfactory means for producing high purity titanium for studying the properties of the metal and its alloys. The ductility of iodide titanium is as much as $55 \%$ elongation in two inches on standard tensile test specimens. Also, the metal can be cold reduced at least $95 \%$ without intermediate anneal.

The physical properties of iodide titanium depend primarily on the impurities in the raw material, and the ease with which those impurities are transferred to the growing rod. The common elements that are either co-deposited with titanium or have a harmful effect on metal transfer are silicon, aluminum, iron, magnesium, calcium and hydrogen. Oxygen, nitrogen and carbon do not appear to be transferred. 
follows:

Typical spectrographic analysis of Foote's iodide deposited titanium is as

\begin{tabular}{lc} 
Element & Composition, percent \\
\cline { 2 - 2 } Silicon & $0.01-0.05$ \\
Iron & $0.01-0.05$ \\
Nickel & 0.001 \\
Magnesium & 0.005 \\
Manganese & $0.005-0.01$ \\
Aluminum & $0.05-0.1$ \\
Calcium & $0.01-0.05$ \\
Copper & $0.001-0.005$ \\
Molybdenum & $0.05-0.10$ \\
Zinc & Trace \\
Tin & Not Detected \\
Zirconium & Not Detected
\end{tabular}
follows:

The average tensile properties of sheet iodide titanium may be recorded as

Ultimate strength, psi.

Yield strength, $0.2 \%$ off set, psi.

Elongation, percent 2-in.

Reduction of area, percent.

Modulus of Elasticity, psi.

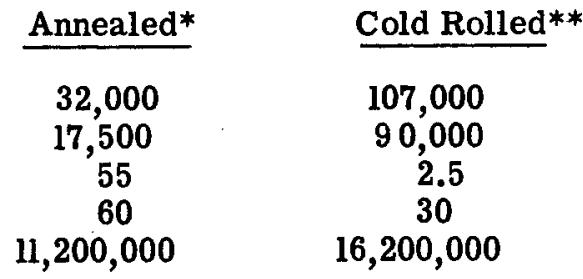

* Vacuum, $\frac{1}{2}$ hour at 750 degrees Centigrade

** Cold rolled from rod.

The average hardness of "as deposited" rod is Rockwell B 38 (equivalent to Brinell Hardness Number 73).

It will be noted that these tensile properties are approximately one-third those reported for titanium produced by DuPont 5 , and the elongation is twice as great. This difference is attributed to impurities in the magnesium-reduced product.

\section{References}

1. A. E. van Arkel and J. H. de Boer, Zeit. Anorg. Allgm. Chemic, 148, 345 (1925).

2. Campbell, Jaffee, Blocher, Gurland and Gonser, Electrochem. Soc., 93-6 (1948).

3. Kroll, Trans, Electrochem. Soc., 78, 35 (1940).

4. Dean, Long, Wartman, and Anderson, Metals Technology 13, 19 (1946).

5. Technical Data and Properties of Titanium Metal, E. I. DuPont de Nemours \& Co., Pigments Dept., Wilmington 98, Delaware. 


\section{DISCUSSION}

In discussion, Dr. Litton remarked that the spectrographic analysis presented in his paper was for iodide titanium produced in a metal bulb. Mr. P. H. Brace (Westinghouse Research Laboratories) commented upon the large difference in the elastic modulus between the annealed and cold-rolled material, and inquired whether it was due to a preferred orientation effect. The modulus measurements were taken from stress-strain curves (measurements made at the University of Pennsylvania) and although the reason for the difference is not known, Mr. Litton replied that there is evidence that preferred orientation may be a responsible factor. In reply to Mr. I. R. Kramer (Office of Naval Research), Mr. Litton stated that density comparisons of annealed and cold-rolled samples had not been made, but that they were believed to be similar. It was not thought that the modulus difference could be attributed to density differences.

Mr. C. H. Moore (National Lead Company) commented that most of the differences in ductility and strength are apparently due to the effect of small indeterminable amounts of oxygen which may exist in solid solution. In connection with the study of these effects, he discussed the possibility of studying etched sections of known compositions and etched sections of pure materials by high magnification - light microscope or electron microscope methods. No work has been done along these lines, but Mr. Litton remarked that impurity content may be satisfactorily studied by means of measurement of the electrical resistance changes or changes in the temperature coefficient of resistance. Mr. Lilliendahl (Westinghouse Electric Manufacturing Company) pointed out that they had observed a difference in photoelectric response in samples of zirconium sintered under different vacuum conditions, which they attributed to the oxygen content of the material, and remarked that such a shift in spectral behavior might provide a sensitive tool for the measurement of small amounts of oxygen. 


\title{
TINDUCTION MELTING OF TITANIUM METAL IN GRAPHITE
}

\author{
By J. B. Sutton \\ Pigments Department, E. I. DuPont de Nemours and Company
}

Before any metal or alloy, which is produced in granular or sponge form, can be used in the fabrication of bar, plate, sheet etc., it must first be consolidated. Conversion to a consolidated form can be accomplished by 1) pressing and sintering using powder metallurgy techniques or 2) melting.

The Bureau of Mines has done extensive work on pressing and sintering of titanium metal powder, results of which are published in Metals Technology, February 1946. This method although satisfactory on a small scale has size limitations and requires expensive equipment for the pressing operation. Also, when the product is sponge instead of powder, a costly grinding step must be carried out before the metal can be pressed and sintered.

Melting and casting of titanium presents many difficult problems; the metal has a high melting point and when molten reacts with virtually everything with which it comes in contact. All oxide refractories are reduced by contact with the molten metal which is then contaminated by both the oxygen and the metallic element and is embrittled. Kroll (Metals Technology, February 1946) was able to melt titanium metal on a small scale in a controlled atmosphere by a special arc melting procedure which did not permit the molten metal to come in contact with anything but titanium powder.

In a later publication by the Bureau of Mines (Metals Technology, January 1948), W. J. Kroll, C. T. Anderson and H. L. Gilbert, describe the use of a new graph. ite resistor vacuum furnace in the melting of zirconium and briefly mention its use in melting titanium. Although some carbon was picked up during the melting operation, the effects of this small amount of carbon on physical properties of the metal were found to be small.

About a year ago, the Pigments Department of the DuPont Company started development work on melting and decided at that time to concentrate attention on induction heating in graphite. A ten-pound ingot scale was selected for the first work and to simplify subsequent scale up to $100 \#$ and larger sizes, the melting and casting operations were carried out in an atmosphere of argon instead of in vacuo. In the beginning, the purest grades of graphite were employed as crucible materials, but difficulties with flow of the molten metal through pores in the graphite soon led to replacement with denser less pure forms. National Carbon grade CS has been used successfully for several months after a preliminary high-temperature bake (2000 degrees Centigrade) prior to its use.

Equipment employed in the prcduction of ten-pound ingots today, as shown in the following diagram, consists of the graphite crucible (1), carbon black insulation (2) between the crucible and an outside silica container (3). A pipe extension from the melting crucible fits tightly into the ingot mold (4) which is graphite or watercooled copper. One induction coil (5) surrounds the silica around the melting crucible and a second (6) is located around the pipe connecting the melting crucible to the ingot mold. A sight glass (7) attached to a graphite pipe (8) extending through the top 
(9) of the melting crucible is used in observing the melting operation and making temperature measurements with an optical pyrometer. Supports $(10)$ for the outside silica container are fastened to a transite top on the main furnace support (11). Argon during heat-up, melting and casting operations is introduced through inlets (12) and (13). The ingot mold is raised and lowered by means of a mechanical jack (14). High frequency power is supplied to the two coils from 20 and $5 \mathrm{KW}$ Ajax spark gap converters.

In charging the melting crucible for a $10 \#$ melt, the opening at the bottom of the crucible is closed with a piece of sponge and the 10\# sponge charge, consisting of crushed sponge particles from $1 / 4$ inch to three inches in size, is added. The bulking density of the sponge is about 1.0. The charge is heated from room temperature to 600 degrees Centigrade in one hour with about $6-\mathrm{KW}$ input to the 20-KW spark gap converter. The power is then stepped up to $18-$ to $20-\mathrm{KW}$ input and the charge is molten in about 30 minutes. The small coil around the pipe between the melting crucible and the ingot mold is turned on at this point and one to three minutes later the molten metal flows into the ingot mold.

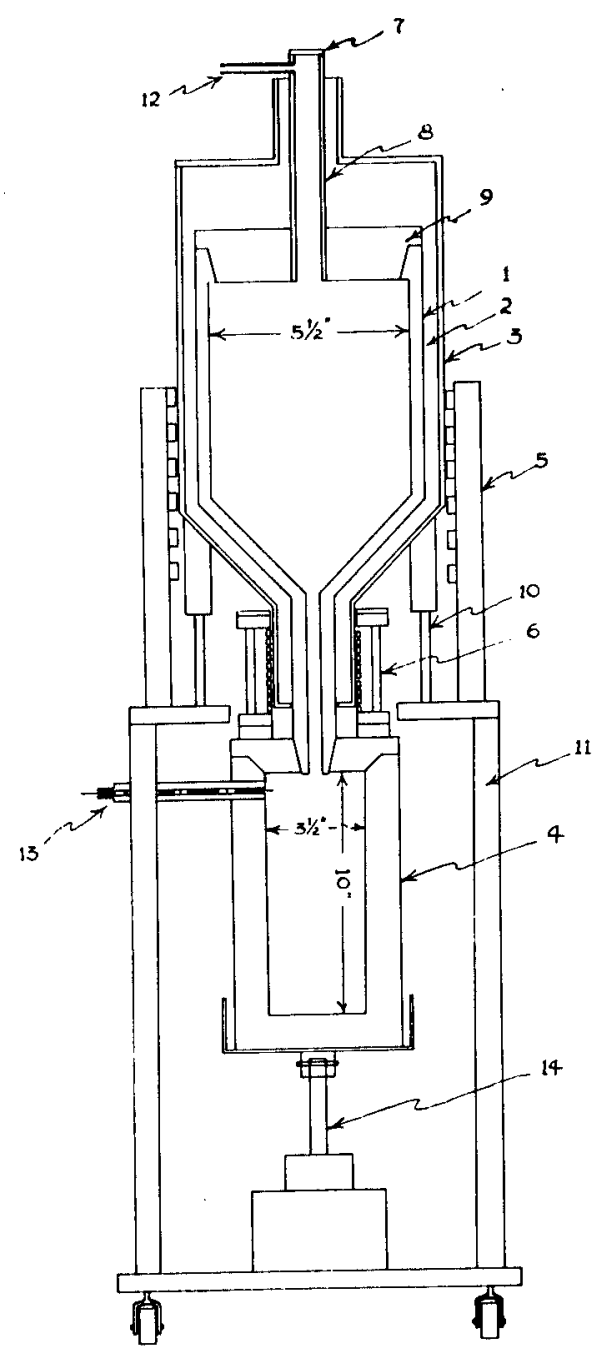

The ingots obtained by this melting procedure contain from $0.4 \%$ to $0.7 \%$ carbon and $99.0 \%$ Ti with the remainder, minor impurities present in the $99.5 \% \mathrm{Ti}$ sponge used in the melt. The ingots vary in "as cast"' hardness from slightly below 200 to 240 on the Vickers hardness scale. They machine about like 18-8 stainless steel and can be readily forged to round or square bar at 1700-1900 degrees Fahrenheit. Hot forged bars can be hot rolled at temperatures of 1200 to 1600 degrees Fahrenheit with about $10 \%$ reduction in thickness per pass.

Facilities have been installed recently for melting and casting 100-pound ingots by direct scale-up of the 10 -pound operation. Operating cycles are being worked out for production of the large ingots at the present time.

\footnotetext{
$10 \mathrm{lb}$. MELTING AND CASTING UNIT
} 


\section{DISC USSION}

In the discussion of the process and apparatus described in his paper, $\mathrm{Dr}$. Sutton stated that some trouble with fogging of the sight tube had been experienced but that this difficulty had been remedied somewhat by reducing the rate of heating above 600 degrees and by introducing argon at that time. Fogging is quite dependent upon the magnesium content of the sponge. Little trouble has been experienced with the formation of shrinkage cavities in the top of the ingot; a few small voids are usually found in the top portion of the ingot but no large holes or deep pipes. The use of forging temperatures between 1700 and 1900 degrees Fahrenheit does result in the formation of a surface oxide layer which has to be removed for subsequent working of the forging to sheet. With forging temperatures of 1800 degrees Fahrenheit, however, the surface layer contaminated with oxygen is not very deep. The metal handles at that temperature as well as, or a little better than, 18-8 stainless steel at its forging temperature, which is a little higher than for titanium.

Dr. Sutton further remarked that there was a definite advantage to be gained by using forging temperatures around 1800 degrees Fahrenheit rather than lower temperatures such as 1200-1400 degrees Fahrenheit. Dr. S. F. Urban (Titanium Alloy Manufacturing Company) corroborated Dr. Sutton's remarks by stating that 1200-1500 degrees Fahrenheit was impractical for large-size ingots and that they also used a forging temperature between 1800 and 1900 degrees Fahrenheit. The oxygen penetration is not high but would be serious for titanium sheet. Reworking of Bureau of Mines bar stock at temperatures of 1800-1900 degrees Fahrenheit, however, was unsuccessful and the samples cracked badly. Apparently, it is essential that the billet be free of voids prior to heating at those high forging temperatures.

Dr. Sutton also stated that the same graphite pot can be reused for numerous melts. Occasional pot failure indicated that a surface layer of titanium carbide, which does not readily crack off, exists in the pot. Difficulties in the pouring operation would result if it did crack off. The main control of carbon content in the melting process is in control of time and temperature. Excess superheating is avoided. The rate of heating of the charge, and of removal from the pot after the charge is completely molten, is as rapid as possible.

In discussing the pick-up of carbon by the melt, Dr. Urban (Titanium Alloy Manufacturing Company) pointed out that, at 3700 degrees Fahrenheit in a graphite mold, about $0.3 \%$ carbon is absorbed by the molten metal. It also seems that the higher the oxygen content of the original sponge, keeping time and temperature essentially constant, the higher the carbon content of the cast material.

Mr. Bradford (Remington Arms Company) remarked that though both DuPont and Remington start with the same sponge material, the final Remington product has a slightly lower carbon content, about $0.3 \%$, than the DuPont cast titanium.

Mr. F. F. Poland (Revere Copper and Brass) commented that, for the furnace design described by Dr. Sutton, if the furnace size was increased to handle larger charges, the melting times must of necessity increase and the carbon pick-up would also increase. He described his experience with a high furnace of a radiant resistor type, operating in the range of 3200-3600 degrees Fahrenheit, which contained a graphite box with carbon walls and carbon bottom, and pointed out that over several months operation it was observed that the graphite was attacked and went into solution at a much more rapid rate than carbon. He inquired whether similar observations had been made by others and whether information was available on the relative rate of solubility of carbon versus graphite and the solubility of boron carbide in titanium. Dr. Urban replied that the relative solubility rates of carbon and graphite in 
titanium would be difficult to obtain, since a high-density carbon was necessary for satisfactory pot operation. In making such high-specific-gravity pots, however, the carbon transforms into graphite (graphitizes). Mr. Poland further stated that the manufacture of graphite products generally depends upon the graphitization of carbon at high temperatures. To obtain the denser forms of graphite, the material, after it has been graphitized, is given a vacuum treatment, impregnated with pitch and then regraphitized. Information obtained from the National Carbon Company, however, reveals that there are certain other forms of carbon, particularly lampblack, which hardly graphitize at all at ordinamy graphitizing temperatures.

With respect to the effect of titanium on bor on carbide, Mr. S. J. Sindeband (American Electro Metal Company) stated that an exothermic reaction will occur with the formation of borides, which will probably be troublesome for subsequent working into sheet. Mr. Poland remarked that he was interested in bor on carbide because the furnace described by Dr. Sutton seemed to be the simplest form possible for a continuous casting process and that he wondered how long such a process might operate successfully with the use of a graphite die. His experience with boron carbide as a die material in continuous casting processes indicated its possibility for use as a substitute for graphite for casting of titanium. He felt that a furnace design permitting continuous withdrawal of molten titanium would offer greater possibility for the production of a high-density material than the procedure of dropping the molten charge into a mold and chilling it. 


\title{
THE PRODUCTION AND ARC MELTING OF TITANIUM
}

\author{
By O.W. Simmons, C. T. Greenidge and L. W. Eastwood \\ Battelle Memorial Institute \\ Introduction
}

It is now well known that nature has supplied titanium with many attributes which make it a desirable material of construction. A very substantial raw material supply, a relatively low specific gravity, good resistance to corrosion, and high tensile properties of titanium are all very desirable characteristics which would normally insure its importance as a structural material. However, nature also endowed titanium with many chemical characteristics which make it difficult, or at least expensive, to obtain in the form of ingots for fabrication into various wrought products. It is to be expected, therefore, that a great deal of effort will be placed on the development of better and cheaper production and melting techniques.

There are at least two methods of producing titanium: the reduction of titanium tetrachloride with a metal such as magnesium, and the Van Arkel process. The Van Arkel process has been described in detail by others. It is sufficient to observe here that, because of the high degree of purity of the so-called iodide titanium, it has been very useful in experimental work. Because of the high purity of the titanium, this method merits further study and development in order to reduce substantially the cost of the product.

The production of titanium by the reduction of the chloride has also been described by others. It is sufficient to observe that the method employed to date consists of a batch operation in which the recovery of the reaction product, and the separation of titanium from it, is a fairly difficult, tedious, and expensive operation. While the cost of producing titanium by either of the two methods undoubtedly can be reduced, it is quite evident that a great deal of progress is necessary if titanium is to be used in other than highly specialized applications.

The production of titanium at a low cost is probably no greater problem than that of melting titanium in fairly large units without damaging contamination. It is important to observe that titanium sponge of present-day purity may be converted with some contamination into ingot form and yet produce unalloyed metal with adequate cold ductility. However, such contamination lowers the ductility sufficiently so that only a limited amount of alloying is possible if adequate cold ductility is retained.

The metallurgist is not only faced with the very difficult problem of possible contamination from the atmosphere during melting, but he has no refractory which is suitable for retaining the titanium melt.

A study has been made of refractories and the results are briefly reviewed.

\section{Refractories}

Investigations on refractories for melting titanium have been carried out by $\mathrm{Kroll}^{2,3}$ and Brace ${ }^{1}$, and to some extent, certain of their findings have been verified by similar investigations at Battelle. Brace investigated the reaction of molten ti- 
tanium with aluminum oxide, beryllium oxide and thorium oxide. He found that both alumina and beryllia severely contaminated the titanium melt presumably through oxygen absorption, causing the metal to be brittle and friable. Thorium oxide also produced some increase in hardness in titanium as a result of oxygen absorption; but of the three oxides studied, this appeared to have the most promise.

$\mathrm{Kroll} 2,3$ reported that $\mathrm{A}_{2}{ }_{2} \mathrm{O}_{3}, \mathrm{Y}_{2} \mathrm{O}_{3}, \mathrm{ZrO}_{2}$, and $\mathrm{MgO}$ all reacted quite readily with titanium at its melting temperature. Calcium oxide was also investigated and it appeared to offer considerable promise, though under a high vacuum there was very real danger of a rapid evolution of calcium vapor as a result of the violent reaction between the calcium oxide and titanium. The use of refractories as a container for molten titanium, therefore, does not appear to be feasible. Carbon, of course, has been employed as a container for molten titanium with some success. While some carbon is absorbed by the melt, it may not be too serious when melting unalloyed titanium. However, as pointed out before, this unavoidable absorption of carbon may seriously limit the amount of more useful alloying elements which can be employed gainfully.

In order to circumvent the difficulties encountered in the use of refractories as a container for molten titanium, Battelle has developed an arc-melting furnace, utilizing a water-cooled crucible which is applicable to the preparation of small or large ingots of titanium or other refractory metals, such as chromium-, molybdenum-, zirconium- and tungsten-base alloys. The preliminary phase of the development of this type of furnace at Battelle under Project RAND has been described by Herres and Davis. ${ }^{4}$

\section{Arc Melting Titanium}

The employment of the arc furnace for melting refractory metals has received a great deal of attention experimentally, and has acquired considerable success commercially. W. Von Bolten ${ }^{5}$, in 1903 , arc melted tantalum buttons on a watercooled copper plate, employing a vacuum chamber to avoid contamination and a consumable electrode of tantalum to facilitate melting. Kroll and co-worker $\mathrm{s}^{5,6}$, have employed a similar technique, with several modifications including the employment of a tungsten electrode, without too much success. Consequently, they directed their efforts toward the successful use of a small-scale graphite-resistor furnace for melting zirconium in a vacuum. The use of a consumable electrode for the arc melting of alloy steel under a flux in a water-cooled metal crucible has been quite successful ${ }^{7}$ commercially, and molybdenum ingots have also been successfully arc melted in a vacuum employing a consumable electrode and a water-cooled copper mold. 8

After considerable experimental work, the arc furnace illustrated by figure 1 was developed under Project RAND at Battelle. The essential elements of the furnace are quite simple. An argon atmosphere of about $99.7 \%$ argon was employed to reduce atmospheric contamination of the titanium melt and to facilitate the stabiliza tion of the arc. The titanium melt does not wet the water-cooled copper crucible and, therefore, contamination from this source is eliminated. The holder for the tungsten tip of the electrode is water-cooled and DC current (electrode negative) is employed to reduce overheating of the tungsten tip and contamination of the melt with the electrode. In order to incorporate these principles in the furnace, the tungsten electrode tip was nickel brazed to the end of a $3 / 4$-inch-diameter steel pipe and a small-diameter concentric copper tube permitted the introduction of the cooling water at a point $1 / 4$ inch from the tungsten. The water-cooled copper crucible was silver solder ed and electrically insulated, the location of the electrical insulation being as shown in Figure 1. The electrode, mounted with two Victor oil seals held firmly in place with a threaded insert, is vertically movable through the furnace cover. 
While this furnace proved to be relatively useful, and a number of melts of refractory metals was successfully made in it, the operation actually was not too satisfactory for the following reasons:

1. It was necessary to reopen the batch-type furnace after each successive charge. This operation was time-consuming, increased the opportunity for contamination, and led to unsatisfactory development of the ingot in successive layers.

2. It was most suited for the production of rather thin cylindrical ingots forgeable only in one direction and at relatively low ratios of reduction, a forging procedure that produced sheet of inferior quality .

3. The lower edges of the ingots furthermost from the electrode tip generally were inadequately melted. Even a large amount of grinding of these edges did not always insure the production of sound sheets from the ingots.

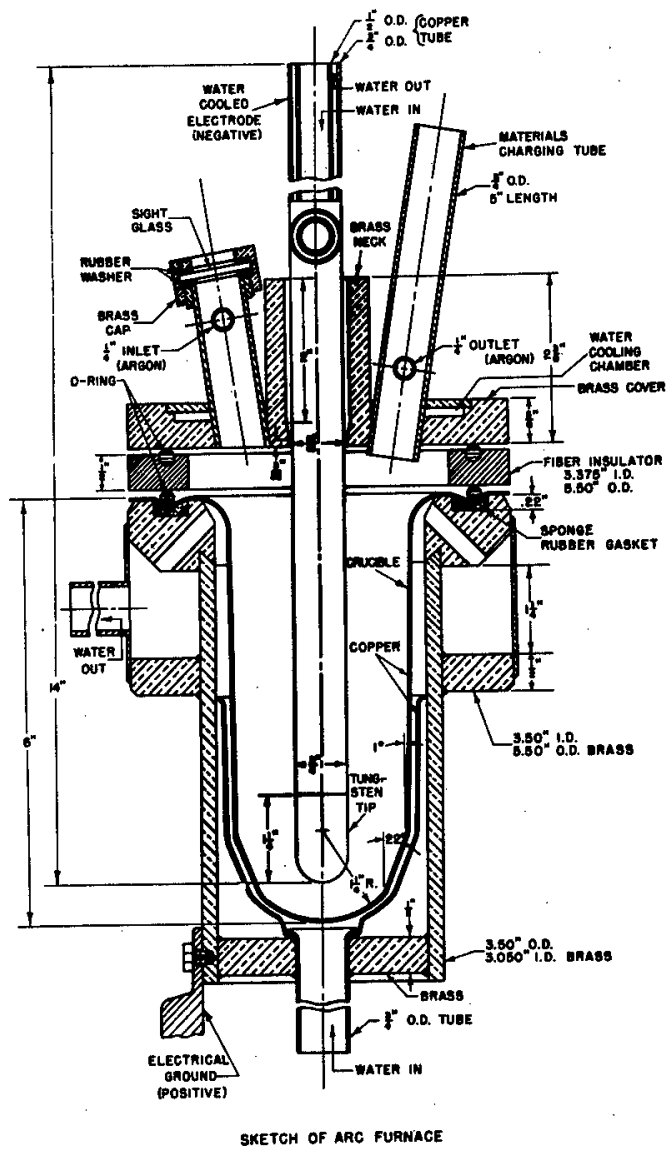

Another furnace developed early in the work on Project RAND is illustrated by Figure 2. ${ }^{4}$ This furnace is quite similar to the preceding one, except that a vibrating device was attached to provide continuous feeding of the charge to the furnace. In order to provide adequate clearance between the electrode and the crucible wall, a minimum inside diameter of $2 \frac{1}{2}$ inches was necessary. Again, this furnace was fairly successful and several $2 \frac{1}{2}$-inch-diameter ingots weighing $\frac{1}{2}$ to $4 \frac{1}{2}$ pounds were made. 

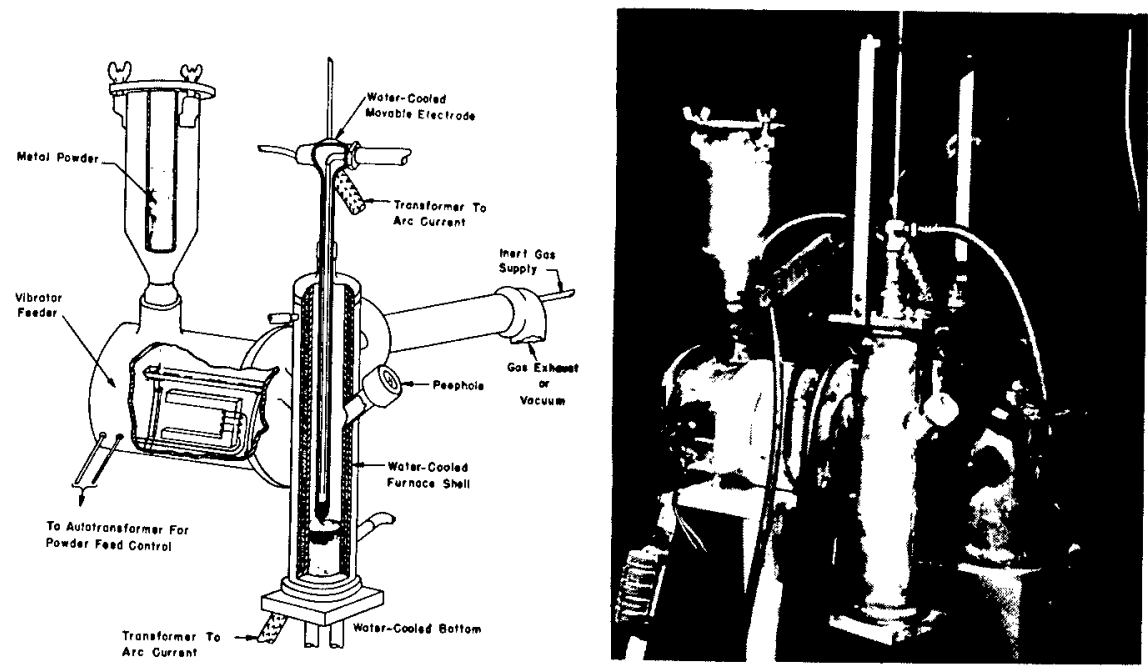

51322

MODIFIED ARC-VELTING FURWACE

However, the furnace was quite difficult to operate. A fine powder was required as a feed material, and if alloys were desired, the vibration tended to produce nonuniformity in the composition of the feed. In addition, when arcing occurred between the electrode and the crucible wall, a large amount of time was lost because the damage could not be quickly repaired.

Under the sponsorship of the Wright-Patterson Air Force Base, an extensive alloy development program was undertaken and it became quite evident that a considerable improvement in the arc-melting furnaces was necessary. Two furnace sizes were required. The first was a $\frac{1}{2}$-pound- to one-pound-capacity furnace in which a large number of different compositions could be readily produced for exploratory purposes. The second furnace was required to melt three- to five-pound ingots in order that alloy compositions of special interest could be investigated in considerably greater detail. These two furnaces naturally contained the fundamental elements of previous designs, namely:

1. The $\in$ mployment of an inert atmosphere.

2. A water-cooled, inert tungsten electrode.

3. A water-cooled copper crucible.

In addition to these basic elements, the following features were also obviously desirable:

1. A hemispherical crucible bottom in order to reduce the cooling area and minimize the heat loss from the ingot and, at the same time, to avoid the poor melting which previously occurred in the lower corners furthermost from the electrode tip.

2. A feeding device to insure a uniform composition for each part of the charge when making alloys. 
3. A more vacuum-tight crucible in order to permit more complete outgassing operations preparatory to melting an ingot.

4. Provision for maintenance of a static rather than a changing argon atmosphere in the furnace, ther eby reducing the quantity of impurities introduced with the argon.

5. Use of high-purity argon of about $99.92 \%$ minimum argon which, with the employment of a static atmosphere, would eliminate the nuisance and hazard of the purification train previously used to purify the argon.

6. Crucibles of a design that would facilitate the $r \in$ placement of the crucible when it was damaged by arcing from the electrode.

7. The control of temperature of the cooling water and the incorporation of a proper design of the water jacket around the crucible to permit close control of the cooling rate during the melting operation.

One of the difficulties which has plagued the arc melting of titanium has been the spattering during the melting operation. The Bureau of Mines acid-leached powder used in the early work, under Project RAND, contained up to about 30 volumes of hydrogen, the major portion of which was rapidly evolved during the melting operation. This rapid evolution of hydrogen caused a very large amount of spattering of the titanium over the hot tungsten electrode, producing serious tungsten contamination. Fortunately, at the time of the initiation of the program under the sponsorship of the Wright-Patterson Air Force Base in July, 1948, "Process A" titanium became available from E. I. du Pont de Nemours and Company. This titanium is produced by the reduction of $\mathrm{TiCl}_{4}$ with magnesium, and practically all of the magnesium and magnesium chloride reaction product are removed by a vacuum-distillation process.

Because the sponge is received in fairly large lumps, it is not suited for the small-scale arc-melting process without further crushing. A method has been developed whereby it can be crushed without contamination. Briefly, the first step consists of the submersion of the "Process A" titanium lump sponge in a bath consisting of methanol and dry ice. After the sponge has been cooled to -70 degrees Fahrenheit in this mixture, it is passed through a gyratory cone-type crusher having a minimum jaw opening of about $3 / 8$ inch. In this manner, the sponge is crushed to $-\frac{1}{2}$ inch, after which it is washed several times in methanol to remove the last traces of magnesium chloride. The methanol adhering to the titanium granules after draining is completely removed at room temperature by evacuating to 0.1 -micron pressure in a vacuum chamber. The over-all purity of the crushed product can be somewhat improved by removing the fine material under 0.05 inch, which comprised $10 \%$ to $12 \%$ of the total. The remaining granular sponge material is an ideal feed for the arc-melting furnace, and the two arc-melting furnaces for this alloy development program were especially designed to employ it as the melting stock.

One-Pound-Capacity Furnace

The new furnace of $\frac{1}{2}$ - to one-pound capacity is illustrated by Figure 3. This furnace contains an easily replaceable crucible, the bottom of which is a slightly modified hemisphere. This shape reduces the area of the ingot in contact with the crucible by $28 \%$ and eliminates the poor melting which previously occurred in the lower corners of the ingot. The one-piece crucible is spun from a copper sheet and a groove for an O-ring seal is incorporated in the rim so that the crucible is easily replaced 
when damage occurs as a result of an "arc blow". The cooling jacket closely follows the contour of the crucible and provides a 1/16-inch annular space for the flow of cooling water. The outside of the crucible rim rests on a sponge rubber gasket which seals the water jacket to prevent water leakage during operation. The positive electrical terminal, not shown on the sketch, is connected to the water jacket and thereby establishes an electrical connection through the rim of the crucible to the charge.

The brass cover is water-cooled and electrically insulated from the crucible by a fiber insulator $\frac{1}{2}$ inch thick which also contains an O-ring seal. A sight glass for observation of the melting operation and the material charging tube are mounted in the cover. The gas inlet is just below the sight glass to sweep fumes from the tube and to keep the sight glass clear.

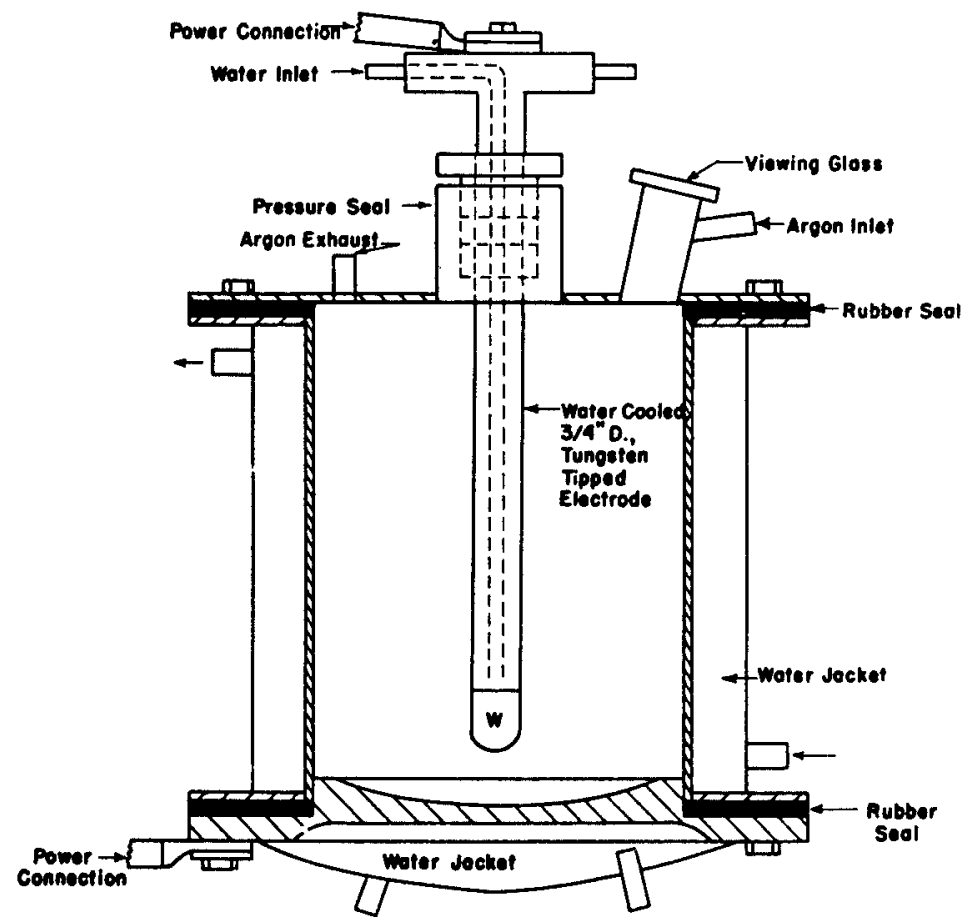

FIGURE 3. EXPERIMENTAL WATER-COOLED ARC MELTING FURNACE

A tungsten-tipped water-cooled electrode is introduced through the brass collar in the cover; a rubber sleeve, not shown in the diagram, is secured to the collar and to the electrode to provide a vacuum seal. The electrode tube is straight, but the ends of the brass collar are of such an internal diameter that the tungsten tip may be moved to describe a circle one inch smaller in diameter than that of the ingot. This circular movement during operation insures that the entire charge will be brought into close proximity with the arc. At the same time, it insures that the tip of the electrode will not approach the crucible wall too closely and cause arcing during the melting operation. 
An electric vibrator is attached to the bottom of the outer brass jacket. This vibrator is operated during the first part of the melting cycle in order to facilitate the production of a smooth ingot. The crushed titanium and alloying additions are introduced through the material charging tube by means of a rubber tube seal which is not shown in the diagram. This permits the production of a complete $\frac{1}{2}$ - to one-pound ingot without opening the furnace to introduce additional charges.

A typical heat is made in the new furnace as follows: Approximately 0.20 pound of titanium under $\frac{1}{2}$ inch in size with the alloy addition, if any is to be used, is placed in the bottom of the crucible. The cover is clamped on the crucible so that the O-rings make a tight seal. The balance of the charge is placed in a glass bottle connected to the charge tube of the furnace with a rubber tube. The crucible and the charge are evacuated by means of a mechanical pump to a pressure below $50 \mathrm{~mm}$. of mercury, or less if desired, and held at this pressure for five minutes. Hot water is circulated through the water jacket during the evacuation period to assist in the outgassing of the crucible and charge. At the end of the evacuation period, tank argon of $99.92 \%$ purity is introduced into the crucible and the temperature of the water in the water jacket is reduced to about 78 degrees Fahrenheit.

The generator is set for 80 volts open circuit and 200 amperes. The arc is struck and the electrode withdrawn to produce an arc voltage of 25 to 30 volts, at which the arc is maintained while the electrode tip is moved slowly around a circle one inch smaller than the diameter of the ingot. This takes about one minute, after which the current is raised to 300 amperes for $\frac{1}{2}$ minute and then to 500 amperes for a two-minute period. The electric vibrator which is attached to the bottom of the outer brass jacket is operated during the last two-minute period, and the rate of rotation of the electrode is increased so that the whole charge will be maintained in a molten condition.

At the end of the two-minute period at 500 amperes, the voltage is reduced, the arc broken, and the vibration discontinued. The electrode is withdrawn about four inches and a 0.15-pound charge added from the glass container through the charging tube. The arc is again struck and the preceding operation repeated, employing a 500-ampere current for $1 \frac{1}{2}$ minutes, but the vibrator is not used. The voltage is again reduced, the arc broken, and the remaining 0.15 -pound charge is added to produce a 0.5 -pound ingot. The arc is again struck, the current set at 500 amperes, which is maintained for $2 \frac{1}{2}$ minutes. The furnace is then allowed to cool from 10 to 15 minutes before the cover is removed and the ingot withdrawn from the crucible.

It will be observed that the above technique not only outgasses the crucible chamber, but also the charge and the space occupied by it. Furthermore, argon is introduced into the furnace during the melting operation to maintain a positive pressure of one to two psi in the melting chamber, but argon is not passed through the chamber excepting to compensate for the small leakage which occurs.

As illustrated by Figure 4, four of these $\frac{1}{2}$ - to one-pound-capacity furnaces have been built and are operated together using a single power source of two 400ampere generators connected in parallel. Figure 5 shows a close-up of a furnace assembled for operation and of a furnace dismantled to reveal its various parts. Although as many as sixteen ingots have been made in eight hours, a two-man crew operating with a single power source and the battery of four furnaces produces an average of ten to twelve $\frac{1}{2}$-pound alloy titanium ingots per day. 
Although the arc-melting process is one which would not be expected to produce excellent uniformity of composition from one part of the ingot to another, little difficulty from this source has been encountered to date but, of course, the few elements whose melting points are substantially greater than that of titanium require special care to obtain complete fusion. Remelting such ingots is sometimes necessary.

The contamination which occurs during the melting operation is quite minor. Iodide titanium can be melted consistently in furnaces of this type with a very small increase in hardness. The nitrogen content of ingots of unalloyed "Process A" titanium has been repeatedly shown to lie in the range of 0.010 and $0.015 \%$, which is only slightly greater than that of the unmelted sponge.

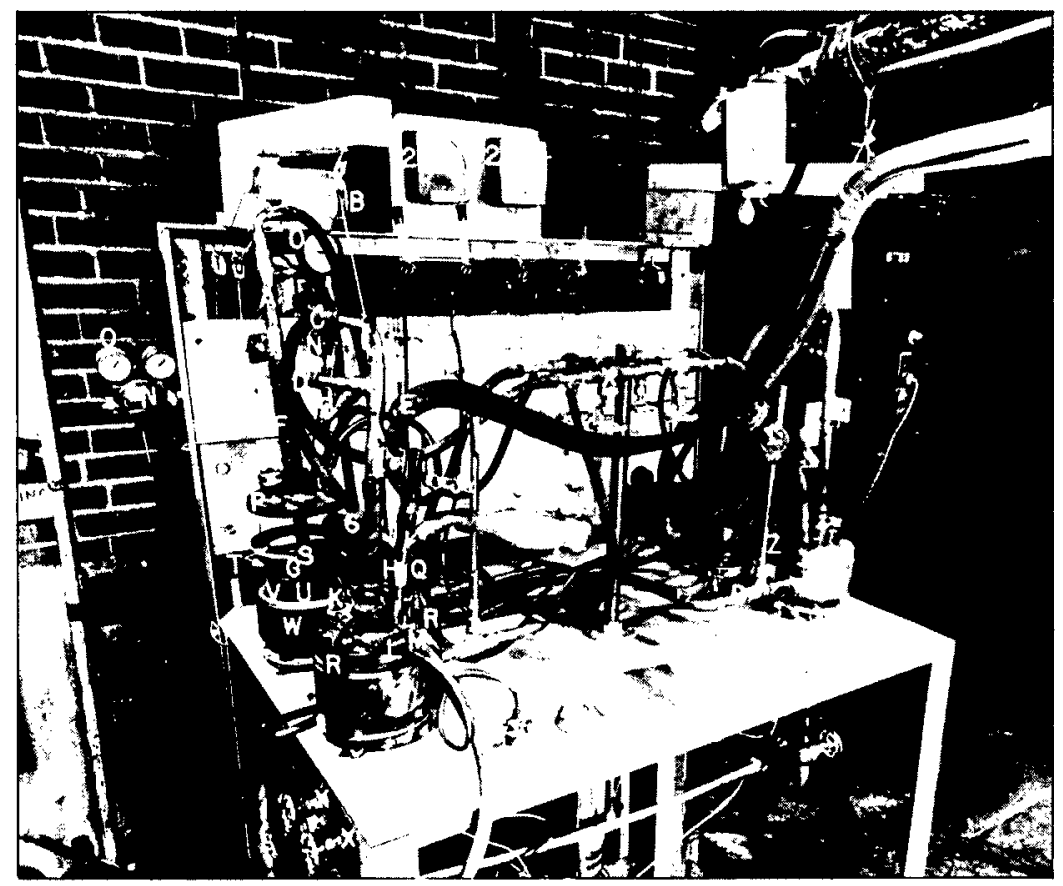

Figure 4. A battery of four $\frac{1}{2}$ - to one-pound-capacity arc furnaces in various stages of assembly.
A. Electrode (-)
B. Electrode Counterbalance
C. " Water Inlet
D. " Water Outlet
E. " Power Lead
F. " Rubber Sleeve
G. " Tungsten Tip
H. Charging Tube
I. " Bottle (Titanium)
J. " Bottle (Alloy)
K. Sight Glass
L. Argon Inlet
M. "Outlet and Connection to Vacuum Pump
N. Argon Regulator
O. " " Gage
P. Brass Cover
Q. " "Water Leads
R. Clamps

S. Insulating Ring (Micarta)

T. O-Ring

U. Copper Crucible

V. Sponge Rubber Gasket

W. Outer Water Jacket

$X$. Water Controls

Y. Water Flow Manometer

Z. Exit Water Thermometer

1. Voltmeter

2. Ammeter

3. Vacuum Manometer

4. Generator Switch

5. Electric Vibrator

6. Vibrator Switch

7. Ti Ingot

8. Ti Billet

9. Ti Sheet 
Figure 5. View showing a small arc furnace assembled for operation and one dismantled to reveal its various parts.

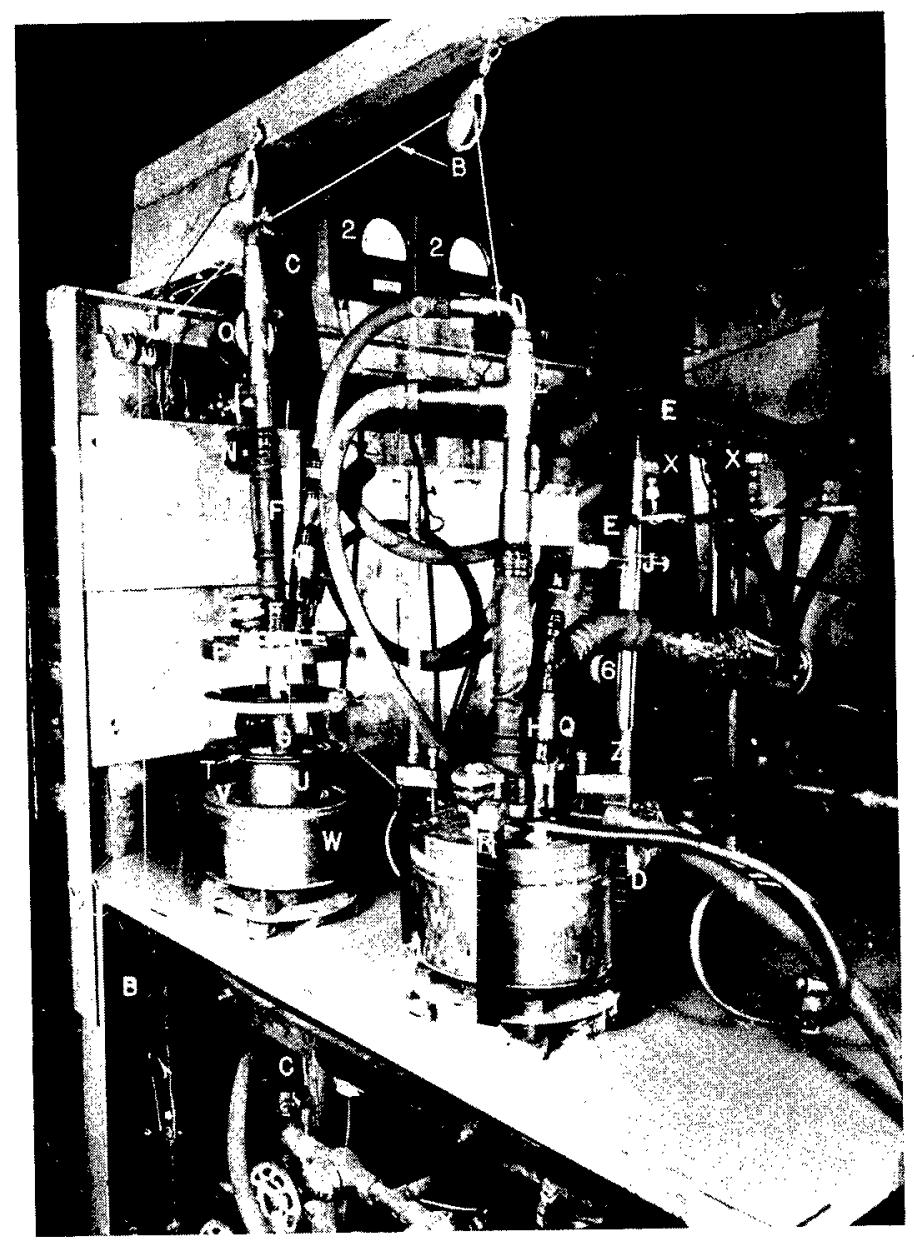
A. Electrode (-)
B. Electrode Counterbalance
C. " Water Inlet
D. " Water Outlet
E. " Power Lead
F. " Rubber Sleeve
G. " Tungsten Tip
H. Charging Tube
I. " Bottle (Titanium)
J. " Bottle (Alloy)
K. Sight Glass
L. Argon Inlet
M. "Outlet and Connection to Vacuum Pump
N. Argon Regulator
O. " " Gage
P. Brass Cover
Q. " " Water Leads
R. Clamps

S. Insulating Ring (Micarta)

T. O-Ring

U. Copper Crucible

V. Sponge Rubber Gasket

W. Outer Water Jacket

$X$. Water Controls

Y. Water Flow Manometer

Z. Exit Water Thermometer

\section{Voltmeter}

2. Ammeter

3. Vacuum Manometer

4. Generator Switch

5. Electric Vibrator

6. Vibrator Switch

7. Ti Ingot

8. Ti Billet

9. Ti Sheet 
Figure 6. An unassembled crucible, $\frac{1}{2}$-pound titanium alloy ingots, a forged billet, and rolled sheets preparatory to alloy evaluation.

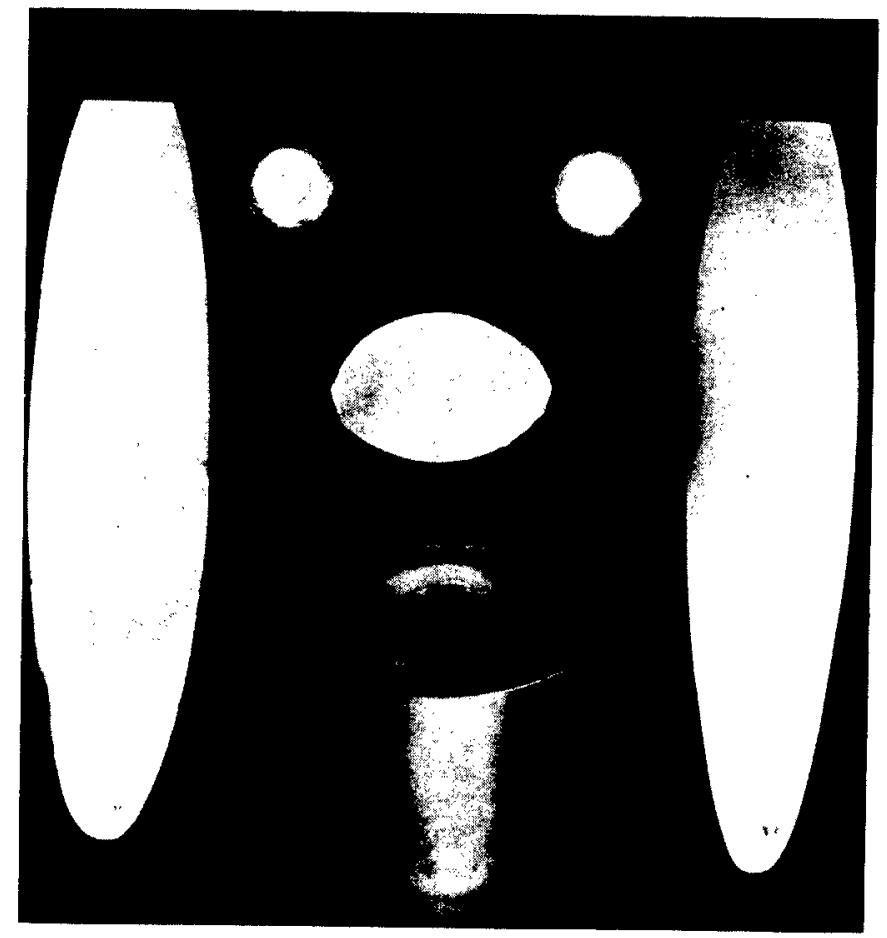

Figure 6 shows a crucible, two $\frac{1}{2}$-pound alloy ingots, a forged billet, and two rolled sheets. The ingots are fabricated by forging at 1700 degrees Fahrenheit, during which operation they are placed on edge and hammered to 0.250 inch. After grinding the surface, the 1/4-inch slabs are hot rolled at 1450 degrees Fahrenheit, using reductions of 0.060 inch per pass and reheating between each pass until a sheet thickness of about 0.064 inch is obtained.

\section{Five-Pound-Capacity Furnace}

As indicated previously, a large furnace is required for the production of alloys of special interest so that a more thorough study can be made of them. In the earlier part of the alloy development work, the furnace of the type illustrated by Figure 1 was used to make 5-pound ingots. The furnace was about three inches inside diameter and the charge weighing several pounds was placed in a rubber charging tube and slowly worked into the melting chamber during the melting operation. While this method was fairly satisfactory, a new furnace, as shown by Figure 7 , is being constructed, the design of which incorporates the features of the smaller furnace. The main design features are (1) an improved method of adding the melting charge; (2) a considerably higher degree of tightness, permitting more thorough outgassing of the melting chamber, the charge, and the space occupied by it; and (3) the employment of $99.92 \%$ argon which will be introduced into the furnace and maintained at a slight positive pressure, the argon flow making up for losses only. 


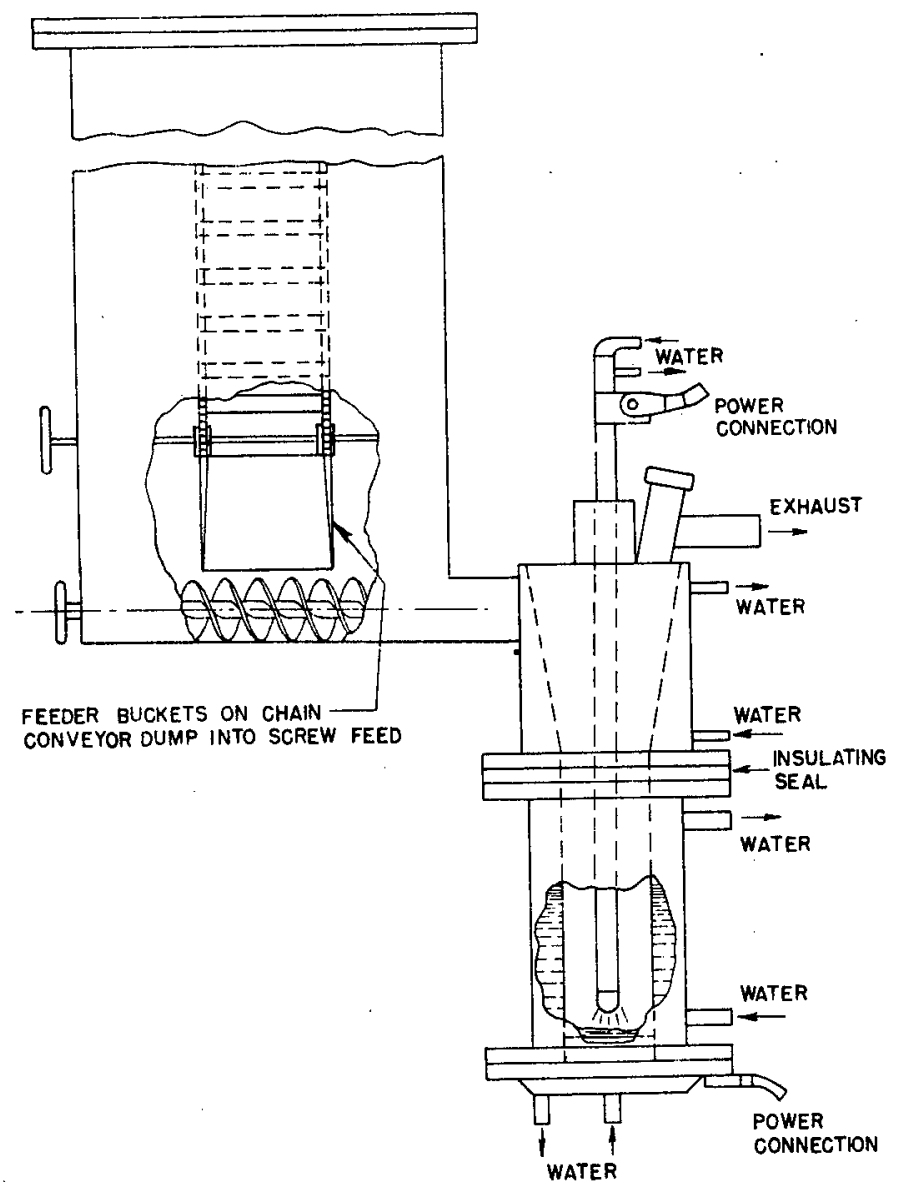

FIGURE 7. SCHEMATIC DRAWING OF A FIVE-POUND ARC FURNACE OF NEW DESIGN

\section{Conclusions}

As now developed, the arc furnace is a useful tool for the rapid production of small ingots of titanium alloys or other refractory metals. Figure 8 shows several ingots of a variety of refractory alloys prepared in an arc furnace of an earlier design. While the arc furnace is particularly suited to the rapid production of small ingots without contamination from the atmosphere or crucible material, it is also adaptable to the production of larger ingots, such as the 19-pound ingot about six inches in diameter shown by Figure 9. As a matter of fact, in many respects, the production of larger ingots in the water-cooled crucible is easier than small ones. The reason for this is quite apparent. The ratio of surface-to-volume of small ingots is high and the heat loss through the crucible wall is therefore large. On the other hand, when making large ingots of some depth, melting is done on top of titanium rather than on top of a water-cooled copper base. Heat losses through the bottom then become negligible and the melting efficiency increases. Furthermore, the larger diameter ingots provide greater space between the rotating electrode and the crucible wall, permitting the continuous addition of charging material without danger of arc blowing to the crucible. As noted previously, the titanium melt does not wet or adhere to the watercooled copper wall. This is the ideal condition which would permit the continuous withdrawal of the ingot from the bottom of the furnace. Although no effort has been 
made as yet to produce a continuous ingot wherein the ingot is withdrawn from the bottom, it is quite certain that this could be readily done with a relatively small amount of development.
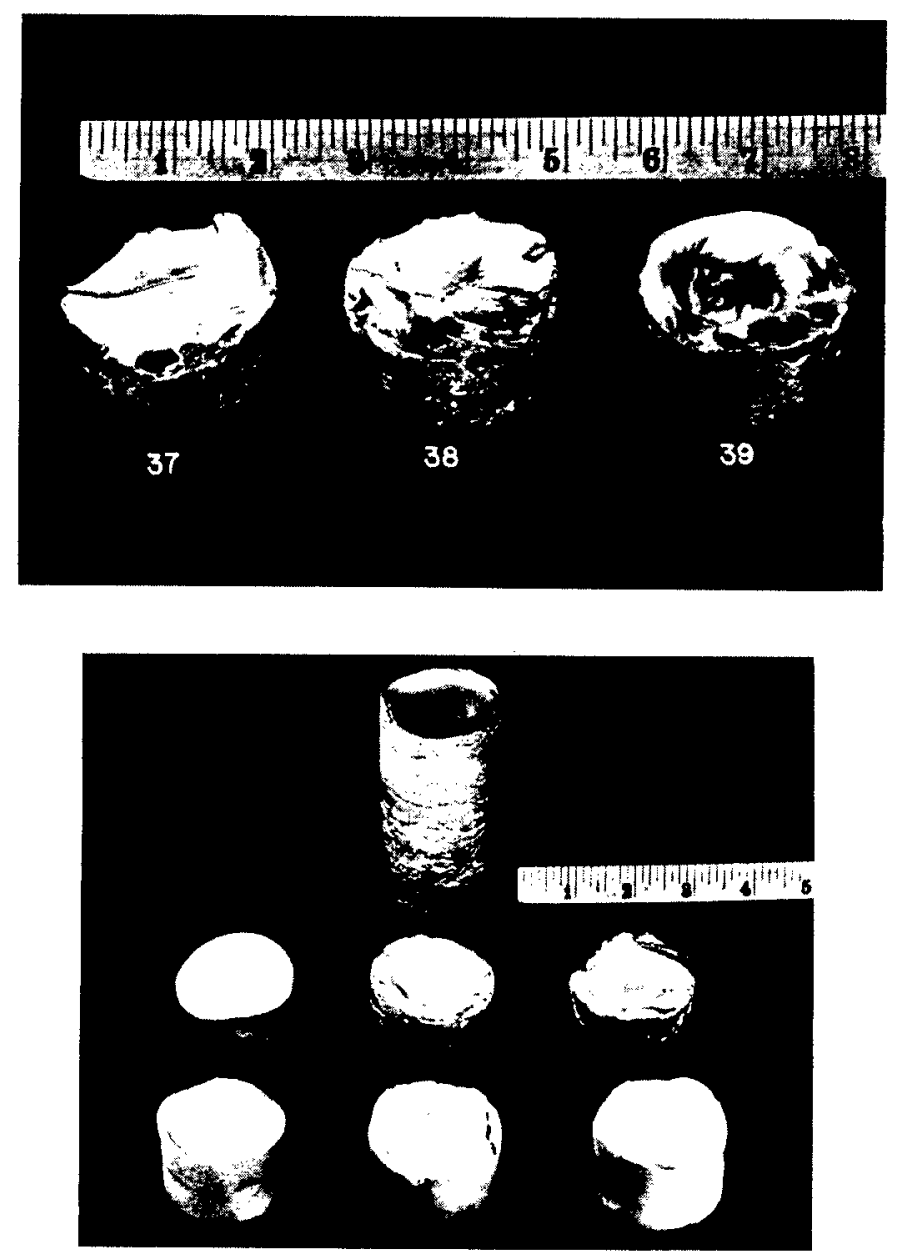

Figure 8. Small ingots of various refractory alloys melted in an arc furnace of an early design.

Top Row: $\quad 20 \mathrm{~W}-80 \mathrm{Mo}, 40 \mathrm{~W}-60 \mathrm{Mo}, 60 \mathrm{~W}-40 \mathrm{Mo}$

Middle Row: $80 \mathrm{Cr}-20 \mathrm{Mo}, 60 \mathrm{Cr}-40 \mathrm{Mo}, 20 \mathrm{Cr}-80 \mathrm{Mo}$

Bottom Row: $99.75 \mathrm{Cr}-0.25 \mathrm{Al}, 99.5 \mathrm{Cr}-0.5 \mathrm{Al}, 99 \mathrm{Cr}-1.0 \mathrm{Ti}$ 
Figure 9. A 19-pound titanium ingot melted in a six-inch-diameter arc furnace. Surface roughness though not deep is ground off before the ingots are forged.

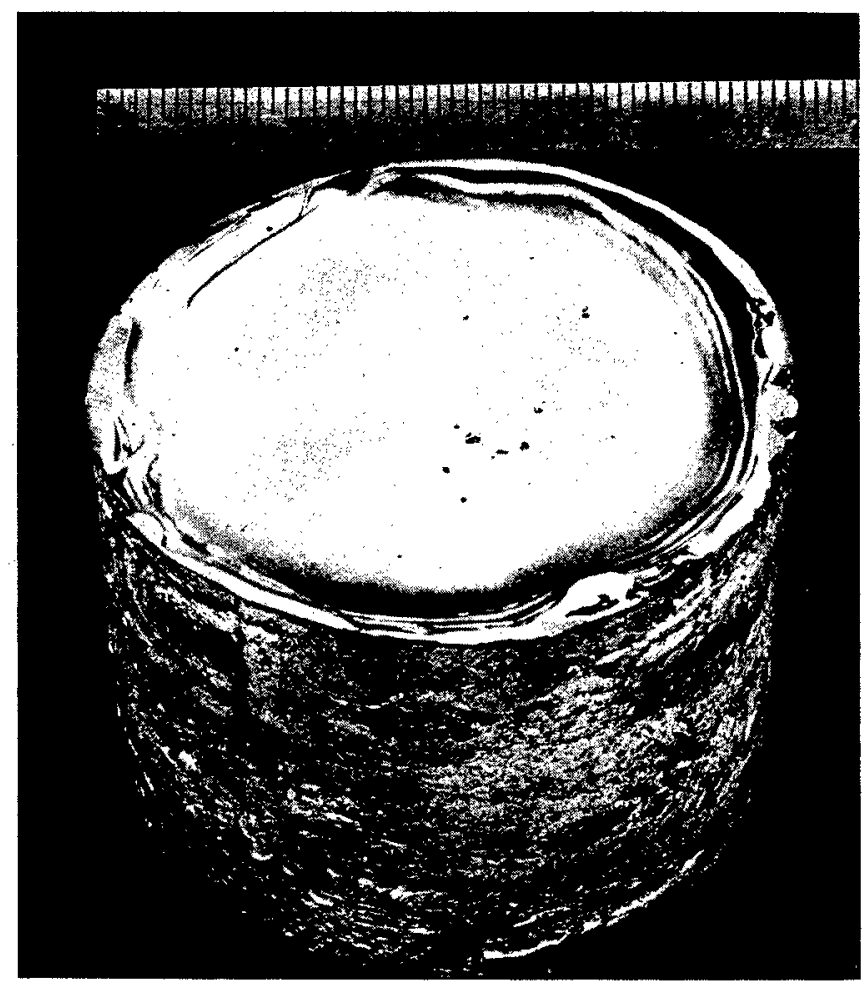

\section{$\underline{\text { Summary }}$}

An arc furnace for melting titanium and titanium alloys as well as other refractory metals has been developed incorporating the following features:

1. A water-cooled tungsten electrode.

2. A water-cooled copper crucible.

3. A fairly tight melting chamber and alloy addition apparatus, wher eby outgassing operations can be carried out.

4. A protective atmosphere consisting of $99.92 \%$ argon which effectively prevents contamination of the melt.

5. A device for the continuous or semi-continuous addition of the melting charge for the production of small ingots.

This furnace is ideally suited for the production of a large number of small titanium or other refractory alloy ingots without appreciable contamination. It is also suitable for the production of large ingots, and it is believed that with relatively little additional work a method of producing continuous ingots of refractory alloys could be developed. 


\section{References}

1. P. H. Brace: Reaction of Molten Titanium With Certain Refractory Oxides. Trans. Electrochemical Society, Vol. 94, October, 1948.

2. W. J. Kroll: Production of Ductile Titanium. Trans. Electrochemical Society, Vol. 78, 1940.

3. W. J. Kroll: Some Properties of Pure Titanium. Metallwirtschaft, 1939.

4. S. A. Herres and J. A. Davis: Arc Melting of Refractory Metals Such as Titanium and Their Alloys. Unpublished.

5. C. W. Balke: The Story of Tantalum, Chemistry and Industry, 1948.

6. W. J. Kroll, A. W. Schlecten, and L. A. Yerkes: Ductile Zirconium from Zircon Sands. Trans. Electrochemical Society, Vol. 89, 1946.

7. H. R. Clauser: Alloys Made by Electric Ingot Process Have Improved Properties. Materials and Methods, January, 1948.

8. R. M. Parke and J. L. Ham: The Melting of Molybdenum in the Vacuum Arc. Metals Technology, September, 1946.

\section{DISCUSSION}

During informal discussion of the arc-melting process, Dr. Eastwood remarked that in the earlier work at Battelle, Bureau of Mines titanium powder was used. Serious spattering on the electrodes occurred, however, as a result of the large volumes of hydrogen evolved at the melting temperature. At room temperature the powder contains about 30 volumes of hydrogen. DuPont titanium, which seems to be gas-free, is currently being used, and after a suitable crushing operation forms an ideal charge for the furnace. The tungsten electrode can either be nickel-brazed to a steel pipe or silver-soldered to a copper tube. Either method is satisfactory.

In reply to questions concerning the pattern of the arc and the use of a magnetic field to prevent arcing to the crucible, Dr. Eastwood replied that at any one time the arc is concentrated in a very small area. The electrode can be moved by the operator through a radius about a half-inch smaller than the radius of the crucible, and can be applied to any portion of the charge. The process can be observed by the operator by means of a sight tube. Magnetic fields have not been employed to control the arc.

Dr. W. J. Kroll (Bureau of Mines) remarked that he was happy to see the application of arc-melting to the production of titanium. He indicated that with the melting of much larger ingots, problems might be experienced with the formation of skin on the outside of the ingot, sticking to the wall and burning through the thin copper crucible wall. He cautioned about the probability of gas expansion at the moment of striking the arc and stated that an excape port should be present. In his apparatus for melting zirconium a rubber tire was used as the escape mechanism. Dr. East- 
wood replied that they had not experienced any of the difficulties mentioned and believe that the method is adaptable to a continuous large-scale casting, since titanium does not stick to the copper mold. Serious gas expansion has not been observed. The furnace is operated under a positive pressure of argon and, in the case of leakage, more argon flows into the furnace to maintain the positive pressure of about two pounds above atmospheric pressure. If an expansion occurs, the automatic regulator will allow a reverse flow. In addition, a mercury exhaust trap is attached to the furnace by a tube, and, if there is a sudden increase in pressure, the gas can flow out through the mercury. 


\title{
SOME PRELIMINARY TESTS TO DETERMINE APPLICATIONS FOR TITANIUM
}

\author{
By W. Lee Williams \\ U. S. Naval Engineering Experiment Station, Annapolis, Maryland \\ $\underline{\text { Introduction }}$
}

Interest in titanium is becoming widespread, due to its successful manufacture in a ductile form and promise of quantity production in the not-too-distant future. Successful commercial exploitation now appears to hinge primarily on the stimulation of demand. In addition, the Nation's critical metal shortage lends impetus to the search for an understanding and utilization of titanium.

From what little is known, titanium will stand well on its own merits as a constructional material in many applications. On the other hand, a material as new as this tends to create over-optimism in those developing new markets, and care must be exercised not to consider the metal a cure-all. Experience demonstrates that one misapplication will undo the favorable impressions left by a number of successful applications.

Until the titanium industry is standing firmly on its own, it seems appropriate that development work include an investigation of the basic properties and promote uses emphasizing the unique characteristics of titanium. Such an attitude is being followed by the Naval Engineering Experiment Station. As the Station's name impliess, the focal point of the experiments is to find successful uses for titanium, particularly where it will serve better than any other material.

Due to the practical objectives of the tests, side trips into more fundamental fields are made only in so far as such information is required from a practical standpoint. It is evident, then, that the Station is making studies of titanium as it is now produced. Possibly the results will indicate a need for changes in manufacture, but such things are not within the scope of the Station's work.

\section{Method of Test}

In evaluating a new material, it is the custom of the Engineering Experiment Station to select a few leading experiments which quickly yield data regarding the more promising lines of attack for more extensive investigation. It is in this first stage that the Station is now operating. The work was begun in June of this year. Already some information is available which should be of interest.

The number of tests performed was rather large. To maintain continuity of thought, it is considered well to describe details of the experiments along with the appropriate test results.

\section{$\underline{\text { Material }}$}

The Station's work was planned to include titanium as produced by the Bureau of Mines and by the Remington Arms Company (DuPont). Up to the present, only Bureau of Mines material has been received, and that in amounts which have limited the number of tests. Arrangements have been made for more material from both sources. 
as follows:

The Bureau of Mines titanium used in the tests consisted of assorted pieces

$$
\begin{aligned}
& 6-1 / 16 " \text { x } 0.0625 " \text { sheet, total length } 99 ", \\
& 7 / 8 \text { " diameter bar, total length } 94 " \text {. } \\
& 0.1265 " \text { diameter wire, total length } 68 " \text {. }
\end{aligned}
$$

The sheet was prepared by hot rolling and finishing with $40 \%$ cold work. The bar stock was prepared by hot rolling and finishing with $35 \%$ cold work as a square bar, followed by machining to $7 / 8^{\prime \prime}$ diameter. The wire had been swaged and finished with $40 \%$ cold work.

\section{Tensile and Hardness Properties}

The tensile properties were determined with standard 0.505 " specimens for the bar stock and with 0.75 ' full thickness specimens for the sheet. The average values from these tests are listed in the table below. They are useful primarily to define the titanium used in subsequent experiments and are not intended to represent precisely the properties of titanium produced in every case.

\begin{tabular}{lccc}
\multicolumn{2}{c}{ Average Tensile Properties and Hardness } & \\
\cline { 2 - 3 } \multicolumn{1}{c}{ Property } & Units & $\underline{\text { Bar }}$ & Sheet \\
Tensile strength & psi & 97800 & 123000 \\
$0.1 \%$ Yield strength & psi & 78800 & 85800 \\
$0.2 \%$ Yield strength & psi & 84900 & - \\
Elongation in 2" & $\%$ & 8.5 & 10.0 \\
Reduction of area & $\%$ & 18.0 & - \\
Elas. modulus & psi X 106 & 14.1 & 15.2 \\
Brinell hardness & - & 198 & $240 *$ \\
Rockwell 30-T hardness & - & - & 82
\end{tabular}

*Converted from $30-\mathrm{T}$ Scale

These results are substantially in line with those of other investigators, especially the yield and tensile strengths. The ductility is fair; occasionally, higher values have been reported for material of equal strength, although none are known for Bureau of Mines titanium. The elastic modulus for the bar stock is somewhat lower than any other previously known value for similar material.

The results substantiate claims that the comparatively pure metal, cold rolled, develops useful strengths from an engineering standpoint. The tensile strength is comparable to that of medium strength steel, and, of prime importance, the yield ratio is high. The ductility is inferior to that of steel of equal strength, although by no means can the material be classed as brittle. 


\section{Endurance Properties}

An understanding of the behavior of titanium under cyclic stresses is most important in regard to machinery applications. A rather extensive fatigue program has been initiated. To date, data have been obtained only with specimens tested in air.

The three types of specimens employed are illustrated in Figure 1. The sheet specimens were tested with as-rolled surfaces; the edges were cut with a circular milling cutter and were not finished subsequently. The other specimens were prepared by alternate longitudinal and transverse polishing operations sufficient to remove. scratches at 200 diameters magnification.

Flexural tests of the bar stock were made at 3500 RPM with the $7.5 \mathrm{~mm}$ specimen. Figure 2 presents the results graphically. The endurance limit was approximately 30,000 psi, although a minor change from this value might have been necessary had sufficient material been available for more specimens. The endurance ratio (ratio of endurance limit to tensile strength) was 0.31 , which value checked well with other investigators. The ratio was considerably lower than the 0.45 to 0.50 found for heat-treated steels and places titanium among nearly all the non-ferrous metals and alloys, which show ratios of about $1 / 3$. It is understood that titanium produced by casting techniques sometimes produces unusually high endurance ratios; this has not been confirmed as yet by the Station's tests.

Also shown on Figure 2 are the results obtained to date with notched specimens of the same dimensions. The notches were cut 0.019 "' deep, with a zero flank angle. The radius of curvature was 0.0092 '. Calculations based on the theory of Neuber* indicated that the 0.019 " depth would produce about the maximum possible stress-concentration factor for a notch of this radius in the size of specimen being used. The calculated factor was 1.53, and, if this be accurate, it is of interest to note that the titanium specimens showed approximately complete sensitivity to the notch.

Alternating torsion endurance tests, made with the 0.375" specimen, for completely rever sed stress cycles at $1450 \mathrm{CPM}$, have not been completed at this writing. Results obtained to date are presented in Figure 3. Whereas the curve is not quite complete, the endurance limit appears to be about $17,000 \mathrm{psi}$. Such a value would yield a torsional endurance ratio of 0.175 . The value is rather low compared to ratios of 0.22 to 0.27 for most non-ferrous metals and about 0.30 to 0.33 for heat-treated steels.

Flexural tests of the sheet specimen were made at 1725 CPM. Results are indicated by the open points in Figure 4. The endurance limit was not reached at stresses as low as $20,000 \mathrm{psi}$. If an estimated limit of $19,000 \mathrm{psi}$ is chosen, the endurance ratio would be only 0.155 , which value is considerably lower than for any other known metal or alloy. Most investigators have obtained normal values around 0.3 in similar tests, although one case has been heard of in which results like the Station's were observed.

Obviously, it is important to learn the reason for the unusual fatigue characteristics exhibited by this sample of sheet titanium. Since the results are not always abnormal, there may possibly be fabrication difficulties which must be controlled to insure a uniform, satisfactory product.

*H. Neuber, "Theory of Notch Stresses: Principles for Exact Stress Calculation," David W. Taylor Model Basin Translation 74 (1945) (J. W. Edwards, Inc., Dec., 1946). 
Several of the sheet fatigue specimens developed fatigue cracks away from the milled specimen edges. The cracks did not appear to be associated with any visible surface imperfection. For these reasons, it was assumed that the sample was abnormal, rather than the test procedure.

Very careful oil-powder and fluorescent powder tests, supplemented by metallographic examination, failed to reveal any surface cracks, even when the sheet was flexed to open any incipient hair-line defects.

It was considered possible, though not probable, that residual stresses from cold rolling were acting in a deleterious manner. If so, a moderate temperature stress relief might help. Brief experiments soon disclosed that temperatures at least as high as $\mathbf{4 5 0}$ degrees Fahrenehit did not lower the hardness; in fact, the hardness may have increased very slightly. Knowing this, a set of sheet fatigue specimens was stress relieved for two hours at 400 degrees Fahrenheit. The solid points in Figure 4 represent the results obtained with these specimens. The endurance limit was not altered significantly. A definite shift to the left in the upper portion of the curve was evident, although the direction of shift was opposite to that, had the heat treatment released undesirable stresses.

Further experiments are now in progress to detect the cause of the abnormal behavior. Bureau of Mines representatives believe the trouble may be traced to oxygen segregation in the surface layers, although this has not been confirmed as yet.

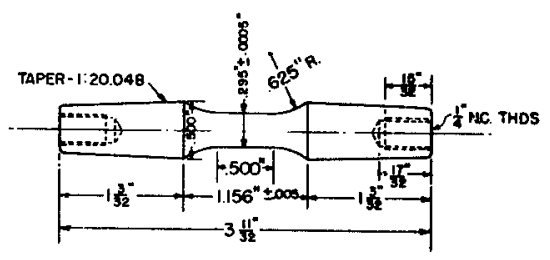

7.5 MM ROTATING BEAM FATIGUE SPECIMEN

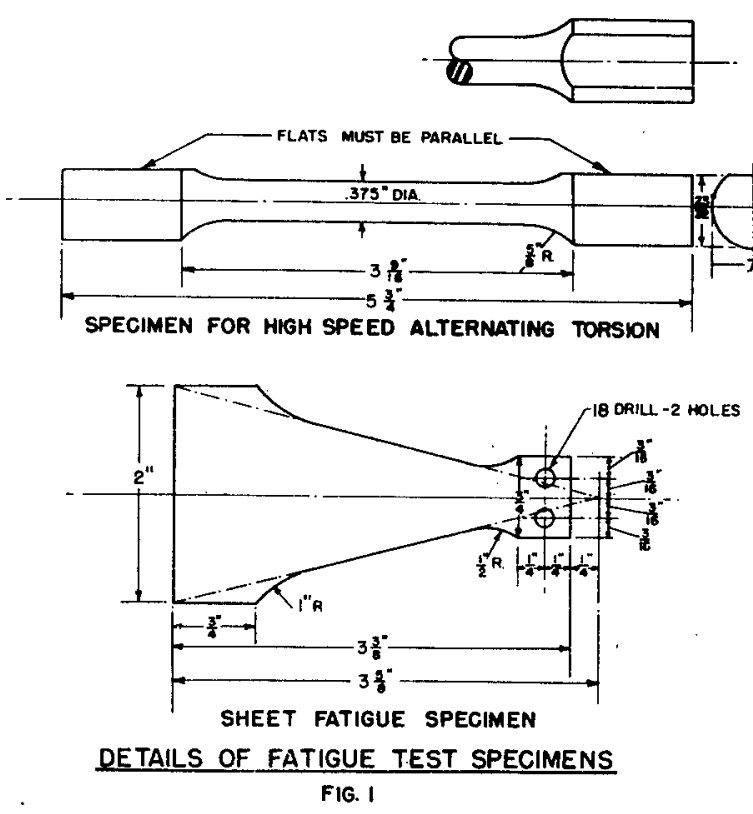




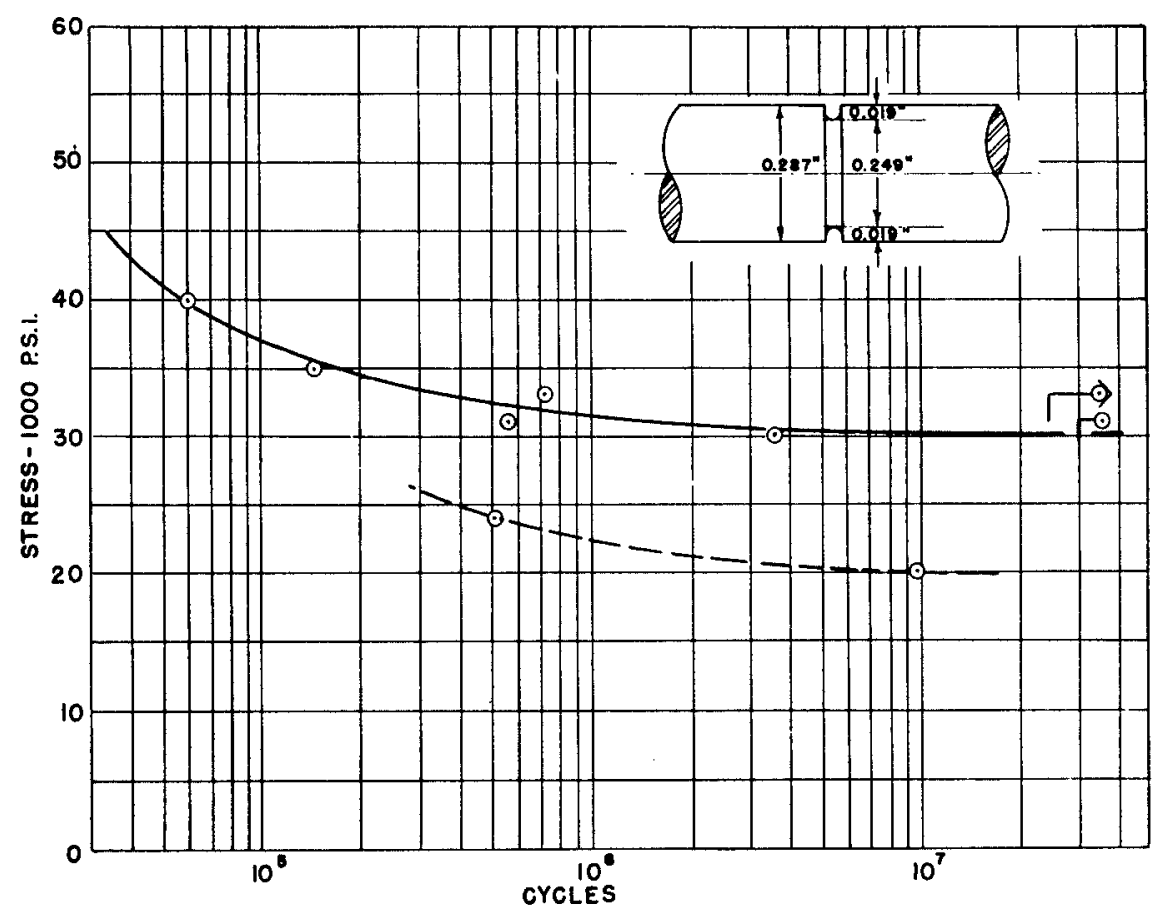

FIG. 2-FLEXURAL FATIGUE TESTS OF TITANIUM BAR $(98,000$ TS.)

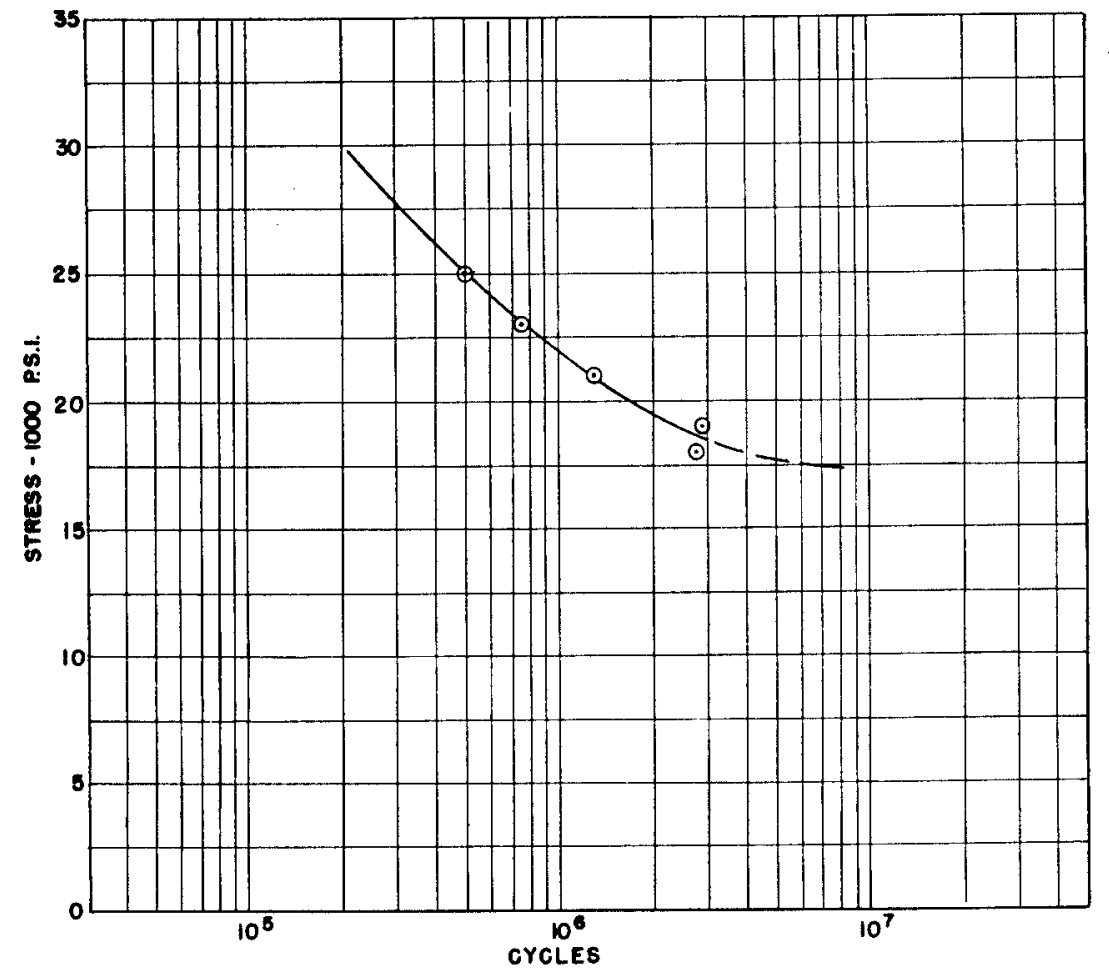

FIG. 3-ALTERNATING TORSION FATIGUE TESTS OF TITANIUM BAR (98,000 T.S) 


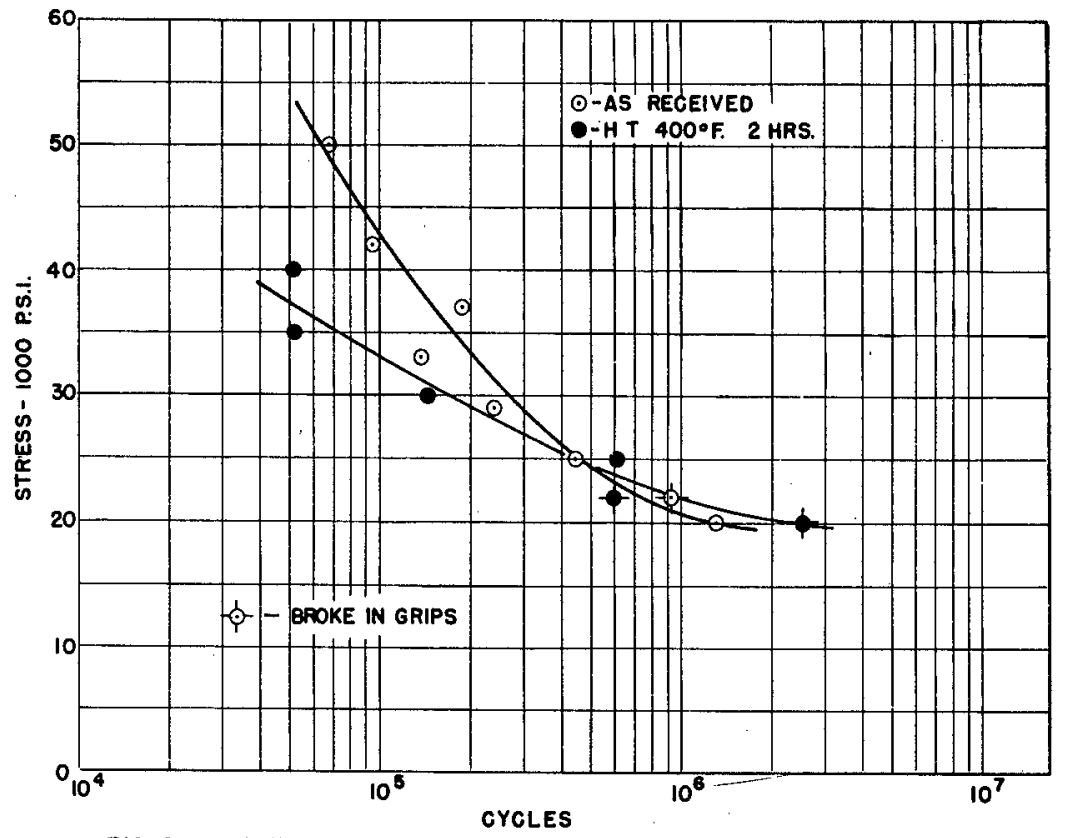

FIG. 4-FLEXURAL FATIGUE TESTS OF TITANIUM SHEET (123,000 T.S.)

\section{Corrosion Properties}

Of great importance to the Navy, for nearly any material of structural significance, is the corrosion behavior in salt water environments. A fairly elaborate array of corrosion-testing equipment has been built up through the years to subject specimens to a variety of corrosive conditions. The tests have been of outstanding assistance in screening materials for all types of service. Naturally, the best of the materials are subsequently tested under actual service or simulated service conditions.

Some corrosion work is carried out at the Station using Severn River water, an estuary water with $1 / 3$ to $1 / 6$ the salinity of sea water, depending on the seasons and the tides. The bulk of the work, however, is done at the Marine Testing Station, Kure Beach, North Carolina, where a constant source of sea water is available. The corrosion work done to date with titanium is described below.

Preliminary tests wrere made in Severn River water using sheet specimens with 9-square-inch exposed surface. The specimens were suspended in the water, which was quiescent but constantly changing, for a period of 60 days. Results were most encouraging, as follows:

\begin{tabular}{|c|c|c|c|c|}
\hline \multicolumn{5}{|c|}{60 Days Severn River water Immersion } \\
\hline \multirow{2}{*}{ Condition } & \multicolumn{3}{|c|}{ Weight Loss } & \multirow{2}{*}{ Appearance } \\
\hline & $\mathrm{gm} *$ & $\mathrm{mg} / \mathrm{in}^{2}$ & $\mathrm{mg} / \mathrm{in}^{2} /$ day & \\
\hline Complete immersion & +0.0002 & - & - & No change \\
\hline$"$ & +0.0003 & - & - & $"$ \\
\hline Partial immersion & +0.0003 & - & - & , \\
\hline ", & +0.0003 & - & - & $"$ \\
\hline
\end{tabular}

*Weight increase 
The next corrosion test, made in sea water at Kure Beach, was considerably more severe. It consisted of mounting a 4.983-inch-diameter disc on the end of a shaft and rotating the submerged disc at a speed of 1140 RPM. The test was made for 60 days in water at 26 degrees Centigrade. In a setup of this nature, the water velocity increases along the radius toward the periphery, where the maximum water velocity is nearly 25 feet per second. The titanium disc in the test lost about $0.1 \mathrm{gram}$ in weight, and in visual inspection showed no change whatever.

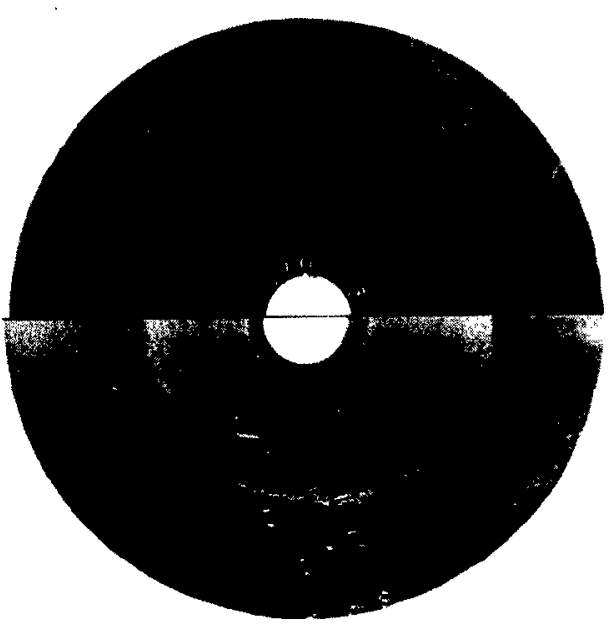

FIG. 5 - PHOTOGRAPHS (XI) OF DISGS ROTATED 60 DAYS IN SEA WATER AT I140 R.P.M. TOP: TITANIUM, BOTTOM $70 / 30 \mathrm{GU} / \mathrm{NI}$
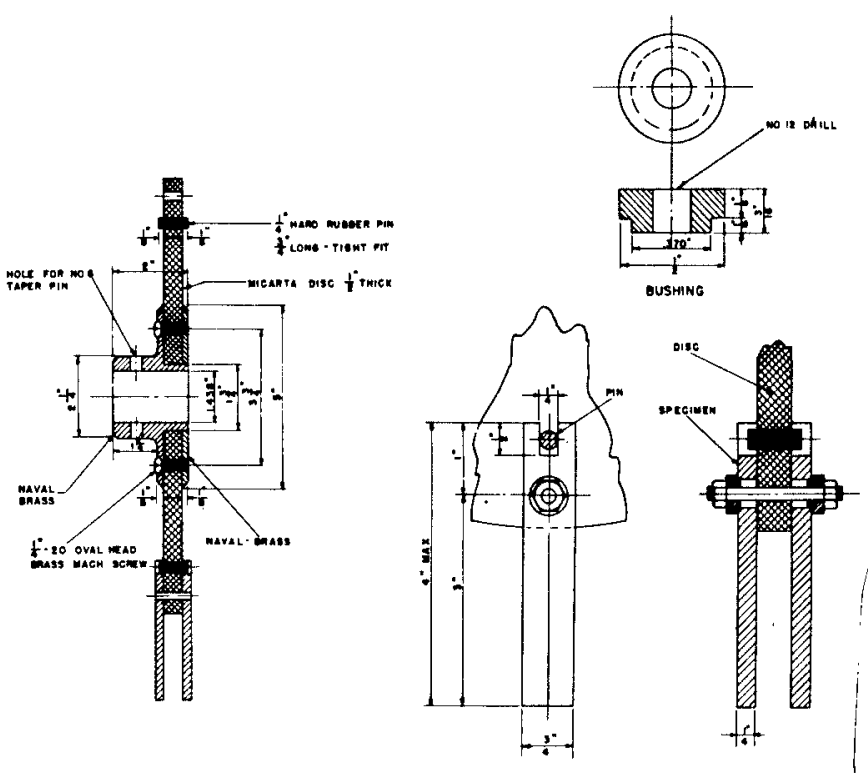

Fig 6- DETALLS OF ROTATING OASC AND TEST SPECMENS

A photograph of half the titanium disc is shown in the upper part of Figure 5. The lower section shows half of a $70 / 30 \mathrm{Cu} / \mathrm{Ni}$ (low iron content) disc run simultaneously. The copper-nickel alloy is considered one of the best commercially produced materials for resisting corrosion and erosion in salt water, and is commonly used for salt-water piping and condenser tubing. The copper-nickel disc lost 28.3 grams, and the severe eroding effect can best be observed in the areas of the stencil markings. (It should be mentioned here that copper-nickel containing a minimum of $0.5 \%$ iron behaves much better in these tests than the low-iron alloy described herein. Whereas the iron-bearing alloy is now specified for Naval use, its service life has not been completely evaluated. Even so, it does not compare as favorably in test as titanium). On the central area of the low-iron copper-nickel, which was about $2 \frac{1}{2}$ inches in diameter, the film remained intact, and corrosion amounted to little more than a lightly attacked surface which appeared frosted on cleaning. The bulk of the weight loss occurred beyond this area. The titanium did not show a similar behavior, and no visible change occurred.

A still more severe test was made in 29 degrees Centigrade sea water for a period of 60 days. The specimen and the manner of mounting on a micarta disc are detailed in Figure 6. The disc was rotated to produce a peripheral velocity of 27 feet per second. With this apparatus the specimen must cut its own path through the water, which produces turbulent action that tends to erode the piece, especially at the leading edges. Results of the tests were as follows: 
60 Days in Sea Water at $27 \mathrm{ft} . / \mathrm{sec}$.

\begin{tabular}{|c|c|c|c|c|}
\hline Test & \multicolumn{3}{|c|}{ Weight Loss } & \multirow[b]{2}{*}{ Appearance } \\
\hline & $\mathrm{gm}$ & mg./in. ${ }^{2}$ & mg./in. ${ }^{2} /$ day & \\
\hline 1 & .0009 & 0.18 & 0.003 & No change \\
\hline 2 & .0019 & 0.37 & 0.006 & ," \\
\hline
\end{tabular}

Still another test, by jet impingement, was made for 30 days in sea water at 26 degrees Centigrade. A titanium panel was placed 1/4"' ahead of a 1/8' jet opening through which water was pumped at $12 \mathrm{ft}$. $/ \mathrm{sec}$. Air at the rate of $77 \mathrm{cc} / \mathrm{min}$. was introduced into the stream. The whole jet and specimen assembly was immersed in sea water. Results of duplicate tests indicated no weight change and no evidence of pitting. In fact, it could not be determined from visual inspection which side was impinged by the jet.

One corrosion test of a practical nature was made in Severn River water to determine the resistance of the titanium bar stock to pitting attack or contact corrosion. Specimens with machined and sanded surfaces were wrapped with a strand of each of four types of packing materials, as shown in Figure 7. These wrere immersed in the river wrater for a period of 46 days. Specimens of $18-8$ and $13 \%$ chromium steel were run for comparison. The results are presented in the table below; a photograph of the specimens is shown in Figure 8.

\begin{tabular}{|l|c|c|c|}
\hline \multicolumn{1}{|c|}{ Packing Material } & $\begin{array}{c}18-8 \\
\text { Spec. 46S18 } \\
\text { Class 1 } \\
\text { Type A }\end{array}$ & $\begin{array}{c}\text { 13\% Cr } \\
\text { Spec. 46S18 } \\
\text { Class 3 } \\
\text { Type E }\end{array}$ & $\begin{array}{c}\text { Titanium } \\
\text { Sample } \\
\text { S89 }\end{array}$ \\
\hline Water Line & Pitted & No change & No change \\
\hline $\begin{array}{l}\text { Plastic mettalic, lead base } \\
\text { Symbol 1433 Spec. 33P25 }\end{array}$ & No change & No change & No change \\
\hline $\begin{array}{l}\text { Metallic flexible } \\
\text { Symbol 1430 Spec. 33P17 }\end{array}$ & No change & No change & No change \\
\hline $\begin{array}{l}\text { Asbestos, braided, plain } \\
\text { Symbol 1103, Spec. 33P26 }\end{array}$ & Pitted & $\begin{array}{l}\text { Severely } \\
\text { pitted }\end{array}$ & No change \\
\hline $\begin{array}{l}\text { Flax, braided } \\
\text { Symbol 1260, Spec. 33P1 }\end{array}$ & $\begin{array}{l}\text { Severely } \\
\text { pitted }\end{array}$ & $\begin{array}{l}\text { Very severe- } \\
\text { ly pitted }\end{array}$ & No change \\
\hline
\end{tabular}

Fouling tests, made in sea water at Wrightsville Beach, North Carolina, have demonstrated that titanium is not resistant to fouling organisms. Figure 9 is a photograph of titanium panels exposed for only five weeks. As a result, probably more care must be exercised in using titanium in place of high-copper alloys for equipment handling sea vrater. Continuous movement of the water, treatment with chemicals or possibly treatment with hot water would be necessary to prevent excessive fouling. So far, none of the panels have shown corrosion of the metal beneath the fouling organisms.

The Station has been conducting a number of corrosion tests on $1 / 8$ ' titanium sheet, produced by the Bureau of Mines and submitted by the Naval Research Laboratory. A number of the specimens were exposed to the atmosphere 40 feet and 800 feet 
from the Kure Beach shoreline. It may be of interest to note that rust quickly developed on these panels. The rust apparently resulted from iron pickup during the rolling operation; hence, care should be exercised to prevent such contamination, particularly when stainless articles are to be manufactured.

Certain special corrosion tests are being made on a number of materials, including titanium, in water and gas-wrater solutions at 500 degrees Fahrenheit. Four pressure vessels have been constructed for the purpose, one of which is equipped to rotate the specimens in the water at $27 \mathrm{ft}$./sec. Up to this writing, results are available for titanium in only one test. This was made for $19 \frac{1}{2}$ days, at $27 \mathrm{ft}$. $/ \mathrm{sec}$., in water saturated with oxygen at 500 degrees Fahrenheit and 700 psi. Weight loss data were as follows:

\begin{tabular}{|l|c|c|}
\hline \multicolumn{1}{|c|}{ Material } & $\begin{array}{c}\text { Weight change, } \\
\text { grams* }\end{array}$ & \begin{tabular}{c} 
Appearance \\
\hline Titanium \#1
\end{tabular} \\
\hline Titanium \#2 & +0.0023 & Slight discoloration \\
\hline Zirconium & +0.0005 & " \\
\hline 2S Aluminum & +0.0004 & " \\
\hline 72S Aluminum & -0.1693 & "sevely eroded \\
\hline Cast beryllium & -0.1738 & "' \\
\hline
\end{tabular}

* Sheet specimens, 1" $\mathrm{X} \frac{1}{2}$ ",

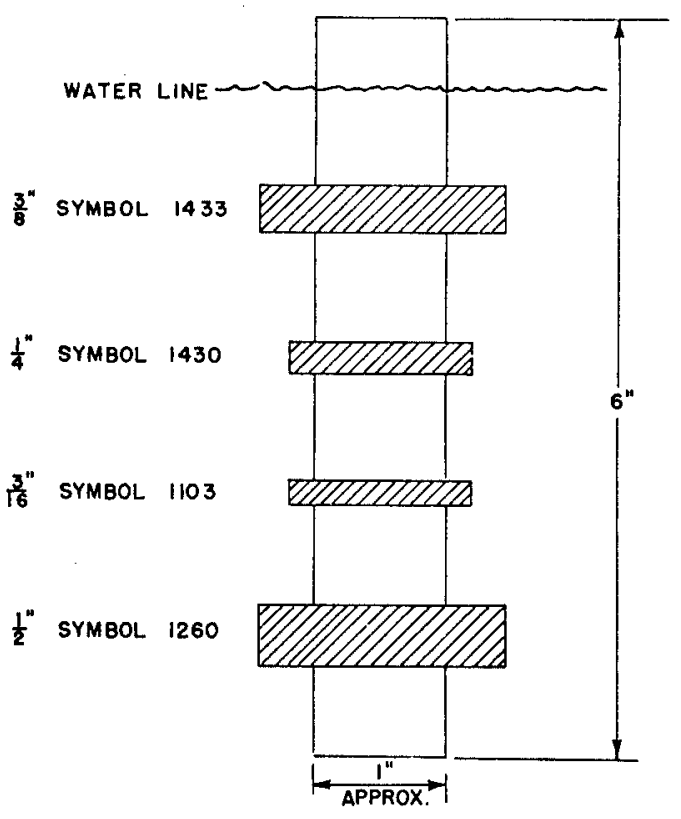

FIG. 7 SPECIMEN FOR GHECKING PITTING ATTACK UNDER PACKING

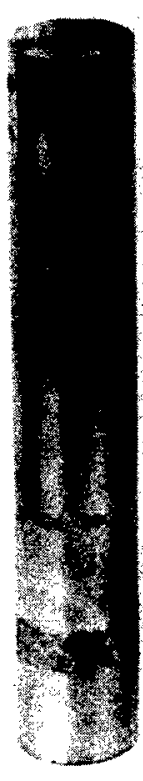

$18-8$

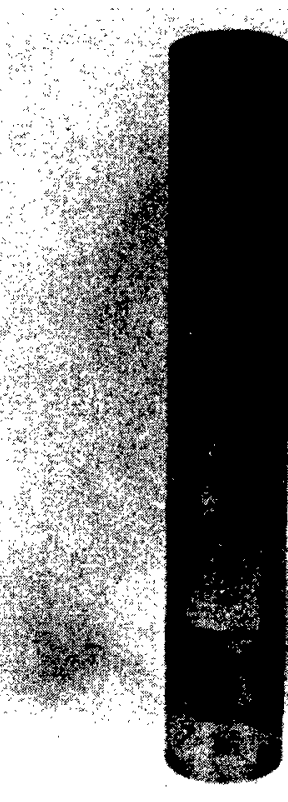

$13 \% \mathrm{Cr}$

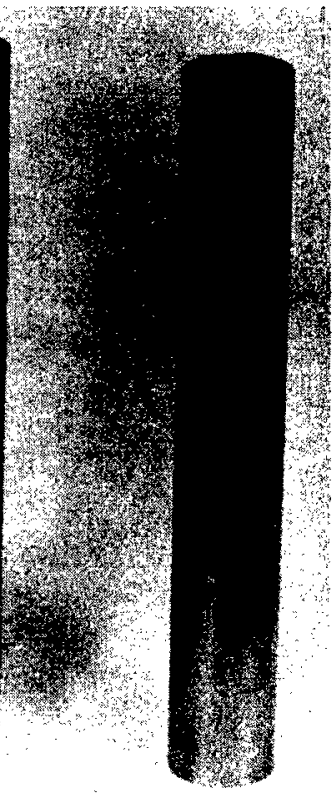

TI
FIG.8 - PHOTOGRAPH $(X \mid)$ OF BARS TESTED WITH PACKING MATERIALS FOR 46 DAYS IN SEVERN RIVER WATER 
Figure 9. Fouling specimens exposed for five weeks at Wrightsville Beach, N. C.

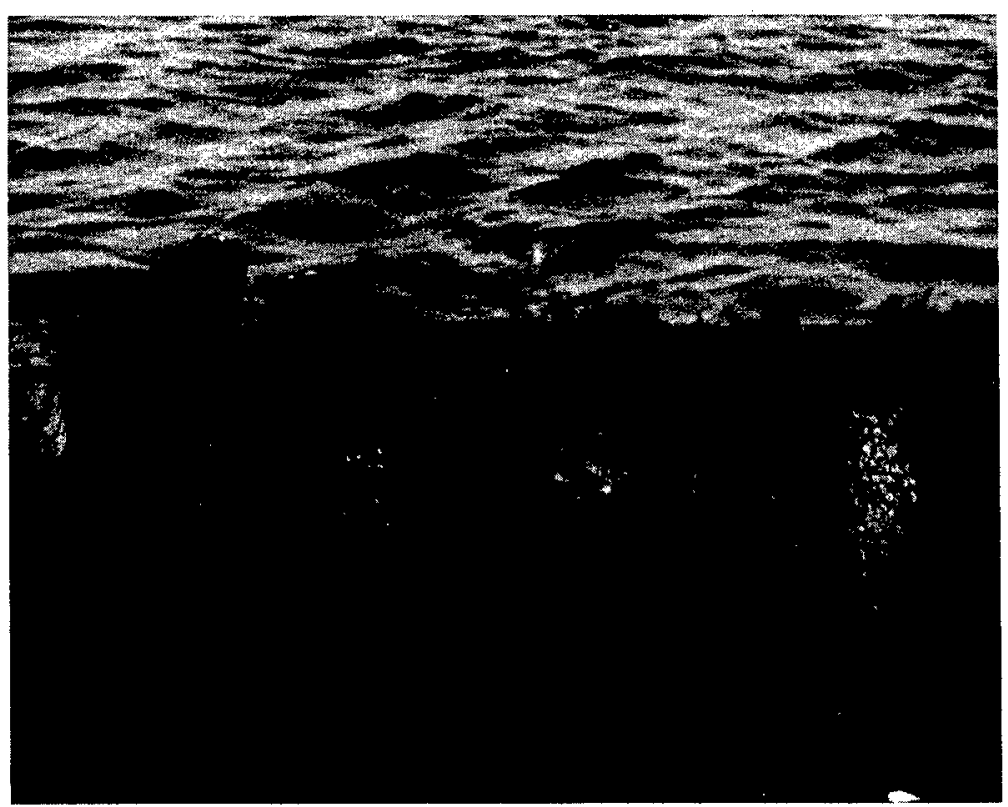

\section{Other Properties}

Thermal expansion coefficients have been determined for the titanium bar stock. Results were as follows:

$$
\begin{array}{ll}
100 \text { deg. }-500 \text { deg. F. } & 5.05 \times 10^{-6} \text { in./in./deg. F. } \\
100 \text { deg. }-900 \text { deg. F. } & 5.15 \times 10^{-6} \text { in./in./deg. F. }
\end{array}
$$

These values correspond to results of other investigators.

As a matter of interest, attempts were made to spray-metallize with titanium wire. Normal gun practices were employed. No difficulties in melting or atomizing the wire were encountered. However, as would be expected, the atomized metal was wasted by oxidation, and no suitable metallic deposit could be obtained.

No machinability tests, as such, were conducted. Shop personnel reported no particular difficulties in sawing, milling, turning, drilling, threading or polishing. The titanium was handled about like 18-8 stainless steel. 


\section{$\underline{\text { Discussion }}$}

The studies being undertaken at the Engineering Experiment Station are in a most preliminary stage. Nevertheless, sufficient information is available to begin outlining the course of things to come.

It is immediately evident from the tensile tests that cold-rolled titanium has adequate tensile properties to suit a large number of applications. On the other hand, many far cheaper materials are equally strong or stronger, and titanium offers no advantage here. Likewise, the fatigue resistance is not outstanding. Already two facts are knowm about the fatigue characteristics. First, this sample of titanium behaves more as a non-ferrous material, and the high endurance ratios associated with heat-treated steels cannot be expected. Second, it appears likely that some damaging operation can creep into the manufacture of the metal, the cause of which is yet to be determined and controlled. More fatigue work, involving notch sensitivity and corrosion fatigue, is now under way. However, as much as these things must be known, it is doubtful that any outstanding characteristic will be found which, by itself, makes titanium worth its expense.

Whereas the static and dynamic strengths of titanium are not particularly outstanding, it is of prime importance that they are satisfactory for many applications and occur simultaneously along with a few other characteristics, the combinations of which are quite unique. In competition with stainless steels, light weight can be an outstanding advantage. In competition with the light metals, corrosion resistance stands out. Against structural steels, corrosion resistance, lightness and possibly ease of surface hardening may be controlling features. Indeed, titanium appears to be most important because it possesses some of nearly everything, and all in a noncritical material.

However, it is the outstanding corrosion resistance in sea water which is most attractive from the viewpoint of the Station. The corrosion tests made so far have hardly touched the metal. In several cases very careful measurements had to be made to detect any effect whatever. No pitting occurred, and erosion was extremely slight in high-velocity water. In fact, titanium has resisted sea water in general better than any other common engineering material investigated so far.

Obviously, if further corrosion experiments bear out these happy experiences, the Navy will be eager to use titanium. If by using a light, strong, non-strategic material the Navy is able to multiply the life span of equipment now turning to rust, it is entirely possible that titanium will even compete economically with materials now produced at far less cost on a per-pound basis.

The salt water resistance offers numerous possibilities for shipboard use. Condenser tubes, operating with high water velocities, are an example. Likewise, titanium has good chance of application in light weight salt water piping systems, especially those in which turbulent conditions downstream from fittings have been causing premature erosion failure. Troubles with monel or stainless steel urinals and other plumbing fixtures, particularly through pitting, might be eliminated by the use of titanium.

The superior pitting resistance under packing materials would indicate that titanium may well serve in pump rods or rotor shafts where stainless steel leaves much to be desired. Interest is high in the application to water-lubricated bearings, and steps have been taken by the Station to determine the possibility of using titanium, hardened by oxidation, in developing high load capacity, anti-friction bearings for operation in salt water. 
Experiments are under way to determine the resistance to stack gases, with the object in mind of using titanium wire for shipboard radio aerials. The metal may even be suitable for small, high-speed propellers if the hydraulic cavitation resistance turns out as well as expected.

\section{Future Work}

Further work at the Engineering Experiment Station is now in progress or is planned for the immediate future. A brief listing of the items may be of interest to those working along similar lines.

(a) Cause of erratic fatigue behavior.

(b) Notch sensitivity in fatigue.

(c) Salt water corrosion fatigue.

(d) Sea water fouling.

(e) Sea water cavitation.

(f) Packing corrosion test of oxidized titanium.

(g) Corrosion when coupled to other metals.

(h) Impact at various temperatures.

(i) Metallographic structures.

(j) Creep at elevated temperatures.

(k) Corrosion in water and gas-water solutions at 500 degrees Fahrenheit.

(1) Load carrying capacity of rollers in salt water (for anti-friction bearings).

The results of these laboratory tests will serve as a basis for positive recommendations leading to actual service or simulated service trial applications.

\section{Abstract}

The mechanical properties have been determined on one lot of titanium bar and sheet stock produced by the Bureau of Mines. The endurance properties were similar to most non-ferrous materials in so far as the endurance ratios were concerned, although there remains a need for determining the cause of certain erratic behaviors. Among other properties investigated, the most interesting was the outstanding resistance to salt water corrosion under a variety of conditions.

The Station's viewrs are presented on the approach necessary to the successful utilization of titanium on a practical and economical basis. Whereas the laboratory tests are by no means complete, certain possible applications are suggested.

\section{DISCUSSION}

In reply to a question concerning a corresponding variation in damping capacity with variation in the endurance limit, Mr. Williams remarked that no damping tests had been conducted as yet by Naval Engineering Experimental Station because of a shortage of materials. Mr. H. C. Cross (Battelle Miemorial Institute) reported that tests of arc-melted titanium (Bureau of Mines Powder) indicate a low damping capacity in the order of 0.001 logarithmic decrement. At 1200 degrees Fahrenheit, values of 0.002 were obtained. Although the minimum damping capacity for engineer- 
ing materials is considered to be about 0.01 , many materials are in use with much lower damping capacities. It was suggested that proper design would minimize the low damping capacity of titanium as an engineering factor.

It was also reported that tests are under way with Remington titanium and results may be available in the near future. Dr. $R$. S. Dean recalled some tests which revealed a damping capacity as high as one percent. He thought that the damping capacity of titanium would be markedly affected by the method of preparation and composition (e.g. tantalum and zirconium containing small amounts of carbon have very high damping capacity). The damping capacity of a number of samples increased upon cold working, which was unusual. He believes that pure titanium has a very low damping capacity, but that large differences will be observed in various samples as a result of impurities peculiar to the method of production. He also attributed the high fatique strengths to the presence of small amounts of carbon or other similar elements.

Dr. E. A. Gee (E. I. DuPont de Nemours and Company) called attention to the fact that the variation in the reported fatigue strengths seemed to be due to the methods of production. Apparently, all melting methods yielded uniformly high results, whereas powder metallurgy methods gave uniformly low results. Nir. Williams agreed that, in general, titanium produced by melting methods had superior endurance properties. He remarked, however, that he had seen results on melted material which did not approach the 65,000 psi endurance limit. He thought that 65,000 psi endurance limit represented a surprisingly high endurance ratio, exceeding even that of steels, which have about $\frac{1}{2}$. Since titanium is a non-ferrous material, it might be expected to have the normal ratio of $1 / 3$. Fatigue tests will be conducted shortly at Naval Engineering Experimental Station on Remington titanium. Mr. J. R. Long (Bureau of Mines) attributed the low figures reported by Williams for Bureau of Mines titanium to abnormalities in the sheet. The endurance limit of this material generally runs about 35,000 psi. Mr. N. E. Promisel (Bureau of Aeronautics) remarked that in discussing damping capacity or fatigue strength, the type of material should be carefully specified to avoid confusion. Mr. Jerome Strauss (Vanadium Corporation of America) remarked that, to avoid such confusion, it would be helpful to record the true proportional limit of the material as well as the tensile strength and the hardness before and after testing. Mr. S. J. Sindeband (American Electro Metal Corporation) added that density should be added to these specifications, particularly in view of the lower fatigue properties of powder metallurgy materials, generally attributed to the presence of pores. Mr. Long replied that fatigue values obtained by the Bureau of Mines were on sheet material, rolled down from powder metallurgy ingots. The sheet had the standard density of 4.5 and was not believed to be porous. Mr. Long remarked further that he was not inclined to admit that powder metallurgy material must necessarily always be low in fatigue, ductility and strength. 


\title{
SOME PRELIMINARY DATA ON ALLOYS OF TITANIUM
}

\author{
By E. I. Larsen, E. F. Swazy, L. S. Busch and R. H. Freyer
}

P. R. Mallory and Co., Inc.

\section{Introduction}

This paper is a resume of developmental work carried out in the Metallurgical Research Department of P. R. Mallory and Company, Inc. under Contract No. NOa (s) 8698 granted by the Bureau of Aeronautics of the Navy Department. The purpose of this contract was to investigate titanium and titanium-rich alloys and determine whether such alloys exhibited physical and mechanical properties superior to known metals and alloys. The project has been entirely exploratory in nature and, in general, has been confined to alloys containing more than $90 \%$ titanium.

The results reported herein are preliminary in nature and constitute physical and mechanical property data of alloys in the hot rolled, cold rolled and annealed conditions. Observations were made on the resistance to oxidation, formation of low melting point alloys or phases, ease with which the alloys could be hot and cold worked, and other metallurgical phenomena, but little qualitative data have been obtained on these factors as yet.

Because of the great affinity of titanium for oxygen, hydrogen, nitrogen and carbon, it was decided to fabricate all alloys in vacuum. Preliminary results of vacuum melting in a graphite crucible indicated a variable carbon "pick-up" ranging from about $.5 \%$ to $1.5 \%$ which was further complicated by segregation of the alloying additives. In order to eliminate these variables, it was decided to fabricate all alloys (with one or two exceptions) by powder metallurgy methods.

To date, binary alloys of titanium and hydrogen, beryllium, boron, aluminum, indium, carbon, silicon, zirconium, vanadium, chromium, tungsten, molybdenum, manganese, iron, cobalt and nickel have been investigated. Spot checks have been made on three ternary alloys consisting of titanium-manganese-aluminum, titanium-manganesesilicon, and titanium-aluminum-chromium.

\section{Materials}

The titanium powder used in all alloys was supplied by the Bureau of Mines from one master lot. This lot of powder had the following physical and chemical properties.

A. Mesh

$\begin{array}{cc}\text { Weight \% } & \text { Through } \\ 8.0 & 200 \\ 20.0 & 100 \\ 41.6 & 60 \\ 99.9 & 30\end{array}$


B. Chemical Composition

\begin{tabular}{lc}
\multicolumn{1}{c}{ Element } & \% By Weight \\
Magnesium & 0.27 \\
Iron & 0.05 \\
Aluminum & 0.01 \\
Silicon & 0.02 \\
Copper & None \\
Manganese & None \\
Chlorine (as chloride) & 0.23 \\
* Hydrogen & $0.0948-0.1110$ \\
* Nitrogen & $0.024-0.035$ \\
* Oxygen & $0.058-0.072$
\end{tabular}

* Analyzed by Mr. Peifer of the Carnegie Institute of Technology.

cially.

All of the alloying elements were of the highest purity obtainable commer-

\section{Preparation of Alloys}

The following program for the fabrication of test specimens was established after various sintering temperatures and periods had been tried on compacts pressed at pressures ranging from 10 to 50 tons per square inch.

Accurately weighed amounts of powders to be alloyed were ballmilled to obtain intimate and uniform mixing of the powders. The blended powder mixtures were then pressed in hardened steel dies at a pressure of 30 tons per square inch. The resulting compacts, which were in the form of small flat bars, semi-rounds or buttons, were sintered for one hour at 1200 degrees Centigrade in a vacuum of less than one micron. Heating from room temperature to 1200 degrees Centigrade was accomplished in two hours and was more or less uniform at the rate of 10 degrees per minute. After the sintering period of one hour, cooling required approximately two hours to reach room temperature.

Sintered specimens were worked in one or two ways. They were cold rolled with intermittent anneals in vacuum or encased in a steel sheath and hot rolled at 800 degrees Centigrade. Certain specimens received both hot and cold working.

In general, the aim was to investigate titanium alloys containing from $1 \%$ to $40 \%$ of a second metal but these limits were ignored in a few instances. Usually the maximum of additive metal was governed by the appearance of low melting point phases, failure of the sample to sinter properly or the formation of a brittle, unworkable alloy.

The alloys will be discussed in the order in which the element used to make the alloys appears in the Periodic Table.

\section{Hydrogen-Titanium}

At temperatures above 500 degrees Centigrade, hydrogen combines directly with titanium to form the hard and brittle hydride. Some experimental sintering of titanium specimens was performed in an atmosphere of hydrogen at a dewpoint of -80 degrees Centigrade. This proved unsatisfactory due to the hydride formation, 
since quenching in various media from the sintering temperature did not prevent the formation of the brittle hydride. However, if specimens sintered in oxygen-free hydrogen are allowed to cool in a vacuum from 1000 degrees Centigrade, ductile mater ial can be produced. All subsequent sintering was performed in vacuo.

\section{Beryllium-Titanium}

Titanium alloys containing $.5 \%$ to $10 \%$ beryllium were investigated. Those containing more than one percent beryllium showed localized melting. An alloy containing three percent beryllium melted at 975 degrees Centigrade and the $10 \%$ beryllium melted at 950 degrees Centigrade.

It was necessary to use -150 mesh beryllium powder and mix it intimately with titanium to prevent segregation and localized melting during sintering. Sintering at 1200 degrees Centigrade wras satisfactory for the $.5 \%$ alloy but higher beryllium contents required lower sintering temperatures and longer time; e.g., a two percent alloy was sintered at 1000 degrees Centigrade for three hours. Normal shrinkage was obtained on properly sintered specimens. Tables 1 and 2 show that chemical analyses indicate very little loss of beryllium during sintering.

Photomicrographs 1,2 and 3 show a $1.07 \%$ beryllium alloy as hot rolled, as water quenched from 1000 degrees Centigrade and as slowly cooled from 1000 degrees Centigrade to 400 degrees Centigrade, respectively. The hot-rolled specimen shows elongated grains in the direction of rolling as did all of the rolled alloys. The quenched specimen completely recrystallized and the cross-hatched lines probably indicate a second phase. Samples slow-cooled from the same temperature showed the presence of a second phase which completely obscured the recrystallized structure.

Table 1 shows the physical properties of cold-rolled $0.5 \%$ and $1.0 \%$ beryllium alloys. In general, the alloys as cold-rolled $70 \%$ to $90 \%$ reduction show tensile strengths higher than that of pure titanium. The highest value recorded was 142,300 psi. It is notewrorthy that sintered alloys up to one percent beryllium may be readily cold rolled. Reductions as great as $50 \%$ may be made before annealing is necessary. The beryllium alloys show a definite drop in hardness when annealed either in vacuum or in air. This is not true of titanium. The tensile strength, elongation and electrical resistivity of the annealed alloys are approximately the same as those of pure annealed titanium.

A hot rolled alloy, containing $1.07 \%$ beryllium after quenching in water from 1000 degr ees Centigrade, had a tensile strength of 151,000 psi with $3 \%$ elongation as shown in Table 2. The resistivity also increased. This indicates that the alloy can be heat-treated to produce high hardness and tensile strength while retaining some elongation.

\section{Boron-Titanium}

Boron in amounts of $0.1 \%, 0.5 \%$ and $5 \%$ was added to titanium, and bars pressed from the powder mixes were satisfactorily sintered at 1200 degrees Centigrade. A spectrographic analysis of the boron powder used indicated about $94 \%$ boron with about $4 \%$ magnesium as the primary impurity.

The sintered bars of $0.1 \%$ and $0.5 \%$ boron were cold rolled to reductions in thickness as much as $45 \%$ before vacuum annealing and, after vacuum annealing, were cold rolled an additional $49 \%$ to $58 \%$. The $5 \%$ boron-titanium sintered bars could not be cold rolled to any appreciable reduction in thickness, since serious cracking resulted. 
As shown in Table 3, the cold-rolled $0.1 \%$ and $0.5 \%$ bor on alloys of titanium had tensile strengths of 130,000 psi and 139,000 psi with $3 \%$ elongation in two inches. Hardness values ranged from 59 Rockwell $A$ to 66 Rockwell A. Vacuum annealing softened the cold-rolled specimens from three to six points Rockwell A (six to 12 points Rockwell C) and lowered the tensile strengths to 99,700 psi and 114,400 psi with $9.4 \%$ and $6.5 \%$ elongation in two inches.

The electrical resistance values, both as cold-rolled and vacuum-annealed, were on the order of $58 \times 10^{-6} \mathrm{ohms}-\mathrm{cm}$. and are the lowest of any values obtained on titanium alone or any of the various alloys of titanium. This value $\left(58 \times 10^{-6} \mathrm{ohms}\right.$ - $\mathrm{cm}$.) compares favorably with the value $56 \times 10^{-6} \mathrm{ohms}-\mathrm{cm}$. for a very pure grade of metallic titanium reported by Dean, Long, Wartman and Anderson in their paper ."Preparation and Properties of Ductile Titanium," February, 1946.

\section{Aluminum-Titanium}

Titanium alloys containing $1.0 \%$ to $10 \%$ aluminum were investigated. The $10 \%$ aluminum alloy was found to contain a considerable amount of a second phase high in aluminum and the aluminum contents were, therefore, held at $1.0 \%$ and $3 \%$. Both of these alloys responded normally to sintering at 1200 degrees Centigrade and were readily hot-rolled at 800 degrees Centigrade to reductions in area of $77 \%$. The chemical analyses given in Tables 4 and 5 show $.33 \%$ and $2.64 \%$ aluminum indicating some loss of aluminum during sintering.

Photomicrographs 4, 5, 6 and 7 show the hot-rolled $2.64 \%$ alloy as vacuumannealed one hour at 1000 degrees Centigrade, heated one hour in air at 850 degrees Centigrade and slowly cooled. to 400 degrees Centigrade, heated one hour in air at 800 degrees Centigrade and after heating 16 hours in air at 900 degrees Centigrade, respectively. The vacuum-annealed specimen shows a typical acicular, Widmanstatten structure. The remaining photomicrographs show polygonal grains, a singlephase structure indicating complete diffusion of aluminum. It will be noted that the specimen heated in air 16 hours at 800 degrees Centigrade shows little or no oxide penetration while the specimen heated at 900 degrees Centigrade for 16 hours shows dark areas betwreen boundaries, probably oxides of titanium and aluminum.

Table 4 shows the physical properties of the hot-rolled $.33 \%$ and $2.64 \%$ aluminum alloys. After annealing, little change in hardness occurred but changes occurred in the tensile strength and elongation. For example, the .33\% aluminum alloy as hot-rolled had a tensile strength of $106,500 \mathrm{psi}$ and an elongation of $6.25 \%$ which, after annealing, became 91,400 psi and $12.5 \%$ respectively. As expected, the $2.64 \%$ aluminum alloy shoured smaller changes, namely from a tensile strength of 118,000 psi to 109,000 psi and an elongation of $6.25 \%$ to $7.8 \%$ aluminum increased the electrical resistivity indicating solid solution of aluminum in titanium.

The cold working characteristics of the aluminum alloys are good as indicated in Table 5 . Reductions in area of $65 \%$ by swaging increased the tensile strength of the $.33 \%$ aluminum alloy to $159,000 \mathrm{psi}$ and that of the $2.64 \%$ alloy to $155,000 \mathrm{psi}$. The elongation was reduced to $3 \%$ and the hardness remained unchanged.

The most noteworthy features of the aluminum-titanium alloys are their ability to hot and cold work and their greatly increased resistance to oxidation over that of pure titanium. 
Indium-Titanium

All indium-titanium alloys were prepared by mixing a -100 mesh powder with the titanium powder supplied by the Bureau of Mines. If the powders used were coarser than this, segregation occurred. Alloys containing up to $5 \%$ indium were prepared.

Indium metal melts at 155 degrees Centigrade but boils at 1450 degrees Centigrade. About two-thirds of the indium added was volatilized during sintering so that the $3 \%$ indium alloy actually contained $.98 \%$ indium by analysis.

Microstructures of the indium alloys indicated that they were essentially the same as the aluminum alloys, being single phase regardless of their heat treatment.

Table 6 shows the properties of an alloy containing $.98 \%$ indium by analysis. This alloy could be readily cold and hot worked. The properties are very similar to those of pure titanium and the aluminum alloys.

\section{Carbon-Titanium}

Carbon wras not added to any of the sintered alloys. The alloys made were the result of melting titanium in a graphite or carbon crucible. Such ingots contained $.5 \%$ to $1.5 \%$ carbon. An ingot which contained $1.28 \%$ carbon was hot rolled $77 \%$ and, after annealing, was cold swaged an additional $19 \%$ before serious cracking occurred.

Photomicrographs indicated that the carbon occurred as massive carbides in the melted ingot. Subsequent working breaks up these massive carbide lakes into small inclusions. It is possible that the ductility of the alloy depends upon how well these lakes are broken up during wrorking.

Table 7 shows the physical properties of carbon-titanium alloys containing $1.18 \%$ and $1.28 \%$ carbon. The properties are not greatly different from pure titanium. The hot-swaged alloy has $19 \%$ elongation as annealed 30 minutes at 700 degrees Centigrade in air but could not be further reduced by cold swaging. The value for electrical resistivity is identical to that for pure titanium, varying from 61 to 66 microhm $-\mathrm{cm}$.

\section{Silicon-Titanium}

Silicon in the amounts of $3 \%$ and $10 \%$ with titanium depresses the melting point of titanium. The $3 \%$ and $10 \%$ silicon-titanium compositions melted during vacuum sintering at 1225 degrees Centigrade and 1100 degrees Centigrade, respectively. The $3 \%$ silicon-titanium composition was satisfactorily (no melting occurred) sintered at 1200 degrees Centigrade.

Since the $3 \%$ and $10 \%$ silicon-titanium compositions melted during sintering, compositions of $0.5 \%$ and $1 \%$ silicon, balance titanium, were prepared and pressed into bars. The bars of $0.5 \%$ and $1.0 \%$ silicon-titanium were satisfactorily sintered at 1200 degrees Centigrade and cold rolled to total reductions in thickness of around $80 \%$.

It was found that as the amount of silicon in titanium was increased, the alloys became less amenable to cold rolling. The $1 \%$ silicon-titanium alloy was cold rolled to a total reduction in thickness of $79.7 \%$ by alternate reductions in thickness of $26 \%$ and $34 \%$ and vacuum annealing for one hour at 1000 degrees Centigrade without appreciable cracking, until the final reduction $(38 \%)$. The $0.5 \%$ silicon-titanium alloy wras readily cold rolled to reductions in thickness of $55 \%$, both as sintered and as vacuum annealed, writhout cracking appreciably.

833626 o $-49-8=-109-$ 
Table 8 shows the physical properties of the $0.5 \%$ and $1.0 \%$ cold rolled silicon alloys are quite good. The tensile strengths were 126,000 psi for the $0.5 \%$ alloy and $160,800 \mathrm{psi}$ for the $1.0 \%$ alloy with $1.5 \%$ elongation in two inches. Vacuum annealing lowered the tensile strengths of both alloys to around $115,000 \mathrm{psi}$. The electrical resistivity values were increased over that of titanium alone. Values of $74 \times 10^{-6}$ and $102 \times 10^{-6} \mathrm{ohms}-\mathrm{cm}$. for the $0.5 \%$ and $1.0 \%$ silicon alloys were observed.

\section{Zirconium-Titanium}

Zirconium-titanium alloys with compositions of $10 \%, 20 \%, 30 \%$ and $40 \%$ zirconium, balance titanium, were vacuum-sintered one hour at 1200 degrees Centigrade and hot-rolled at 800 degrees Centigrade in steel tubes to $77 \%$ reductions in area. All alloy compositions sintered satisfactorily and underwent normal shrinkage. In some instances, small craters formed on the surfaces of the specimens when comparatively large pieces of sponge zirconium were used.

The microstructures of the hot-rolled alloys show a two-phase banded structure indicating undiffused zirconium.

Physical data determined on the hot-rolled alloys indicate an increase in hardness and resistivity and a decrease in tensile strength and ductility with increasing zirconium content.

Zirconium appears to be soluble in titanium in proportions up to at least $40 \%$, and the resistivity values indicate solid solubility throughout the range studied.

\section{Nitrogen-Titanium}

No attempt was made specifically to form the nitride.

Nitrogen combines with titanium to form a hard and brittle nitride, but apparently the nitride will not readily form if there is any free oxygen present in the atmosphere.

\section{Vanadium-Titanium}

A $95 \%$ grade of lump vanadium was crushed in a hardened steel mortar to about 30 mesh, mixed with titanium in amounts of $0.5 \%, 5 \%$ and $15 \%$, pressed into bars and vacuum-sintered for one hour at 1200 degrees Centigrade. No depression in melting point was observed.

The $15 \%$ vanadium-titanium sintered bar could not be cold-rolled to any appreciable reduction in thickness, since considerable surface cracking resulted. The $0.5 \%$ and $5 \%$ vanadium alloys, however, were readily cold-rolled to reductions in thickness varying from $25 \%$ to $58 \%$ without serious edge cracking. As the amount of vanadium increased, the alloys became more difficult to cold roll satisfactorily.

The $0.5 \%$ and $5 \%$ vanadium alloys of titanium had no distinctive physical properties. The 5\% alloy showed a tensile strength of 153,000 psi as cold-worked, but substantially no elongation. of titanium.

Table 10 contains some data on the cold-rolled $0.5 \%$ and $5 \%$ vanadium alloys

\section{Oxygen-Titanium}

Oxygen combines with titanium at comparatively low temperatures to form oxide films which destroy the ductility if the penetration is great enough. The oxide 
is not adherent and usually spalls off readily from large, fully dense specimens.

The titanium powder, as received from the U.S. Bureau of Mines, contained between $0.058 \%$ and $0.072 \%$ oxygen. A series of oxygen analyses made on the powder, sintered and hot-rolled specimens and hot-rolled specimens heated in air at $850 \mathrm{de}-$ grees Centigrade indicated that the powder contained far more oxygen than the specimens made from it. The prepared specimens contained oxygen in amounts varying from $0.0007 \%$ to $0.0079 \%$.

\section{Chromium-Titanium}

A bar with the composition of $10 \%$ chromium, balance titanium, was unsatisfactorily vacuum-sintered at 1200 degrees Centigrade due to melting. A bar was satisfactorily sintered at 1125 degrees Centigrade and shrank $3 \%$ in thickness.

The sintered bar was cold-rolled to a $26 \%$ reduction in thickness and vacuumannealed one hour at 1000 degrees Centigrade. Annealing did not soften the bar, and it could be further reduced in thickness only $9 \%$ : The hardness was 62.5 Rockwell A (24 Rockwell C) and the resistivity was 93 microhms - $\mathrm{cm}$.

Ten percent chromium in titanium depresses the melting point to $1200 \mathrm{de}-$ grees Centigrade.

Chromium increases the electrical resistance of titanium, and there is probably some solid solubility of chromium in titanium as indicated by the increase in electrical resistance.

\section{Molybdenum-Titanium}

Molybdenum-titanium alloys with compositions of $10 \%, 20 \%, 30 \%$ and $40 \%$ molybdenum, balance titanium, were investigated. The $10 \%$ and $20 \%$ alloys were satisfactorily vacuum-sintered one hour at 1200 degrees Centigrade with shrinkage vary-
ing from $2 \%$ to $4 \%$. The $30 \%$ and $40 \%$ alloys could not be satisfactorily sintered, due to expansion, bending and cracking.

A specimen with the composition of $10 \%$ molybdenum, balance titanium, was cold-rolled to a total reduction in thickness of $68 \%$. Rods of $10 \%$ and $20 \%$ molybdenum-titanium were hot-rolled at 800 degrees Centigrade to $77 \%$ reductions in area for determination of physical data.

The cold-rolled $10 \%$ alloy, which analyzed $5.10 \%$ molybdenum, had a tensile strength of 157,500 psi as cold-rolled and 140,000 psi as vacuum-annealed. There was no elongation in either condition. The hot-rolled $10.21 \%$ and $12.52 \%$ molybdenumtitanium alloys had no distinctive physical properties except electrical resistances, which were high, and did not respond to various heat treatments at 850 degrees Centigrade and 1000 degrees Centigrade. The resistivity measurements are consistent with a complete solid solubility of titanium and molybdenum showing a maximum resistance at about $20 \%$ molybdenum.

\section{Tungsten-Titanium}

A bar of the composition $10 \%$ tungsten, balance titanium, was satisfactorily vacuum-sintered one hour at 1200 degrees Centigrade. The bar shrank $8 \%$. The sintered bar was cold-rolled to a $21 \%$ reduction in thickness and vacuum-annealed one hour at 1000 degrees Centigrade. Annealing lowered the hardness from 67 Rockwell A (33 Rockwell C) to 62.5 Rockwell A (24 Rockwell C). The annealed bar was further cold-rolled to a $10 \%$ reduction in thickness and the resistivity was determined as 87 microhm-cm. 
Small amounts of tungsten increased the electrical resistance of titanium and did not adversely affect the cold-rolling characteristics.

\section{Manganese-Titanium}

Alloys of titanium with $.25 \%$ to $14.88 \%$ manganese were successfully sintered and worked. Alloys containing up to $40 \%$ manganese were prepared but could not be successfully sintered, due to expansion and warpage. As much as $50 \%$ loss of manganese occurred during sintering. This element has a very high vapor pressure and apparently volatilizes in a vacuum below its melting point. An alloy with an intended composition of $10 \%$ manganese and $90 \%$ titanium analyzed only $.26 \%$ manganese melting in a graphite crucible.

The powders used for making the pressed bars segregated badly during mixing and this segregation was very noticeable in microstructures of some hot-rolled specimens. Wet mixing improved this condition but did not entirely eliminate it.

The best powders available for mixing contained as much as $1 \%$ oxygen. However, oxygen analyses of alloys made from such powders showed less oxygen than was present in the titanium powder used to make them, indicating possible combination with hydrogen or magnesium and removal during sintering in vacuum.

Microstructures of sintered and worked alloys indicated a decided difference, due to thermal history. The properties of the first hot-rolled samples were not consistent. Both cooling rate during hot rolling and after annealing and segregation of alloying constituent affected the properties.

Photomicrographs 8, 9, 10, and 11 show the effects of quenching from 850 degrees Centigrade, slow cooling from 850 degrees Centigrade, quenching from 1000 degrees Centigrade and slow cooling from 1000 degrees Centigrade on an alloy containing 5.65\% manganese. Quenched alloys were essentially single-phase and recrystallized as shown in photomicrographs 8 and 10. The small dots and obscured structure are also present in pure titanium, polished and etched in the same manner. The slowly cooled alloys show a second phase. The alloy slow-cooled from 1000 degrees Centigrade shows an almost completely obscured recrystallized grain size. Slowcooled pure titanium would show an equiaxed single-phase structure.

These indications of change due to thermal history are confirmed by the changes in physical properties. These changes are dependent upon manganese content also. An alloy containing $4.3 \%$ manganese had a tensile strength of 138,000 psi, while an alloy of $7.22 \%$ manganese had a tensile strength of 164,500 psi, both as hot-rolled. Quenched alloys usually were harder than the same alloys as slow-cooled, but the difference was not always consistent, particularly in alloys containing more than $6 \%$ manganese. The properties of the alloys as hot-rolled and fast-cooled are most readily compared and are given in Table 12 for several compositions. Electrical resistivity can be controlled over a range of 80 to $120 \mathrm{microhm}-\mathrm{cm}$. by controlling manganese content and heat treatment.

\section{$\underline{\text { Iron-Titanium }}$}

A bar with a composition of $10 \%$ iron, balance titanium was sintered in vacuo one hour at 1200 degrees Centigrade and underwent normal shrinkage. 'The sintered bar was cold-rolled to a $14.5 \%$ reduction in thickness and vacuum-annealed one hour at 1000 degrees Centigrade. The annealed bar could be further cold-rolled to only a $5 \%$ reduction in thickness. Iron in amounts of approximately $10 \%$ does not improve the cold-working characteristics of titanium. 
An X-ray diffraction analysis of the sintered bar indicated that the iron alloyed with the titanium.

\section{Cobalt-Titanium}

An alloy with the composition of $10 \%$ cobalt, balance titanium, was investigated. Attempts to vacuum sinter this alloy at 1200 degrees Centigrade were unsatisfactory, due to melting. Sintering at 1125 degrees Centigrade was unsatisfactory, due to the formation of blisters on the specimens. Sintering at 1050 degrees Centigrade produced a satisfactory specimen which shrank approximately $3 \%$.

The sintered bar was cold-rolled to a $15 \%$ reduction in thickness and vacuum-annealed one hour at 1000 degrees Centigrade. The annealed bar could not be further cold-rolled more than $1 \%$, due to surface cracking.

Approximately $10 \%$ cobalt depresses the melting point of such alloys to 1200 degrees Centigrade. Cobalt does not improve the cold-working characteristics of titanium.

\section{Nickel-Titanium}

A bar with a composition of $10 \%$ nickel, balance titanium, was vacuum-sintered one hour at 1200 degrees Centigrade, and it shrank approximately $2 \%$ in thickness.

The sintered bar could not be cold-rolled to more than a $6 \%$ reduction in thickness.

An X-ray diffraction analysis of the sintered specimen indicated that the nickel alloyed with the titanium.

Nickel adversely affects the cold-working characteristics of titanium.

PHYSIOAI PROPERTIBS BERYLLIOM-TITMAYIOM AIIOYS

INTENDH COMPOSITION $0.5 \% \mathrm{BE}-99.5 \% \mathrm{mI}$

$$
\text { COLD ROLLID }
$$

\begin{tabular}{|c|c|c|c|c|c|c|c|c|c|}
\hline \multirow{3}{*}{$\begin{array}{c}\text { PIRR CBNT } \\
\text { WORKED } \\
90\end{array}$} & \multicolumn{4}{|c|}{ EOCKTHEL HARDNTSS } & \multicolumn{2}{|c|}{$\begin{array}{l}\text { ULTIMATE TENSILT } \\
\text { STRENGMA - P.S.I. }\end{array}$} & \multicolumn{2}{|c|}{ HLONGATION } & \multirow{2}{*}{ 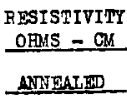 } \\
\hline & \multicolumn{2}{|c|}{ FORIID } & \multicolumn{2}{|c|}{$\triangle N N$ NAC TD } & MORKED & AUNEALERD & FORK ED & ANNEALED & \\
\hline & 664 & 310 & $56 A$ & - & 142,300 & 86,000 & $2.48 \ln 2^{11}$ & $6.25 \%$ in $2^{11}$ & $67 \times 10^{-6}$ \\
\hline 73 & $67 \AA$ & 330 & 61.54 & 220 & 141,000 & 100,000 & $3 \%$ in 11 & 9.58 in 2"1 & $65 \times 10^{-6}$ \\
\hline & & & \multicolumn{3}{|c|}{$\begin{array}{c}\text { INTHADED COMPOSITION } \\
14 \mathrm{BI}-99 \% \mathrm{TI}\end{array}$} & \multicolumn{3}{|c|}{$\begin{array}{l}\text { COSPOSITI ON BY ANALTSIS } \\
0.37 \% \text { BE - BAIANCE TI }\end{array}$} & \\
\hline & & & \multicolumn{6}{|c|}{ COLD ROLLTD } & \\
\hline 70 & $64 A$ & 270 & $59 \mathrm{~A}$ & $\rightarrow$ & 115,000 & 93.000 & $3.2 \%$ in $1^{11}$ & $25 \%$ in 14 & - \\
\hline 71 & $66 A$ & $31 \mathrm{C}$ & 614 & 210 & 124.700 & 86,000 & $3 \%$ in 1" & $12.5 \%$ tn 11 & $66 \times 10^{-5}$ \\
\hline
\end{tabular}


Table 2

PHYSICAL, PROPERTIES

BERYLLIUM-TITANIUM ALLOYS

INTENDED COMPOSITION
$0.5 \% \mathrm{BE}-99.5 \% \mathrm{TI}$

HOT ROLLED

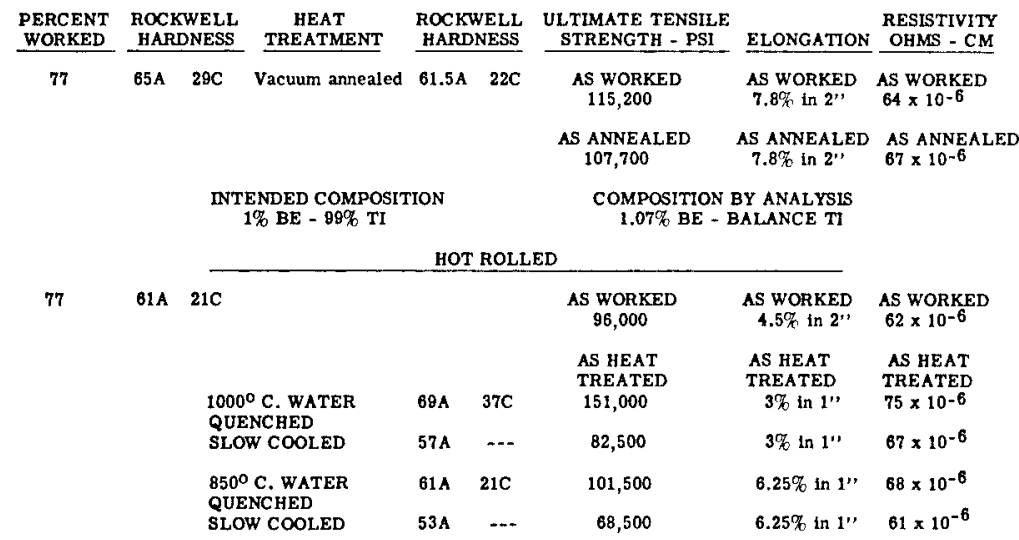

Composition: $1.07 \%$ Beryllium - Balance Titanium

Hot-Rolled at $800^{\circ} \mathrm{C}$. to a $77 \%$ Reduction in Area

Fig. 1

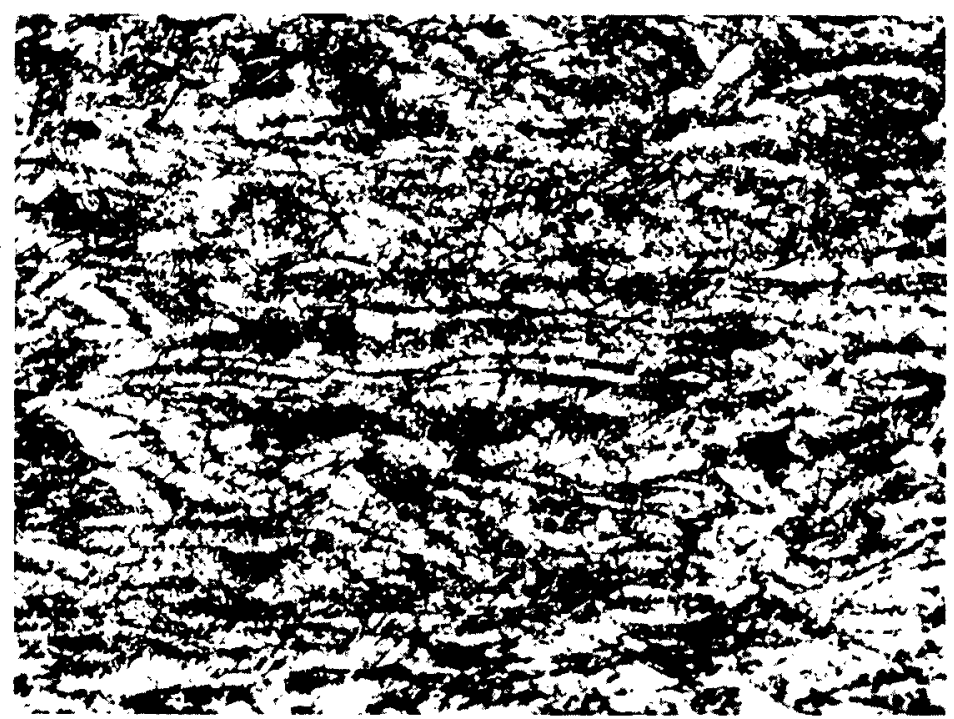

Longitudinal View

Magnification $200 \mathrm{X}$

Hot-Rolled Structure. Direction of Rolling Indicated. 
Table 3

PHYSICAL PROPERTIES OF TWO BORON-TITANIUM ALLOYS

\begin{tabular}{|c|c|c|c|c|c|c|c|}
\hline \multirow[b]{2}{*}{$\begin{array}{l}\text { PERCENT } \\
\text { WORKED } \\
\end{array}$} & & & \multicolumn{2}{|c|}{$\begin{array}{c}\text { INTENDED COMPOSITION } \\
0.1 \% \mathrm{~B}-99.9 \% \mathrm{TI} \\
\end{array}$} & \multirow{2}{*}{\multicolumn{2}{|c|}{$\begin{array}{l}\text { ELONGATION } \\
\% \text { in } 2^{\prime \prime} \\
\end{array}$}} & \multirow[b]{2}{*}{$\begin{array}{c}\text { AVERAGE } \\
\text { RESISTIVITY } \\
\text { OHMS - CM } \\
\end{array}$} \\
\hline & \multicolumn{2}{|c|}{ ROCKWELL HARDNESS } & \multicolumn{2}{|c|}{$\begin{array}{l}\text { ULTIMATE TENSILE } \\
\text { STRENGTH - P.S.I. } \\
\end{array}$} & & & \\
\hline & Cold Worked & Annealed & Cold Worked & Annealed & \multirow{2}{*}{$\frac{\text { Cold Worked }}{3}$} & \multirow{2}{*}{$\frac{\text { Annealed }}{9.4}$} & \multirow[b]{2}{*}{$58 \times 10^{-6}$} \\
\hline 76.5 & $66 \mathrm{~A}$ & $60 \mathrm{~A} \quad 19 \mathrm{C}$ & 130,000 & 99,700 & & & \\
\hline & & - & \multicolumn{2}{|c|}{$\begin{array}{c}\text { INTENDED COMPOSITION } \\
0.5 \% \mathrm{~B}-99.5 \% \mathrm{TI}\end{array}$} & & & \\
\hline 72 & $67 \mathrm{~A} \quad 33 \mathrm{C}$ & $63 \mathrm{~A} \quad 25 \mathrm{C}$ & 139,000 & 114,400 & 3 & 6.5 & $58 \times 10^{-6}$ \\
\hline
\end{tabular}

Composition: $1.07 \%$ Beryllium - Balance Titanium

1 Hour at $1000^{\circ} \mathrm{C}$. in Air, and Water-Quenched

Fig. 2

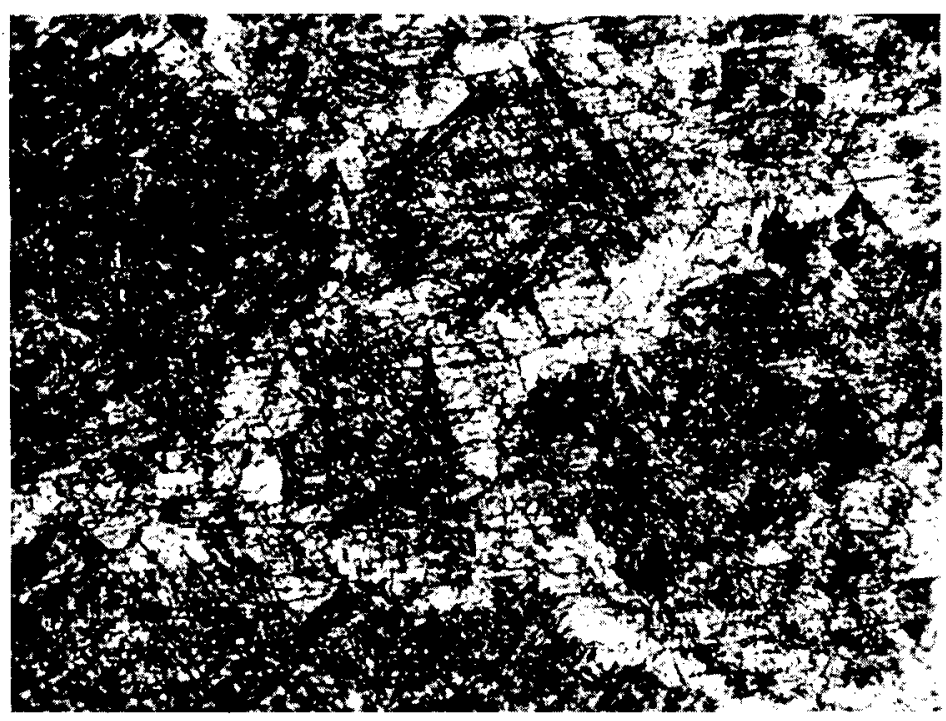

Longitudinal View

Magnification $200 \mathrm{X}$

Recrystallization. Large Grains Have Formed. Acicular Structure within Grains Is Partial Decomposition of $\beta$ Titanium into $\alpha$ Titanium Forming a Pseudomartensitic Structure. 
Composition: $1.07 \%$ Beryllium - Balance Titanium

1 Hour at $1000^{\circ}$ C. in Air and Slowly Cooled in Fig. 3 the Furnace to $400^{\circ} \mathrm{C}$.

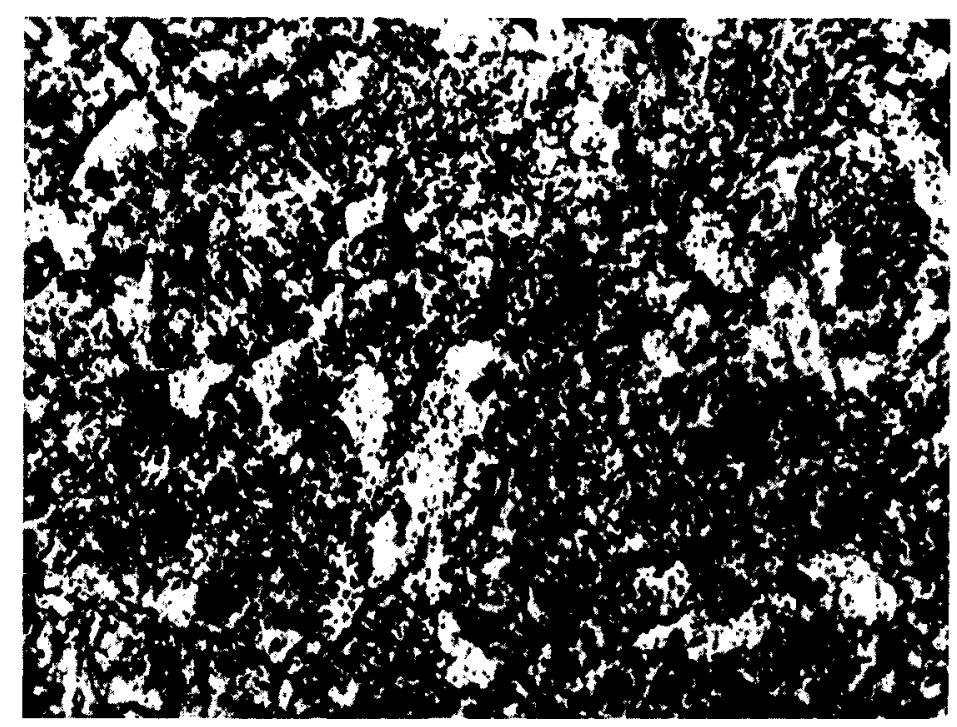

Longitudinal View Magnification $200 \mathrm{X}$

Specimen Did Not Recrystallize.

Composition: $2.64 \%$ Aluminum - Balance Titanium Hot-Rolled Specimen Vacuum-Annealed 1 Hour at $1000^{\circ} \mathrm{C}$.

Fig. 4

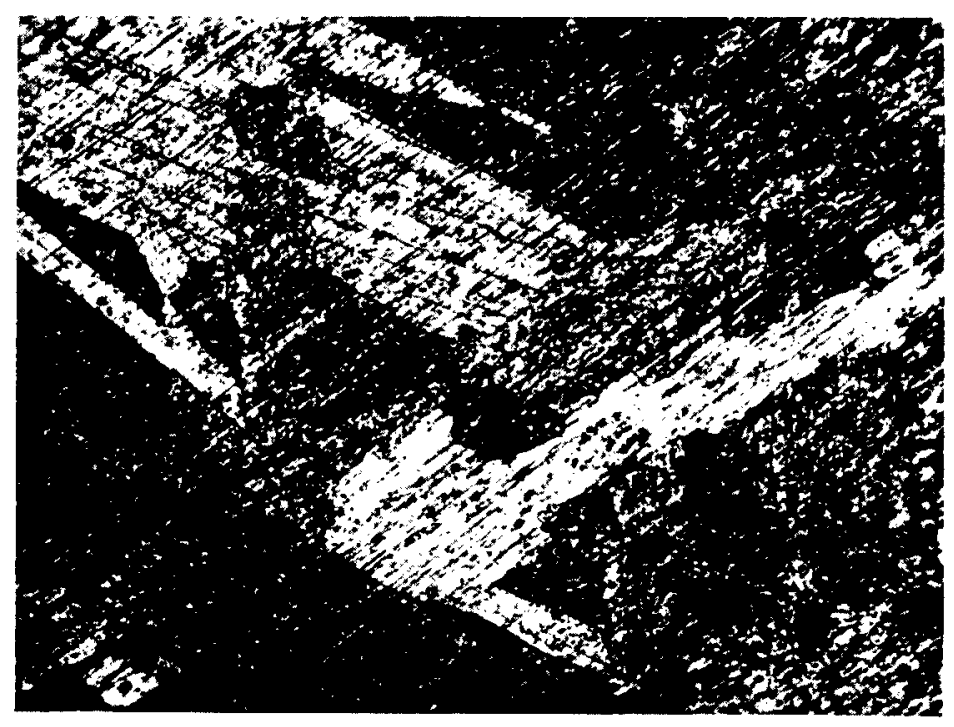

Longitudinal View Magnification $200 \mathrm{X}$

Typical Structure Obtained upon Vacuum Annealing. 
PHYSICAL PROPERTIES OF TWO ALUMINUM-TITANIUM ALLOYS

INTENDED COMPOSITION

$1 \% \mathrm{AL}-99 \% \mathrm{TI}$
COMPOSITION BY ANALYSIS $0.33 \%$ AL - BALANCE TI

\begin{tabular}{|c|c|c|c|c|c|c|c|c|c|}
\hline \multirow[t]{2}{*}{$\begin{array}{l}\text { PERCENT } \\
\text { WORKED }\end{array}$} & \multicolumn{4}{|c|}{ ROCKWELL HARDNESS } & \multicolumn{2}{|c|}{$\begin{array}{l}\text { ULTIMATE TENSILE } \\
\text { STRENGTH - PSI } \\
\end{array}$} & \multicolumn{2}{|c|}{$\begin{array}{l}\text { ELONGATION } \\
\% \text { in } 2 "\end{array}$} & \multirow{2}{*}{$\begin{array}{r}\text { RESISTIVITY } \\
\text { OHMS - CM } \\
\text { Hot Rolled }\end{array}$} \\
\hline & Hot & olled & An & aled & Hot Rolled & Annealed & Hot Rolled & Annealed & \\
\hline \multirow[t]{2}{*}{77} & $65 \mathrm{~A}$ & $29 \mathrm{C}$ & $62 \mathrm{~A}$ & $23 \mathrm{C}$ & 106,500 & 91,400 & 6.25 & 12.5 & $78 \times 10^{-6}$ \\
\hline & & \multicolumn{4}{|c|}{$\begin{array}{c}\text { INTENDED COMPOSITION } \\
3 \% \mathrm{AL}-97 \% \text { TI }\end{array}$} & \multicolumn{3}{|c|}{$\begin{array}{l}\text { COMPOSITION BY ANALYSIS } \\
2.64 \% \text { AL - BALANCE TI }\end{array}$} & \\
\hline 77 & $66 \mathrm{~A}$ & $31 \mathrm{C}$ & $62 A$ & $23 \mathrm{C}$ & 118,000 & 109,000 & 6.25 & 7.8 & $130 \times 10^{-6}$ \\
\hline
\end{tabular}

\section{Composition: $2.64 \%$ Aluminum - Balance Titanium}

1 Hour at $850^{\circ} \mathrm{C}$. and Slowly Cooled to $400^{\circ} \mathrm{C}$.

Fig. 5

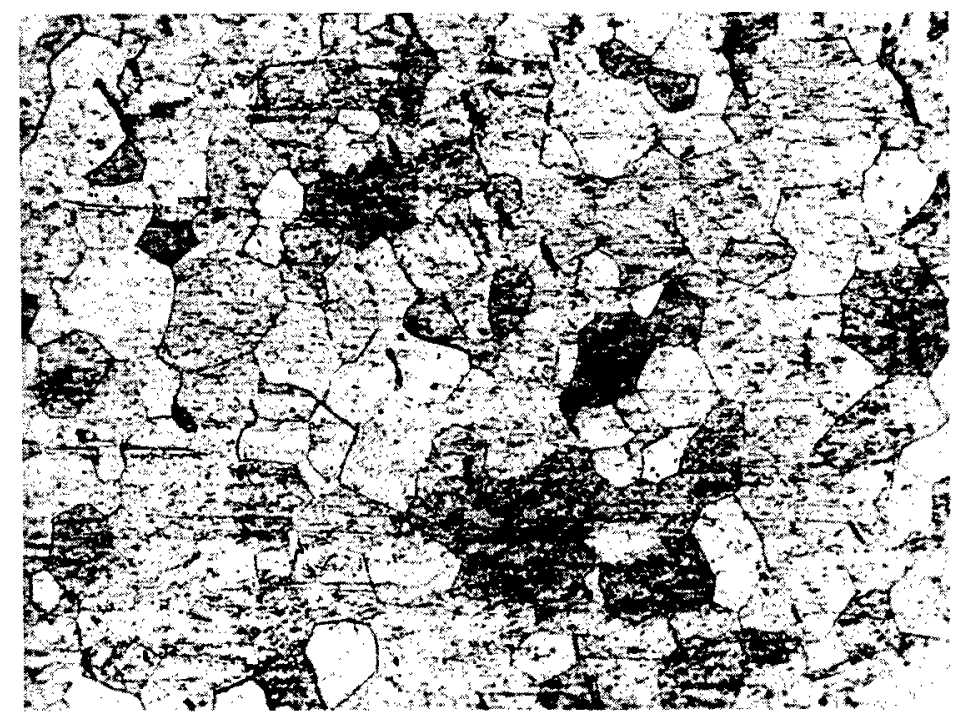

Longitudinal View

Magnification $200 \mathrm{X}$

Recrystallization. Grains Larger than Those of the Quenched Specimen Due to More Time at Temperature. 
Table 5

PHYSICAL PROPERTIES OF TWO ALUMINUM-TITANIUM ALLOYS HOT WORKED 77 PERCENT FOLLOWED BY COLD SWAGING 65 PERCENT

\begin{tabular}{|c|c|c|c|c|}
\hline \multirow{2}{*}{\multicolumn{2}{|c|}{ ROCKWELL HARDNESS }} & $\begin{array}{l}\text { POSITION } \\
\mathrm{TI}\end{array}$ & \multicolumn{2}{|c|}{$\begin{array}{l}\text { COMPOSITION BY ANALYSIS } \\
0.33 \% \text { AL - BALANCE TI }\end{array}$} \\
\hline & & $\begin{array}{l}\text { ULTIMATE TENSILE } \\
\text { STRENGTH - PSI } \\
\end{array}$ & $\begin{array}{l}\text { ELONGATION } \\
\% \text { in } 2, \\
\end{array}$ & $\begin{array}{c}\text { RESISTIVITY } \\
\text { OHMS - CM } \\
\end{array}$ \\
\hline \multirow{3}{*}{$65 \mathrm{~A}$} & & & & Cold Swaged \\
\hline & $29 \mathrm{C}$ & 159,000 & 3 & $77 \times 10^{-6}$ \\
\hline & \multicolumn{2}{|c|}{$\begin{array}{l}\text { INTENDED COMPOSITION } \\
3 \% \mathrm{AL}-97 \% \mathrm{TI}\end{array}$} & \multicolumn{2}{|c|}{$\begin{array}{l}\text { COMPOSITION BY ANALYSIS } \\
2.64 \% \text { AL - BALANCE TI }\end{array}$} \\
\hline $67 \mathrm{~A}$ & $33 \mathrm{C}$ & 155,000 & 3 & $125 \times 10^{-6}$ \\
\hline
\end{tabular}

Composition: $2.64 \%$ Aluminum - Balance Titanium Hot-Rolled Specimen Heated 16 Hours in Air at $800^{\circ} \mathrm{C}$.

Fig. 6

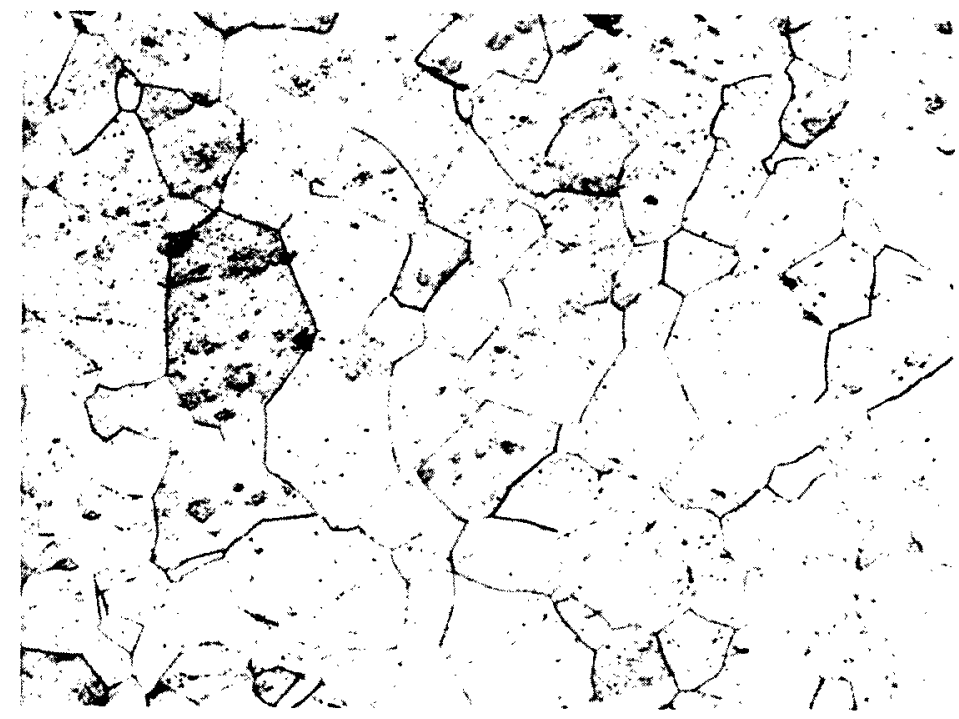

Longitudinal View

Magnification $200 \mathrm{X}$

Hot-Rolled Specimen Recrystallized. Polygonal Grains. Single Phase Indicates Complete Diffusion of Aluminum. 
Table 6

\begin{tabular}{|c|c|c|c|c|c|c|c|c|c|}
\hline \multirow[b]{3}{*}{$\begin{array}{c}\text { PERCENT } \\
\text { WORKED }\end{array}$} & \multicolumn{8}{|c|}{ PHYSICAL PROPERTIES OF INDIUM-TITANIUM ALLOYS } & \multirow[b]{3}{*}{$\begin{array}{l}\text { RESISTIVITY } \\
\text { OHMS - CM } \\
\end{array}$} \\
\hline & & $\begin{array}{r}\text { INTENI } \\
3 \% \\
\end{array}$ & $\begin{array}{l}\text { ED CO } \\
\text { IN }-97\end{array}$ & $\begin{array}{l}\text { IPOSI } \\
0 \mathrm{TI}\end{array}$ & ITION & $\begin{array}{r}\text { COMPOS } \\
0.98 \% \\
\end{array}$ & $\begin{array}{l}\text { TION BY ANA } \\
\text { N - BALANCE }\end{array}$ & $\begin{array}{l}\text { LYSIS } \\
\text { ETI }\end{array}$ & \\
\hline & \multicolumn{4}{|c|}{ ROCKWELL HARDNESS } & \multicolumn{2}{|c|}{$\begin{array}{c}\text { ULTIMATE TENSILE } \\
\text { STRENGTH - P.S.I. }\end{array}$} & \multicolumn{2}{|c|}{ ELONGATION } & \\
\hline \multirow{3}{*}{73} & \multicolumn{2}{|c|}{ Cold Worked } & \multicolumn{2}{|c|}{ Annealed } & \multirow{2}{*}{$\frac{\text { Cold Worked }}{132,500}$} & \multirow{2}{*}{$\frac{\text { Annealed }}{100,000}$} & \multirow{2}{*}{$\frac{\text { Cold Worked }}{\text { None }}$} & \multirow{2}{*}{$\frac{\text { Annealed }}{7.8 \% \text { in } 2^{\prime \prime}}$} & \multirow{2}{*}{$\frac{\text { Cold Swaged }}{99 \times 10^{-6}}$} \\
\hline & $67 \mathrm{~A}$ & $33 \mathrm{C}$ & $60.5 \mathrm{~A}$ & $20 \mathrm{C}$ & & & & & \\
\hline & \multicolumn{2}{|c|}{ Hot Worked } & & & \multicolumn{2}{|l|}{ Hot Worked } & \multicolumn{2}{|l|}{ Hot Worked } & Hot Worked \\
\hline 76 & $63 \mathrm{~A}$ & $25 \mathrm{C}$ & $63 \mathrm{~A}$ & $25 \mathrm{C}$ & 110,000 & 106,800 & $4.7 \%$ in $1 "$ & $12.5 \%$ in 2 & $85 \times 10^{-6}$ \\
\hline
\end{tabular}

Composition: $2.64 \%$ Aluminum - Balance Titanium

Hot Rolled Specimen Heated 16 Hours in Air at $900^{\circ} \mathrm{C}$.

Fig. 7

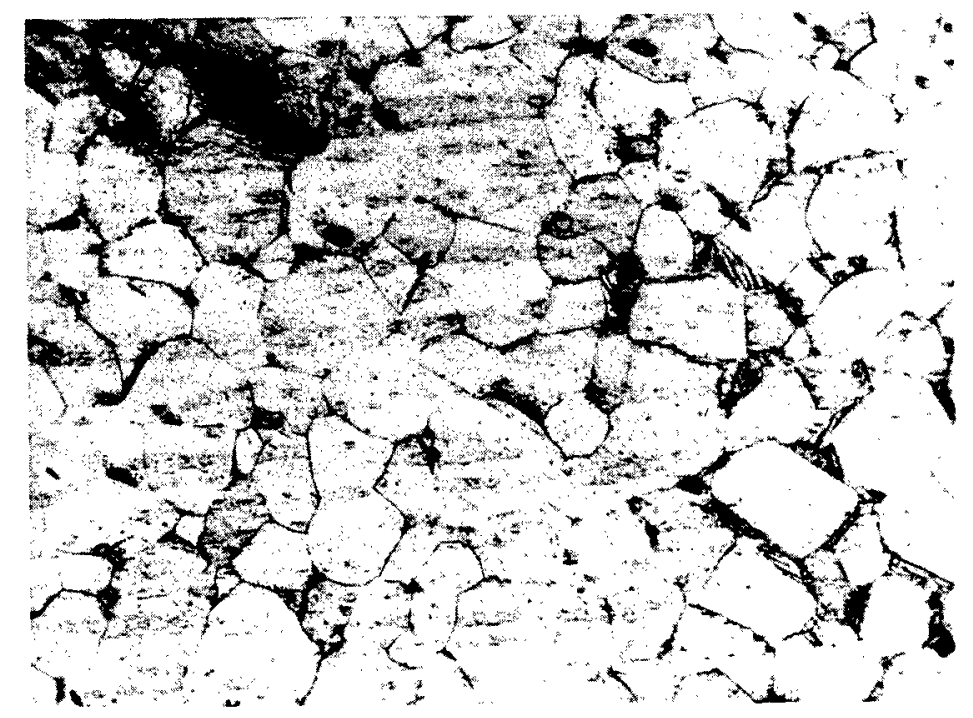

\section{Longitudinal View \\ Magnification $200 \mathrm{X}$ \\ Dark Areas in between Grain Boundaries Are Probably Oxide Penetration.}


Composition: $5.65 \%$ Manganese - Balance Titanium

1 Hour at $850^{\circ} \mathrm{C}$. in Air and Water Quenched

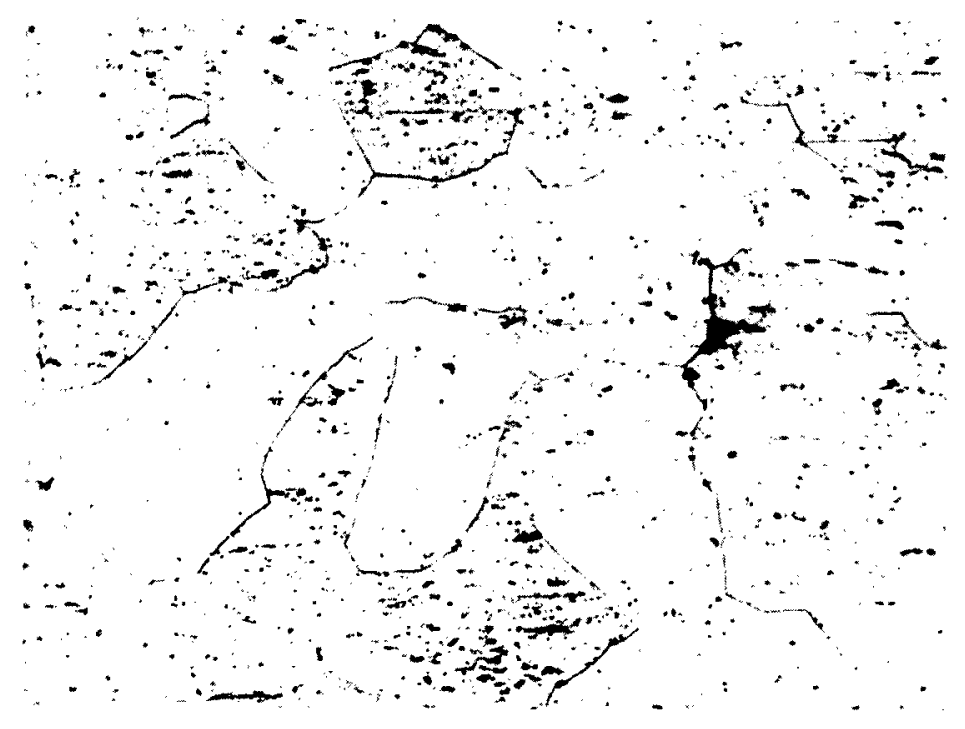

Fig. 8

Longitudinal View Magnification $200 \mathrm{X}$

Recrystallization Has Occurred. All Manganese Dissolved.

Composition: $5.65 \%$ Manganese - Balance Titanium 1 Hour at $850^{\circ} \mathrm{C}$. in Air and Slowly Cooled to $400^{\circ} \mathrm{C}$.

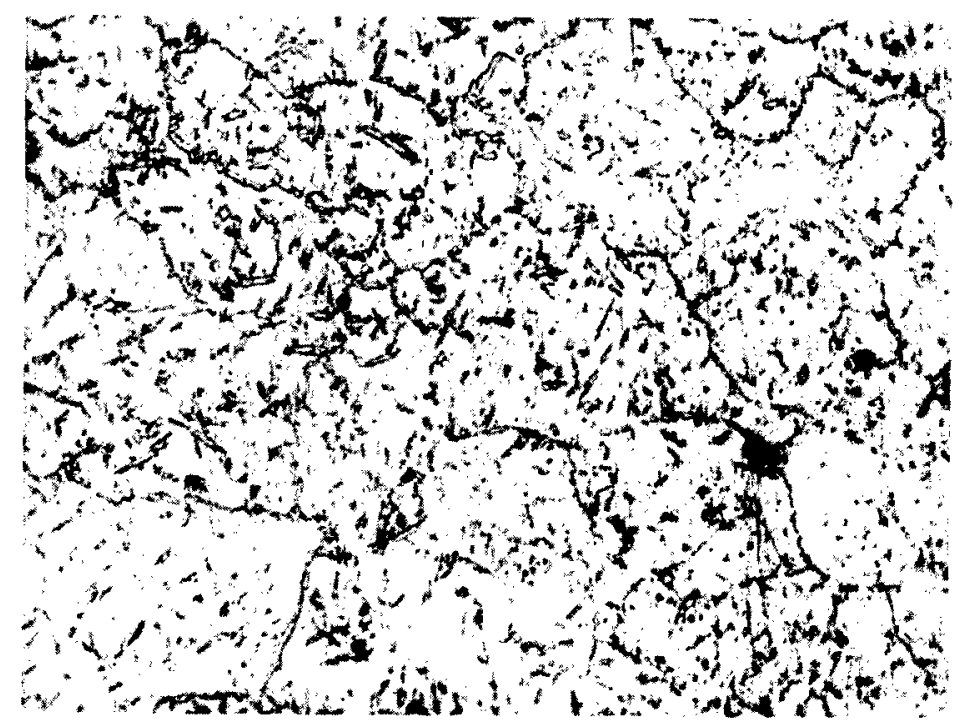

Fig. 9

Longitudinal View Magnification $200 \mathrm{X}$

Precipitation Has Occurred at Grain Boundaries Predominantly but also within Grains. 
Composition: $5.65 \%$ Manganese - Balance Titanium

1 Hour at $1000^{\circ} \mathrm{C}$. in Air and Water-Quenched

Fig. 10

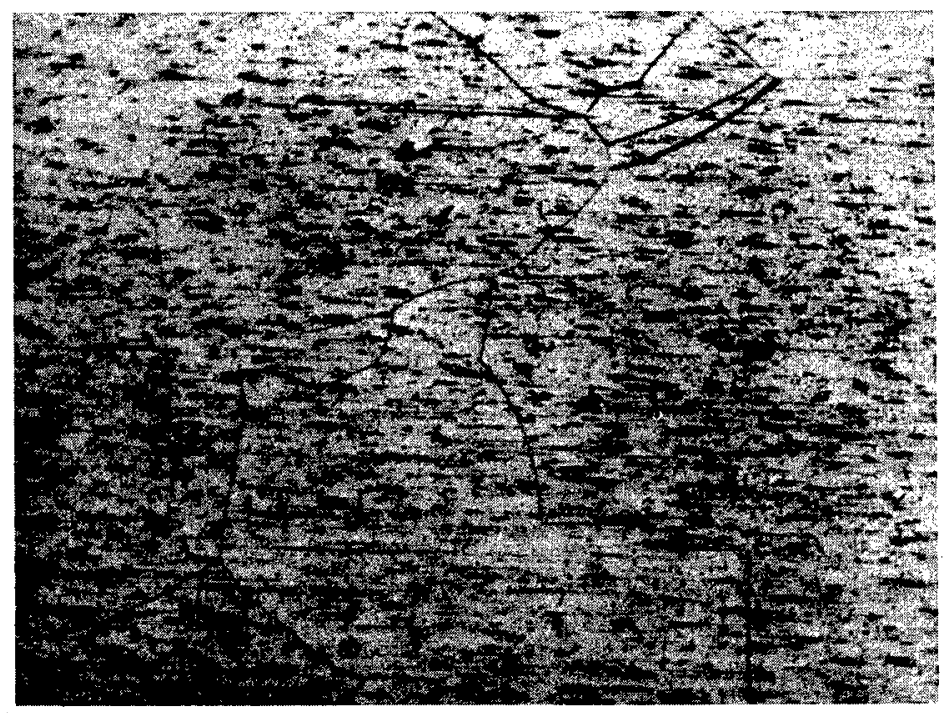

Longitudinal View Magnification $200 \mathrm{X}$

Recrystallization Complete. Single-Phase Material.

Composition: $5.65 \%$ Manganese - Balance Titanium

1 Hour in Air at $1000^{\circ} \mathrm{C}$. and Slowly Cooled

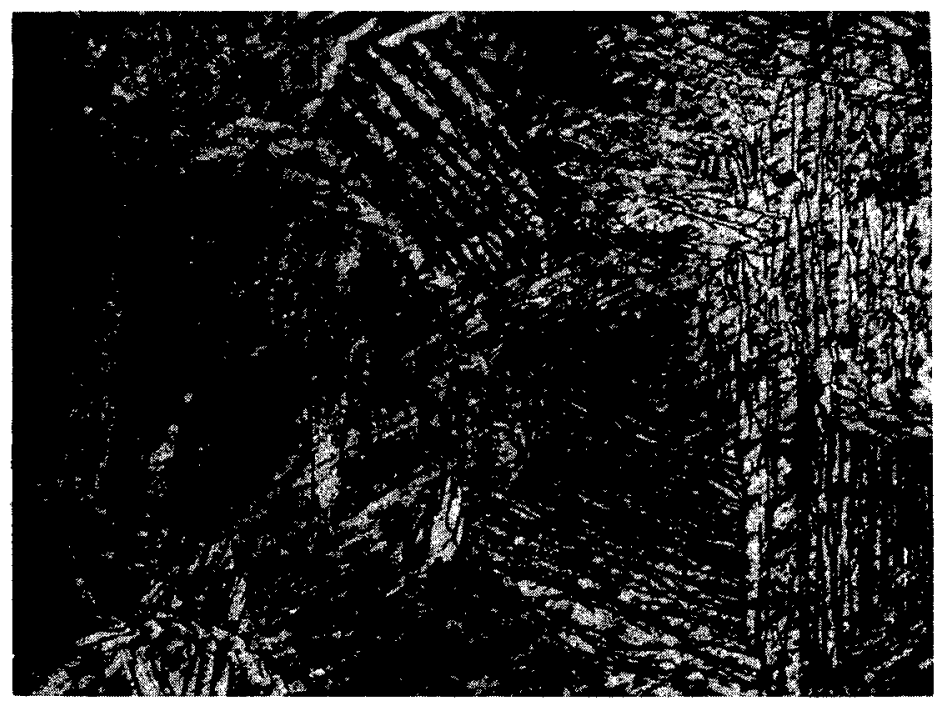

Longitudinal View

Magnification $200 \mathrm{X}$

Fig. 11

Precipitation of Second-Phase Evident. 
Table 7

PHYSICAI EROP IFTIES OF TITARTUM VACUTM YELTEO IN A GRAPHITE CNUCIPLI

\section{COMPOSITION BY ANALYSIS}

1.28\% C - BALANCE TI.

HOT ROLIED I7 PER CENT AND FOLIOWED BY COLD SWAGINC 12 PBF CENT

\begin{tabular}{|c|c|c|c|c|c|}
\hline FOCKYYIL FARDNESS & $\begin{array}{l}\text { UTIMAT } \\
\text { STRBSGM }\end{array}$ & $\begin{array}{l}\text { TENSILE } \\
- \text { P.S.I. }\end{array}$ & $\begin{array}{r}\mathrm{M} O \mathrm{~N} \\
61 \\
\end{array}$ & $\begin{array}{l}\text { ATron } \\
2^{\prime \prime}\end{array}$ & $\begin{array}{l}\text { FESISTIVI TK } \\
\text { OFEIS - CMI }\end{array}$ \\
\hline SHAGED & $S N A G E D$ & PIN EALED & $\underline{S F A G D D}$ & ANIEALED & SFAGDD \\
\hline 634 & 137,000 & 114,500 & 4.6 & 8.3 & $61 \times 10^{6}$ \\
\hline
\end{tabular}

COMPOSITION EY NILIYSIS

$1.18 \% \mathrm{C}$ - BALANCE TI

HOT STAGEO 88 PE CENT

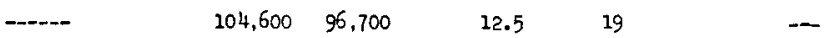

Table 8

PHYSICAL PROPEFTIES OF TWO SILICON-TITANIUM ALIOTS

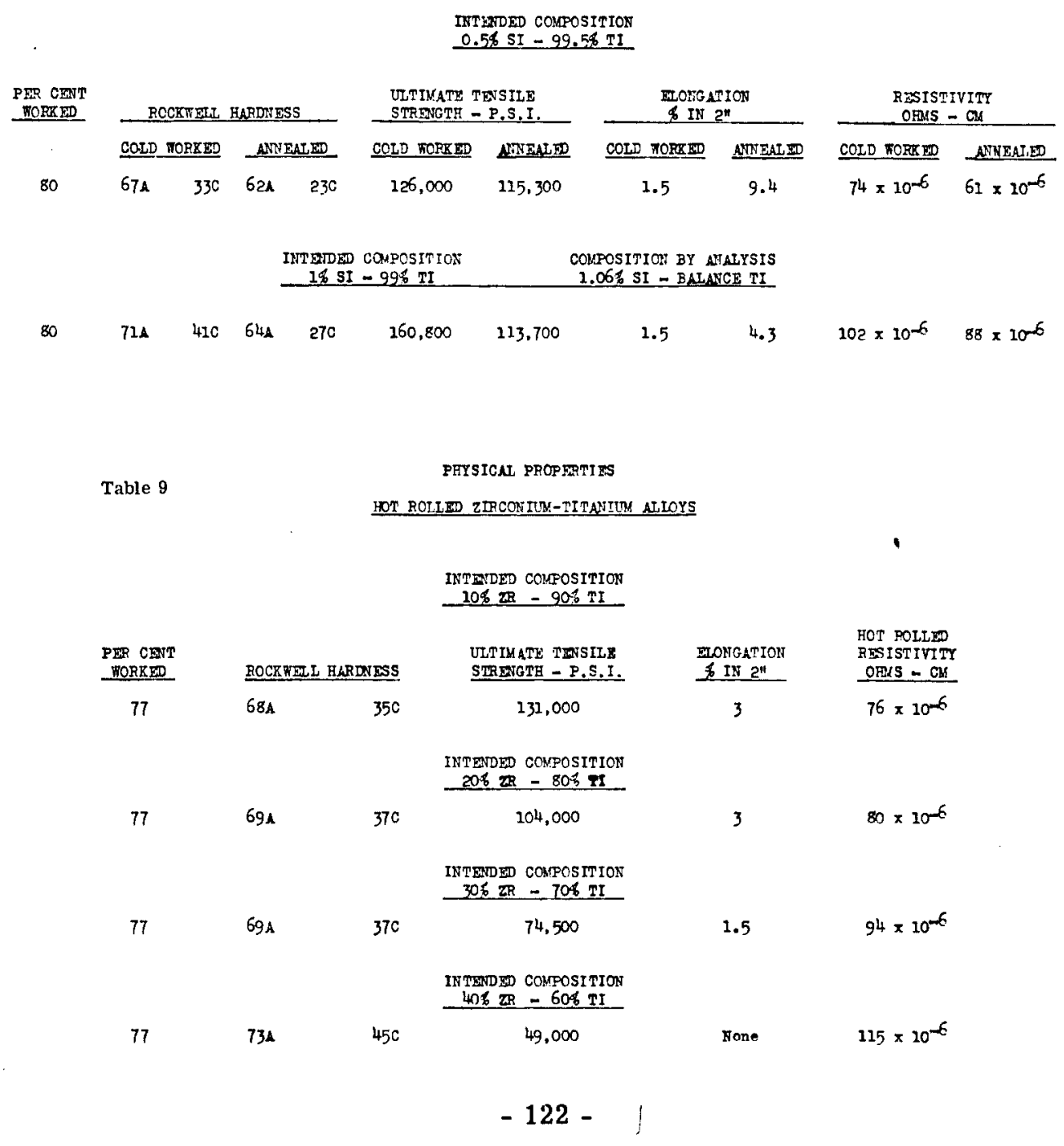




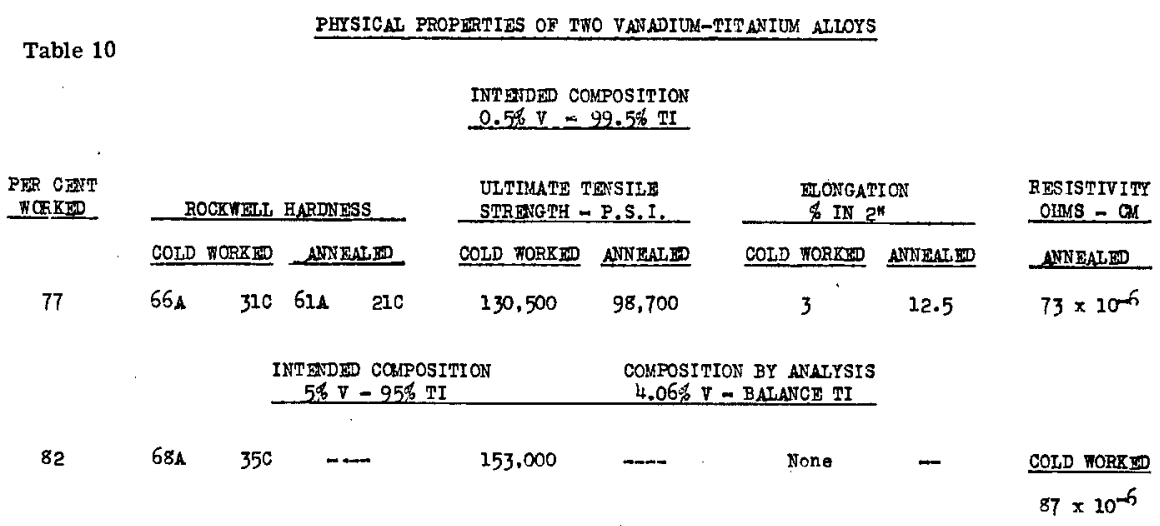

\begin{tabular}{|c|c|c|c|c|c|c|c|}
\hline \multirow{2}{*}{ Table 11} & \multicolumn{7}{|c|}{ 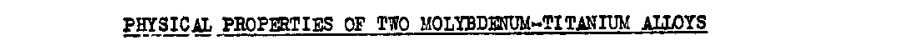 } \\
\hline & & & DID & $\begin{array}{l}\text { POSITIOR } \\
\text { O\& TI }\end{array}$ & $\begin{array}{l}\text { COMPOSII } \\
10.218\end{array}$ & $\begin{array}{l}\text { BY LNASYSIS } \\
\text { EALASCE II }\end{array}$ & \\
\hline \multirow[t]{2}{*}{$\begin{array}{l}\text { PER CENT } \\
\text { MOREEDT } \\
\end{array}$} & \multicolumn{4}{|c|}{ ROCKMHLL HARDNASS } & $\begin{array}{l}\text { ULTIMATE TENSIIIE } \\
\text { STRENGTE }- \text { P.S.I. }\end{array}$ & $\begin{array}{l}\text { MHOOMGAMION } \\
\text { OIN } 2^{n}\end{array}$ & $\begin{array}{l}\text { RESISTIVITY } \\
\text { OHSS - CM }\end{array}$ \\
\hline & \multicolumn{2}{|c|}{ HOI TORRINO } & \multicolumn{2}{|c|}{ ANYRALTD } & $\angle N N$ WAIED & ANEATED & $A D E Z M C D D$ \\
\hline \multirow[t]{2}{*}{77} & $66 \AA$ & 310 & 6en & $23 \mathrm{C}$ & 110,000 & Yone & $80 \times 10^{-6}$ \\
\hline & \multicolumn{4}{|c|}{$\begin{array}{l}\text { INTHND COMPOSI TION } \\
206 \mathrm{MO}-80 \% \mathrm{TI}\end{array}$} & \multicolumn{2}{|c|}{$\begin{array}{l}\text { COAPOSIII ON BY ANAISSIS } \\
12.52 \% \text { MO - BATANCE TI }\end{array}$} & \\
\hline 77 & $68 \mathrm{~A}$ & 350 & $66 \mathrm{~A}$ & $31 \mathrm{c}$ & 135,000 & 3.9 & $98 \times 10^{-6}$ \\
\hline
\end{tabular}

Table 12

FHYSICAL PROPERTI

MANGANASERTITANTOM ALIOYS

COLD ROLLID

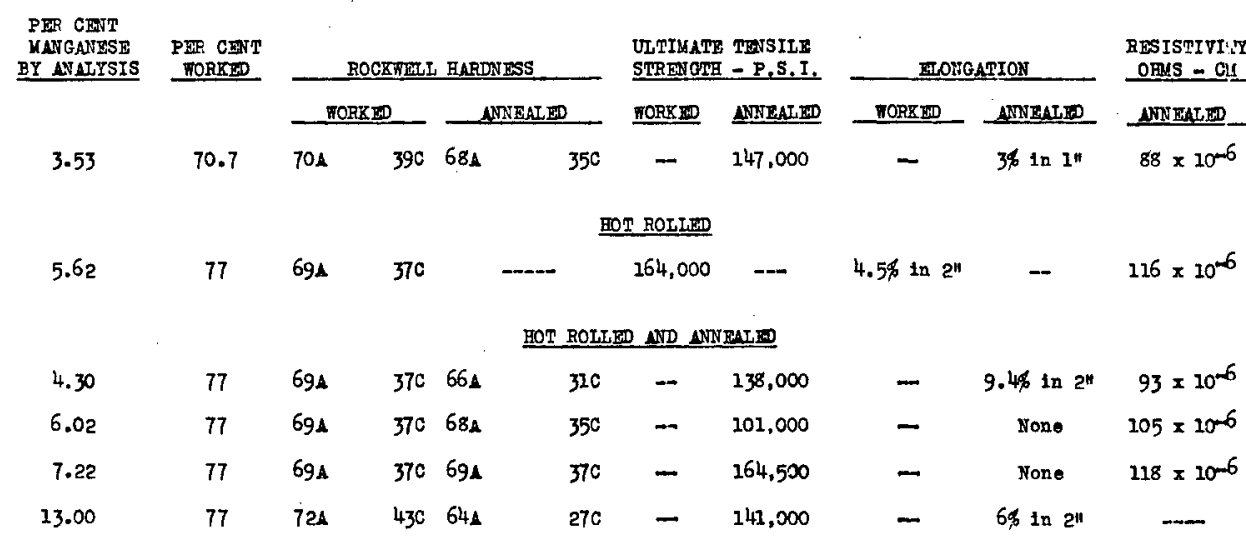




\section{Summary}

Of the alloy systems investigated, the following have characteristics which might be of practical value:

1. Aluminum alloys containing up to $5 \%$ aluminum.

2. Manganese alloys containing about $5 \%$ manganese.

3. Beryllium alloys containing up to $1 \%$ beryllium.

4. Boron alloys containing up to $1 \%$ boron.

5. Silicon alloys containing up to $1 \%$ silicon.

\section{Future Work}

Various alloys of titanium are now being made by melting in graphite either in vacuo or in a purified argon atmosphere. This work is being done under Bureau of Aeronautics, Navy Department Contract No. NOa(s)9919.

\section{Acknowledgment}

The interest, advice, and guidance of Mr. N. E. Promisel of the Bureau of Aeronautics has been invaluable and appreciation of his efforts in behalf of our work upon titanium alloys is acknowledged.

Appreciation also is expressed for the technical assistance of Dr. R. S. Dean, metallurgical consultant.

\section{DISCUSSION}

In discussing the ductility values reported, Mr. Larsen believed that higher values would be obtained with arc-melted or cast titanium alloys. In addition, small specimens of rectangular cross sections were used which also contributed to low ductility. Mr. J. R. Long (Bureau of Mines) called attention to the fact that it would be some time before the various melting techniques would be fully developed and that powder metallurgy procedures provide a means for evaluating titanium alloys and indicating directions for future research. He stated that, when using powder metallurgy methods, care should be exercised to avoid the introduction of impurities as part of the alloying additions.

Mr. Larsen also stated that a Globar furnace with a silica tube was used for sintering the alloys. 


\title{
TTITANIUM-BASE ALLOYS
}

\author{
By Howard Cenoss \\ Battelle Memorial Institute
}

Alloys of titanium have been investigated at Battelle, using both powder metallurgy methods and an arc-melting technique for their production from titanium powder produced by the magnesium reduction method as used by the Bureau of Mines, and also using titanium produced by the deBoer process of hot-filament decomposition of titanium iodide.

It must be kept in mind that alloy additions to titanium metal will vary in effect as a result of the differences in purity of the metal produced by the various processes.

General statements in the literature point out that oxygen, nitrogen and hydrogen are embrittling to titanium, but no quantitative measurements had ever been made that associate mechanical properties with the amounts of oxygen, nitrogen and hydrogen present. One reason for this was the unavailability of titanium that is pure enough to be considered a good base-line material. Iodide titanium produced by the deBoer process is very low in oxygen, nitrogen and hydrogen and serves admirably as a base-line. Another reason for the lack of quantitative information on the effect of these gases, particularly oxygen, is that there have been no reliable analytical methods for the determination of these gases in titanium. Iodide titanium shows impurities less than $0.2 \%$, and probably less than $0.1 \%$, principally silicon and iron.

Alloys of titanium and oxygen, nitrogen or hydrogen were made up by the gas absorption and diffusion method using iodide titanium as the starting material in the form of specimens six inches long and about 0.080 inch square. The general procedure consisted of adding known volumes of the various gases to an evacuated system within which the titanium, in the form of wire, was suspended. The wire was then heated to 700-1000 degrees Centigrade (1290-1830 degrees Fahrenheit), for the time interval required to obtain absorption by the metal, and then uniform diffusion of the gases throughout the metal. Absorption of oxygen was rapid and complete. With hydrogen, the specimen temperature had to be lowered to 650-700 degrees Centigrade (12001290 degrees Fahrenehit) to obtain complete absorption. Nitrogen was absorbed so slowly that after complete absorption, diffusion was effected at 1100 degrees Centigrade (2010 degrees Fahrenheit) in a separate treatment.

"Zero" or base-line samples of titanium, containing no gas, were prepared using fresh samples of iodide titanium under similar heating cycles in an evacuated system. The alloy compositions investigated were $0.25,0.50$ and one atomic percent additions of each of oxygen, nitrogen and hydrogen.

Unalloyed titanium cooled from 1000 degrees Centigrade consists of large plates of alpha-titanium arranged in a somewhat Widmanstätten-like manner. The general effect of oxygen is to refine the structure making the plates of alpha-titanium smaller and the Widmanstätten arrangement more regular. The effect of nitrogen is to promote the formation of needles of alpha-titanium. This needle-like structure is characteristic of most of the magnesium-reduced titanium that has been annealed above the alpha-beta transformation temperature and suggests that the needle-like structure in titanium of lower purity than iodide titanium is caused by nitrogen in solid solution. 
The structures of the hydrogen alloys are not materially different from unalloyed titanium.
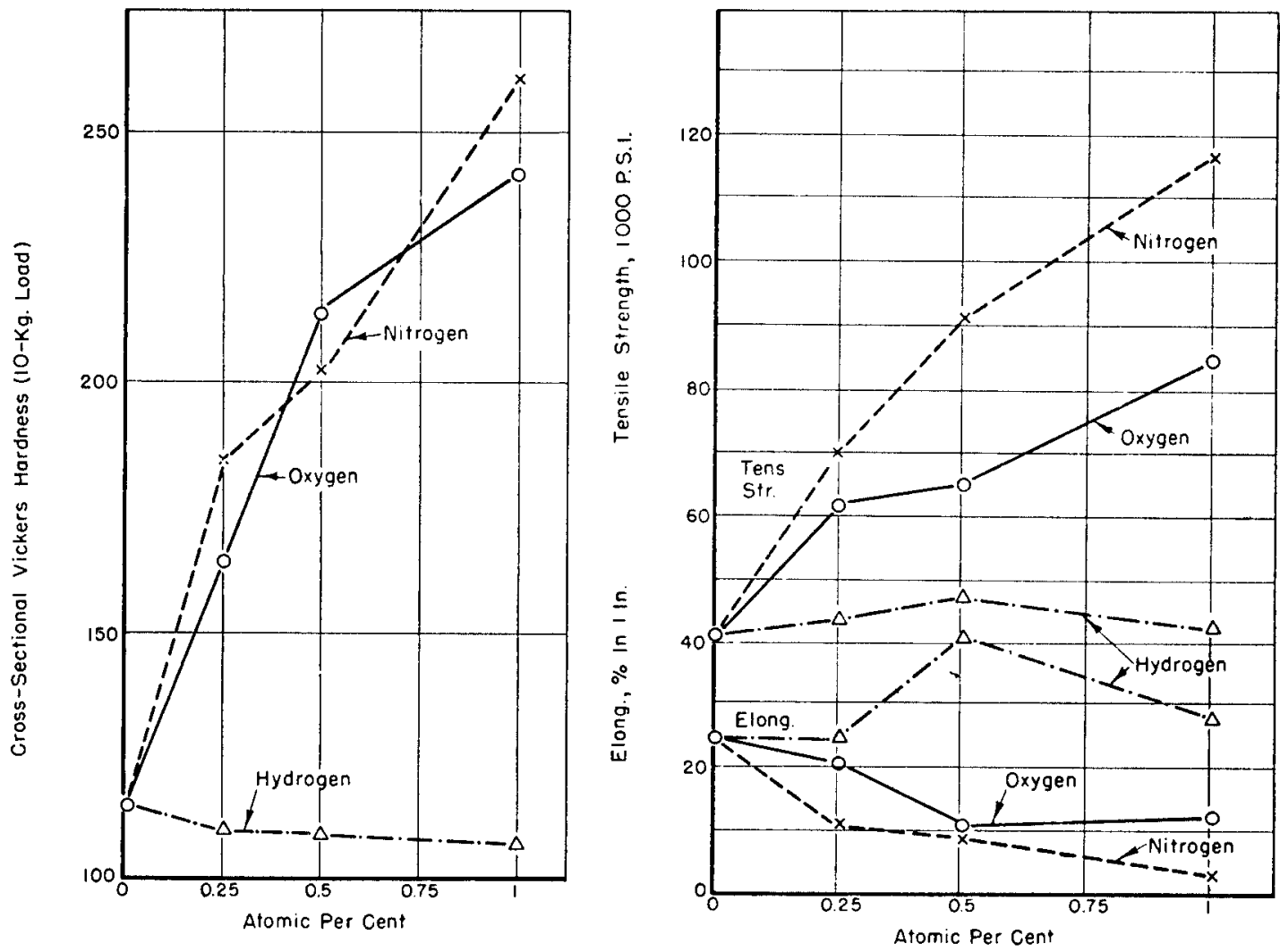

FIGURE I. AVERAGE CROSS-SECTIONAL HARD
NESS VALUES FOR ALLOYS OF NESS VALUES FOR ALLOYS OF
IODIOE TITANIUM WITH OXYGEN, NITROGEN, AND HYDROGEN

FIGURE 2. TENSILE STRENGTHS AND ELONGATIONS OF ALLOYS OF IODIDE TITANIUM WITH OXYGEN, NITROGEN, AND HYDROGEN

Hardness and tensile tests were made on the various alloys. The hardness data are shown in Figure 1. The data for the oxygen and nitrogen alloys are somewhat erratic, but indicate that oxygen and nitrogen harden titanium to about the same extent with nitrogen possibly having a greater effect. The hardnesses increased from 120 Vickers to $240-260$ Vickers. Hydrogen up to one atomic percent (0.021 weight percent) does not increase the hardness of iodide titanium, and actually appears to decrease it slightly, although the apparent decrease may have been caused by hardness variations in the original iodide titanium rod.

Figure 2 shows the effect of the gaseous additions on the tensile strengths and elongations of iodide titanium. Nitrogen has a consider ably greater strengthening effect on iodide titanium than oxygen, increasing the tensile strength almost threefold, while for oxygen the increase was about twofold. Nitrogen correspondingly decreases the ductility to a greater extent. Hydrogen appears to have a very slight strengthening effect, although this indication may be the result of variations in the initial material.

Determinations of cold-rolling characteristics indicate nitrogen is more deleterious to cold rollability than oxygen. The work-hardening characteristics of titanium-hydrogen alloys were similar to those for pure titanium. 
Similar experiments on the effect of oxygen and nitrogen additions have been made in arc-melted titanium prepared from powder produced either by the Bureau of Mines or by Batelle. During the arc-melting process, the oxygen additions were made in the form of titanium dioxide and the nitrogen additions in the form of titanium nitride. Table 1 shows the mechanical properties obtained.

TABLE 1. EFFECT OF OXYGEN, NITROGEN, AND CARBON ON MECHANICAL PROPERTIES OF ARC-LELTED AND HOT-FORGED TITANIUM

\begin{tabular}{|c|c|c|c|c|}
\hline Alloy Gomposition, $\%$ & $\begin{array}{l}\text { Rockwell c } \\
\text { Hardness }\end{array}$ & $\begin{array}{l}\text { Tensile } \\
\text { Strength, } \\
\text { p.s.i. }\end{array}$ & $\begin{array}{l}\text { Yield } \\
\text { Strength, } \\
\text { p.s.i. }\end{array}$ & $\begin{array}{l}\text { Elongation } \\
\text { in } \frac{1}{\phi} \text { Inch, }\end{array}$ \\
\hline Arc-melted titanium & 19 & 95,000 & 80,000 & 25 \\
\hline $\begin{array}{l}0.14 \text { oxygen, } 0.11 \text { nitrogen, } 0.3 \text { tungsten } \\
0.25 \text { oxygen, } 2.23 \text { tungsten } \\
0.67 \text { oxygen, } 0.16 \text { nitrogen, } 0.24 \text { tungsten }\end{array}$ & $\begin{array}{l}31 \\
40 \\
42\end{array}$ & $\begin{array}{l}112,000 \\
168,000 \\
160,000\end{array}$ & $\overline{-}$ & $\begin{array}{l}1.5 \\
0.5(a) \\
0.5\end{array}$ \\
\hline $\begin{array}{l}0.15 \text { nitrogen, } 1.41 \text { tungsten } \\
0.29 \text { nitrogen, } 1.88 \text { tungsten } \\
0.46 \text { nitrogen, } 1.69 \text { tungsten }\end{array}$ & $\begin{array}{l}34 \\
31 \\
45\end{array}$ & $\begin{array}{l}145,800 \\
169,400 \\
191,400\end{array}$ & $\overline{-}$ & $\begin{array}{c}2.5 \\
3.5 \\
0\end{array}$ \\
\hline $\begin{array}{l}0.15 \text { carbon, } 1.5 \text { tungsten } \\
0.25 \text { carbon, } 2.5 \text { tungsten } \\
0.39 \text { carbon, } 3.8 \text { tungsten }\end{array}$ & $\begin{array}{l}27 \\
35 \\
31\end{array}$ & $\begin{array}{l}130,800 \\
147,000 \\
169,000\end{array}$ & $\begin{array}{l}177,600 \\
129,800 \\
-\end{array}$ & $\begin{array}{l}21 \\
10 \\
11\end{array}$ \\
\hline
\end{tabular}

(a) Defective bar may have influenced measured ductility.

Unfortunately, the titanium powder used in preparing these melts was gassy and it was found that some degree of contamination resulted in every heat. The data indicate substantial increases in strength and hardness for these melts with intentional additions of oxygen and nitrogen but it is not proper to ascribe the total effects measured to these gaseous elements because of the indeterminate effect of the tungsten contents. However, most of the strengths shown in Table 1 are considerably in excess of those usually associated with the small tungsten contents indicated, all of which are less than $4 \%$.

Table 1 also shows the effect of carbon additions to arc-melted titanium. As with oxygen and nitrogen, the effect of carbon is clouded by tungsten contamination, but the data do serve to indicate that a high level of strength and ductility is obtainable in a titanium alloy with both carbon and tungsten present. There are no indications that carbon in moderate amounts is detrimental.

Battelle is continuing the study of titanium-base alloys with additions of carbon, oxygen, nitrogen, and tungsten under the sponsorship of the Remington Arms Company.

In a previous technical report to Project RAND (Titanium and TitaniumBase Alloys, RA-15080, April 2, 1948) a broad screening of titanium-base alloys prepared by powder metallurgy techniques with up to $50 \%$ of the high melting point metals chromium, molybdenum, tungsten, columbium, and tantalum was presented. These metals, along with titanium itself, are the most important and potentially plentiful metals, with higher melting points than iron, nickel, and cobalt, the metals on which the present commercial high-temperature alloys are based. The results obtained at that time indicated that the compositions of interest for engineering properties lay below the $20 \%$ addition level. Since the initial survey work, a more intensive investigation of the binary alloy range from 0 to $10 \%$ additions has been made. The 
data obtained are summarized in Figure 3.

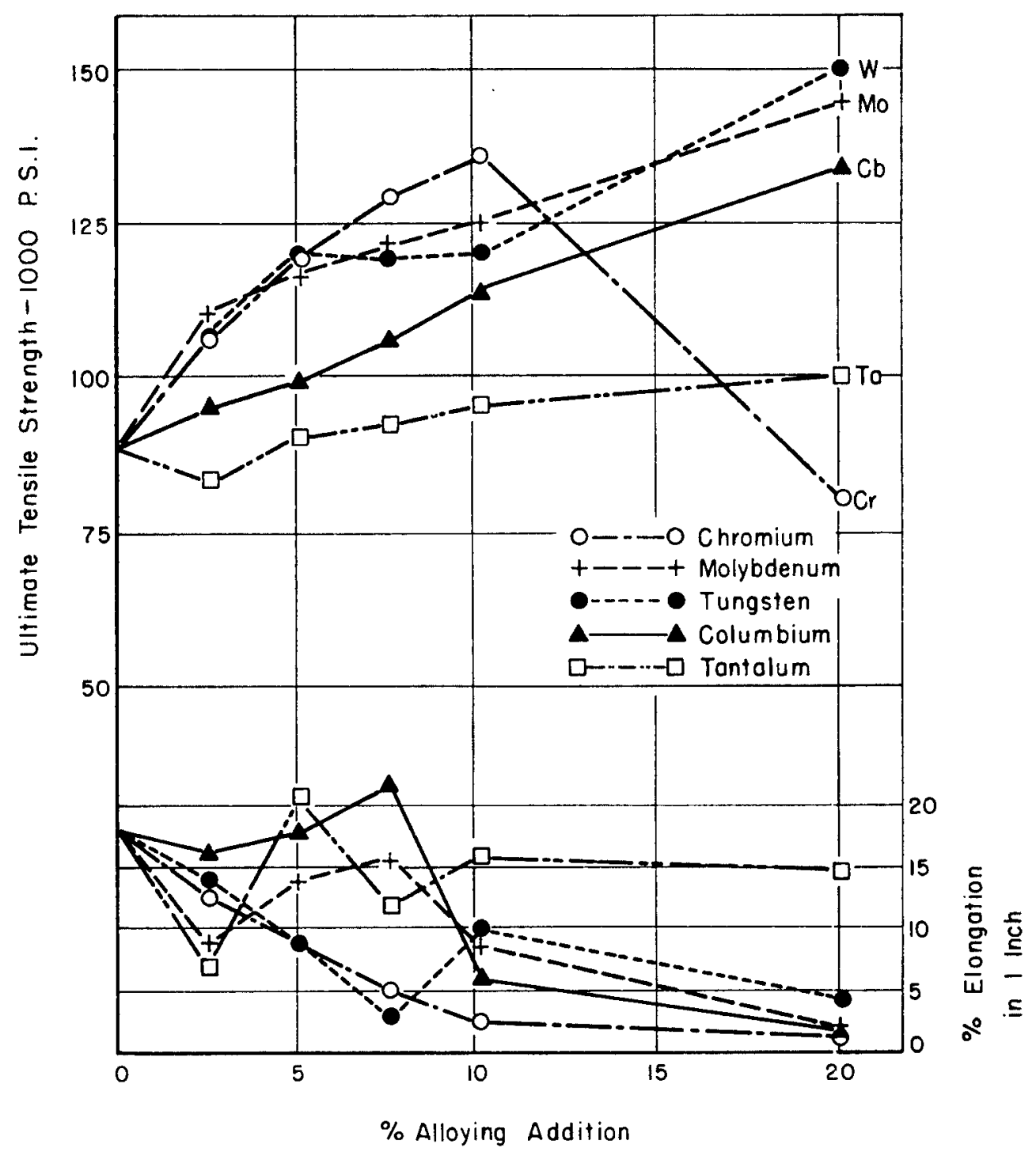

FIGURE 3. EFFECT OF CHROMIUM, MOLYBDENUM, TUNGSTEN, COLUMBIUM, AND TANTALUM ON THE TENSILE STRENGTH AND DUCTILITY OF TITANIUM. CONDITION, HOT ROLLED AT $1650^{\circ} \mathrm{F}$. AND FURNACE COOLED.

ALLOYS PREPARED BY POWDER METALLURGY METHODS.

Molybdenum, tungsten, columbium and tantalum, in amounts up to $20 \%$, increase the tensile and yield strengths progressively. Chromium has the same effect, but only in the alloys with chromium up to $10 \%$, because of the excessive amount of intermetallic compound present in the $20 \%$ chromium alloy. The metals chromium, molybdenum and tungsten of Group VI-A of the periodic table strengthen titanium to 
a greater extent than columbium and tantalum, metals of Group V-A.

The strength levels attained even at $20 \%$ additions by these alloys prepared by powder metallurgy methods are not so high as those shown by arc-melted alloys with less than four percent of tungsten and with additions of oxygen and nitrogen. So while the data show strengthening effects for chromium, molybdenum and tungsten additions, their greatest usefulness may well be in combination with other additions.

The tensile properties of ternary alloys of chromium, molybdenum or tungsten with titanium are slightly better than those of the binary alloys with equivalent alloy content.

The most ductile binary alloys, as indicated by elongation in the tensile test, were tested for their work-hardening characteristics and the data are shomn in Figure 4. It is apparent that the rate of work hardening of these alloys is about.the same as, or slightly less than, that of unalloyed titanium. Results of tensile tests carried out on the alloys cold rolled to $50 \%$ reduction in thickness are given in Table 2 . The tests on the same alloys in the original hot-rolled and furnace-cooled condition are included for ease of comparison. The alloy with $2.5 \%$ chromium cold rolled to the greatest strength $(148,000 \mathrm{psi})$, and the $2.5 \%$ tungsten and $7.5 \%$ columbium alloys to an intermediate value $(140,000 \mathrm{psi})$ while the $5 \%$ tantalum alloy behaved very similarly to the unalloyed titanium specimen.

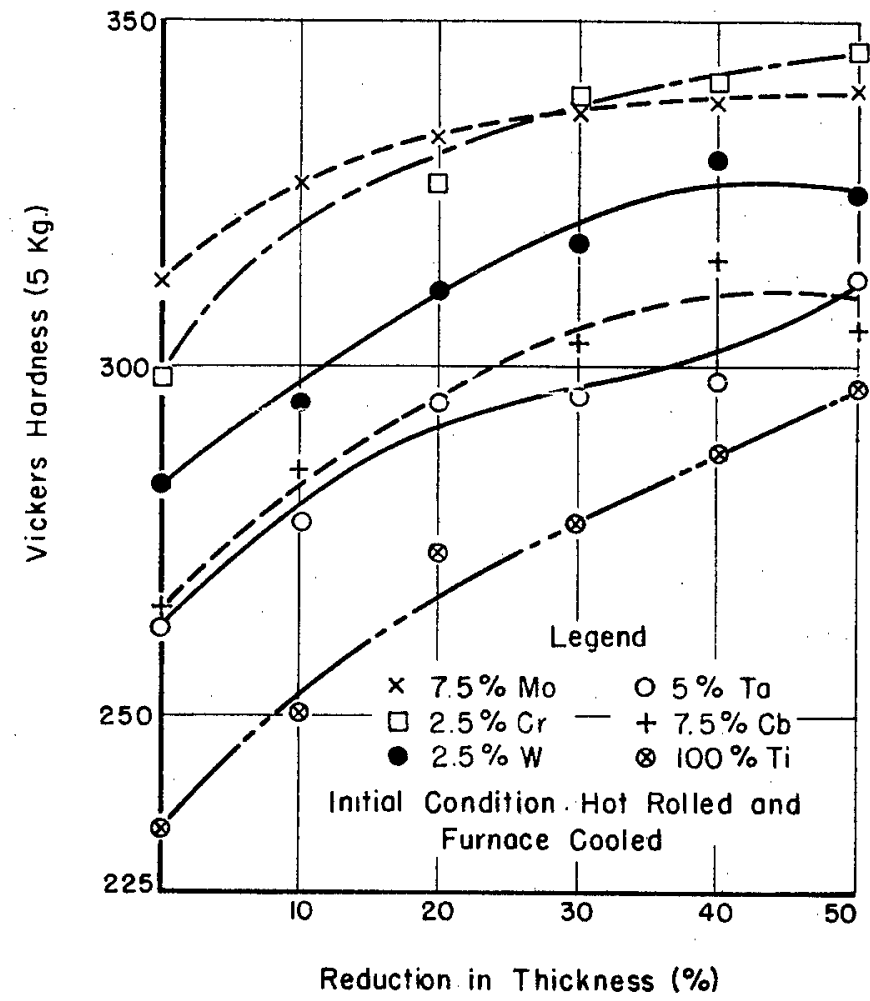

FIGURE 4. WORK-HARDENING CURVES OF TITANIUMBASE ALLOYS PREPARED BY POWDER METALLURGY METHODS. 
TABLE 2

CHANGES IN TENSILE PROPERTIES OF TITANIUM-BASE ALLOYS ON COLD ROLLING TO 50 PERCENT REDUCTION IN THICKNESS

(Prepared by Powder Metallurgy Methods)

\begin{tabular}{|c|c|c|c|c|c|c|c|c|}
\hline \multirow[b]{2}{*}{$\begin{array}{c}\text { Alloy } \\
\text { Composition }\end{array}$} & \multicolumn{4}{|c|}{ As Hot Rolled and Furnace Cooled } & \multicolumn{4}{|c|}{ As Cold Rolled to $50 \%$ Reduction } \\
\hline & $\begin{array}{c}\text { Ultimate } \\
\text { Strength, } \\
\text { p.s.i. }\end{array}$ & $\begin{array}{c}\text { Yield } \\
\text { Strength } \\
(0.2 \% \\
\text { Offset), } \\
\text { p.s.i. }\end{array}$ & $\begin{array}{l}\text { Elonga- } \\
\text { tion in } \\
1 \text { Inch, } \\
\%\end{array}$ & $\begin{array}{c}\text { Modulus of } \\
\text { Elasticity, } \\
\text { Million } \\
\text { p.s.i. }\end{array}$ & $\begin{array}{l}\text { Ultimate } \\
\text { Strength, } \\
\text { p.s.i. }\end{array}$ & $\begin{array}{c}\text { Yield } \\
\text { Strength } \\
(0.2 \% \\
\text { Offset), } \\
\text { p.s.i. }\end{array}$ & $\begin{array}{l}\text { Elonga- } \\
\text { tion in } \\
1 \text { Inch, } \\
\%\end{array}$ & $\begin{array}{c}\text { Modulus of } \\
\text { Elasticity } \\
\text { Million } \\
\text { p.s.i. }\end{array}$ \\
\hline 100 titanium & 89,000 & 66,000 & 18 & 16.4 & 128,000 & 119,000 & 4 & 14.9 \\
\hline $\begin{array}{l}2.5 \text { chromium, } \\
97.5 \text { titanium }\end{array}$ & 107,000 & 85,000 & 13 & 16.6 & 148,000 & 133,000 & 2 & 15.3 \\
\hline $\begin{array}{l}2.5 \text { tungsten, } \\
97.5 \text { titanium }\end{array}$ & 108,000 & -- & 14 & -- & 140,000 & 133,000 & 1 & 15.3 \\
\hline $\begin{array}{l}7.5 \text { columbium, } \\
\text { 92.5 titanium }\end{array}$ & 106,000 & 86,000 & 22 & 15.2 & 139,000 & 120,000 & 3 & 14.6 \\
\hline $\begin{array}{l}5.0 \text { tantalum, } \\
95.0 \text { titanium }\end{array}$ & 91,000 & 69,000 & 21 & 15.7 & 131,000 & 116,000 & 4 & 15.5 \\
\hline
\end{tabular}

Note 1. Test specimens were taken parallel to rolling direction and were three inches in length with 1 -inch-long by 0.25 -inch-wide gage lengths.

2. The tensile specimen of the $\mathbf{7 . 5}$ molybdenum -92.5 titanium alloy was defective.

In the work at Battelle on arc-melted alloys, gas evolution from the titanium powder during melting sometimes resulted in considerable spattering with resultant tungsten contamination from the tungsten-tipped electrode in some alloys, and ingot defects in others. Despite these difficulties which made an accurate evaluation of alloy additions difficult, practically all of the elements studied produced a hardening and strengthening of titanium. Some of the more interesting alloy compositions and their properties based on individual bar values are as follows:

1. $0.4 \%$ carbon, $3.8 \%$ tungsten, as hot forged. $169,000 \mathrm{psi}$ tensile strength, $11.5 \%$ elongation, hardness Rockwell C 32 .

2. $0.5 \%$ oxygen (intended analysis), $2.04 \%$ tungsten, after heating at 1750 degrees Farhenheit and water quenching. 167,500 psi tensile strength, 4.5\% elongation, hardness Rockwrell C 43.

3. $0.3 \%$ nitrogen, $1.88 \%$ tungsten, as hot forged. 169,500 psi tensile strength, 3.5\% elongation, hardness Rockwell C 31 . 
4. $0.6 \%$ nitrogen, $0.13 \%$ tungsten, after heating at 1750 degrees Fahrenheit and water quenching. 155,000 psi tensile strength, $7 \%$ elongation, hardness Rockwell C 38.

5. $4.7 \%$ tungsten (gas content not determined), as hot forged. 198,000 psi tensile strength, $2 \%$ elongation.

6. $5.0 \%$ chromium and $0.25 \%$ carbon (intended), also $0.01 \%$ tungsten, $0.063 \%$ nitrogen. $171,000 \mathrm{psi}$ tensile strength, $2 \%$ elongation, hardness Rockwell C 41.

In these tests, the beneficial effects on physical properties of carbon, oxygen, nitrogen, molybdenum, tungsten and chromium were confirmed. Much more work is needed to thoroughly investigate alloys of titanium with these and other interesting additions.

Additional work is now in progress for Wright-Patterson Air Force Base on determining the effect of alloying additions to titanium of chromium, molybdenum, nickel, copper, lead, magnesium, silicon, manganese, vanadium, iron and cobalt. Hemispherical $\frac{1}{2}$-pound ingots two inches in diameter are being made by arc melting of titanium powder. The ingots are being forged and rolled to 0.064 -inch sheet. Physical properties to be evaluated are tensile strengths and hardness, and cold bending characteristics. Response to heat treatment will also be investigated.

Only limited data are available on the properties of titanium at elevated temperatures. On a rough qualitative fashion, arc-melted and hot-forged titanium shows strengths about 400 degrees Fahrenheit better than the best aluminum- and magnesiumbase alloys. That is, the short-time tensile properties for titanium at 800 degrees Fahrenheit are similar to those of the aluminum alloys at 400 degrees Fahrenheit.

The creep strength for titanium at 1000 degrees Fahrenheit is similar to that for the best aluminum-base alloy at 600 degrees Fahrenheit. Titanium appears useful for service up to 1000 degrees Fahrenheit, with its most likely use for temperatures in the range 400 to 800 degrees Fahrenheit. At the lower temperatures of 300 to $\mathbf{4 0 0}$ degrees Fahrenheit, titanium will serve at stresses many times those possible with magnesium- and aluminum-base alloys, while in the upper temperature ranges, titanium will serve satisfactorily at temperatures considerably in excess of those possible with magnesium- and aluminum-base alloys, since these are consider ed to have no useful engineering load-carrying ability in excess of 600 degrees Fahrenheit.

Acknowledgment for support and permission to publish this paper is hereby extended to the U. S. Air Force and the RAND Corporation.

\section{DISCUSSION}

Mr. Cross added that, if degassed titanium powder or sponge is used, then no splashing occurs and contamination by the tungsten-tipped electrode is eliminated. A titanium tip does not stand up in the arc. 
Paper 14

$\sigma$

\title{
SOME ASPECTS OF THE METALLURGY OF TITANIUM ALLOYS
}

\author{
By. P. H. Brace \\ Westinghouse Research Laboratories
}

Most readers of this will no doubt be aware of the spectacular rise of interest in the metals titanium and zirconium that has followed the remarkable and extremely valuable results of the development work, done under the sponsorship of the U. S. Bureau of Mines, that has gone so far toward making those metals available in quantity in a relatively pure state and as articles of commerce. The writer wishes here to pay tribute to the pioneering efforts of Kroll and to the skillful and fruitful work that he and his collegaues have done in recent years in association with the Bureau of Mines and under the able guidance of $\mathbf{O}$. C. Ralston, Chief, Metallurgical Division. It seems to me that the advent of titanium as a commercial structural material may have revolutionary effects upon design, engineering and performance particularly in the fields of aeronautics and of rotating and reciprocating machinery, especially where high operating temperatures must be endured.

For several years past the writer has been keenly interested in the development of titanium alloys for structural purposes and the present writing is an attempt to summarize what appear to be the more intriguing results of investigations that have been carried out at Westinghouse Research Laboratories, partly on our own initiative and partly under Government sponsorship, with particular reference to alloys suitable for use at elevated temperatures. Because we were interested in high-temperature capabilities we have been more concerned with titanium alloys than with the metal itself because, as is now generally recognized, the high-temperature strength is disappointingly low, although the ductility is spectacular. Also the high-temperature oxidation characteristics of the pure metal are not particularly favorable.

When an alloy program involving temperatures as high as 1800 degrees Centigrade is undertaken it can be expected that refractories problems will be quite serious. In the case of titanium those problems have been very obtrusive indeed.

Preliminary experiments quickly showed that ordinary silicate-bonded bodies were quite out of the question. In the hope that some one of the pure oxides, $\mathrm{Al}_{2} \mathrm{O}_{3}$, $\mathrm{BeO}, \mathrm{ThO}_{2}$ might prove serviceable, experiments were made in the course of which small blocks of substantially pure titanium were melted in vacuo while in contact with compacted and sintered test-pieces of the respective oxides. It was found that molten titanium would react exothermically with $\mathrm{Al}_{2} \mathrm{O}_{3}$ to produce a brittle alloy that bore no resemblance to either of the metals concerned. In the case of $\mathrm{BeO}$ the reaction was less vigorous and the resultant alloy, although less fragile than that resulting from the reaction of $\mathrm{Ti}$ and $\mathrm{Al}_{2} \mathrm{O}_{3}$, was nevertheless quite a different substance than pure titanium. With thorium oxide the reaction was relatively slight and the properties of the test block after melting were enough like the original material to encourage the thought of using thoria crucibles for preparing a series of titanium alloys.

Our first successful crucibles were made by plastering the inner surfaces of cylindrical molybdenum capsules with a paste made from ground, electrically-fused thorium oxide plasticised with an acid-treated slip made by wet-grinding fused thorium oxide in a porcelain ball mill. After air-drying and baking at approximately 300 degrees Centigrade, firing was.accomplished by inductively heating the molybdenum 
capsule in vacuo at approximately 2000 degrees Centigrade for a few hours. Such crucibles were used for vacuum melting a number of high-titanium alloys and were fairly satisfactory provided the temperatures of the melts were kept within reason. Later thoria crucibles were obtained from commercial sources. Some bodies resisted attack fairly well, while others behaved toward the titanium alloy melts as a blotter to ink. Although we have succeeded in preparing approximately 50 titanium alloys in thoria crucibles it cannot be said that the refractories problem is solved, only that the best of the crucibles were fairly satisfactory while the worst were quite hopeless. It appears that the best results are to be expected from a dense body of high-purity thorium oxide fired at quite high temperatures, say 2000 degrees Centigrade.

In the light of the work of Kroll some attempts were made to use graphite crucibles. Under our conditions the results were so unsatisfactory that we based our work on thoria crucibles.

The melting program comprised two phases. In the first a number of exploratory alloys were prepared by melting weighed charges in vacuo and simply allowing them to freeze in the crucible. From hot-hardness and oxidation tests, inferences were drawn as to the potentialities of the various nominal compositions with respect to serviceability at temperatures in the neighborhood of 900 degrees Centigrade in air.

\section{Casting of Titanium-Base Alloys}

In order to obtain some more accurately quantitative information concerning the high-temperature tensile characteristics of a variety of titanium-base alloys the second phase of the program was undertaken and during the past few months a considerable number of tensile specimens were cast from titanium alloys by means of novel vacuum and controlled-atmosphere induction-melting and casting system. The general arrangement of the system is shown by Figure 1. A "clam-shell" vacuum casing, approximately 30 inches in diameter, and arranged to rotate about a horizontal axis, enclosed the inductor coil, melting assembly and mold assembly. The exhaust system comprised a four-inch multiple-stage metal oil-vapor high-vacuum pump, an oil-vapor booster pump and a two-stage Kinney mechanical fore-pump. With the vacuum casing clean and cold pressures below $10^{-5} \mathrm{~mm} \mathrm{Hg}$ as measured by a Philips Ion gauge could be obtained. During melting and casting the pressures ranged between 1 and $30 \mathrm{mi}-$ crons.

With some metals, notably chromium, considerable vaporization occurred when "vacuum" conditions were maintained, particularly after fusion had occurred. By "outgassing" for a time without melting and casting under a purified argon atmosphere at a pressure of a few millimeters of mercury the vaporization, with its attendant losses and uncertainties could largely be avoided without having enough gas in the system to cause interference with the flow of metal into the mold when casting.

Therefore an important adjunct to the melting system was a "thermo-siphon" purification system for providing a supply of high-purity argon for use as a melting atmosphere. In essence this system consisted of two vertical stainless steel tubes connected top and bottom by pipes so that the gas to be purified could circulate up through one tube (heated) and down the other under the aerostatic pressure difference between the gas in the hot tube and that in the cold. In the hot tube calcium metal, in the form of chips, supported on a series of wire-mesh trays acts as a "getter" for any reactive gases in the argon. The argon is held under a pressure of approximately $\mathbf{5 0}$ psi while the maximum temperature of the column of calcium chips is maintained in the neighborhood of 700 degrees Centigrade. 


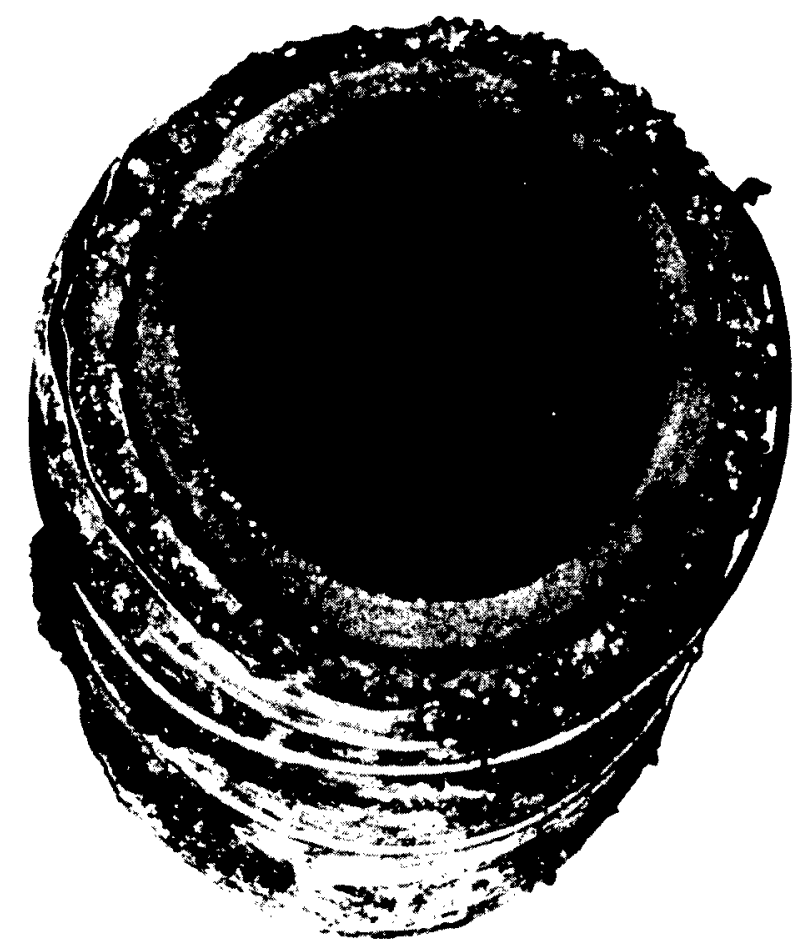

Fig. 1 Inside of Thoria Crucible (Wrapped with Mo Sheet) after 12 Melting Runs.

After a fresh charge of commercial tank argon has "soaked" overnight, it usually shows, by mass spectrograph analysis, no detectable amounts of impurity within the mass range between approximately 12 and 90 where the sensitivity is of the order of $0.005 \%$. No hydrogen (measured as mass 2) was detected but in that case it must be said that the sensitivity was approximately $0.1 \%$. By and large it appears that we were able to prepare quite good argon with very little inconvenience.

The vacuum melting routine comprised weighing and assembly in the crucible of the components of the charge, mounting the crucible and charge in a silica-tube container and mounting within the inductor coil, assembling the mold components, evacuation of the melting chamber, out-gassing of mold, preliminary heating and out-gassing of the charge, heating, fusion and adjustment of the temperature of the melt and finally casting.

The mechanical arrangements for vacuum casting are shown by Figure 2. The mold was carried on an arm that could rotate about an axis parallel to that of the melting assembly. During melting the mold stood at one side leaving a clear view of the interior of the melting chamber by way of the sight window. Preparatory to casting the furnace casing was rotated slightly and the mold under its own weight swung over the furnace and by means of a spring and latch was held with its opening over the pouring nozzle and bedded against an asbestos gasket that provided a metal-tight seal between the melting chamber and mold inlet.

Casting was then effected by a counter-rotation of the furnace through approximately 180 degrees that inverted the whole arrangement and discharged the molten metal into the mold.

The mold assembly comprised a casing that enclosed refractory thermal in- 
sulation, a heating element of Mo wire wound on an Alundum tube and within the Alundum tube granular refractory material that surrounded and supported the mold. See Figure.

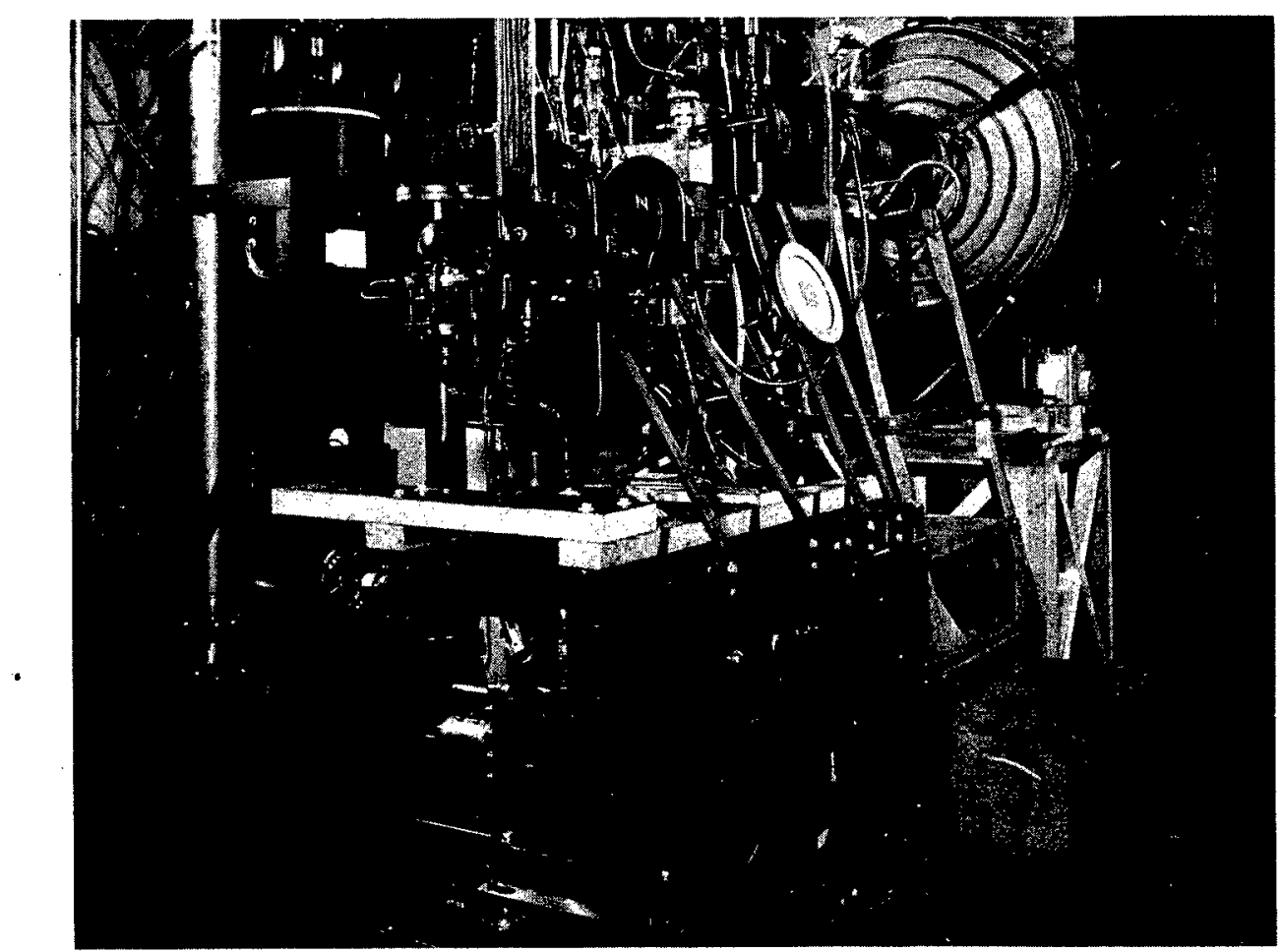

Fig. 2 Photograph Showing General Appearance of the Vacuum Casting Furnace and Cross-Country Pumping System as Seen from the Pump End. After Rehabilitation.

The mold proper comprised a "pouring cup" and either three or four mold cavities formed by machining from round bars of either graphite or refractory material such as the "soft bodied" magnesia that we obtained from The Stupakoff Company, Latrobe, Pa.

The castings thus produced were separated from the excess of metal in the pouring cup as a sink-head and prepared for test by grinding the fillets under the heads concentric with the central gauge portion by means of a three-jawed chuck and a three-part collet-like fixture that gripped the specimen at opposite extremities of the gauge length. By this means it was assured that the axis of the gauge-length was as nearly as possibly concentric with the ground surfaces which bore upon the split nuts in the grips of the tensile testing machine. Thus was obtained a satisfactory approximation to axial loading.

The majority of the tensile test data were obtained by way of the constant strain rate procedure using a screw driven machine developed at Westinghouse Research Laboratories by Messrs. Nadai and Manjoine. The strain rate chosen was $0.5 \%$ per hour and test data so obtained are set forth by Tables 1 to 4 inclusive and Figure 3 showing the values for $0.2 \%$ yield stress at 1750 degrees Fahrenheit for a group of 
Ti-Cr-W-Mo alloys, together with corresponding data for a few others, and more familiar materials. Creep-rupture test data on some of these alloys are included in Tables 5 and 6. The nominal compositions of the tension tested alloys are listed in Table 7.

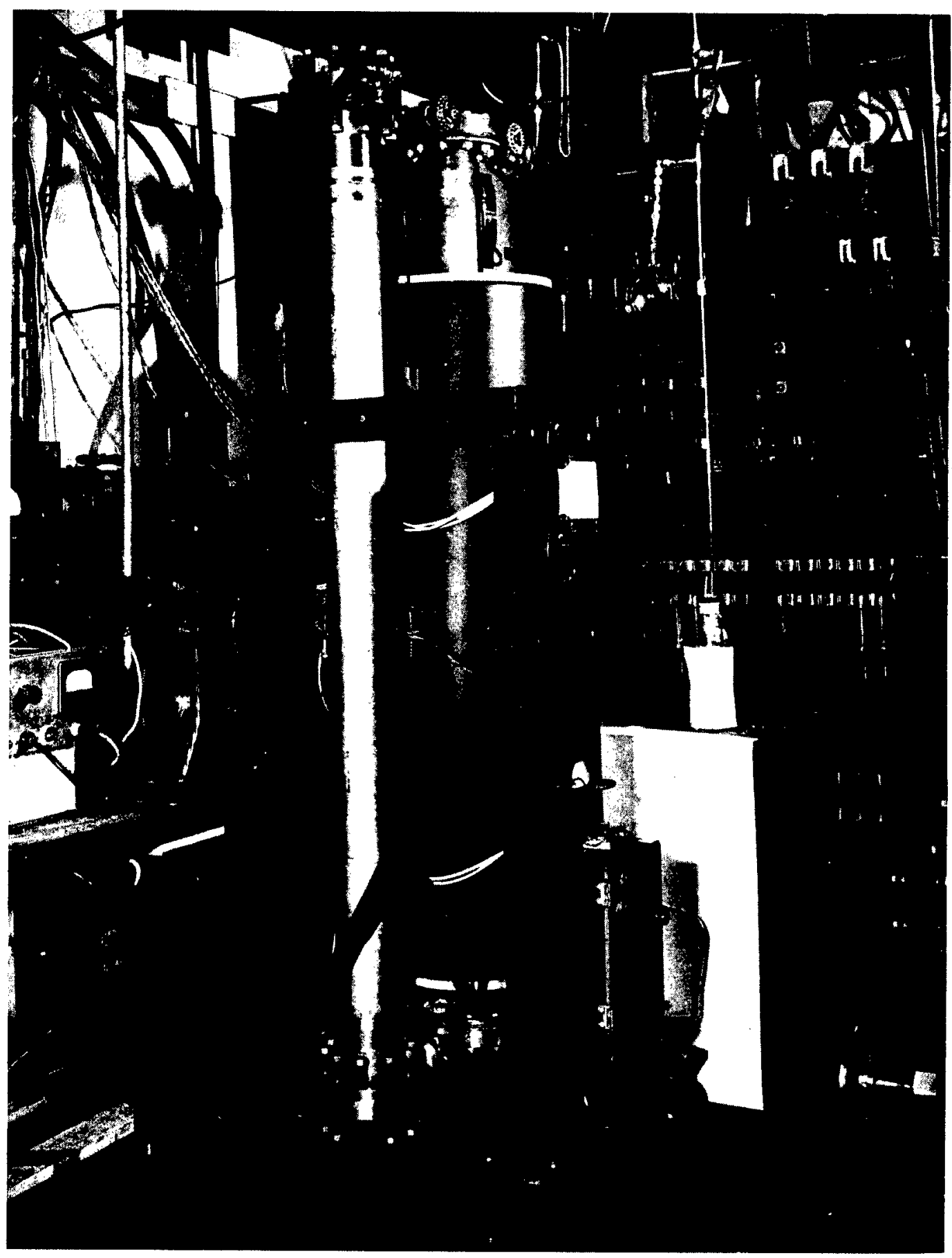

Fig. 3 Photograph Showing General Appearance of "Thermo-Siphon" Arg m Purifier with Sampling Bulb in Place. 

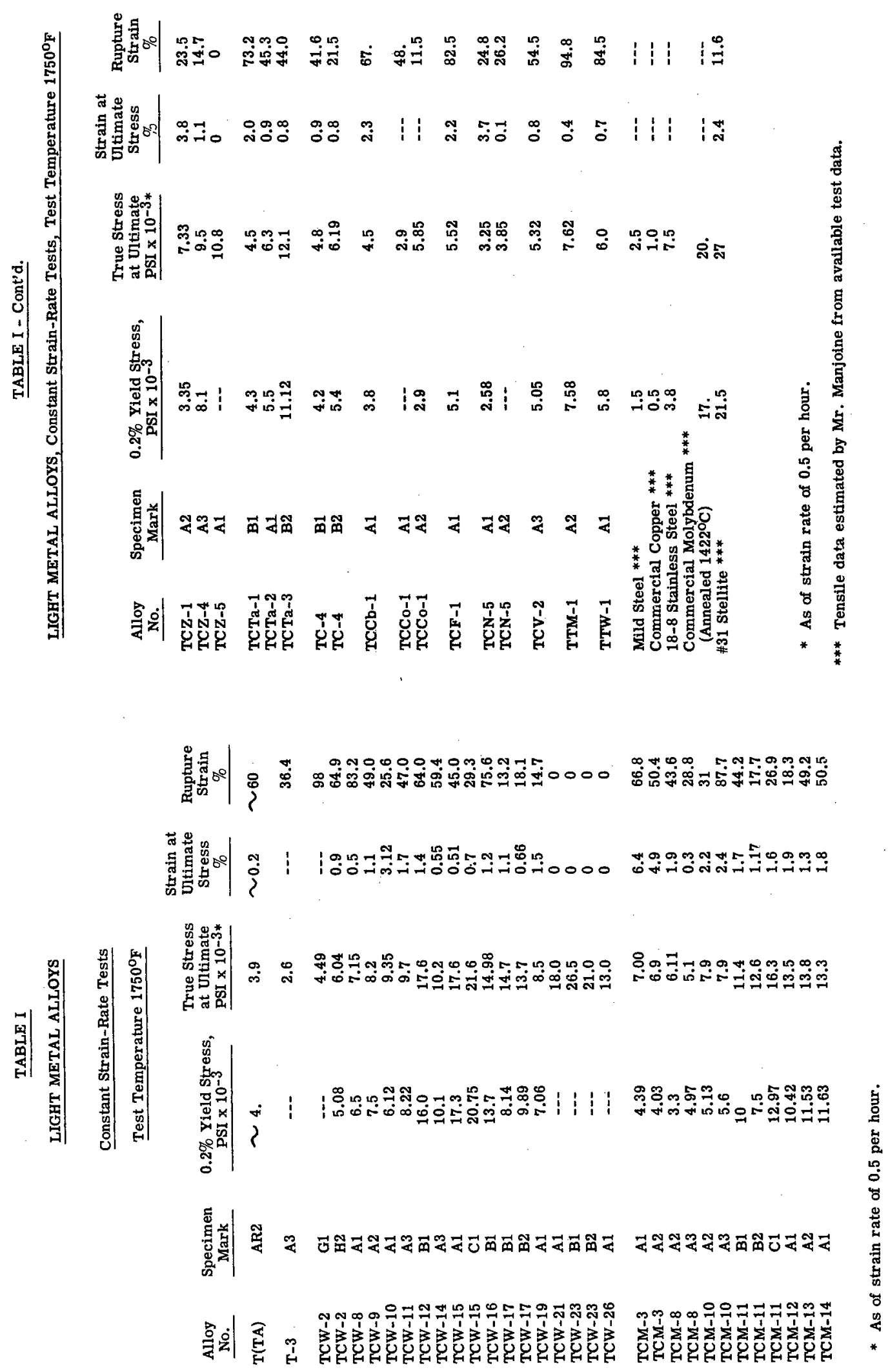


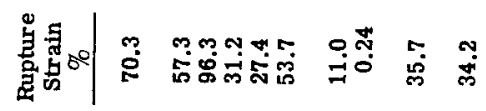

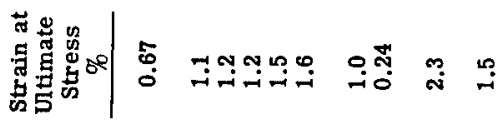

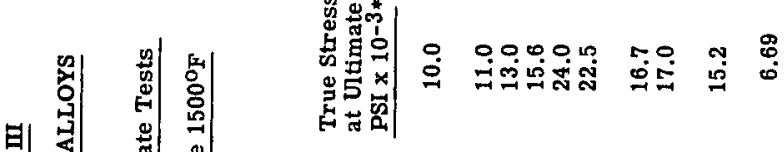

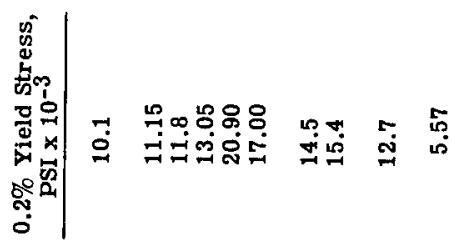

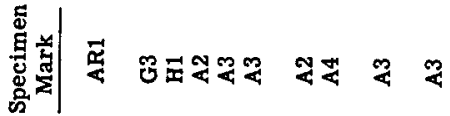

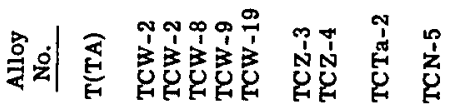

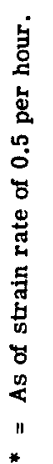

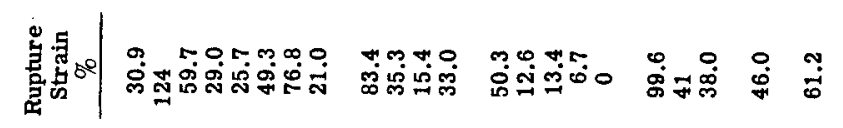
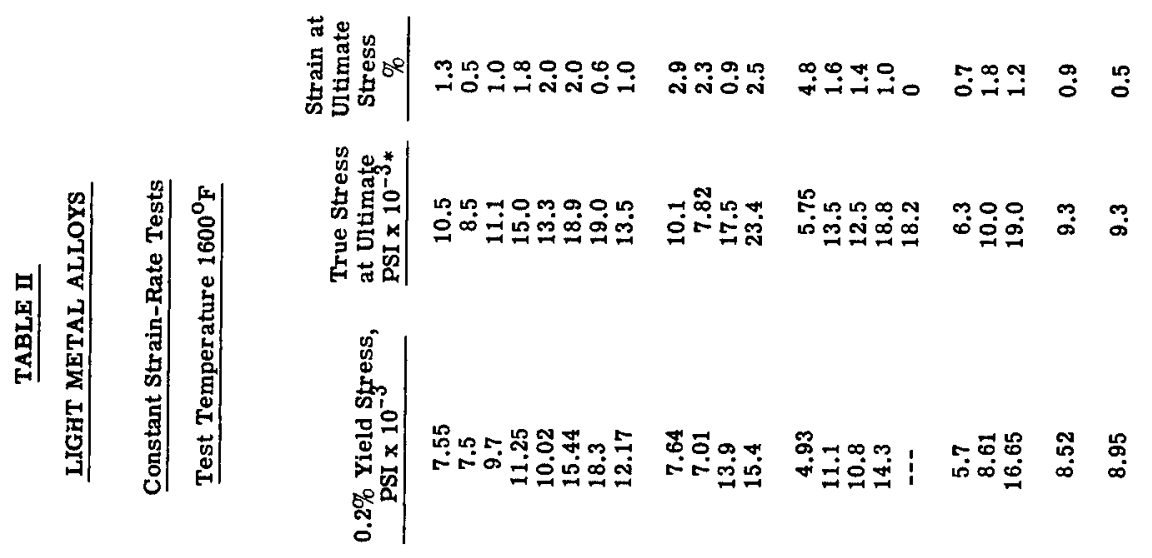

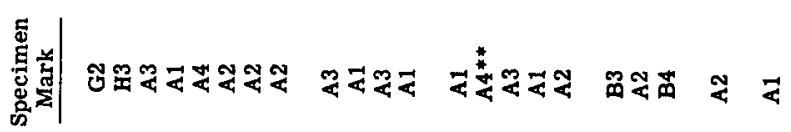

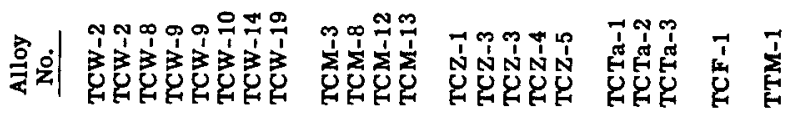

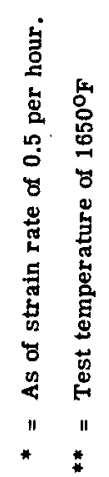



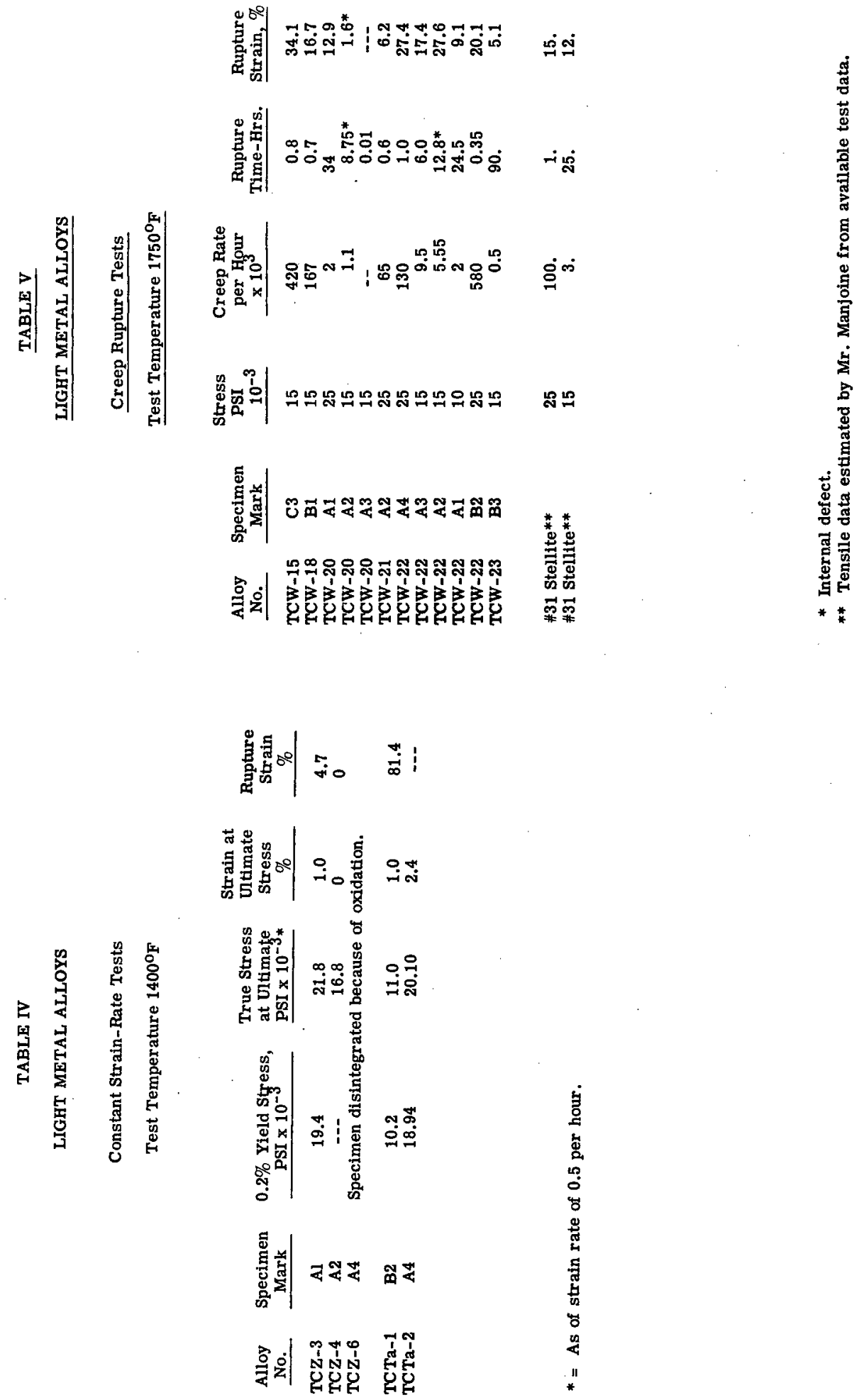


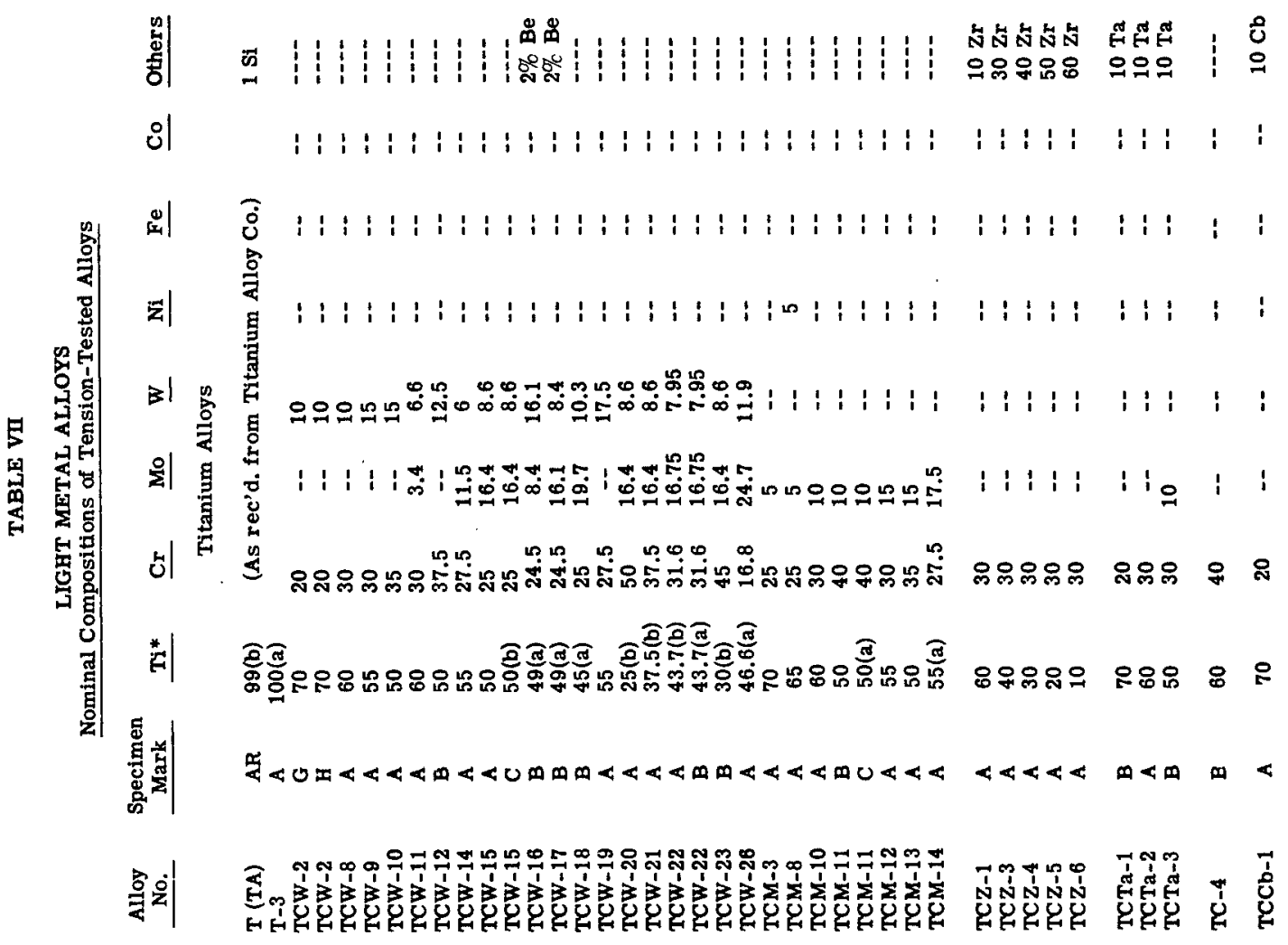

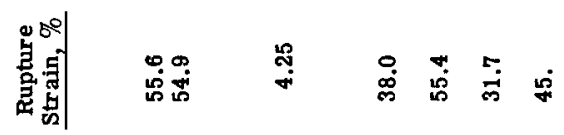

$$
\begin{aligned}
& \text { 悹离 }
\end{aligned}
$$

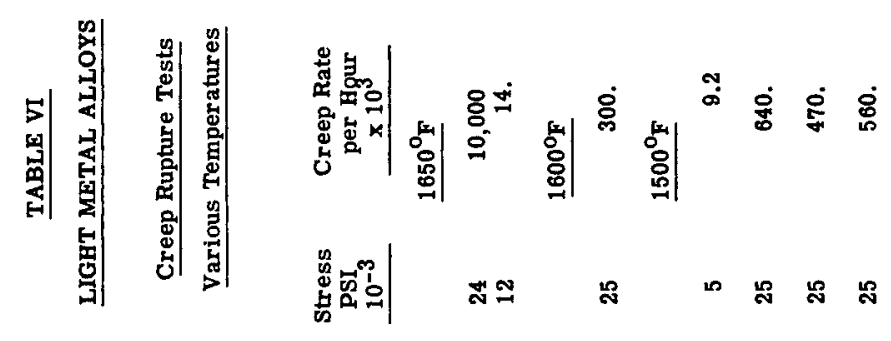

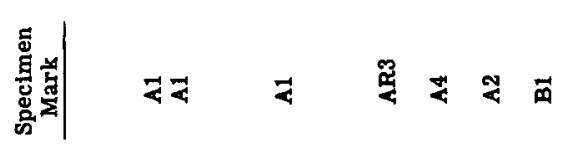

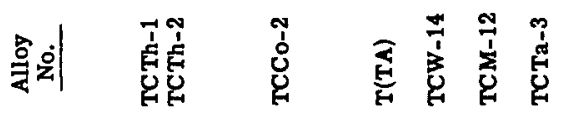


TABLE VII (Cont'd)

\begin{tabular}{|c|c|c|c|c|c|c|c|c|c|}
\hline \multirow[b]{2}{*}{$\begin{array}{l}\text { Alloy } \\
\text { No. }\end{array}$} & \multicolumn{8}{|c|}{$\begin{array}{l}\text { LIGHT METAL ALLOYS } \\
\text { Nominal Compositions of Tension-Tested Alloys }\end{array}$} & \multirow[b]{2}{*}{ Others } \\
\hline & $\begin{array}{l}\text { Specimen } \\
\text { Mark }\end{array}$ & $\underline{T i}^{*}$ & Cr & Mo & $\underline{\mathbf{w}}$ & $\underline{\mathrm{Ni}}$ & $\mathbf{F e}$ & $\mathrm{Co}$ & \\
\hline $\begin{array}{l}\text { TCCo-1 } \\
\text { TCCo-2 }\end{array}$ & A & $\begin{array}{l}60 \\
\mathbf{5 0}\end{array}$ & $\begin{array}{l}30 \\
30\end{array}$ & -- & -- & -- & $=$ & $\begin{array}{l}10 \\
20\end{array}$ & $-\cdots$ \\
\hline TCF -1 & A & 60 & 30 & - & -- & - & 10 & -- & --- \\
\hline TCN-5 & A & 65 & 30 & -- & -- & 5 & -- & -- & -.- \\
\hline TCV-2 & A & 65 & 30 & -. & -- & -- & -- & -- & $5 \mathrm{~V}$ \\
\hline $\begin{array}{l}\text { TCTh-1 } \\
\text { TCTh-2 }\end{array}$ & A & $\begin{array}{l}90(a) \\
94(a)\end{array}$ & $\begin{array}{l}9 \\
5\end{array}$ & - & -- & -- & -- & -- & $\begin{array}{l}1 \mathrm{Th} \\
1 \mathrm{Th}\end{array}$ \\
\hline TTM-1 & A & 60 & - & 10 & -- & -- & - & -- & $30 \mathrm{Ta}$ \\
\hline TTW-1 & A & 60 & -- & - & 10 & $=$ & -- & - & $30 \mathrm{Ta}$ \\
\hline
\end{tabular}

* Except as otherwise noted, Titanium Powder, Bureau of Mines.

(a) Titanium Bar - Bureau of Mines

(b) Titanium Alloy Manufacturing Company

It is interesting to compare the various alloys on the basis of weight-strength ratios and to note their favorable standing with reference to some of the more conventional high-temperature alloys. Such a comparison is set forth by Tables 1 to 6 where it will be seen that some of the complex alloys based on Ti-Cr-Mo-W show up quite favorably at high temperatures both as to yield strength and ductility at elevated temperatures. However, they suffer from the disadvantage of brittleness at room temperatures. This may in part be due to absorption of oxygen from the refractories.

Studies are under way to learn the oxygen contents of the alloys so far prepared and to decide whether or not oxygen may contribute to brittleness without cor responding enhancement of strength.

In conclusion the following points may be emphasized.

(1) Some 50 alloys based on titanium have been melted by induction and cast into tensile test specimens in a novel type of vacuum casting furnace.

(2) Thorium oxide was found the most satisfactory of the various refractories used and the only one that could be used at all under our melting routine.

(3) Molten titanium and many titanium alloys were found to wet thorium oxide and in some cases to soak through the crucible-wall "like oil through sand" and it was evident that in most, if not all, cases some oxygen and thorium entered the melts from the crucibles.

(4) Tensile test data at 1750 degrees Fahrenheit were obtained by means of a screw-driven autographic tensile test machine.

(5) At 1750 degrees Fahrenheit the best $0.2 \%$ yield strengths found were shown by $\mathrm{Ti}-\mathrm{Cr}$ bașe alloys containing molybdenum and tungsten in equi-atomic ratios. 
(6) The results to date suggest that the use of $\mathrm{W}$ and Mo together give more favorable properties than are obtained when either metal is used alone.

(7) The role of oxygen in determining the physical properties of the alloys is a subject of continued study but it is believed that oxygen is not a particularly desirable alloying element.

(8) Certain of the alloys prepared on a base of sodium-reduced titanium obtained from Titanium Alloy Manufacturing Company yielded better physical properties than corresponding alloys based on high-purity titanium obtained from U. S. Bureau of Mines. The difference is attributed to the presence of small proportions of "impurity" elements in the Titanium Alloy Manufacturing Company product, principally $\mathrm{Cu}, \mathrm{Si}$ and $\mathrm{V}$.

(9) Remarkable improvements in the oxidation resistance of substantially pure titanium resulted from melting in a thoria crucible. The titanium melting stock "as received"' showed a weight-gain of $165 \mathrm{Mg} / \mathrm{Cm}^{2}$ in 64 hours of heating in air as compared with $7.3 \mathrm{Mg} / \mathrm{Cm}^{2}$ for the remelted melted material. The indications are that the increased oxidation resistance was due to the pick-up of thorium from the thoria crucible used for melting. This question is a matter of considerable interest and is being studied further.

\section{DISC USSION}

The thoria crucibles made by the Westinghouse Research Laboratories were slipcast and fired at about 2000 degrees Centigrade. Most of the crucibles were received from the Norton Company and were fired at Cone 35; the other manufacturing details were not known. The types of carbon used for the molds were the AGU or AGW type from National Carbon Company.

In reply to Mr. Holger (Carnegie nlinois Steel Company) concerning nitrogen absorption during testing at elevated temperature, Mr. Brace stated that the general appearance of the test specimens indicated the presence of superficial films.

The specimens, however, were not analyzed for nitrogen or oxygen after testing. $\mathrm{Mr}$. Cross (Battelle Memorial Institute) added that in tests at 1000 degrees Fahrenheit the nitrogen pick-up would be superficial, since metallographic examination of specimens exposed at 1400 degrees Fahrenheit indicated a film about $0.002-0.003$ inch deep. He remarked, however, that even if a film is not detected metallographically, a measurable change in surface hardness occurs after exposure at 1400 degrees Fahrenheit, indicating a surface reaction. But, at 1000 degrees Fahrenheit, this has not been experienced. Dr. L. W. Eastwood (Battelle Memorial Institute) added that samples exposed to air at 1700 degrees Fahrenheit developed a scale about 0.004 inch thick. Mr. I. R. Kramer (Office of Naval Research) remarked that some recent work at the National Physical Laboratory in England indicated that the rate of diffusion of oxygen in titanium at 1000 degrees Fahrenheit in an oxygen atmosphere was immeasurably low. It was thought that a surface oxide formed which inhibited further diffusion. 
Mr. M. G. Fontana (Ohio State University) emphasized the importance of crucible preparation. In vacuum melting titanium-chromium alloys using beryllia crucibles, a marked reduction in beryllium pick-up was observed with denser, higher fired crucibles.

In discussing segregation in cast titanium, Mr. Brace stated that little or no segregation was observed. Dr. Eastwood added that, in general, no difficulties have been experienced as a result of non-uniformity in the arc-melted ingots. For the addition to titanium of the refractory metals, however, particularly tungsten, special care must be taken to promote complete diffusion and reasonable uniformity. 
$\sqrt{1}$

\title{
THE TITANIUM-BASE ALLOYS PROGRAM OF THE NAVAL RESEARCH LABORATORY
}

\author{
By_E. J. Chapin \\ Metallurgy Division, Naval Research Laboratory
}

The program of research and development of high strength titanium base alloys being conducted by the Metallurgy Division of the Naval Research Laboratory includes the following phases:

(1). An investigation to disc'over satisfactory materials and procedures for melting and casting titanium and its alloys by induction and electric arc methods.

(2). An investigation to determine the relation between titanium and oxygen under equilibrium conditions and to construct a titanium-oxygen equilibrium diagram.

(3). An investigation of methods of fabrication and physical, mechanical and chemical properties of various titanium alloys prepared by melting and casting techniques.

(4). To construct equilibrium diagrams of those titanium alloys that appear to warrant extensive consideration.

\section{Discussion of the aims:}

Problems involved in evaluating titanium and its alloys for possible engineering applications include not only development of such alloys that may have the most attractive mechanical and physical properties but also careful consideration of methods by which such alloys can be prepared and fabricated. The manner in which the metal is prepared generally determines the properties it will exhibit in a finished state. Any large scale applications of titanium and its alloys will depend upon their availability in a form commensurate with the needs and at a reasonable cost. The preparation of large metal shapes by powder metallurgy methods has serious size limitations. It is more desirable from several standpoints to cast the metal and then fabricate it by forging and rolling methods. Ther efore, a part of the current effort at the Naval Research Laboratory is directed toward discovering and developing satisfactory refractory crucible materials that will not react with molten titanium. This problem is not an easy one, since the high degree of reactivity of molten titanium restricts seriously the choice of materials that can be considered to only those which display great stability at high temperatures. Other factors, such as purity, density and surface imperviousness, are also very important considerations in such a refractory material.

The ready absorption of gases by titanium at elevated temperatures and the reactivity of the molten metal with most materials pose difficult melting problems and it is necessary to employ high-vacuum techniques or purified inert atmospheres to prevent ready contamination of the metal with gaseous impurities. In the research work being done on titanium at the Naval Research Laboratory, particular attention is being given to preventing, as far as possible, accidental contamination of the metal with oxygen or nitrogen. These gases are believed to form solid solutions and to exert 
potent effects on properties in extremely small amounts, resulting in increased hardness and loss of workability. Since it is very difficult to produce ductile titanium metal commercially without the introduction of small amounts of oxygen, the relationship between this gas content and hardness, workability and mechanical properties is of considerable practical importance. A proper evaluation of other alloy systems with titanium can only be made after the effects of small amounts of oxygen on the properties are known.

\section{Progress:}

High-vacuum induction melting apparatus has been assembled and is in use. This is capable of producing melts up to about three pounds with vacuums in the 10-6 $\mathrm{mm}$. mercury range while hot. Melting experiments are being conducted on selected refractory materials to determine their value as crucibles for containing molten titanium. Pure materials are being given prior consideration in order to take advantage of their maximum refractory characteristics and to study their resistance to molten titanium. The prime objective is to discover a satisfactory refractory that will not react with the metal and embrittle it. Such materials as spectroscopic graphite, pure carbon, beryllia, thoria, stable carbides and borides are being studied. No entirely satisfactory crucible material has yet been found.

An arc furnace using either a high vacuum or an inert atmosphere has

been built.

For the purpose of sintering compacted powdered metal alloys prior to melting them, high-vacuum sintering apparatus has been assembled. This apparatus is capable of handling samples up to one inch in diameter and 12 inches in length at temperatures up to 1000 degrees Centigrade in vacuums down to $10^{-6} \mathrm{~mm}$. mercury.

Analytical apparatus for the determination of oxygen in titanium and its alloys by the vacuum fusion method has been built and the method is being investigated. Analytical standards based on pure titanium prepared by the iodide process are to be established.

Facilities have been assembled for refining commercial metal by the iodide process to provide very high purity titanium metal for the titanium-oxygen study.

\section{DESCRIPTION OF HIGH-VACUUM EQUIPMENT FOR MELTING TITANIUM BY INDUCTION}

In connection with the study of melting titanium by induction and the rigid requirements imposed on apparatus to avoid contaminating the metal during melting with incidental gaseous impurities, it is believed that the description of the apparatus used might be useful to others engaged in similar work.

The apparatus has the following desirable features:

a.) A high pumping speed.

b.) A high ultimate vacuum.

c.) Rapid attainment of high temperature.

d.) A minimum amount of insulation to facilitate degassing and

cooling.

e.) A rugged construction and simple operation.

In high temperature fusion work where there are appreciable quantities of material to be heated, a large amount of gas is evolved during heating. Thus a crucible $1 \frac{1}{2}$ inches outside diameter by $3 / 16$ inch wall by four inches tall made of such

833626 O $-49-11$ 
materials as beryllia, zirconia or graphite will give off several thousand liters of gas measured at one micron of mercury pressure upon being heated to 1000 degrees Centigrade. The initial rate of gas evolution falls off rapidly with time; however, it is absolutely essential to have a high pumping speed in the region of the heated metal if there is any possible reaction between the evolved gases and the metal. Since titanium is a gas-sensitive metal at elevated temperatures, it is quite important that any gas evolved be rapidly removed from the vicinity of the heated metal.

The precaution and techniques for the attainment and maintenance of a high vacuum are so many and so varied that only a summation can be offered here. Sound engineering, cleanliness, ruggedness, good materials and tightness are all very essential, and high vacuum should be attainable without the use of waxes, greases, lacquers, soft solders, etc. Careful attention was paid to the design of the pumping system and the melting furnace so that the conductance of the line joining the diffusion pump and the melting chamber was such that the speed of the diffusion pump was not materially throttled by the line.

The use of cold traps was considered necessary to prevent the migration of oil vapor from the diffusion pump to the melting chamber on the one hand and from the diffusion pump to the mechanical pump and vice versa on the other hand. Refrigerated traps are essential in attaining pressures at rapid rates below 0.01 micron, and without them the low pressures are attained only with difficulty and excessively long pumping periods.

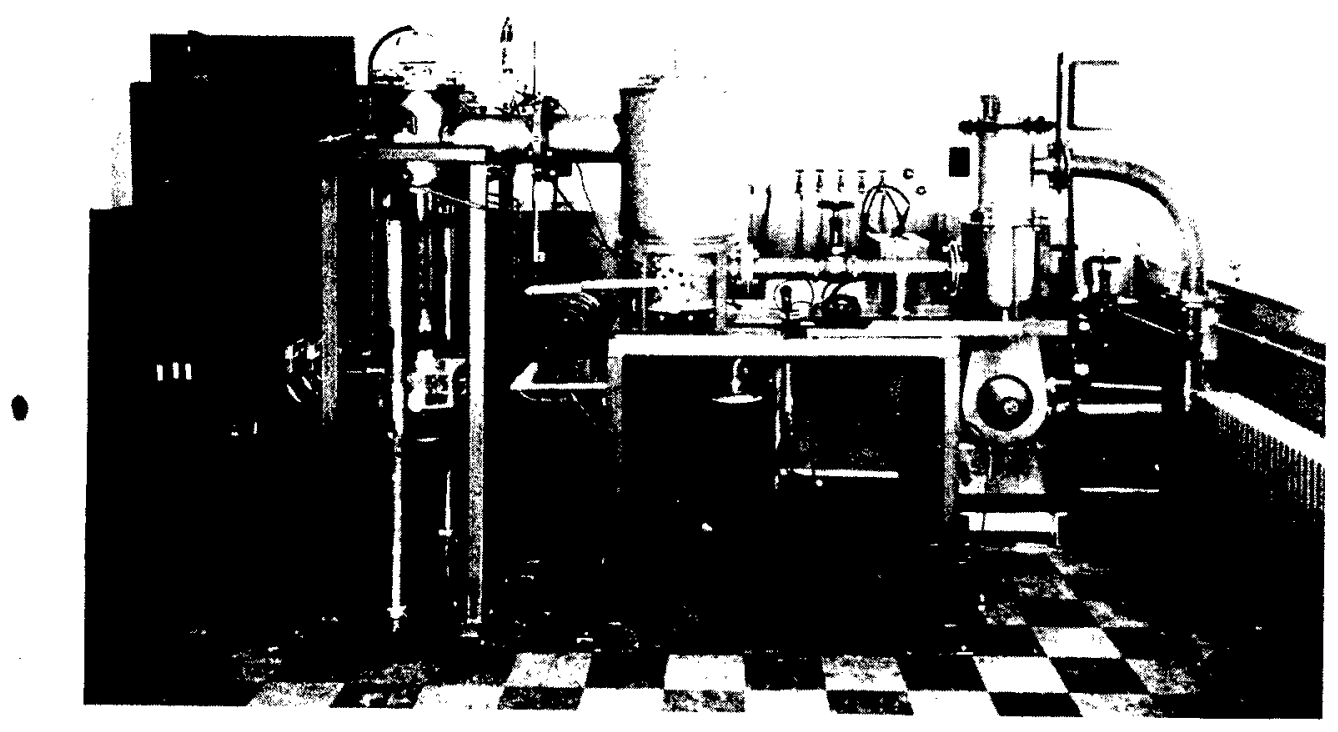

Figure 1 is a photograph of the apparatus comprising the pumping system and the high vacuum melting furnace. The entire system is of metal construction 
with the exception of the furnace body which is of "Vycor" glass. The roughing lines are constructed of copper tubes two inches inside diameter with bronze packless vacuum valves for cutoffs. The cold traps and all parts on the high-vacuum side are made from stainless steel. Heliarc welding was used in attaching flanges and in the fabrication of all stainless parts.

The pumping system consists of a National Research Corp. H-6 type 104 oil diffusion pump with a capacity of 590 liters per second measured at 0.1 micron using Octoil-S as a pump fluid. This unit is backed by a Stokes model 149-F Microvac Mechanical pump with a capacity of 60 cubic feet of free air per minute. One cold trap, refrigerated with dry ice and acetone, is located in the roughing line between the diffusion pump and mechanical pump to prevent back-streaming of oil vapors in either direction. The second cold trap is refrigerated partly by dry ice and acetone and partly with liquid nitrogen and is placed directly above the diffusion pump and mounted on top of a six-inch butterfly high-vacuum valve. This trap is joined to the watercooled furnace head from which the "Vycor" furnace tube is suspended. Soft copper gaskets are used to seal the flanges on the cold traps, and special butyl rubber gaskets having low vapor pressure characteristics are used to seal all other joints. All flanged joints are made up with a torque wrench so that flange pressures against the gaskets are equally distributed over the entire gasket area.

Pressures from 1000 microns down to one micron are measured with a National Research Corp. type 501 thermocouples gauge, while below one micron and down to 0.001 micron an ion gauge type 507 is used. Roughing pressures are maintained between five and 10 microns except when outgassing becomes appreciable during heating, when the forepressure rises to a maximum of about 30 microns. A pressure of 0.01 micron is attained in about 15 minutes after the diffusion pump has reached operating temperature on a cold system, and a pressure of 0.001 micron in about another $1 \frac{1}{2}$ hours of pumping. The cold traps are not charged with refrigerant until the pressure has been reduced to 0.01 micron. The pumping system as well as the furnace assembly is kept under vacuum during periods of idleness.

The furnace consists of a water-cooled furnace head and a round bottom "Vycor" tube. The head is so designed that tubes of from three inches to $5 \frac{1}{2}$ inches in diameter can be used interchangeably depending on the size of the melt desired. The "Vycor" tube is attached and sealed to the furnace head with a butyl rubber gasket of special design. The crucible containing the metal charge with all the necessary insulation or radiation shields is contained in a beryllia crucible, $2 \frac{1}{2}$ inches outside diameter by eight inches tall by $1 / 8$ inch wall. The $\mathrm{BeO}$ crucible is suspended from the furnace head on a stirrup made up of a molybdenum disc and 0.050 inch diameter molybdenum wire. The assembly hangs freely inside the "Vycor" tube.

A "Lepel" $20 \mathrm{KW}$. output high-frequency spark gap converter, supplying current at frequencies from $125 \mathrm{kc}$. per second to $450 \mathrm{kc}$. per second, is used to energize the load coils for heating the charge. The load coil and the flexible leads are mounted on an adjustable elevating device.

Temperature measurements are made with a "Pyro" optical pyrometer by sighting at a 45 -degree total reflecting prism placed over a "Pyrex" window sealed in the center of the furnace head top.

The apparatus described above has been found to be very satisfactory in performance. Temperatures up to 2400 degrees Centigrade have been attained with vacuums in the 0.001 micron range while hot. An ultimate vacuum of 0.001 micron is regularly obtained. The titanium melts obtained have all appeared bright and clean looking. 


\section{EQUIPMENT FOR THE REFINING OF COMMERCIAL TITANIUM BY THE IODIDE PROCESS}

The refining of commercial titanium by thermal decomposition of the tetra-iodide requires as a preliminary step a thorough removal of contaminating elements from the thermal decomposition cell, particularly water vapor, carbon dioxide, oxygen and nitrogen. To accomplish this satisfactorily, the cell and the auxiliary parts must be baked out under high vacuum at a temperature sufficiently high to release the adsorbed gases within the system. A vacuum pumping system is required that will remove these gases effectively, and that will attain a very low ultimate pressure, so that the residual gas content is a decided minimum. While the use of cold traps is generally found necessary to attain very low pressure, it is sometimes not convenient to use refrigerated traps to maintain a system at low pressure for several days in apparatus which cannot be conveniently sealed off from the pumps. In the system to be described, activated charcoal was substituted for the refrigerated traps for the attainment of low pressure and for protecting the cell and its contents against back-streaming oil molecules. Like a refrigerated trap, a charcoal trap acts like a vacuum pump and removes condensible gases such as carbon dioxide, water vapor and others that may be liberated from the cell during the bakeout.

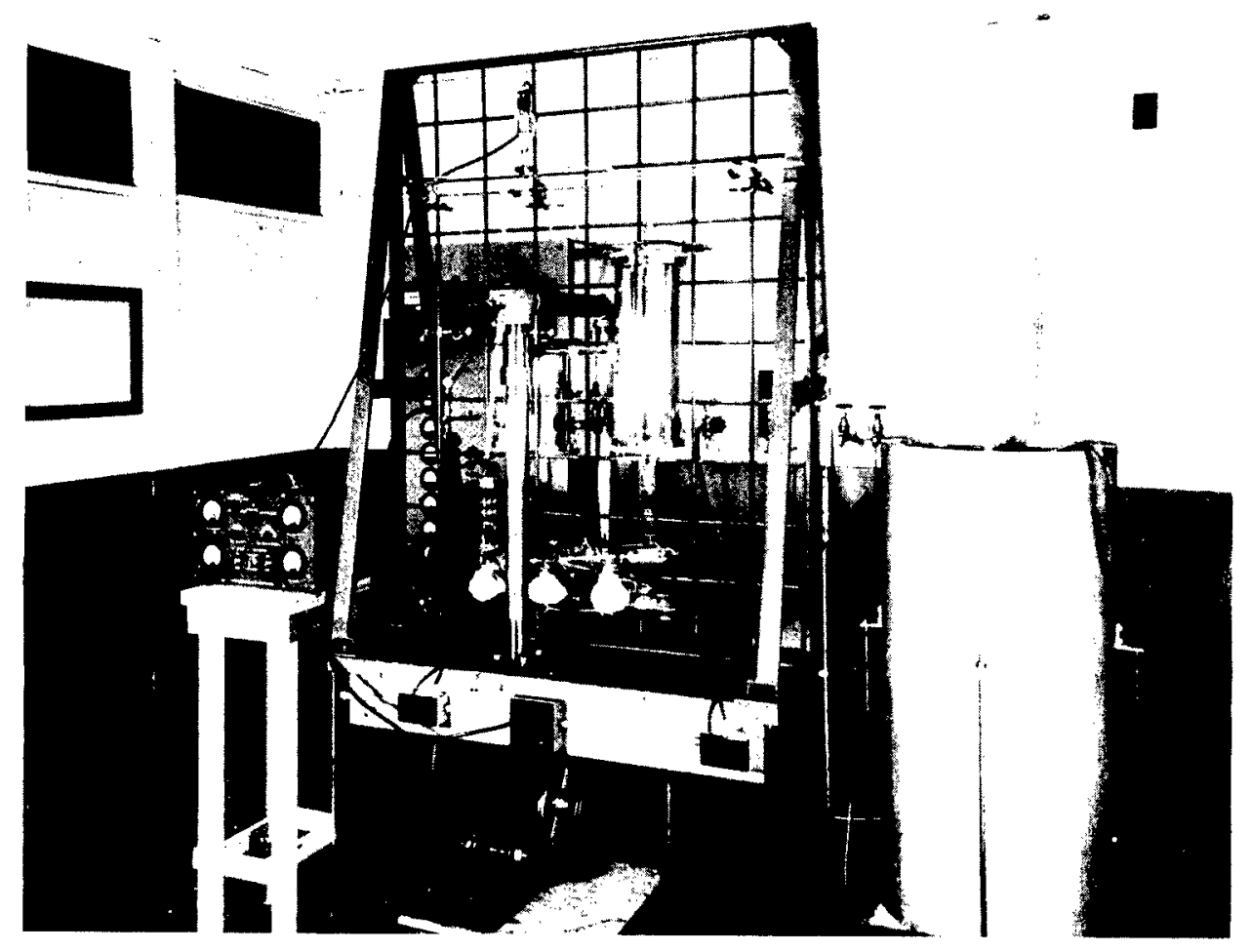

Figure 2 illustrates the apparatus comprising the vacuum system and the furnace containing the thermal decomposition cell.

The vacuum system is of glass construction and consists of a threestage fractionating oil diffusion pump having a speed of 25 liters per second measured at 0.1 micron. This is backed by a mechanical pump with a capacity of 58 liters per minute. One charcoal trap is connected to the high-vacuum side of the diffusion pump 
and consists of a glass tube $54 \mathrm{~mm}$. outside diameter by $508 \mathrm{~mm}$., long-necked down at both ends to $35 \mathrm{~mm}$. outside diameter. Activated charcoal is contained in three nickel mesh cylinders, two of which are hollow. The hollow cylinders measure $50 \mathrm{~mm}$. outside diameter by $30 \mathrm{~mm}$. inside diameter by $152 \mathrm{~mm}$. long. The completely enclosed cylinder measures $36 \mathrm{~mm}$. outside diameter by $120 \mathrm{~mm}$. long. The three cylinders are arranged so that the completely enclosed one is in between the two hollow ones, all being spaced the correct distance apart by nickel wire spiders. With this arrangement it is virtually impossible for an oil molecule to pass through the trap without striking the charcoal at least once. Little resistance is offered to the passage of permanent gases which are not appreciably absorbed by the charcoal. A second trap, which is a re-entrant type, is placed in the for eline; its charcoal container measures $50 \mathrm{~mm}$. outside diameter by $24 \mathrm{~mm}$. inside diameter by $203 \mathrm{~mm}$. long.

Split circular resistance wound furnaces facilitate heating the traps. This keeps the charcoal clean and enhances its absorptive powers. These furnaces can be opened and withdrawn from around the traps when desired.

The thermal decomposition cell consists of a pyrex glass bulb $6 \frac{1}{2}$ inches outside diameter and 24 inches long with a round bottom. The opposite end is necked down to approximately three inches in outside diameter. Four 1/4-inch tungsten electrodes are sealed into the top of this necked part. Many loops of 10-mil tungsten wire are fastened to the ends of the electrodes within the cell to facilitate attachment of the titanium starter wire.

A double-walled cylinder 16 inches tall of 10-mil molybajenum sheet perforated on the inside wall provides the container for the commercial titanium metal to be refined.

The cell is contained in a nichrome-wound furnace which is used to heat it during outgassing and also serves as an operating furnace.

Power for operating the trap furnaces, the oil diffusion pump, the nichrome-wound furnace and the filament is controlled through a panel board.

\section{HIGH-VACUUM ANNEALING EQUIPMENT}

Figure 3 illustrates the apparatus showing the vacuum pumping system, the porcelain tube furnaces and the control panel.

The vacuum pumping system consists of a six-inch National Research Corp. oil diffusion pump H-6 type 104 with a capacity of 590 liters per second measured at 0.1 micron using Octoil-S as a pump fluid. The backing pump is a Stokes model 149-F Micro-vac with a capacity of 60 cubic feet per minute. One cold trap using dry ice and acetone is located in the foreline, and the other cold trap, on the highvacuum side, using both dry ice and acetone and liquid nitrogen in separate compartments, is located over the diffusion pump and bolted to a six-inch butterfly high-vacuum valve. Independent roughing lines are provided for each tube so that it is not necessary to rough down through the diffusion pump. The high-vacuum connection to the individual porcelain tubes is obtained through three-inch lines leading from the cold trap. Cutoff valves allow operation of the two porcelain tubes simultaneously or separately as desired. Pressures down to 0.001 micron have been attained.

The tube furnaces are heated with Globars and are pyrometer controlled. 


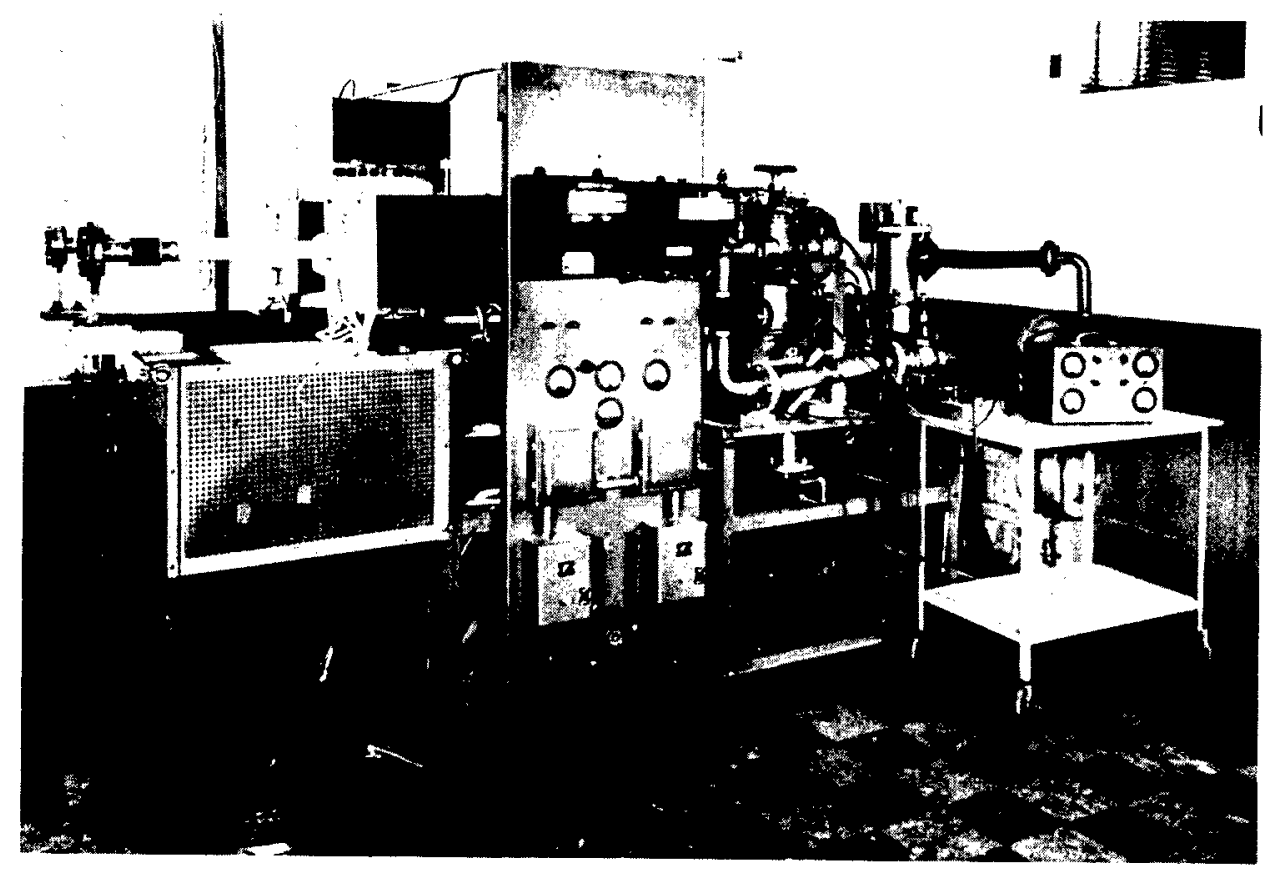

Fig. 3

The porcelain tubes are McDanel high-temperature type and are gastight up to 1000 degrees Centigrade. The tubes are $13 / 4$ inches inside diameter and five feet long with 16 inches of the mid-section in the heated zone of the furnace. Sylphon bellows are used on each end to allow for expansion and to facilitate making a vacuum connection from ceramic to metal.

\section{DISCUSSION}

Mr. P. H. Brace (Westinghouse Research Laboratories) remarked that the sight tubes in the Westinghouse furnace would cloud up in a few seconds, as a result of metal-vapor condensation, unless a little argon was introduced into the system. Mr. Chapin replied that fogging of the sight windows was not encountered in the Naval Research Laboratory apparatus, probably because of the presence of a water-cooled system in the furnace which may shock-cool any vapors. In addition, their sight windows are about two feet above the melt, whereas in the Westinghouse apparatus the distance is about one foot.

In discussing their crucible experiences, $\mathrm{Mr}$. Chapin stated that the penetration of the melt into the crucible, as well as the effect on the metal itself, had been under study. In the case of carbon, the results have been puzzling, in that penetration occurred in certain dense grades of carbon where it was least expected. Apparently, impurities in the carbon concentrate in regions which are susceptible to severe preferential attack by the molten metal. Translucent beryllia crucibles are currently being used. 
The Naval Research Laboratory arc furnace was designed so as to be used for vacuum or atmosphere operations or a combination of both. It can be evacuated down to 10-6 mm. pressure when cold. The anode is water-cooled and the cathode consists of a tungsten tip attached to a water-cooled tube. The charge is heated in a crucible and bottom-tapped into a copper mold in the same chamber without opening the chamber or exposure to outside environments. Bureau of Mines titanium, both in the powder and sintered form, has thus far been melted. The materials are outgassed prior to melting, giving a blank pressure of at least $10^{-6} \mathrm{~mm}$. The temperature is increased carefully and the pressure during melting never exceeds $5 \times 10-6 \mathrm{~mm}$. 


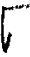 \\ THE CARBON-OXYGEN RELATIONSHIP IN TITANIUM MELTED IN CARBON REFRACTORIES}

By S. F, Urban and A. C. Haskell

Titanium Alloy Manufacturing Division, National Lead Company

Editor's Note: The paper originally scheduled as Paper 16, by S. F. Urban and A. C. Haskell, on the carbon-oxygen relationship in titanium melted in carbon refractories, was not presented at the Symposium. Because of circumstances beyond the control of the research men who were to present the paper, necessary replacement parts for their vacuum fusion apparatus could not be obtained, and ther efore the data needed for the preparation of the paper were not available at the time of the Symposium.

At the time this report went to press, Dr. Urban and Dr. Haskell were still unable to obtain their data, but were planning to submit a paper to the Office of Naval Research at a later date. Reprints of the paper will be made available by this Office to those interested. 


\title{
FIRST PROGRESS REPORT ON TITANIUM-CARBON AND TITANIUM-NITROGEN PHASE DIAGRAMS
}

\author{
By I. P. Nielsen. \\ College of Engineering, New York University
}

The objectives of this investigation are to construct the phase diagrams for the titanium-carbon and titanium-nitrogen systems. The phase diagrams are to be constructed from experimental data and will be confined only to the regions considered of practical interest for structural material, namely, from pure titanium to the compounds $\mathrm{TiC}$, and $\mathrm{TiN}$, respectively, and from the liquidus to about room temperature, the pressure being atmospheric. Before starting the actual experimental program, preliminary phase diagrams were constructed from theoretical considerations and from information found in the literature. The actual experimental work has not been started as yet, but the general program and some of the techniques have been planned, and some of the necessary equipment is now under construction.

I. Preliminary Phase Diagrams

A. Titanium-Nitrogen System

The phase diagram characteristics justified by experimental data found in the literature, and by analogies with related phase diagrams, are listed in Table I. The second column gives the references for the information, while the fourth column gives some explanatory remarks. Some of the data are not precise enough to fully justify the indicated characteristics, and hence the probability for their existence is less than one. The probabilities were arbitrarily estimated for such cases and are indicated in column 3. Analogies with related alloy systems yielded various features that we might look for in the titanium-nitrogen system. For example, $\mathrm{M}_{2} \mathrm{X}$ and Mi4X type of compounds, where $M$ is a transition metal, and $X$ an interstitially dissolving element, occur in such systems with some measure of regularity, and hence might also be present in the Ti-N system. Items 7,8 and 9 of Table $I$ are the features which are suggested by these analogies, but they are given only partial weight in the "estimated probability" column.

These phase diagram characteristics are incorporated in the diagram shown in Figure I. The real diagram may not be so complex as this preliminary one, since some of the features, such as the existence of the $\mathrm{T}_{4} \mathrm{~N}$ phase, have a rather low probability. The interesting age-hardening feature of the alpha solid solution region is optimistically drawn, as the evidence for low solubility of nitrogen in alpha at room temperature has no well established basis.

B. Titanium-Carbon System

Table II gives the list of characteristics for the titanium-carbon phase diagram that might be expected from the data found in the literature and from analogies with related systems. There are more carbon-transition metal systems published than nitrogen- transition metal systems, and the estimated probability indicated for the characteristics from analogies with related systems should perhaps be somewhat more accurate than for those of the titanium-nitrogen system. 


\begin{tabular}{|c|c|c|c|c|c|c|c|c|}
\hline 悹 & & 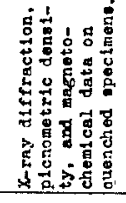 & 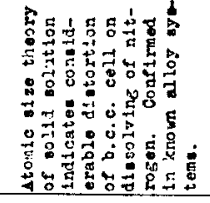 & & 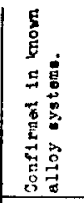 & 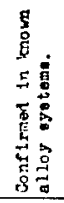 & 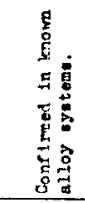 & 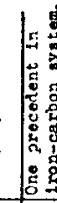 \\
\hline 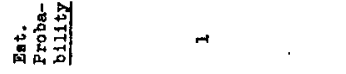 & -1 & $*$ & $+\infty$ & $\rightarrow$ & $\stackrel{20}{=}$ & $\stackrel{\Xi}{\Xi}$ & 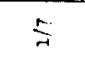 & F \\
\hline 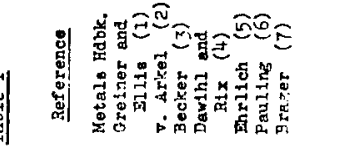 & 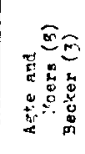 & 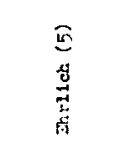 & 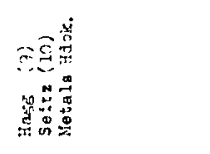 & 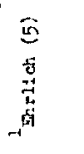 & $\begin{array}{l}\widehat{\tilde{a}} \\
\hat{y} \\
\underline{y}\end{array}$ & $\begin{array}{l}\widehat{3} \\
: 0 \\
\text { : }\end{array}$ & 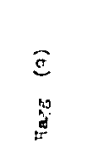 & \\
\hline 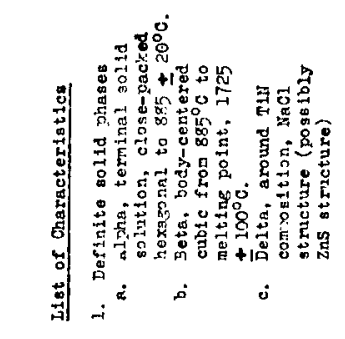 & 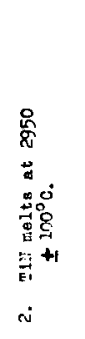 & 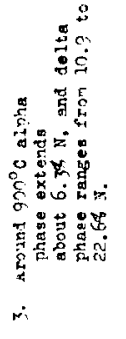 & 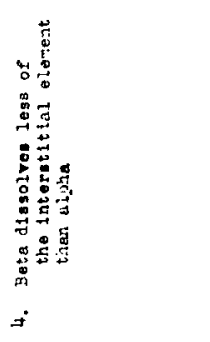 & 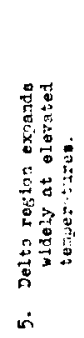 & 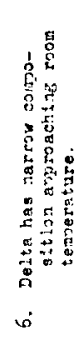 & 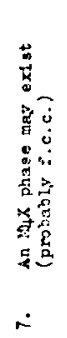 & 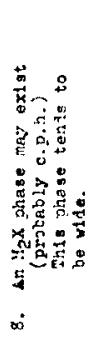 & 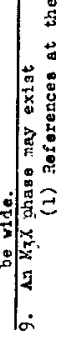 \\
\hline
\end{tabular}

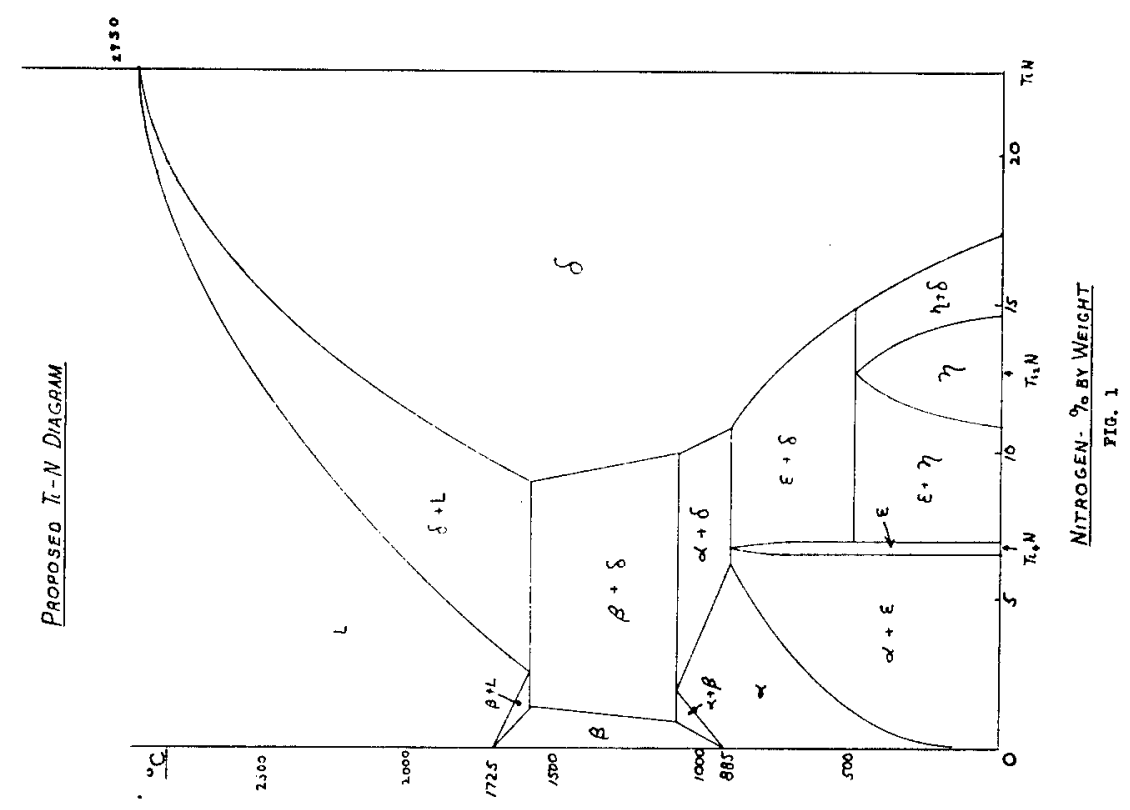



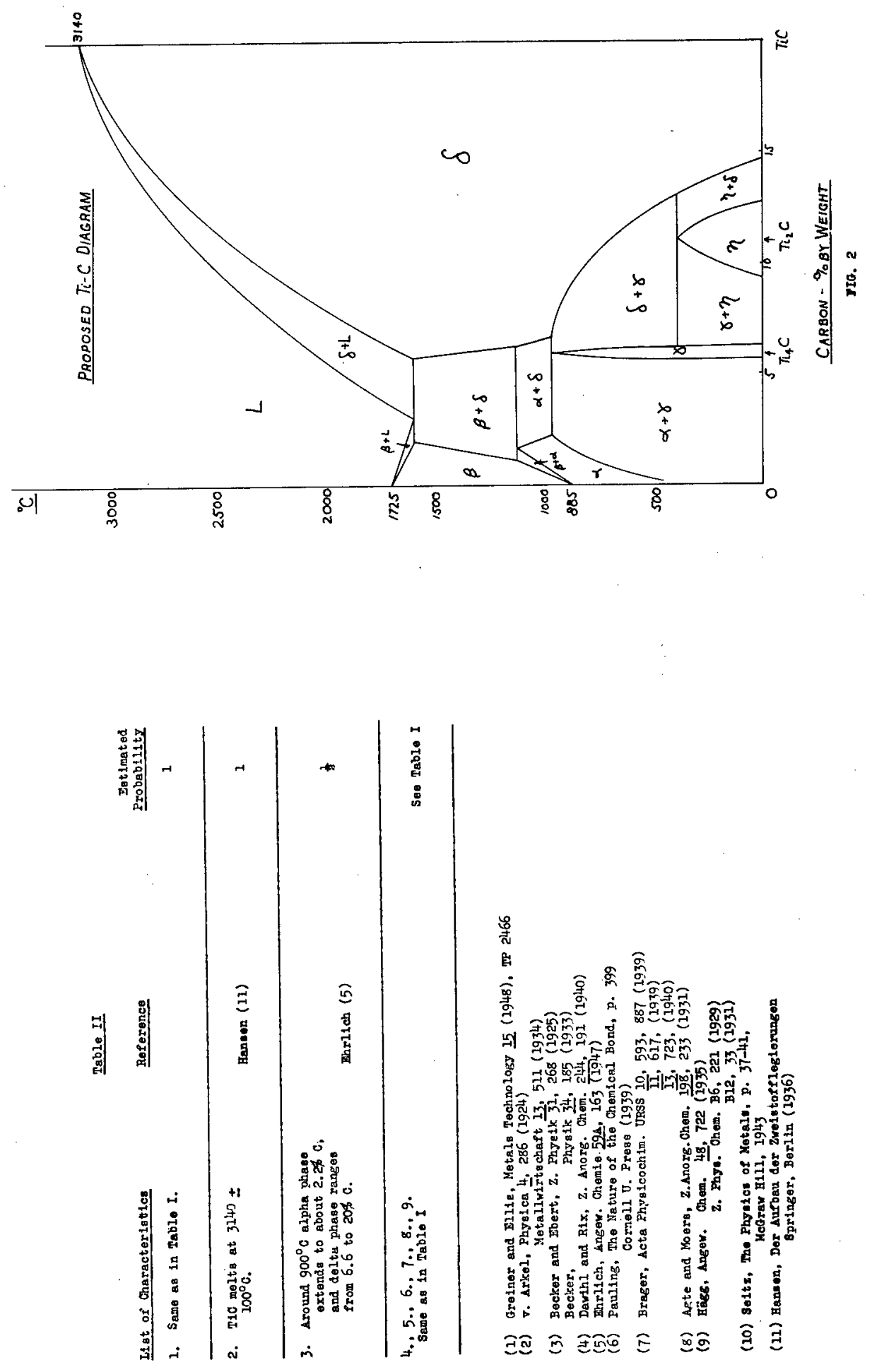
Figure 2 shows the preliminary TiC phase diagram consolidating the list of characteristics given in Table II. The alpha and beta regions are narrower than those for the titanium-nitrogen system. Also the delta region extends rather closely to the $\mathrm{Ti}_{4} \mathrm{C}$ compound. The existence of a $\mathrm{Fe}_{3} \mathrm{C}$ compound in the iron-carbon system establishes a precedence for the possibility of a $\mathrm{Ti}_{3} \mathrm{C}$, which, however, is not shown in the diagram. It is worthwhile to mention that it is possible but rather improbable that a graphite phase may appear, for the TiC compound is quite stable. At any rate, the diagram is probably metastable with respect to one dealing with graphite and titanium.

II. Experimental Program

A. Production of the Alloys

The titanium for the production of all the critical alloys to be investigated will be that produced by the iodide process with Vickers hardness below 90 or Rockwell " $B$ " below 45. Spectrographic and chemical analysis will be made on the titanium to establish the particular impurities present.

\section{B. Titanium-Nitrogen System}

Because of the ease with which titanium reacts with nitrogen at $800^{\circ} \mathrm{C}$, it is planned for our first attempts to produce alloy specimens in a high vacuum furnace in which a controlled amount of pure nitrogen will be introduced, followed by a homogenization in high vacuum. The alloy specimens will be small $5 \mathrm{~cm}$ rods suitable for use in a Leitz dilatometer.

The analysis for nitrogen will be attempted by the Kjeldahl method in which the nitrogen in the specimen will be converted to ammonia gas. Some reports have indicated that this method is not sufficiently accurate for our purposes, and two alternative methods are contemplated, viz, vacuum fusion, and sodium fusion in the presence of carbon, producing a cyanide, which is easily determined quantitatively.

The principal technique planned for determining points on the phase diagram is dilatometry and a Leitz dilatometer has just been acguired for this. This instrument requires small specimens, and can operate to $1100^{\circ} \mathrm{C}$. with specimen maintained in a vacuum. Microstructure studies will also be made of quenched and ordinary specimens. X-ray diffraction will be used to confirm the presence of specific constituents indicated by other methods. The high electrical resistivity of titanium suggests that electrical resistance measurements would yield accurate data, and the use of this technique will be considered.

\section{Titanium-Carbon System}

Because of the difficulty of melting titanium without contamination from the crucible material, it is planned to produce low-carbon alloys by gas carburizing small pure titanium specimens, followed by a homogenization treatment in vacuum. Methane gas will be used and the hydrogen that will enter the titanium will be driven off by heating in vacuum, probably in the homogenization treatment. A vacuum furnace is under construction in which the titanium will be heated by its own electrical resistance. The production of high carbon alloys will be attempted by induction melting of pure titanium in pure graphite crucibles. Should these methods fail, powder metallurgy will be attempted using vacuum sintering. A possible method to be considered for 
producing the powder is the blowing of methane gas through the arcing point of two pure titanium electrodes. The carbon analysis will be made in a carbon train.

Essentially the same techniques are planned for determining points on the phase diagram for this system as for the titanium-nitrogen system.

\section{DISCUSSION}

In discussing the atomic radii and the types of bonding existing in the various phases, Dr. Nielsen stated that the atomic radii for solutions of carbon (up to two percent) and solutions of nitrogen (up to six percent) are known and are very close to the atomic radius of pure titanium. The lattic parameters that have been determined for the delta and epsilon phases, i. e. $\operatorname{Ti}_{4} \mathrm{~N}, \mathrm{Ti}_{2} \mathrm{~N}$ and $\mathrm{TiN}$, suggest homopolar bonding or ionic bonding. Dr. A. E. Palty (New York University) added that the bonding in the alpha and beta phases is mainly metallic with a possibility of resonance. pauling has suggested resonance and that about six bonds would have to be satisfied for a maximum titanium valence of four. The delta structure is definitely ionic, with varying valence over its existence range. In the case of carbide, the valence of titanium may become trivalent at the higher limits. 